Essays on the Implications of European Union Sanitary and Phytosanitary Measures and Technical Barriers to Trade on African Exports

Dissertation to obtain the Ph.D. degree in Economics at the Faculty of Economics Sciences, Georg-August-Universität Göttingen, Germany.

\title{
By
}

Fatima Olanike Kareem

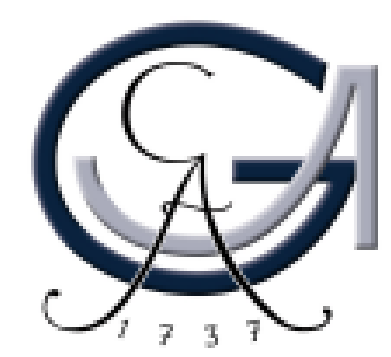

Georg-August-Universität Göttingen

Göttingen, 2016 


\section{Essays on the Implications of European Union Sanitary and Phytosanitary Measures and Technical Barriers to Trade on African Exports}

Dissertation to obtain the Ph.D. degree in Economics at the Faculty of Economics Sciences, Georg-August-University of Göttingen, Germany

Written and Presented by:

Fatima Olanike Kareem

Born in Ibadan, Nigeria

Date of Submission: March 18, 2016

Date of disputation: June 2, 2016

Under the Supervision of:

Professor Dr. Bernhard Brümmer

Professor Inmaculada Martínez-Zarzoso (PhD)

Professor Stephan Klasen (PhD) 


\section{Acknowledgements}

I am grateful to the Almighty God for making it possible for me to successfully complete this academic hurdle.

Undergoing a $\mathrm{PhD}$ studies is an eye-opener and a truly learning process. I had benefited immensely from various supports that ensure the $\mathrm{PhD}$ to be a smooth process throughout my stay in Göttingen. In particular, I am heartily grateful to my first supervisor, Professor Bernhard Brümmer for his willingness to supervise me considering the fact that I joined the research training group at a later stage. Among many others, I acknowledge his open-door policy, his willingness to share ideas with me, the confidence he has in my work which make him to allow me to work independently with interventions at the right time. I am equally grateful to my second supervisor, Professor Inmaculada Martínez-Zarzoso, my mentor and academic mother for painstakingly closely co-supervising me and the numerous valuable discussions and feedback I received on research work. In addition, I am heartily grateful to both Professors Brümmer and Martinez-Zarzaso for introducing me to the gimmicks of publishing and their relentless guidance in this regard. My sincere gratitude also goes to Professor Stephan Klasen for accepting to serve as part of my supervision committee and to my International Food Policy Research Institute (IFPRI) external supervisor, Laurian Unnevehr for feedback on early version of the research.

I also appreciate friends and colleagues for making my stay at Göttingen wonderful. In particular, it has been wonderful knowing Nana Asiedu and Fatao Camara for their wonderful friendship and companionship at Göttingen. Special acknowledgment also goes to all my colleagues at my chair particularly, Anisa Utami and Huang Wei (Vivian), Anna Mareike Holtkamp, Amjad Masood, Malte Enrich, Marwan Benali; and also to the following colleagues in Göttingen: Ramona Rischke, Rajuis Idzalika, Ana Lucian Abeliansky, Bumi Camara, Farah Pangestuty; and Melanie Groose for her swift coordination support and to both Iris Butzlaff and Katrin Pape for fruitful exchange of parental experience. I equally thank Adam Walker for the excellent editing service and Dela-Dem Fiankor and Adeniyi Adegoke for rending research assistantship. I also acknowledge my fellow Nigerians in Goettingen particularly Alice Eseola, Olabisi Olagunju Olukunle Ekeade, Adeniyi Adegoke and Tomi Tayo. I also thank my friends in Nigeria for their friendship: Maja Raheema, Khadijah Azeez, Fadila Oduyebo, Zainab Adepegba and Kudirat Omotosho.

Furthermore, I express my appreciation to the GlobalFood Research Training Group and to the German Research Foundation (DFG) for generously funding this research through the GlobalFood project and for financial grant for study visit and conferences which allowed me to disseminate the findings of my research. I am equally grateful the Georg-August University for the family finishing grant, and the numerous support extended by both the DFG and the University which ensure the compatibility of family and work life. These supports are all gratefully acknowledged. I am also grateful to United Nations University - World Institute for Development Economics Research (UNU-WIDER) for the financial support during my research stay in UNU-WIDER, Finland. 
Lastly, the most admirable appreciation goes to my family; my children, Farzeen Olawonuola Kareem, Fawwaz Olatomiwa Kareem, Farouq Olamide Kareem for their endurance during the course of my PhD studies and my husband, Olayinka Idowu Kareem for his support, love and understanding which kept me moving ahead. Appreciations also goes to my brothers (Ismail Ojetunde and Azeez Ojetunde) and my sister (Dr. Adijat Temitope Ajibola) for their family support and also to my late parents who had always wanted me to be a PhD holder - a dream which is now fulfilled.

Finally, and most importantly, I thank Almighty Allah for smoothing my path for me and making this dream a realization.

Fatima Olanike Kareem

Göttingen, March, 2016. 


\section{Dedication}

This research work is dedicated to the loving memory of those two rare souls whose efforts, love and perseverance led to the realization of my dreams - my mum and dad. 


\section{Table of Contents}

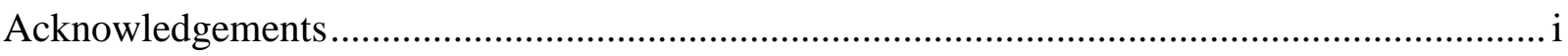

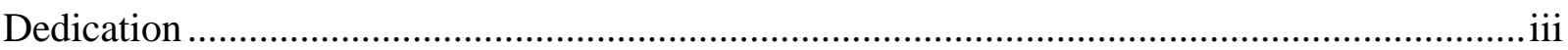

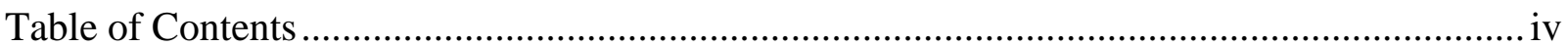

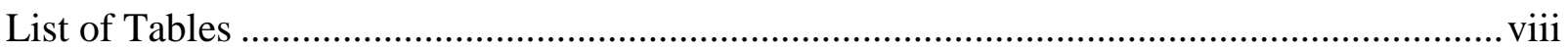

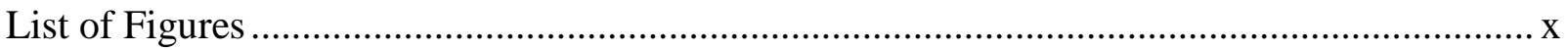

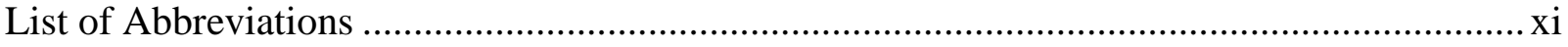

An overview of the Article Published from the Thesis ................................. xiv

\section{CHAPTER 1}

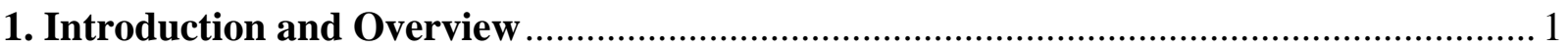

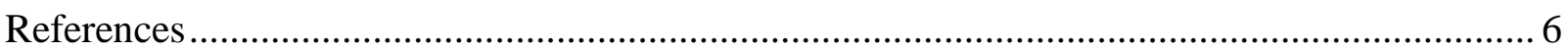

\section{CHAPTER 2}

2. Trade Effects of EU SPS and TBT measurli.es When Zeros are Frequent: A Comparison of Estimation Techniques Using African Data ............................................................ 9

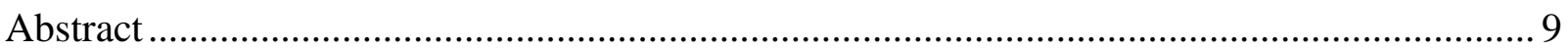

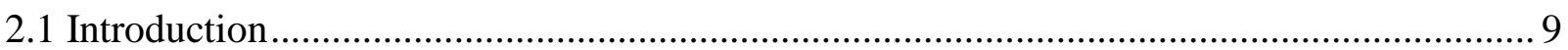

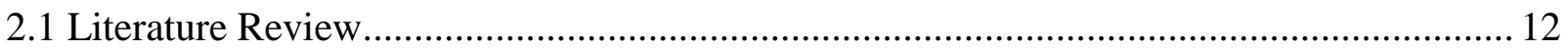

2.2.1 Heterogeneity, Zeros and a New Development in the Theoretical Foundation ............ 12

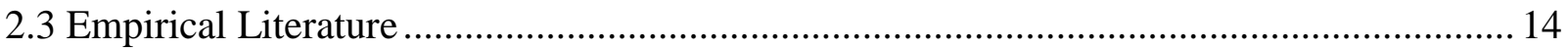

2.3.1 Estimation Issues in Gravity Modeling - The Debate ............................................ 14

2.3.2 Empirical Literature on SPS and TBT measures and International Trade Flows ......... 25

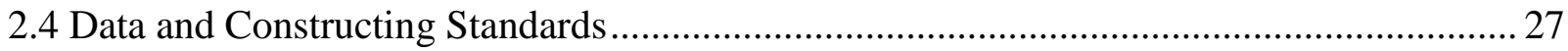

2.4.1 Constructing Protectionism Indices of Standards ................................................... 28

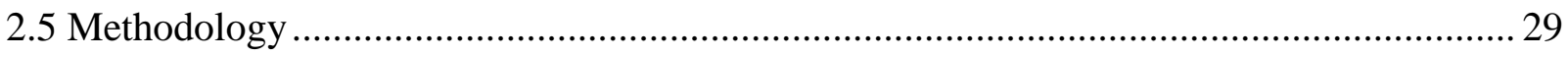

2.5.1 Model Specification and Estimation Techniques........................................................ 29

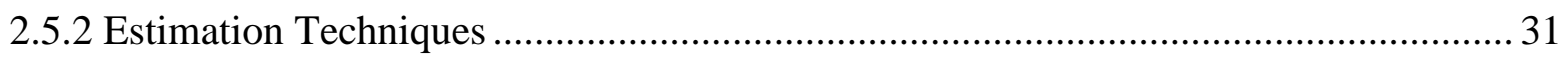




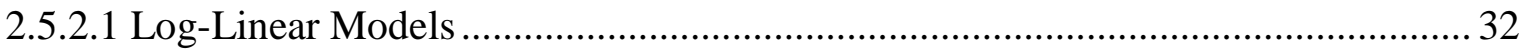

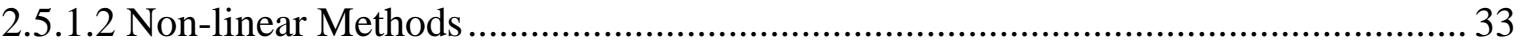

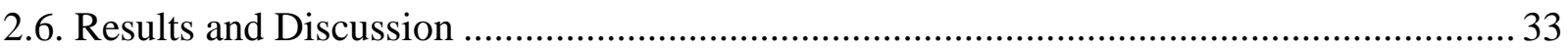

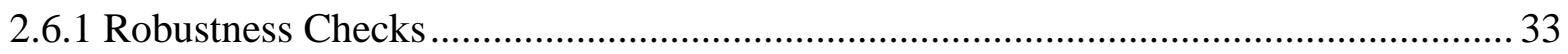

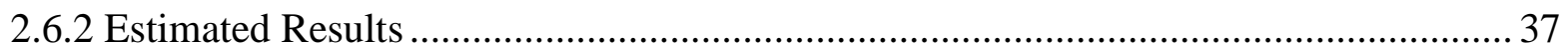

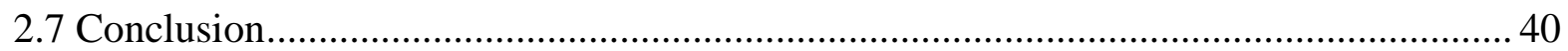

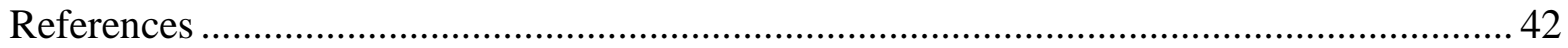

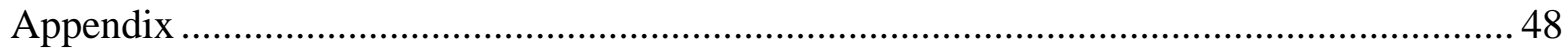

\section{CHAPTER 3}

3. Effect of Food Regulations on the Extensive and Intensive Margins of Trade: Evidence

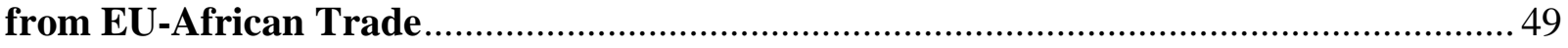

Attribution ..................................................................... 49

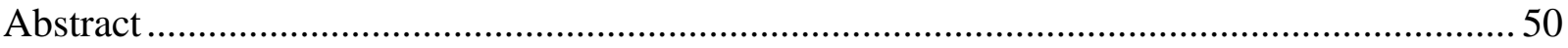

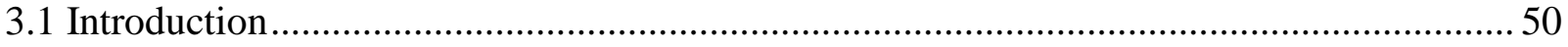

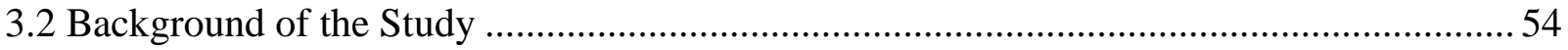

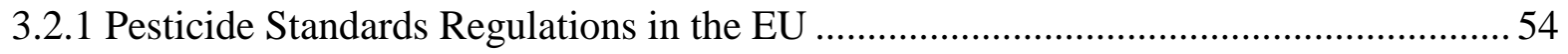

3.2.2 EU Border Rejection of Feed and Food and the Reasons for the Rejection .................57

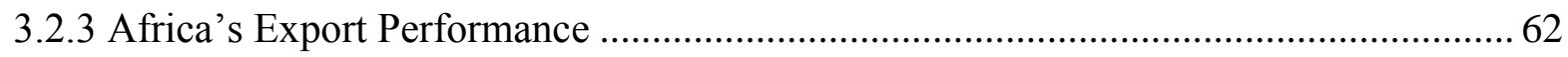

3.2.4 EU Pesticide Standards and Market Access of Africa's Exports - A Preliminary Analysis

3.2.5 EU Entry Price Procedure for Certain Fruits and Vegetable ..................................... 69

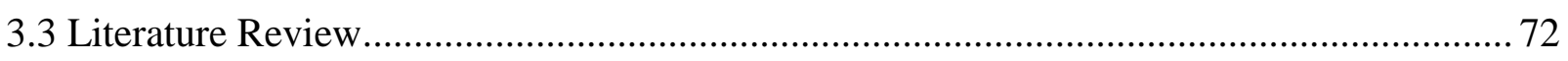

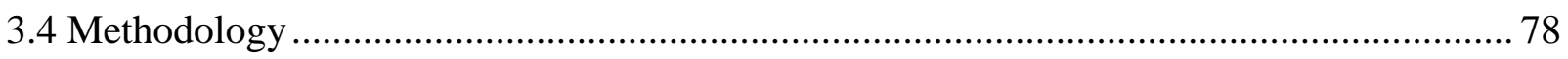

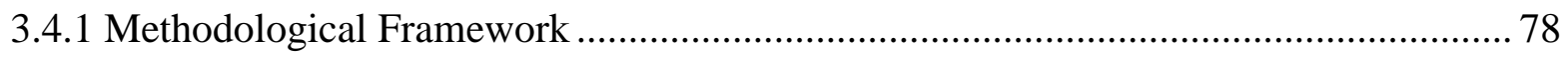

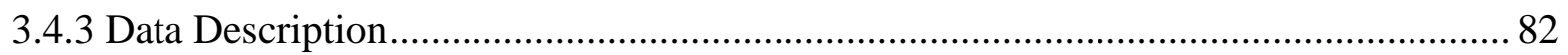

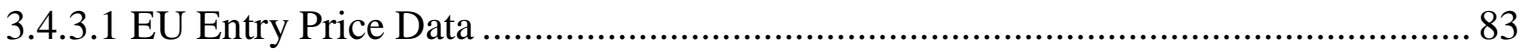

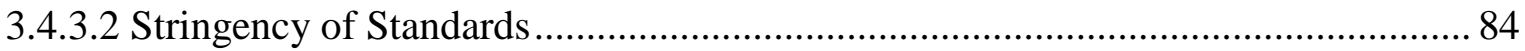




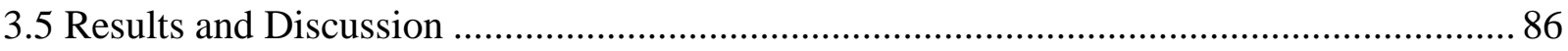

3.5.1 Main Result: Impacts of EU Standards on African Exports ..................................... 86

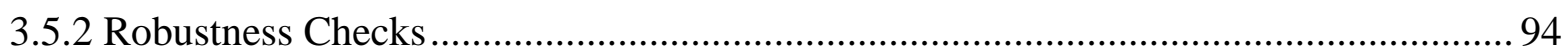

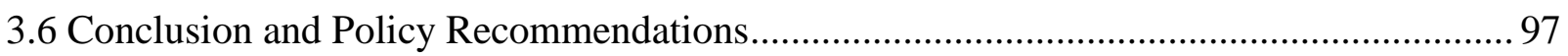

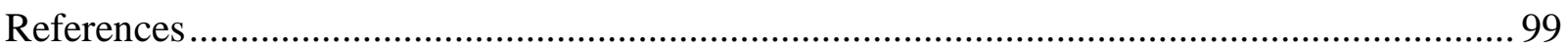

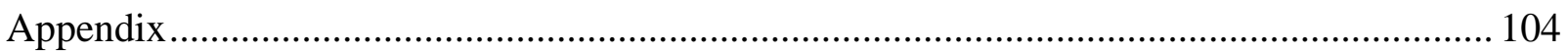

\section{CHAPTER 4}

4. Protecting Health or Protecting Imports? Evidence from EU Sanitary and

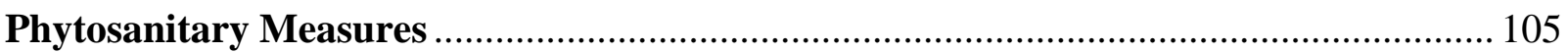

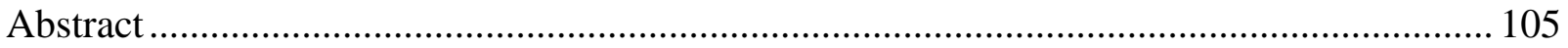

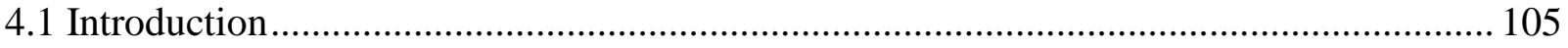

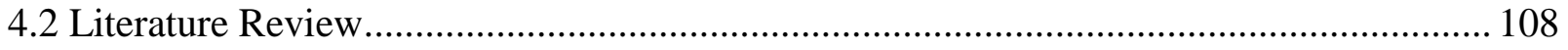

4.2.1 The Political Economy of Government Standards ................................................... 109

4.2.1.1 The Protection for Sales Model ......................................................................... 109

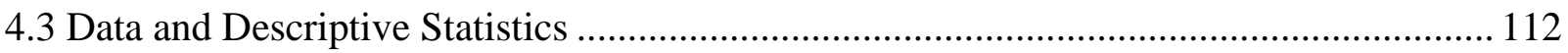

4.3.1 Measuring Protectionism - a Protectionism Index of Standards ............................ 112

4.3.2 Overview of EU and FAO/WHO Pesticide Safety Standards................................. 114

4.3.3 Structure of EU Production and Trade in the Selected Products. ............................. 116

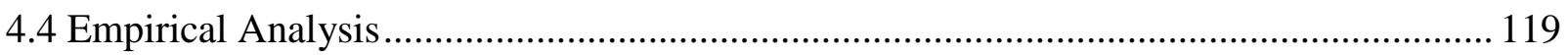

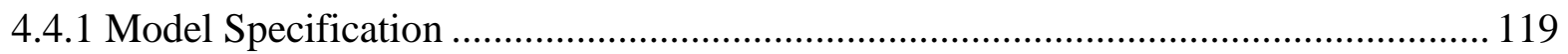

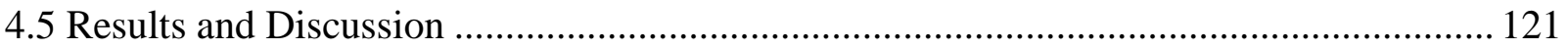

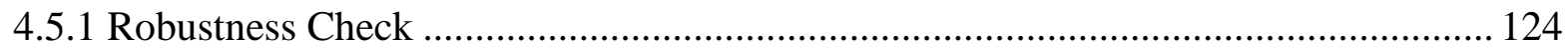

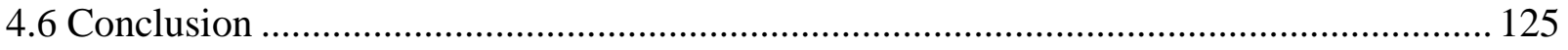

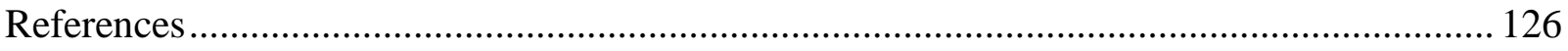

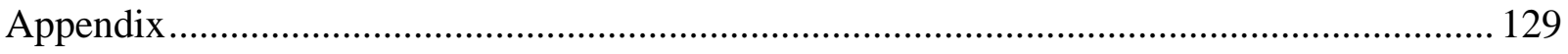




\section{CHAPTER 5}

5. What drive Africa's Inability to Comply with Standards? Evidence from the EU Border

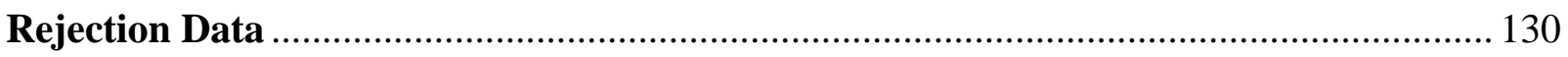

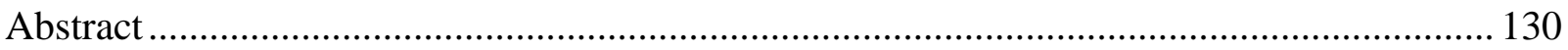

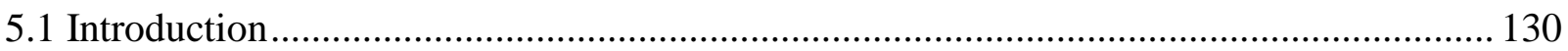

5.2 EU Food Safety Standards and Its Conformity Assessment........................................... 133

5.2.1 Reasons behind EU Border Rejection of Feed and Food........................................ 133

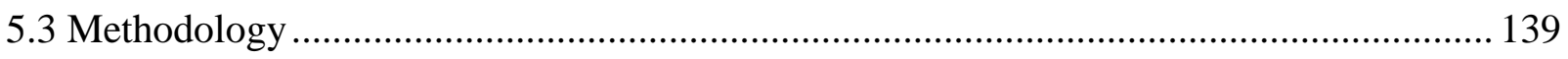

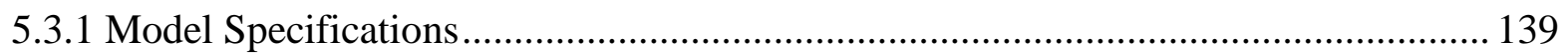

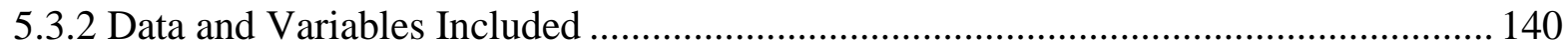

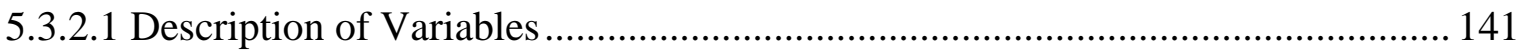

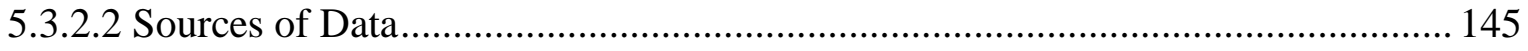

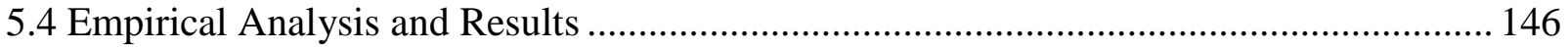

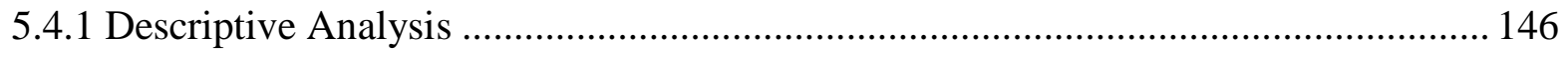

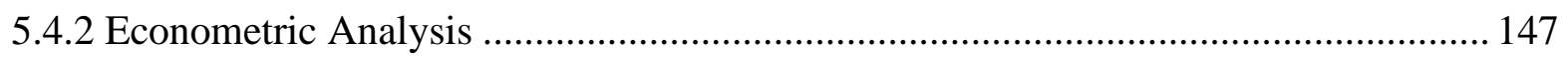

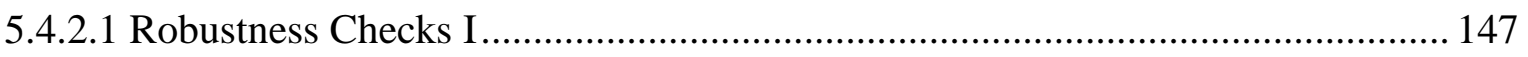

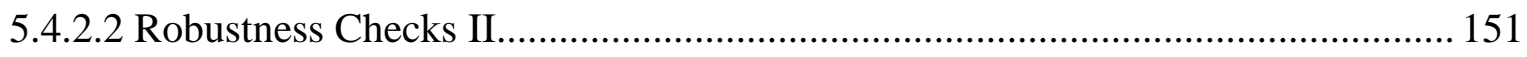

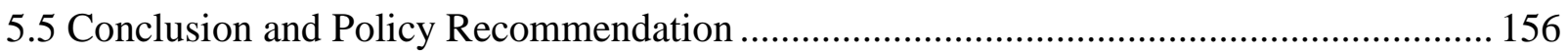

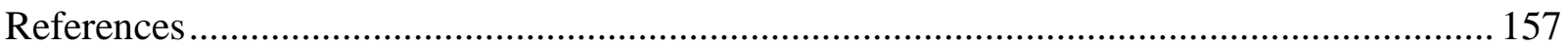

\section{CHAPTER 6}

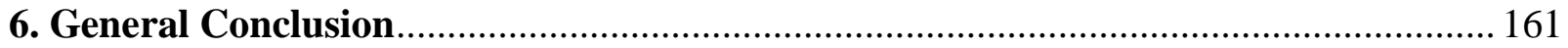

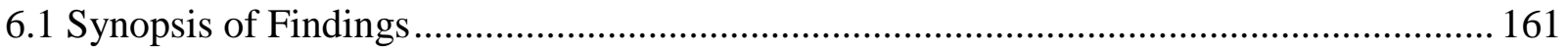

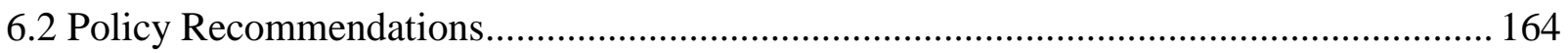

6.3 Limitations of the Study and Outlook for Further Research......................................... 166

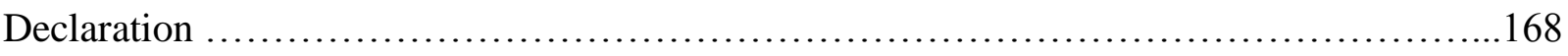




\section{List of Tables}

Table 2.1: Testing for the Pattern of Heteroscedasticity......................................................... 35

Table 2.2: Ramsey Reset and Information Criterion Test ..................................................... 37

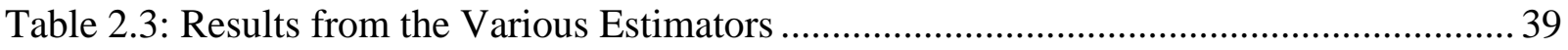

Table 2.4: Top Three Estimators with the Lower, Lowest and Highest Standard Errors.......... 40

Table A2.1: List of Countries in the Dataset ........................................................................ 48

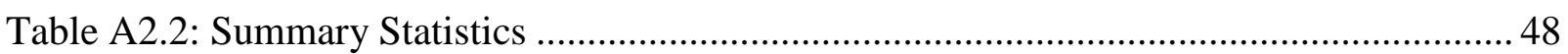

Table 3.1: EU Number of Pesticide Regulated in EU, 2005 to 2013 ........................................ 55

Table 3.2: EU Border Refusal by 10 Most Affected Product 2008 to 2013 ............................. 58

Table 3.3: Reasons for the EU Border Refusal of Third Countries' Food and Feed by Type of

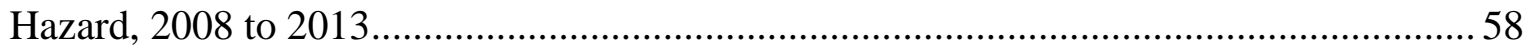

Table 3.4: EU Border Refusal of African Exports by Most Affected Countries and Products, 2008 to 2013

Table 3.5: Reasons for the EU Refusal of Africa's Food and Feed by Hazard Category, 2008 to 2013

Table 3.6: EU Refusal of African Fruits and Vegetable Exports by Pesticide Residue 2008 to 2013 61

Table 3.7: African Exports and Production in Millions US\$, 1995-2011 63

Table 3.8: Direction of Trade of Selected Africa's Fruit and Vegetable Exports, 1995 to 2013

Table 3.9: EU Food Safety Standards and Imports from Africa, 2005 to 2013 ......................... 68

Table 3.10: Schedule of EU Entry Price Control and the Applicable Duties ........................... 70

Table 3.11: Detailed EPS Schedule for Tomato: 01.04 to 30.04 .............................................. 71

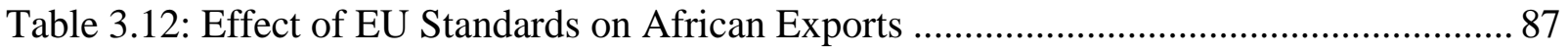

Table 3.13: Robustness Checks with an Alternative Sample: Eliminating Economically Small

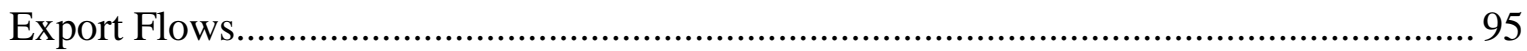

Table 3.14: Robustness Checks: Sensitivity to Outliers ........................................................... 96

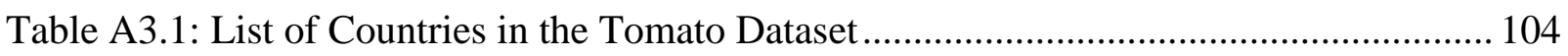

Table A3.2: List of Countries in the Lime and Lemon Dataset............................................. 104

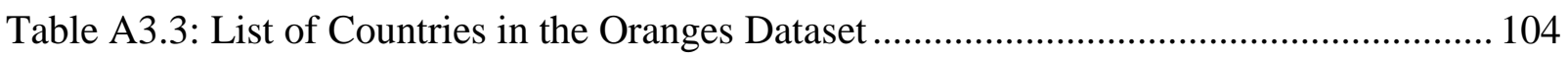

Table 4.1: Structure of Production of the Selected EU Products, averaged 2008 to 2013 ...... 117

Table 4.2: Structure of Trade with Extra EU countries, 2008 to 2013 .................................. 118 
Table 4.3: Protectionist Extent of EU Standards Relative to International Benchmarks ........ 122

Table 4.4: Extent of Protectionism during and after the 2008/2009 Financial Crisis. 123

Table 4.5: Robustness to a Different Estimation Technique - using Tobit Model. 125

Table A4.1: List of Countries in the Tomato Dataset 129

Table A4.2: List of Countries in the Lime and Lemon Dataset............................................. 129

Table A4.3: List of Countries in the Oranges Dataset ............................................................ 129

Table 5.1: Reasons for EU Rejection of Food and Feed, 2008 to 2013 ................................ 134

Table 5.2: EU Rejection of African Exports from the Most Affected Products and Countries, 2008 to 2013

Table 5.3: Reasons for EU Rejecting Africa's Food and Feeds, 2008 to 2013 ...................... 138

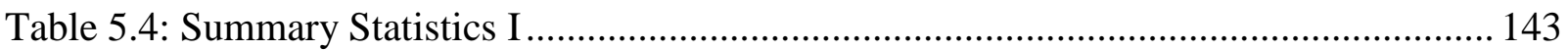

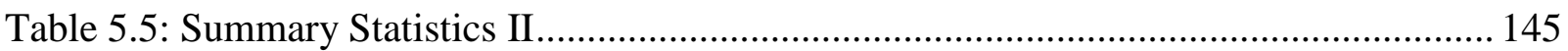

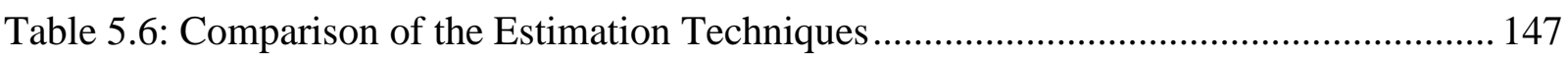

Table 5.7: Economic and Geographical Factors influencing Rejections of Africa's Exports at

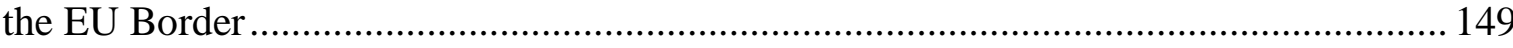

Table 5.8: Robustness Checks on the Estimation Techniques.............................................. 152

Table 5.9: Impact of Trade Procedures, Infrastructure and Institution on Border Rejection .. 153 


\section{List of Figures}

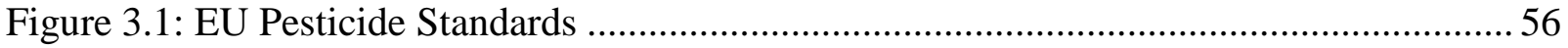

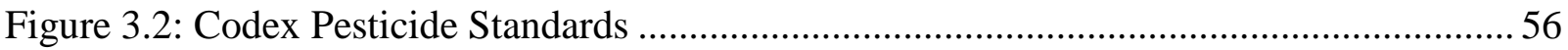

Figure 4.1: Tomatoes MRLs..................................................... 114

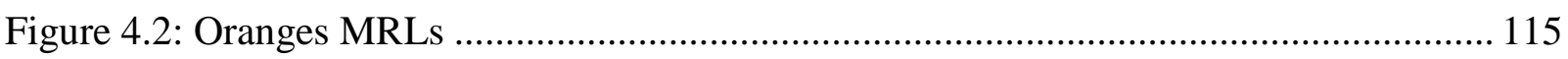

Figure 4.3: Lime and Lemon MRLs ......................................... 115

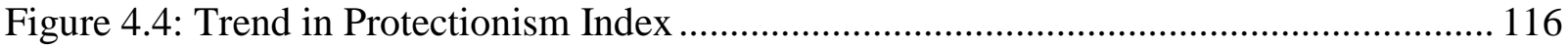

Figure 5.1: EU Border Rejection of Third Countries Exports by Most Affected Product, 2008

to 2013

Figure 5.2: Proportion of EU Export Rejection in Total Rejection (\%) ................................. 136

Figure 5.3: The Distribution of Border Rejection of the Selected African Exports, 2008 to 2013 


\section{List of Abbreviations}

AGOA

AIC

BIC

CAC

CCV

CEPII

\section{CIF}

CVMR

EBA

EC

EK

ET

EP

EPA

EPS

EU

EWG

FAO

FE

FGLS

FOB

GDP

GLM

GSP

HIT

HMR

HS

ICS

ICT

ISO

MFN
African Growth and Opportunity Act

Akaike Information Criterion

Bayesian Information Criterion

Codex Alimentarius Commission

Constant Coefficient of Variance

Centre d'Etudes Prospectives Et d'Informations Internationales

Cost, Insurance and Freights

Constant Variance to Mean Ratio

Everything But Arms

European Commission

Eaton and Kortum

Eaton and Tamura

Entry Price

Economic Partnership Agreement

Entry Price System

European Union

Environmental Working Group

Food and Agricultural Organization

Fixed Effects

Feasible Generalized Least Square

Free on Board

Gross Domestic Products

Generalized Linear Models

Generalised System of Preference

Heterogeneity Index of Trade

Helpman, Melitz and Rubinstein

Harmonised System

International Classification for Standards

Information and Communication Technology

International Standard Organization

Most Favoured Nation 
MRL

MPML

MRT

NBPML

NGO

NLS

NTB

NTM

OECD

OLS

PA

PQL

PPML

RASFF

RE

RTA

SITC

SIV

SPS

TARIC

TBT

UN COMTRADE

UNCTAD

UNESCAP

UNIDO

WDI

WHO

WITS

WTO

ZINBPML
Maximum Residual Limit

Multinomial Pseudo Maximum Likelihood

Multilateral Resistance Term

Negative Binomial Pseudo Maximum Likelihood

Non-Governmental Organisation

Non-Linear Least Square

Non-Tariff Barrier

Non-Tariff Measure

Organization of Economic Cooperation and Development

Ordinary Least Square

Population Average

Poisson Quasi Likelihood

Poisson Pseudo Maximum Likelihood

Rapid Alert System for Food and Feed

Random Effects

Regional Trade Agreement

Standard International Trade Classification

Standard Import Value

Sanitary and Phytosanitary

Integrated Tariff of the European Union

Technical Barriers to Trade

United Nations Commodity Trade

United Nations Conference on Trade and Development

United Nations Economic and Social Commission tor Asia and the

Pacific

United Nations Industrial Development Organisation

World Development Indicators

World Health Organisation

World Integrated Trade Solution

World Trade Organisation

Zero Inflated Negative Binomial Pseudo Maximum Likelihood 
ZIPPML

Zero Inflated Poisson Pseudo Maximum Likelihood 


\section{An overview of the Article Published from the Thesis}

Kareem, F. O., Brümmer, B., and Martinez-Zarzoso, I. (2016). European Union Market Access Conditions and Africa's Extensive Margin of Food Trade. The World Economy. DOI: $10.1111 /$ twec. 12466

(C) 2016 John Wiley \& Sons Ltd.

Part of the second essay of this thesis embodied in the third chapter of the thesis has been published at The World Economy journal and is cited as: Kareem, F. O., Brümmer, B., and Martinez-Zarzoso, I. (2016). European Union Market Access Conditions and Africa's Extensive Margin of Food Trade. The World Economy. DOI: 10.1111/twec.12466

The appropriate permission for re-use has been requested by me (Fatima Olanike Kareem) as the corresponding author of the article. A formal permission licence for re-use in this thesis/dissertation has been granted by John Wiley and Sons via the RightsLink service. 


\section{Chapter 1}

\section{Introduction and Overview}

As tariffs have been negotiated down, an array of non-tariff measures (NTMs) are assuming increasing importance in international trade. In particular, among the NTMs, technical barriers to trade (TBT) and sanitary and phytosanitary (SPS) measures have been found to constitute a more significant barrier to export especially through the associated costs of complying with standards (Disdier et al., 2008; Nicita and Gourdon, 2013). More so, about $80 \%$ of world trade is affected by these measures (OECD, 1996), signifying their importance in international trade. By definition, SPS measures are regulations that seek to guarantee consumers' health and safety and are levied on food, drink and feed in order to ensure food safety, plant and animal health and prevent pests, diseases and food hazards. In addition, sanitary (human and animal) and phytosanitary (plant) measures also include the procedures for the conformity assessment measures on compliance regarding food safety, animals and plant health such as product testing, accreditation, certification and inspection of the product (WTO, 2015).

On the other hand, TBT refers to both voluntary standards and mandatory technical regulations that dictates the characteristics that a product should possess including its production process and methods such as labeling, packaging and other technical requirements. In addition, TBT also covers conformity assessment measures regarding technical specifications other than those that are SPS-related, and includes measure such as inspection, certification, testing and accreditation, etcetera (ibid). These TBT measures can be voluntary or mandatory requirements. Technical regulations are imposed by the government and compliance is mandatory, and as such, it is also popularly referred to as mandatory standards ${ }^{l}$. Thus, non-conforming products are denied market access to countries where these mandatory technical regulations are imposed. However, standards are imposed by user groups, trade association or can be non-mandatory government guidelines, but compliance is voluntary. Such voluntary standards are now de facto mandatory as they are increasingly being required by chains of retail groups (Henson and Jaffee, 2008).

While SPS standards can be levied on food, drink and feed to achieve food safety, plant and animal health objectives, TBT are however broader in scope and exist in all sectors of the economy. However, in the context of agricultural food sector, SPS measures on food products are aimed at ensuring food safety, while TBT on food products are levied to achieve health and safety purposes and to prevent against deceptive purposes and other related objectives other than food safety (WTO, 2015). Thus, the major focus of this thesis is on both SPS standards as well as TBT measures that govern agricultural food products.

The advantages of both SPS standards and mandatory standards (technical regulations) in international trade have been highlighted by some studies. Standards and technical regulations

\footnotetext{
${ }^{1}$ In this chapter, the term standards refer to SPS standards and technical regulation (mandatory standards) unless it is explicitly stated otherwise.
} 
increase the value of certified products and processes by providing consumers vital information and assurance about their health and safety (Blind, 2001; Baller, 2007). Compliance can therefore ensure increased market access. However, there are concerns that they can also be used as protectionist tools, particularly when such measures are overly more stringent relative to those needed to achieve health and safety or to those internationally recommended, thus constituting a barrier to trade (Fischer and Serra, 2000; Grandal and Shy, 2001; Otsuki, et al., 2001; Czubala et al., 2009: Marette and Beghin, 2010; Shepherd and Wilson, 2013). Although, the SPS and TBT Agreements encourage countries not to use SPS and TBT measures to create unnecessary barriers to trade, and to use international standards when these are available, the agreements also permit countries to set stricter standards and regulations if their risk assessments have scientific backing (WTO, 2015). However, these measures may become barriers to trade because compliance with them imposes enormous costs on producers and exporters (Markus, et al., 2005; Czubala, et al. 2009). For instance, the average investment costs that can be incurred in order to comply with standards and technical regulations can be up to about $124 \%$ of firms' sales in sub Saharan Africa, $44.1 \%$ in the Middle East, $15.75 \%$ in South Asia and $13.36 \%$ in Latin America (Maskus, et al., 2005). Such costs affect the price and profitability of the export, thereby reducing net national welfare (ibid).

In addition, the increased stringency and plethora of these measures imply rising costs of compliance which are aggravated for exporters from developing countries, particularly in Africa, due to the lack of the necessary technology and infrastructure which incapacitate them from complying with such standards (Jaffee and Henson, 2004). Many of these countries have a dearth of minimum food safety infrastructure, the manpower and financial resources needed to facilitate their participation in the development of standards and to ensure their compliance with food standards (ibid). Their lack of technical and financial resources make it hard for them to come up with commodities which meet high quality standards and also make it difficult for them to challenge measures that deviate from international ones, especially those without scientific justification (Jaffee and Henson, 2004; Mayeda, 2004).

Given this scenario, SPS and TBT measures have been identified as the single most important market access condition for Africa's food exports and have been linked to one of the causes of the weak integration of African countries in global markets (Otsuki, et al., 2001; Czubala et al., 2009; Nicita and Gourdon, 2013). Consequently, this may jeopardize the significant role played by food exports in stimulating economic growth and as a means of poverty reduction, especially in African countries, many which rely heavily on agriculture for sustenance. This weak integration of most African countries into the global economy can be an impediment to the developmental progress of the continent, primarily because deep trade integration is widely viewed as the most promising avenue to achieving economic growth (Nicita and Roll, 2015). Consequently, a better comprehension of the role of SPS and TBT measures on market access is of paramount importance for the continent which largely depends on agricultural activities for livelihood. It is therefore important to gain a greater understanding and insights into the specific implications of these measures on exports coming from Africa in order to make well-informed policies that will enhance continuous market access for the continent. 
The proliferation and stringency of standards have generated a lot of attention with a growing number of studies demystifying the challenges and opportunities emerging for farmers, producers, and exporters as a result of compliance with standards (Otuski, et al., 2001; Martens and Swinnen, 2007; Disdier et al., 2015; Ferro et al., 2015; Fontagné et al., 2015; etcetera). Nevertheless, among the existing literature, the effects of standards on African trade flows are significantly less well studied and considerable research gaps remain, particularly in the areas of how standards are represented and the approaches involved in estimating the impacts on trade flows. Thus, we contribute to the existing pool of literature by investigating the trade effects of non-tariff measures on Africa's exports, focusing on SPS and TBT measures governing agricultural food products. We achieve this by focusing on both SPS measures on food safety and technical regulation aspects of TBT that govern the agricultural food sector, and their consequence for African exports. This dissertation fills some important identified gaps in the literature by addressing the following four concerns.

First, in modeling bilateral trade relationships, the gravity model is usually used in modeling the impacts of standards on bilateral trade. The majority of gravity models used in the literature show scope for improvement in three identified areas. These areas include the way in which the models are specified, the way food standards and regulations are represented, and the estimation techniques used to tackle the occurrence of zero trade observations which are usually pervasive in trade data. Extensive methodological rigor is therefore important so as not to distort the information provided to policy makers; a naive approach to estimating the impacts may result into biased and distorted results capable of straining established trade relationships. This necessitates a cautious examination of the methods and representation of food standards and regulations in order to produce reliable policy estimates.

Second, studies that examine the implications of EU standards in the food sector on Africa's exports have predominantly concentrated on estimating the impacts at the intensive margin of trade (trade relationships that are already in existence). These include Gebrehiwet, et al. (2007), Scheepers et al. (2007) and Otuski, et al. (2001). However, with the exception of Xiong and Beghin (2011), studies that investigated the impacts of standards on Africa's exports along the extensive margin (the creation of new trade relationships such as exporting existing products to new partners or markets, exporting new products to new or existing markets) is rare. This is in spite of the fact that the ability of developing countries to initiate or penetrate new markets might ultimately be constrained by stringent importing countries' market conditions. In addition, recent literature on firm heterogeneity reveals that changes in developing countries' trade were predominantly due to the expansion of trade along the extensive margin rather than due to changes in the volume of trade (Debaere and Mostashari, 2010; Reis and Farole, 2012; Nicita and Roll, 2015). Thus, in addition to exploration of the intensive margin, the analysis of importing countries' standards on Africa's extensive margin is equally crucial to the understanding of the process of entries and exits in export markets and also identifying which factors may be the biggest constraints to Africa's export competitiveness. 
Third, previous research has identified that while SPS standards represent a legitimate concern for health and safety, they can also be used as a protectionist tool, particularly when their specifications are much more stringent in comparison to the internationally approved standards (Grandal and Shy, 2001; Marette and Beghin, 2010). However, the protectionist use of standards and the implications for exporting countries is not yet understood. This is mainly because studies investigating whether the uses of standards have protectionist intent are rare with the exception of Xiong and Beghin (2014) whose areas of focus were Canada and the US. This dearth of empirical studies can largely be attributed to the difficulty of differentiating health and safety objectives from protectionist objectives and the lack of globally accepted benchmarks for doing this (Li and Beghin, 2014).

Fourth, past research has attributed the inability of African countries in complying with importing countries' food safety standards and consequential market access problems to domestic market constraints (Henson and Jaffee, 2004; Rios and Jaffee 2008; Xiong and Beghin, 2011). This is a consequence of corruption and weak government regulatory policies alongside poorly developed trade facilitation measures, especially in the aspects of infrastructure, customs and border procedures, as well as transportation and communication. These factors have all been said to constitute significant barrier to Africa's integration in the global trading system (Djankov, et al., 2010; Freud and Rocha, 2011). Africa's competitive advantage in terms of its abundance of agricultural resources and relatively low labour costs could easily be lost through inefficient logistics and poorly developed trade facilitations. In addition, these barriers might offset any potential benefits of the preferential market access given by the EU to most African countries, especially the preferential tariffs and quotas, thereby significantly dampening gains from trade. Thus, attributing the inability to comply with stringent importing countries' standards might be only half of the story. Nonetheless, while there is a considerable number of studies which supports the notion that an improved institution and strengthening of infrastructure are a catalyst for trade (North, 1990; Rodrik, et al., 2004; Dollar and Kray, 2003; Djankov, et al, 2010), little is known about the extent that such factors may help in attenuating or driving compliance with standards, as this has rarely been investigated.

This dissertation thus addresses each of these concerns guided by the following four objectives. Our first objective is to determine the appropriate econometric technique that would give unbiased estimates of EU standards on African fish exports in the presence of zeros. We achieve this objective using EU's SPS standards and technical regulations imposed on fish. The second objective involves estimating the implications of EU SPS measures on Africa's food exports at both the intensive and extensive margins of trade. This we did using the EU SPS measures on food safety with particular focus on pesticide standards. The third objective is to investigate if EU SPS standards on allowable pesticides limits on particular food products are protectionist in nature. Finally, we examine the extent to which domestic conditions in African countries affect their capacity to comply with EU food safety standards. In all our objectives, we have focused on EU measures as the EU is the most important trading partner of African countries, absorbing more than $50 \%$ of African exports (Rakotoarisoa, et al., 2011). In addition, the EU set one of the most stringent collections of food standards and regulations in the world and usually exercise 
the 'precautionary principle ${ }^{2}$, which generate a lot of controversies and complaints from WTO countries about the lack of the appropriate scientific basis of the standards (Henson and Jaffee, 2008). Thus, EU policies and regulations would have significant implications on African countries, whose major export destination is the EU. This dissertation therefore seeks to provide the necessary policy insights to ensure targeted policy intervention.

This dissertation consists of four essays which are structured into chapters. Following the introductory chapter, the rest of the dissertation is organised as follows. The second chapter embodies the first essay and focuses on methodology issues emanating from the logarithmic transformation of the gravity model of trade and the occurrence of zeros in trade data. We compare different estimation techniques that have frequently been used to deal with these issues in order to identify the estimator that would give unbiased and consistent estimates of EU SPS standards and technical regulations on African fish exports for end-use policy makers. In the third chapter, we focus on the second essay and investigate the trade implications of EU food safety standards covering allowable pesticides residue limits on selected fruit and vegetable exports from Africa. In the fourth chapter which contains the third essay, we investigate the protectionist intent of EU food safety standards on allowable pesticides residues using a sample of selected fruit and vegetable exported from African countries to the EU. The fifth chapter which houses the fourth essay focuses on the drivers, causes, and reasons behind what propels or inhibits the ability of African countries to comply with EU food safety standards. Chapter six concludes with a brief synopsis of each essay, some policy implications and outlook for future research.

\footnotetext{
${ }^{2}$ The EU exercises the 'precautionary principle' by setting the most stringent standards on perceived food risks when there are plausible reasons for health concerns but sufficient scientific information or evidence on the food risks is still lacking, incomplete or inconclusive.
} 


\section{References}

Baller, S. (2007). Trade effects of regional standards: a heterogeneous firms approach. World Bank Policy Research Working Paper 4124. Washington DC: The World Bank.

Blind, K. (2004). The economics of standards: theory, evidence and policy. Cheltenham: Edward Elgar.

Czubala, W., Shepherd, B., and Wilson, J. S. (2009). Help or hindrance? The impact of harmonised standards on African exports. Journal of African Economies, 18(5), 711-744.

De Groot, H., Linders, R., Sumbramanian, U. (2004). Institutional determinants of bilateral trade patterns. Kyklos, 51(1), 103-124.

Debaere, P., and Mostashari, S. (2010). Do tariffs matter for the extensive margin of international trade? An empirical analysis. Journal of International Economics, 81(2), 163-169.

Disdier, A. C., Fontagne, L., and Cadot, O. (2015). North-South standards harmonization and international trade. World Bank Economic Review, 29(2), 327-352.

Djankov, S., Freund, C., and Pham, C. S. (2010). Trading on time. Review of Economics and Statistics, 92(1), 166-173.

Dollar, D., and Kray, A. (2003). Institutions, trade, and growth. Journal of Monetary Economics 50(1), 133-162.

Henson, S., and Jaffee, S. (2008). Understanding developing country strategic responses to the enhancement of food safety standards. The World Economy, 31(4), 548-568.

Ferro, E., Otsuki, T., and Wilson, J. S. (2015). The effect of product standards on agricultural exports. Food Policy, 50, 68-79.

Freund, C., and Rocha, N. (2011). What constrains Africa's exports? The World Bank Economic Review, 25(3), 361-386.

Fischer, R., and Serra, P. (2000). Standards and protection. Journal of International Economics, 52(2), 377-400.

Fontagné, L., Orefice, G., Piermartini, R., and Rocha, N. (2015). Product standards and margins of trade: Firm-level evidence. Journal of International Economics, 97(1), 29-44.

Gandal, N., and Shy, O. (2001). Standardization policy and international trade. Journal of International Economics, 53(2), 363-383.

Gebrehiwet, Y., Ngqangweni, S., and Kirsten, J. F. (2007). Quantifying the trade effect of sanitary and phytosanitary regulations of OECD Countries on South African food exports. Agrekon, 46(1), 1-17.

Henson, S., and Jaffee, S. (2008). Understanding developing country strategic responses to the enhancement of food safety standards. World Economy, 31(4), 548-568.

Jaffee, S. M., and Henson, S. (2004). Standards and agro-food exports from developing countries: rebalancing the debate. World Bank Policy Research Working Paper 3348. Washington DC: The World Bank.

Iwanow, T., and Kirkpatrick, C. (2009). Trade facilitation and manufactured exports: is Africa different? World Development, 37(6), 1039-1050.

Levchenko, A. (2007). Institutional quality and international trade. Review of Economic Studies, 
74(3), 791-819.

Li, Y., and Beghin, J. C. (2014). Protectionism indices for non-tariff measures: an application to maximum residue levels. Food Policy, 45, 57-68.

Maertens, M., and Swinnen, J. (2007). Standards as barriers and catalysts for trade, growth, and poverty reduction. Journal of International Agricultural Trade and Development, 4(1), 4761.

Marette, S., and Beghin, J. (2010). Are standards always protectionist? Review of International Economics, 18(1), 179-192.

Maskus, K. E., Otsuki, T., and Wilson, J. S. (2005). The cost of compliance with product standards for firms in developing countries: An econometric study. World Bank Policy Research Working Paper 3590. Washington DC: The World Bank.

Mayeda, G. (2004). Developing disharmony? The SPS and TBT agreements and the impact of harmonization on developing countries. Journal of international Economic Law, 7(4), 737764.

Nicita, A., and Gourdon, J. (2013). A preliminary analysis on newly collected data on non-tariff measures. Policy Issues in International Trade and Commodities. UNCTAD Study Series 53, 1-32. Geneva: United Nations Conference on Trade and Development (UNCTAD)

Nicita, A., and Rollo, V. (2015). Market access conditions and sub-Saharan Africa's exports diversification. World Development, 68, 254-263.

North, D. C. (1990). Institutions, institutional change and economic performance. Cambridge: Cambridge University Press.

Otsuki, T., Wilson, J. S., and Sewadeh, M. (2001). Saving two in a billion: quantifying the trade effect of European food safety standards on African exports. Food Policy, 26(5), 495-514.

OECD, (1996). Standardisation and Conformity Assessment: Issues in the Global Marketplace, DAFFE/ CP (96)1, Paris: Organisation for Economic Cooperation and Development (OECD).

Portugal-Perez, A., and Wilson, J. S. (2012). Export performance and trade facilitation reform: hard and soft infrastructure. World Development, 40(7), 1295-1307.

Rakotoarisoa, M., Iafrate, M., and Paschali, M. (2011). Why has Africa become net food importer? Explaining Africa's agricultural and food trade deficit. Rome: Food and Agriculture Organization of the United Nations (FAO).

Reis, J. G., and Farole, T. (2012). Trade competitiveness diagnostic toolkit. Washinton DC: The World Bank. Retrieved from http://dx.doi.org/10.1596/978-0-8213-8937-9 [Accessed 14 December, 2013].

Rodrik, D., Subramanian, A., and Trebbi, F. (2004). Institutions rule: the primacy of institutions over geography and integration in economic development. Journal of Economic Growth, 9(2), 131-165.

Rios, L. B. D., and Jaffee, S. (2008). Barrier, catalyst, or distraction? Standards, competitiveness, and Africa's groundnut exports to Europe. Agriculture and Rural Development Discussion Paper, 39. Washington, DC: The World Bank.

Scheepers, S., Jooste, A., and Alemu, Z. G. (2007). Quantifying the impact of phytosanitry standards with specific reference to MRLs on the trade flow of South African avocados to the EU. Agrekon, 46(2), 260-273. 
WTO (2015). Understanding the WTO (5th ed., pp 1-116). ISBN 978-92-870-3748-0. Geneva: World Trade Organization (WTO).

Xiong, B., and Beghin, J. (2011). Does European aflatoxin regulation hurt groundnut exporters from Africa? European Review of Agricultural Economics, 39(4), 589-609.

Xiong, B., and Beghin, J. (2014). Disentangling demand-enhancing and trade-cost effects of maximum residue regulations. Economic Inquiry, 52(3), 1190-1203. 


\title{
Chapter 2
}

\section{Trade Effects of EU SPS and TBT measures When Zeros are Frequent: A Comparison of Estimation Techniques Using African Data}

\begin{abstract}
The issues of zero trade observations and the validity of the logarithmic transformation of the gravity model have generated a number of debates in the literature with differing claims about the most suitable estimation technique. To produce unbiased and consistent estimates for policy making, we undertake a careful comparison of a number of widely used estimators to investigate if the European Union (EU) sanitary and phytosanitary standards and technical regulations on fish products are protectionist following recurring rejection of Africa's fish products at the EU border. Analysis was based on a dataset of Africa's exports of fish to the EU between 2007 and 2012, which contains about $63 \%$ zero trade observations. Our results from the robustness checks are in favour of the Multinomial Poisson Maximum Likelihood (MPML) technique as the most consistent estimator in relation to the impacts of standards and other explanatory variables. In addition, we find that the EU food measures are indeed non-protectionist in spite of the high level of Africa's fish exports rejected at the EU border since 2008. Thus, deeper trade negotiations between these trading partners involving a significant transfer of science and technology to Africa could help improve their compliance rate to EU standards and ensure increased export penetration.
\end{abstract}

Keywords Gravity model, Zero trade, Estimation techniques, SPS measures, TBT measures, European Union, African Exports

\section{JEL Classification C18 F13 F14 L15}

\subsection{Introduction}

The gravity model has emerged as an important model in predicting bilateral trade flows. While its theoretical justification is no longer in doubt, its empirical application has generated several controversies; these specifically concern the appropriate estimation technique in the presence of both zero trade observations and log linearization of the gravity equation. The first challenge arises from the choice of the estimation technique that would produce $u$ iased and consistent estimates when zero trade flows occurs. These zeros are particularly pervasive in disaggregated trade data. The second arises from the proposition that the log linear gravity equations, which are usually estimated with linear estimation techniques, fail to produce homoscedastic residuals. Santos Silva and Tenreyro (2006) posited that as a result of the logarithmic transformation of the equation, linear estimators may be inconsistent in the presence of heteroscedasticity, and therefore a Poisson-like estimator commonly known as Poisson Pseudo Maximum Likelihood (PPML) should be used. The study argued that the method is consistent when heteroscedasticity 
is present in the data and that it also deals naturally with zero trade flows. Consequently, they deem it fit to be a workhorse for estimating the gravity equation.

However, their assertion has generated some controversies in the literature resulting in the recommendation of alternative estimation techniques that can also accommodate zero trade values. These include the zero inflated models (Burger et al., 2009); sample selection models (Martin and Pham, 2008; Gomez-Herrera, 2013); feasible generalized least square model (Martinez-Zarzoso, 2013) and the Tobit model (Eaton and Kortum, 2001). Head and Mayer (2014) posited that there is no single best estimation technique, because choosing the best method depends on the dataset, the research questions and a lot of robustness tests. This conclusion has also been supported recently by Santos Silva et al. (2015) who posited that the choice of the most appropriate estimation is contingent on the dataset. In other words, these estimation techniques might outperform one another under specific circumstances.

In their search for the most appropriate model, the aforementioned studies have explored the gravity model and estimated the effects of free trade agreements using the gravity model (Santos Silva and Tenreyro, 2006: Martinez-Zarzoso, 2013). However, as a departure from these techniques, we model the trade effects of both sanitary and phytosanitary standards (SPS) measures aimed at achieving food safety objective, and technical barriers to trade (TBT) measures, specifically technical regulations that govern agricultural food sector. On the one hand, SPS are standards, rules and regulations levied on food, drink and feed with the major aim of ensuring plant, animal, wildlife and human health and safety including the conformity assessment measures regarding food safety, animals and plant health. On the other hand, technical regulation is an aspect of technical barriers to trade and is sometimes termed mandatory standards. It specifies product's characteristics, process and production methods such as product weight, package and label, quality and may also include conformity assessment procedures that determine whether the products comply with the stipulated technical requirements, such as testing, inspection, accreditation and certification.

While SPS measures are levied on food, drink and feed, to achieve plant and animal health as well as food safety, however, TBT are wider in scope, exist in all sectors of the economy and are aimed at achieving national security, preventing deceptive practices as well as achieving health and safety, other than those aimed at achieving food safety, plant and animal health which are those covered by SPS measures. Thus, our focus in this essay is on TBT measures specifically technical regulations ${ }^{3}$ governing food products, and SPS measures on food safety. Both technical regulations/standards and SPS standards (hereafter standards ${ }^{4}$ ) in line with the World Trade Organisation (WTO) principle of non-discrimination, are usually applied on the most favoured nation (MFN) basis, implying that the same set of rules apply to domestic and

\footnotetext{
${ }^{3}$ These could include technical specification about packaging size of the food cartoons, weights of food products, labelling of the nutritional contents of food products, etc.

${ }^{4}$ Technical regulations are commonly referred to as mandatory standards while SPS measures on food have been commonly referred to as food standards, so in this chapter, the term 'standards' refers to a combination of both SPS measures and technical regulations (mandatory standards) unless stated otherwise
} 
foreign firms, so, exporters must comply with the importing country standards to ensure unrestricted market access. An exception to this MFN rule is when a specific country has been identified as posing considerable safety risks. In this case, the standards are levied only on the identified country.

Theoretically, standards have been posited to be capable of having both trade promoting and inhibiting effects. On the one hand, standards may be a catalyst for international trade as they increase the value of certified products and processes by providing consumers vital information and assurance about their health and safety (Blind, 2001), and may thus trigger a higher demand for imports. On the other hand, standards can constitute a barrier to trade as complying with stringent standards implies that huge compliance costs would be borne by producers. This can result in the erosion of export competitiveness and affect profitability of the export product, particularly those from developing countries (Fisher and Serra, 2000; Xiong and Beghin, 2014). For instance, the higher cost of compliance may drive out less productive firms and discourage potential exporters from entering the export market, which might result in zero trade flows. In addition, the imposition of standards can result in the rejection of non-conforming products at the importing countries' borders, consequently leading to the occurrence of zeros in the trade flows matrix of the affected product. Non-compliance can also bring about decisions not to export, thereby aggravating the occurrence of zeros in the trade flow matrix. This is particularly true for many African countries whose exports have been allegedly rejected at the EU border due to non-conformity to the latter's standards.

This study is motivated by the methodological challenges which can be posed by standards levied on food as it is anticipated that their imposition can bring about zero trade flows. While it is true that some of the zeros can be attributed to statistical zeros such as rounding up, or not meeting a declaration threshold, many of these zeros may in fact reflect the inability to trade due to the lack of export profitability resulting from prohibitively high compliance costs of meeting food standards. As an empirical application, we analyse the implications of EU food standards on Africa's fish exports using trade data from 2007 to 2012 across a sample of 27 EU and 40 African countries. We primarily focus on fish and fishery products. Our choice of the fish trade hinges on the premise that these products attract a relatively significant number of standards compared to other products due to them being highly perishable in nature. In addition, the available evidence shows that fish products are the highest rejected African exports at the EU border, constituting about $70 \%$ of all Africa's food exports refused entry into the EU due to not meeting the required EU food standards requirements (RASFF, 2014). Furthermore, the stringency of standards has increased in the EU (Felbermayr and Jung, 2011). EU standards are said to be overly stringent compared to other international standards, resulting in more tedious conditions for the exporting countries to meet. Thus, our objective is to investigate if EU fish standards are indeed protectionist in nature such that they increasingly cause rejections from certain countries at the border. This is based on antecedent concerns that standards can also be used as protectionist tool, particularly when such standards are more stringent than internationally recommended ones (Xiong and Beghin, 2014). 
Our study makes two important contributions to the existing literature. Firstly, we investigate if stringent EU standards are indeed protectionist in nature using both mandatory standards (technical regulations) levied on food products and SPS measures levied on food products with the aim of ensuring food safety. However, with the exception of Xiong and Beghin (2014), empirical investigation into the protectionist extent of standards are rare due to the difficulty and complexity of measuring the stringency of standards and the lack of an acceptable globally recognized benchmark for distinguishing standards with legitimate intent from those with protectionist intent. Secondly, we make a methodological contribution by consistently estimating the trade impact of standards when zeros are frequent, most likely due to the high stringency of standards which prevents exporters from exporting to the EU. Africa's dataset is somewhat peculiar in terms of missing data and or missing trade which necessitates the comparison of different estimators. We therefore find it appropriate to apply several of the recommended techniques to compare the performances of the different estimators using the appropriate robustness analyses in order to provide policy makers with unbiased and consistent estimates that could be used as tools in future trade negotiations with the EU. Extensive methodological rigour is important so as not to distort the information provided to policy makers. In other words, a naive approach to estimation may lead to biased and frequently misinterpreted results capable of straining already established trade relationships between any two trading partners.

The rest of the paper is structured as follows. The next section reviews the theoretical framework of the gravity model. Section 2.3 gives a short review of various gravity model estimation techniques and the challenges presented by them with the occurrence of both zero trade observations and heteroscedasticity; this section also reviews related empirical literature. Section 2.4 previews the construction of the standard data while section 2.5 provides the methodology. In section 2.6, we discuss the results while the final section concludes.

\subsection{Literature Review}

The gravity equation was first employed by Ravenstein (1889) to analyse migration patterns in the United Kingdom. However, the first formal usage of the model in analyzing trade flows dates back to Tinbergen (1962). According to early versions of the model, bilateral exports from country $i$ to $j$ are predicted by exporters' and importers' economic masses which are used as proxies for their income, and the geographical distance between the trading country-pairs.

\subsubsection{Heterogeneity, Zeros and a New Development in the Theoretical Foundation}

After more than two decades of the influx of models providing theoretical justification of the gravity model, emphasis thereafter turned to making sure that the empirical results are well rooted in theories. One important contribution in this regard relates to the equation's structural form and the implication of mis-specification or omitted variable bias. These relate to the way that trade costs and firm heterogeneous behavior are both incorporated into the gravity equation.

One important contribution relates to the incorporation of multilateral trade resistance and trade costs into a gravity equation that was micro-founded (Anderson and van Wincoop, 2003). Another important addition relates to the structural form of the equation. An important area of 
contribution details the methodological issue associated with the presence and behavior of heterogeneous firms operating in international markets which was led by Bernard et al. (2003) and Melitz (2003). Firm heterogeneity arises as not every existing firms in a country is able to export its products; indeed, only a minority of these firms participates in the international market (Bernard et al, 2003). Furthermore, not every exporting firms are able to export to the rest of the world; they are often only active in a subset of countries and may choose not to sell specific products to specific markets (due to their inability to do so). This firm heterogeneity behavior arises because fixed costs are specific to a market and such costs are relatively much for international markets compared to domestic. Thus, it is those firms that are most productive that would be able to cover these costs, and firms' inability to export may be due to the high cost involved. Consequently, some countries will have zero trade observations. An example in this regard is mostly seen in greater levels of product data disaggregation at the Harmonised System (HS) such as HS6 and HS8.

The prevalence of zero bilateral trade flows has significant implications for modelling the gravity equation as the observed zeros might contain important information about the countries (such as why they are not trading) and such information can be analysed to obtain efficient estimates (Helpman, Melitz and Rubinstein, 2008). The standard gravity equation usually neglects the issue of the prevalence of zero bilateral trade flows and predicts theory consistent with only positive bilateral trade flows. However, Chaney (2008), Helpman et al. (2008), Melitz and Ottaviano (2008), Chen and Novy (2011) derived theoretical gravity equations which highlights the presence of zero trade records and gives theoretical interpretations for them. The 'new new' trade model of trade which accounts for firm heterogeneity can be traced to Melitz (2003) and is usually adopted in order to give the gravity equation a theoretical basis.

In a bid to providing a theoretically consistent gravity equation, Helpman et al. (2008) argue that "by disregarding countries that do not trade with each other, these studies give up important information contained in the data" (Helpman et al., 2008, p. 442), and that the symmetric relationship imposed by standard gravity models bias the estimates as it is inconsistent with the data. To correct for this bias, Helpman et al. (2008) provides a theoretical gravity equation which explains and incorporates firm heterogeneity behavior and positive asymmetric trade flows which was thus able to predict both positive and zero trade flows between country-pairs. Given firm level heterogeneity, they assume that products are differentiated and firms are faced with both fixed costs and variable costs when exporting. According to Helpman et al. (2008), firms have varying degrees of productivity, such that those that have higher productivity find it profitable to engage in exportation, with profitability varying by export destinations. Since not all firms found exporting to be profitable, this gives rise to positive and zero trade flows across country-pairs. Furthermore, this difference in productivity gives rise to asymmetric non-zero trade flows in both the exporters and importers' directions for some country-pairs. These nonzero asymmetric trade and the zero bilateral trade flows are then used to establish the extensive margin of trade flows (number of firms that export). Moreover, given that firms in the exporting countries are not productive enough to enable them to profitably engage in exportation activities to other countries, this implies that there will be bilateral zero trade for some pairs of countries. 
This generates a model of firm heterogeneity that predicts not only positive trade flows from exporting countries to importing countries for some country-pairs, but also zero bilateral trade flows between trading countries in both directions.

In summary, a more recent wave of contributions to the gravity equation has come from the development of a theoretical gravity equation that provides a theoretical basis for the occurrences of both observed and unobserved trade (zero trade flows). This is coupled with an influx of theoretically consistent estimation techniques including those that aim to consider the occurrence of zero trade flows.

\subsection{Empirical Literature}

The gravity model is very popular in explaining trade relations. First, this is due to the rigorous theoretical foundation given to it with the emergence of trade theories - especially the new new trade theory. Second and more important, this is attributed to model's success in the empirical analysis of international trade relations. However, in spite of the popularity it enjoys, questions still remain regarding the appropriate specification of the equation as well as the appropriate econometric estimation technique(s) that would give consistent estimates when zeros are frequent in the dependent variable. This section therefore sheds light on the various estimation techniques used to tackle this problem. Particular attention is focused on the problems and advantages of each technique with the occurrence of zero trade observations in the data, which is prominent as a consequence of the disaggregated dataset in which a large proportion of trade values are found to be zero. The section ends by reviewing the techniques employed in the standard-trade literature.

\subsubsection{Estimation Issues in Gravity Modeling - The Debate}

In the past, most empirical studies have relied on cross-sectional dataset in estimating the gravity equation, thus the economic framework for the model was based on cross-sectional analysis, (c.f. Anderson, 1979; McCallum, 1995; and Deardorff, 1998; etcetera). For such cross-sectional analyses, the Ordinary Least Square (OLS) estimation technique or pooled OLS technique is normally employed. However, cross-sectional technique is reported to be prone to problems relating to misspecification problems and thus previous estimates are likely to be unreliable (Carrerè, 2006). This is because the cross-sectional gravity model is usually specified to control for time invariant variables (e.g. language, distance, cultural and other historical variables), but the model suffers from misspecification as it does not control for country specific unobservable effects which are time invariant. These unobservable factors are instead absorbed by the error term, but are likely to be correlated with the independent variables and since OLS technique is usually used, this renders the least square estimator to be inconsistent, and makes its classical assumptions invalid. In addition, OLS does not control for heterogeneity among the individual countries. This has the potential of resulting into estimation bias as the estimated parameters may vary depending on the countries considered. As a result, estimating cross-sectional models with the omission of unobservable effects gives biased estimates of the intended effects on trade. This renders the conclusions on cross-sectional based trade estimates problematic (ibid). 
Conversely, over the last decade, there has been a proliferation in the usage of panel data in gravity modeling and panel methods (Rose and van Wincoop, 2001; Egger, 2000; Egger and Pfaffermayr, 2003, 2004; Baltagi, et al., 2003). The panel specification is much more adequate as the extra time series data points give more degrees of freedom, resulting in more accurate estimates. A unique advantage of panel data is that the panel framework allows the modeling of the evolvement of variables through time and space, serving as controls for variables omitted due to unobserved heterogeneity which, if not accounted for, can cause omitted variable bias (Baltagi, 2008). In addition, with panel data the time invariant unobserved trade effects can easily be modeled by including country specific effects such as time dummies, and thus avoiding the consistency issue mentioned above.

With the availability of panel data, the two common techniques used in fitting the data are the fixed effect and random effect estimation techniques, where the choice between the two hinges on their assumptions. The assumption underlying the fixed effects model is that unobserved heterogeneity is correlated with the residual term. Conversely, the random effects model assumes that unobserved heterogeneity is strictly exogenous. That is, it does not impose any correlation between the independent variables and unobserved heterogeneity (ibid). The acceptance of the null hypothesis of orthogonality will be in favour of the random effects model implying that the model is more efficient and the rejection of the null hypothesis is in favour of the fixed effect model implying that it is consistent while the random effects model is neither consistent nor efficient. In addition, studies have also used the OLS technique to estimate panel data. However, the pooled OLS technique can only give estimates which are precise and test statistics that have higher power only if the relationship between the regressant and the regressors remains constant over time.

Early gravity model estimation techniques used in estimating the gravity equation was OLS, where the model is log linearized as a common practice. The validity of a log-linear gravity model hinges on the homoscedastic assumption, as the residual term and the dependent variable must be statistically independent of the regressors. However, in recent times, Santos Silva and Tenreyro (2006) have identified flaws with this practice. Their position is that due to the nature of trade data that are intrinsic to heteroscedasticity and pervasive zero trade flows, log linearizing the equation and then applying OLS technique is problematic.

First, problems arise in the logarithmic transformation due to heteroscedasticity which is usually present in trade data. Santos Silva and Tenreyro (2006) noted that a common habit of obtaining the logarithm of dependent variable of the gravity model and then applying OLS technique is not appropriate. According to them, this is because the expected values of the log linearized error term will be dependent upon the variables of the regression, thus rendering OLS technique inconsistent, and this situation will still hold if the dependent variable does not have any zero observation. This is due to the fact that a logarithmic transformation of the model alters the characteristics of the error term (ibid). In other words, OLS would give consistent results in so far as the error term $\left(\varepsilon_{i j}\right)$ of the $\log$ linear specification $\left(\ln \varepsilon_{i j}\right)$ remains a linear function of the independent variables, i.e., if $E\left[\ln \left(\varepsilon_{i j t} \mid x_{i j t}\right)\right]=0$, which is the homoscedasticity assumption. 
However, the logarithmic transformation generates estimates of $E\left(\ln \varepsilon_{i j}\right)$ and not $\ln E\left(\varepsilon_{i j}\right)$, but $E\left(\ln \varepsilon_{i j}\right) \neq \ln E\left(\varepsilon_{i j}\right)$, here $\ln E\left(\varepsilon_{i j t} \mid x_{i j t}\right)=0 ; E\left(\ln \varepsilon_{i j t} \mid x_{i j t}\right) \neq 0$, which is known as Jensen's inequality ${ }^{5}$.

Consequently, due to Jansen's inequality, the error term $\left(\varepsilon_{i j t}\right)$ is not equal to the log of the error term $\left(\ln \varepsilon_{i j}\right)$ because the error term of the log linear model is not statistically independent of the regressors but are rather heteroskedastic, leading to inconsistent estimates of the elasticity coefficients. Given Jansen's inequality, Santos Silva and Tenreyro (2006) argue that the log linearizing the gravity model makes it intrinsic to heteroscedasticity and applying OLS technique results in biased and inefficient estimates. They argue that even though economists have long known about this inequality and that the logarithm equation's concavity could create a download bias if OLS is employed, this important drawback has been overlooked in many bilateral trade studies. They confirm their argument with empirical evidence which confirms the presence of heteroskedasticity and inconsistency in the log linear gravity model; this subsequently renders the estimates of elasticity obtained from the least squares estimation technique to be both inefficient and inconsistent.

Second and probably more problematic is that the trade matrix is characterized with a prevalence of zero trade flow observation in the trade matrix and the appropriate estimation technique. While the Newtonian theory on gravity which is where the gravity model was theoretically derived allows for a very small non-zero gravitational force, in trade, there are frequent occurrences of zero ${ }^{6}$ trade flow observations and the estimated the log linear gravity equation with the occurrence of these zeros gives rise to both methods and theory issues; particularly in cases when the occurrence of such zeros are pervasive. In estimating the gravity model, the model is log linearized and estimated using these linear regression techniques. However, given the predominance of zero trade records in the trade matrix, particularly at the more disaggregated level where zero records can constitute over $50 \%$ of trade flow observation, the logarithm transformation of the dependent variable is therefore problematic at least in cases in which the zeros contain relevant information. This is due to the fact that the logarithm of zero is indeterminate and not feasible.

The common practices in the literature which are used to tackle the problem of zero records are truncating and censoring methods and thereafter, applying linear estimation techniques. With respect to the truncation method, the zero observation are dropped completely from the trade matrix, whereas the censoring method involves substituting the zeros with arbitrary small

\footnotetext{
${ }^{5}$ Jensen's inequality is named after Johan Jensen, the Danish mathematician who discovered it in 1906: the secant line of all the convex function (i.e., the means of the convex function) lies above the graph of the function (i.e., the convex function of the weighted means) at every point. The reverse is true for a concave function. His inequality has appeared in many contexts. An example in this case is the arithmetic mean inequality. Thus, in simplified terms, his inequality states that the convex (or concave) transformation of a mean is less or equal to (greater or equal to) the mean after a convex (concave) transformation. Thereafter, economists have adopted his intuition to show that the logarithm transformation of an equation generates the expected value (mean) of the logarithmic transformation of the dependent variable $E\left(\ln Y_{i j}\right)$ and not the logarithm of the mean of the dependent variable $\ln E\left(\mathrm{Y}_{i j}\right)$; and $E\left(\ln \mathrm{Y}_{i j}\right) \neq \ln E\left(\mathrm{Y}_{i j}\right)$.

${ }^{6}$ Frankel (1997) argued that these zero observations occur due to the absence of trade between country-pairs, or can also result from rounding up which occurs when bilateral trade between country-pairs falls below a threshold or can arise when they are rounded-down as zero; it can also result from measurement errors where observations are mistakenly recorded as zeros.
} 
positive values. However, these methods are somewhat indiscriminate and without any strong theoretical or empirical justification (Linders and de Groot, 2006). Consequently, they can distort the results significantly, leading to inconsistent estimates (Flowerdew and Aitkin, 1982; Eichengreen and Irwin, 1998; Linders and de Groot, 2006; Gomez-Herrera, 2013). Furthermore, Flowerdew and Aitkin ${ }^{7}$ (1982) show that the results are sensitive to (small) differences in the constant which is substituted; such differences can cause serious distortions in the results. Eichengreen and Irwin (1998) noted that deleting these zero values led to a loss of information as important information on the zero trade levels is left out of the model and can generate biased results if the zero trade flows are not randomly distributed. In addition, Heckman (1979) and Helpman et. al. (2008) posit that omitting the zeros can result into sample selection bias. The loss of information is said to reduce efficiency and the omission of data produces biased estimates (Xiong and Beghin, 2011; Gomez-Herrera, 2013). In addition, Xiong and Beghin (2011) noted that deleting the zero trade observations prevents the possibility of exploring the extensive margin of trade. Furthermore, according to them, the deletion also implies that the results are based on bilateral trade that has already occurred - the intensive margin of trade, while ignoring the information on the extensive margin of trade. They concur that ignoring zeros constrain the economic interpretation as nothing can be said on the implication for new trade.

Likewise, Linders and de Groot (2006) argued against truncating and censoring, positing that zero trade observations may provide vital information on bilateral trade and therefore one should refrain from eliminating. According to them, disregarding the zero trade flows may give bias results if such flows are not random. This is because zero trade flows provide information about the probability to engage in bilateral trade. Thus, if distance, a lack of cultural ties and low GDP, etcetera makes trade non-profitable, thereby reducing trade or bringing about no trade, then eliminating zero flows from the analysis is tantamount to sample selection bias and applying OLS will lead to underestimating the gravity equation coefficients (ibid).

In recent times, there has been focus on the appropriateness of the estimation technique especially in relation to the problems revolving around zero trade including the log linearization of the gravity model, and the constant emphasis on the inappropriateness of linear estimators in taking care of these two problems. Consequently, more appropriate estimation techniques are being increasingly employed to deal with these two issues in the context of gravity trade literature. The Tobit and Probit models, truncated regression, Poisson and modified Poisson models, Feasible Generalized Least Square (FGLS), including the Heckman (1979) and Helpman, et al. (2008) models have all been employed to tackle the problem related to log linear gravity model and the high occurrence of zero trade flows.

Early studies have relied on the Tobit model to deal with the zero trade problems. For instance, the Tobit model has been employed by Rose (2004) and Andersen and Marcoiller (2002) in tackling the occurrence of zero trade flows which occur as a result of the actual trade flows not been observable or as a result of measurement errors from rounding. The Tobit estimator is

\footnotetext{
${ }^{7}$ They varied the substituted constant between 0.01 and 1 and found that the regression coefficient decreases with the size of the chosen constant.
} 
applied to fit the data when outcome/data are only observable over some range. It is applied in cases of measurement errors (for example, rounding up) or when actual outcomes do not seem to reflect the desired outcomes. The Tobit censoring method involves rounding (censoring) part of the observation to zero or rounding up the zero trade flows below some positive value.

Nevertheless, Linders and de Groot (2006) have debated on the usefulness of employing a Tobit estimator in fitting zero trade flows in a gravity model. According to the, the use of a Tobit model will depend on if the level of trade can be negative or if rounding up trade values is necessary. Their argument is that in the gravity model, the zero trade flows cannot be censored at zero as the desired trade cannot be negative in the gravity equation; this can only occur if the gross domestic product (GDP) of a country-pair equals zero which is unlikely in real life. They further argue that censoring at a positive value is also not appropriate. Their intuition is that the United Nations Commodity Trade (UN COMTRADE) statistical database reports trade values, even for very small values (up to one US dollar), indicating that rounding to zeros is not an important cause of zero observation as most zeros are caused by economic reasons such as lack of profitability. This implies that zero trade flows are likely to occur from binary decision making about the profitability of engaging in trade, and not from rounding up (censoring), thus the model might not be appropriate for taking care of zero trade flows. In addition, Frankel (1997) and Rose (2000) noted that the Tobit estimator involves an artificial censoring of positive albeit small trade values; however, the trade flow is subject to measurement errors, and they may have a larger influence on the regression results.

Furthermore, Martin and Pham (2008) show that although both the truncated OLS and censored Tobit models lead to biased results, the censored method generally produces much worse results in comparison to the truncated method. They affirm that the Eaton and Tamura (1994) threshold Tobit model gives the lowest bias and outperforms all other estimators in their simulation exercise. In contrast, in a simulation exercise, Santos Silva and Tenreyro (2011) found the Tobit model to have a large bias, which increases with sample size; this also confirmed its inconsistency as an estimator. Nevertheless, Head and Mayer (2014) recently proposed the use of an alternative Tobit procedure that avoids the problem of selecting arbitrary values to replace zero trade flows without any criteria. In particular, based on Eaton and Kortum (2001) they propose to replace the zeros by the minimum level of trade for a given importing country $i$ from all destination $j$, which is denoted as $\underline{y}_{i j}$. Thereafter, all the zeros contained in $y_{i j}$ (the dependent variable) are then replaced by $\underline{y}_{i j}$ and the newly coded $\ln y_{i j}$ represents the new dependent variable in the Tobit model. According to Head and Mayer (2014), this model can be termed an Eaton and Kortum (EK) Tobit, and has two advantages. First, it does not require any exclusion restrictions and second, it is easily estimated using Stata's 'intreg' command.

There is also the usage of the Poisson model and its variants in analysing trade flows within the framework of the gravity model. For instance, Santos Silva and Tenreyro $(2006,2011)$ used the PPML estimator to estimate the gravity equation when the dependent variable features some zeros and also to avoid the logarithm transformation of the gravity model. According to them, 
in the presence of zero valued observations and due to the logarithm transformation of the gravity equation, the OLS (both truncated and censored OLS) estimator is inconsistent and has very large biases which do not vanish as the sample size increases; this confirms that they are inconsistent (Santos Silva and Tenreyro, 2011). However, PPML technique estimates the dependent variable in the gravity model in levels in contrast to taking its logarithms; this allows the researcher to avoid the problem posed when using OLS following the logarithm transformation of the dependent variable. According to Santos Silva and Tenreyro (2006), the PPML model which is a variant of the Poisson model is a more appropriate estimation technique in analyzing zero flows due to a number of factors. First, the model control for the presence of observed heterogeneity. Second, fixed effects PPML estimation technique naturally deals with the zero trade observations due to the fact that it is estimated in its multiplicative form. Third, the method also avoids the underprediction of huge trade volumes and flows by producing estimates of trade flows instead of the log of the trade flows. In their influential 2006 paper, they find the PPML estimator, which does not need to be log-linearized, to be the best performing estimator that naturally deals with zero trade flows. According to them, this estimator is consistent and gives the lowest bias among the other estimators. They therefore suggest it as the new estimation workhorse for typical constant elasticity equations like the gravity model.

Despite its success, their influential paper has generated some controversy in the literature (c.f. Martinez-Zarzoso et al., 2007; Martin and Pham, 2008; Burger et al., 2009; etcetera). For instance, Burger et al. (2009) identified some important limitations of the PPML model. They noted that the model is highly proned to overdispersion (that is, when the variance of the dependent variable is not proportional to its mean) of the dependent variable and excess zero flows. They posit that the model only takes account of observed and not unobserved heterogeneity, and that this is an important limitation of the model. While a key condition of the PPML is the assumption of equi-dispersion (variance being equal to the mean) of the dependent variable, due to the presence of unobserved heterogeneity there is an over-dispersion in the trade flows (dependent variable). This over-dispersion is said to generate inefficient but consistent parameters (Burger, et al, 2009; Turkson, 2010).

Contrary to Burger et al. (2009) who noted that the PPML model is vulnerable to the problem of over-dispersion in the dependent variable and excess zero flows, Santos Sliver and Tenreyro (2011) find the PPML to be consistent and well-behaved in situation of overdispersion and that the predominance of the huge number of zeros rarely affect it. In addition, Soren and Brümmer (2012) find that the PPML performs quite well under over-dispersion, and show that the PPML method is well-behaved under bimodal distributed trade data.

More recently, Head and Mayer (2014) find that a Multinomial Pseudo Maximum Likelihood (MPML) approach performs better in simulations than the PPML. According to them, assuming that it is reasonable to assume that market shares, are an appropriate dependent variable for the gravity model, then the MPML is the model recommended by Eaton et al. (2012) in a situation where there are finite firms. 
The MPML model was the estimation technique which was suggested by Eaton et al. (2012) and used in Head and Mayer (2014). One advantage of the MPML is that it is closer to the PPML approach as the estimator also tackles the zero problems. Furthermore, as proved by Sebastian Sotelo in his unpublished notes, the model is easily estimated in Stata by using the 'poisson' command in Stata to estimate the impacts of the independent variables on the dependent variable which is the 'market share' variable (Head and Mayer, 2014). In a footnote of Eaton et al. (2012), the properties of this model are highlighted as distinct from the log linear and PPML models. Their distinction is in terms of the penalties (weights) they give to deviations in large and small trade flows. The log linear approach treats proportional deviations as equally likely across large and small trade flows; while PPML assigns a greater penalty to proportional deviations in large trade flows than it would for small trade flows. However, MPML normalizes bilateral trade flows by the importers' total trade absorption (it gives lower weights to relatively larger trade volumes and shares, preventing the dependent variable from obtaining values over one), thereby eliminating different penalties for proportional deviations in the large and small trade flows.

Attempts have also been made to correct for the overdispersion and the vulnerability of the PPML to excessive zero flows using other estimation techniques such as a Negative Binomial Pseudo Maximum Likelihood (NBPML) and the two zero inflated models - the Zero Inflated Poisson Pseudo Maximum Likelihood (ZIPML) and Zero Inflated Negative Binomial Pseudo Maximum Likelihood (ZINBPML) models (Burger et al., 2009). They posit that the NBPML corrects for overdispersion by allowing the estimator to incorporate unobserved heterogeneity in the mean. However, one important drawback of the NBPML and PPML relates to the high percentage of zeros that is present in the observations, implying that the number of zeros is greater than the number predicted by the models. The excessive zeros are said to be derived from the "non-Poissoness ${ }^{8}$ of the model (Johnson and Kotz, 1969). Thus, Burger et al. (2009) posit that even though the Poisson and NBPML techniques can technically handle zero flows, both models are not appropriate for cases where the number of zero flows is greater those that the model predict.

However, Burger et al. (2009) find that both ZIPPML and ZINBPML perform better as they account for excess zeros and overdispersion in the dependent variable. They also noted that zeroinflated models have an added advantage as they are theoretically well suited in modeling the origin of zero counts because the models account for two different types of zero flows. The first type of zeros results from countries which have never been involved in trade before (the nonPoisson group), implying a data that strictly have zero counts. The second type of zeros results from those countries that presently do not engage in bilateral trade but however have a high propensity to trade (the Poisson group ${ }^{9}$ ). Given this information, Turkson (2011) argued that the

\footnotetext{
${ }^{8}$ Burger et al. (2009) identified that one of the causes of non-Poissoness arise when some of the zero observations are generated by another process compared to the other observations (including some other zeros)

${ }^{9}$ The zero inflated models consider two different groups within the population: the Poisson group and the non-Poisson group. The non-Poisson group are countries which have strict zero probability of trading but do not trade at all. The non-Poisson zeros might be caused by lack of trade due to bans or other trade embargoes or simply the lack of resources. The Poisson group consist of those country pairs that have non-zero propensity to trade and are actively involved in trade, and countries that have non-zero propensity to trade and are not trading. The Poisson zeros might be caused by huge distance or large differences in country pairs preferences and specialization.
} 
choice of the appropriate model would depend on whether or not the zero trade observations are excessive.

Head and Mayer (2014) also finds that the PPML and Gamma Pseudo Maximum Likelihood (GPML) remain consistent even under overdispersion and advise that confirming the presence of overdispersion should not be used in justifying the usage of the NBPML. This is because estimates obtained by the NBPML method vary according to the dependent variable's units of measurement (Bosquet and Boulhol, 2012). For instance, and Bosquet and Boulhol (2012) show that representing trade in thousand dollars and later changing it to billion dollars leads to huge difference in the magnitude of the estimates and also changes the signs obtained for some explanatory variables.

Contrary to Burger et al. (2009), Staub and Winkelmann (2012) find that the PPML is consistent even when zeros are excessive. They also show that both ZIPPML and ZINBPML are not consistent when the underlying assumptions of the distribution of the model are violated, i.e. if the models are mis-specified. Instead, they propose the usage of the Poisson Quasi Likelihood (PQL) model which was shown to be unaffected by unobserved heterogeneity and also consistent when there are excessive zeros and is unaffected by unobserved heterogeneity. Furthermore, they find the method to be robust to misspecification as it consistently estimates the regression coefficients irrespective of the true distribution of the counts, while ZIPPML and ZINBPML demonstrate a considerable bias in the medium sample. Staub and Winkelmann (2012) also posit that the PQL can be less efficient compared to zero inflated estimators if the zero inflated model is correctly specified.

Martinez-Zarzoso (2013) also finds that the PPML was outperformed by both the OLS and FGLS estimates in out of sample forecast and deduced that it is not always the best estimator. The PPML assumption regarding the pattern of heteroscedasticity was rejected by the data in most cases. The author posits that even in the presence of unknown forms of heteroscedasticity, FGLS can still be applied as it is an efficient estimator within the class of least squared estimators; however, the variance of the disturbances should then be re-estimated to correct for heteroscedasticity errors. Consequently, it was argued that comparison ${ }^{10}$ of the best performing estimator should be between FGLS and the class of generalized linear models ${ }^{11}$ (GLM) such as the Non-linear least square (NLS), GPML and PPML (Martinez-Zarzoso, 2013). However, in their response, Santos Silva and Tenreyro (2008) provided justification for the PPML estimator, acknowledging that in some cases, PPML can be outperformed by other estimators.

Martinez-Zarzoso (2013) compares the performance of different estimators via a Monte Carlo simulation exercise and finds that although PPML is less affected by heteroscedasticity compared to FGLS, NLS and GPML, nonetheless, its performance is found to be similar both in regard to biasness and standard errors to the performance of the FGLS technique, particularly in

\footnotetext{
${ }^{10}$ Santos Sliver and Tenreyro (2006) paper have majorly centred on comparing OLS to the class of GLS models, particularly the PPML model.

${ }^{11}$ Generalized linear models are class of multiplicative models.
} 
small sample sizes. The least biasness and standard errors are found in GPML during her simulation exercise when the dependent variable contains non-zero observations. The author's further empirical analysis using three different real datasets ${ }^{12}$ reveals that the choice of the performance of the model is sensitive to the sample size. Martinez-Zarzoso (2013) find out that for a small sample size, FGLS can also be a good way to tackle the heteroscedasticity problem, while the PPML will be appropriate for large sample and when the dependent variable has measurement error. Nonetheless, in large sample size, she finds the PPML bias to decrease while FGLS bias is found to remain almost constant. In addition, the PPML standard error falls considerably but still remains twice as large as the FGLS standard errors. Conclusively, Martinez-Zarzoso (2013) posited that the choice of the best estimator is dependent on the specific dataset used in the estimation, and there is generally no best estimator for the three datasets used by her. Thus, she argued that the appropriate estimator for any application is data specific, and can be determined using a number of model selection tests.

Martin and Pham (2008) has also challenged the assertions of Santos Sliver and Tenreyro (2006) and posit that although the PPML estimator may be less subjected to the biasness from the heteroscedasticity problem, it is not robust to problems of zeros and heteroscedasticity. Based on this, they concluded that the estimator could be appropriate for other multiplicative models ${ }^{13}$ which have relatively few zero observations. Their results shows that the Eaton and Tamura (1994) threshold Tobit model performs better than the PPML and other estimators considered, as it had recorded the smallest bias in their simulation exercise.

The Monte Carlo simulation detailed by Santos Silva and Tenreyro (2006) has also generated another line of debate. Although the authors find that the PPML is able to deal with zero trade flows, interestingly, their simulation was conducted in order to determine the best performing models without any zeros, except where the dependent variable was contaminated with measurement errors. This has led some studies to question the performance of the PPML in cases where there are excessive zeros in the dependent variable (c.f. Martinez et. al., 2007; MartinezZarzoso, 2013; Martin and Pham, 2008). Martin and Pham (2008) therefore used a data generation process ${ }^{14}$ different from that used by Santos Sliver and Tenreyro (2006), which consisted of a high proportion of zero values and shows PPML to be vulnerable to bias when the dependent variable has a high percentage of zeros. Similar result was found by Martinez-Zarzoso (2013).

In response to these studies, Santos Silva and Tenreyro (2011), argued that those simulations done by Martinez-Zarzoso et al. (2007); Martin and Pham (2008) reveal no information on the performance of the PPML model as the data used in their simulation exercises were not generated by a model of constant elasticity. Santos Silva and Tenreyro (2011), further investigated PPML's

\footnotetext{
${ }^{12}$ The 3 datasets consist of about $13 \%, 15 \%, 25 \%$ of zero trade values.

${ }^{13}$ For instance, the Cobb-Douglas production function, the consumer-demand systems and the Stochastic impact by regression on population, affluence and technology, which is a popular model used in environmental economics.

${ }^{14}$ Santos Silva and Tenreyro (2006) employed a data generation process that generates no zero values but only positive values. Martin and Pham adopted a similar design to the Monte Carlo simulation from Santos Silva and Tenreyro (2006), but modified it by including a threshold trade level that must be exceeded before positive trade levels are observed. (where the chosen threshold generates zero trade frequencies, which is similar to those observed in studies using aggregate trade flows.)
} 
performance when the dependent variable has a high percentage of zeros and when the data generating process is given by a constant elasticity model (both of which are typical in trade data used in gravity modeling). Similar to their previous findings, they also find the PPML estimator is consistent and generally well-behaved with high percentage of zeros, as well as being more robust to departures from the heteroscedasticity assumption (overdispersion).

It is worth noting that the simulation results presented by Head and Mayer (2014) support the findings of Martinez-Zarzoso (2013) and indicate that the selection of the most appropriate estimation has to be made in accordance with the process generating the error term. Head and Mayer (2014) thus acclaimed that other methods should be used along with the PPML "rather than selecting the Poisson PML as the single 'workhorse' estimator of the gravity" equation (Head and Mayer, 2014, p.176). According to their simulations, under a Poisson-like error (the Poisson assumption of variance proportional to the mean), a MPML is preferred, whereas under the log-normal error (the normality assumption), the EK Tobit is the preferred estimator.

Among the class of the generalized linear models, the GPML technique has also been used in taking care of the zero trade values and associated problem of the logarithm transformation (c.f. Manning and Mullahy, 2001). The GMPL can be an efficient estimator under the assumption that the variance is a greater than its mean, as it gives more weight to the mean (MartinezZarzoso, 2013). Santos and Silva and Tenreyro (2011) find the GPML to be consistent under a Monte Carlo simulation in the presence of excessive zero values whose data generation process follows the constant elasticity model. However, it is found to have a larger bias than the PPML suggesting that the PPML is the best performing estimator (c.f. Santos Sliver and Tenreyro, 2011). In addition, Martinez-Zarzoso (2013) simulation results show that the GPML may also suffer from substantial loss of precision, particularly if the variance function is mis-specified or if the log scaled residuals exhibit high kurtosis.

Another class of the generalized linear model is the nonlinear least squares (NLS) technique, which has been used in the trade literature (Frankel and Wei, 1993) or in comparison to other non-linear estimators (e.g. Santos Silva and Tenreyro 2006; Gomez-Herrera, 2013; MartinezZarzoso, 2013). Santos Silva and Tenreyro (2006) show that although both GPML and NLS can take care of these two problems, the PPML is still the preferred estimator as the NLS technique assigns a higher weight to observations that are noisier, which reduces its efficiency. This is because while PPML assigns the same weight to every observation, GPLM and NLS give higher weights to observations with larger means. This is due to the fact that the curvature of the conditional mean is more prominent at the places where the observations has larger means, a feature which is generally typical of observations with large variance, implying nosier observations. In addition, it was noted that the estimator can also be very inefficient because it generally ignores the heteroscedasticity in the data (Santos Silva and Tenreyro, 2006).

Another approach that has been considered and is frequently used in the literature is the Heckman's sample selection model ${ }^{15}$ (Heckman, 1979). Heckman (1979) noted that the standard

\footnotetext{
${ }^{15}$ Heckman's model is also referred to as sample selection or Tobit II model. The model makes a selection of trading and non-trading country-
} pairs - sample selection 
practice of excluding zero bilateral trade observations can potentially give rise to sample selection bias, especially if the eliminated zeros were non-random, and estimating non-randomly selected samples is a specification error and can potentially bias the results. Heckman invented a model which corrects sample selection bias, consisting of a two-step statistical approach in which the model is estimated under the normality assumption. The first step of the Heckman model involves estimating an equation (Probit regression) of the probability of exporting, whie a trade equation is estimated in the second step using linear method. The Heckman (1979) correction model allows one to correct for selection bias in non-randomly selected samples and has been frequently employed in gravity model trade literature to correct for problems relating to zero valued trade flows (c.f. Linders and de Groot, 2006; Munasib and Roy, 2011). Linder and de Groot (2006) noted that the sample selection model uses the information provided by the zero valued trade observations, thus providing information on the underlying decision process regarding the zero trade flows. Arbitrary truncating and censoring are both crude ad hoc methods which do not give accurate results compared to the sample selection model. They argued that unlike truncated OLS, without sound theoretical background, the sample selection model is theoretical and offers an econometric solution for the estimation of gravity equation that includes zero trade flows.

In recent years, there has been an extension to the Heckman (1979) sample selection model. In a methodological paper, Helpman, et al. (2008), noted that estimating trade impacts with a gravity model is not only subjected to sample selection bias (if the non-zero exports do not occur randomly), but that estimates may also be vulnerable to omitted variable bias when the number of exporting firms within an industry (extensive margin of trade) is unaccounted for. The idea is that due to trade costs, firms differ in productivity (firm heterogeneity) and only firms with productivity levels beyond a threshold end up exporting. They therefore extended the Heckman (1979) procedure by controlling for both sample selection and firm heterogeneity biases and approached the zero issue by also developing a two-step estimation procedure which exploits the non-random occurrence of zeros. The aim of Helpman, et al. (2008) two-step approach is to correct both the bias caused by unobserved firm heterogeneity which results from the omitted variable and the sample selection bias resulting from eliminating zero trade flows when estimating the logarithmic form of the gravity equation. The first step involves estimating an equation (Probit regression) for the probability of exporting based on the firms' decisions to export or not to; this gives the effects on the extensive margin of trade (the probability of establishing new trade). The second step estimates the gravity equation in its logarithm form and imposes an exclusion restriction and using the probabilities that were predicted previously in the first step to estimate the effects on the intensive margin of trade (the existing trade relationship).

To give unbiased estimates, Helpman, et al. (2008) posit that the variable excluded from the second stage equation must not be correlated with the error term of the second stage equation but must be correlated instead with the probability of trading (the dependent variable in the first stage equation). In addition, the excluded variable must influence trade through fixed trade cost and not through variable trade cost because of the latter's impact on the extent of trade volume. 
However, Burger et al. (2009) noted that one important drawback of both the Heckman (1979) and Helpman, et al. (2008) sample selection models is that it can be difficult to satisfy the exclusion restrictions as the instrumental variable is most often difficult to find. Examples of exclusion variables that have been used are religion and language variables (Helpman et al., 2008); historical occurrences of non-negative trade between country pairs (Linders and de Groot, 2006); and indicators of governance (Shepotylo, 2009). However, both Linders and de Groot (2006) include the excluded variable in the two equations and impose normality on the error term in the two equations - which is said to be an identification criterion which implies that the covariance between both equations is zero.

Notwithstanding the aforementioned advantages of the Helpman, et al. (2008) model, some limitations have been identified regarding its application. Both the Heckman (1979) and the Helpman, et al. (2008) trade flow equations are usually transformed to the logarithmic form before being estimated and may yield biased coefficients (Haworth and Vincent, 1979; Santos Silva and Tenreyro, 2006). In addition, Santos Silva and Tenreyro (2009) and Flam and Nordström (2011) show that Helpman, et al. (2008) model does not control for heteroscedasticity which is usually pervasive in most trade data. For instance, Santos Silva and Tenreyro (2009) illustrated that the Helpman, et al. (2008) assumption of a homoscedasticity ${ }^{16}$ error term for all country-pairs results in serious misspecifications as the Helpman, et al. (2008) does not control for heteroscedasticity, consequently casting doubt on the validity of inferences drawn from the model. Furthermore, their study reveals that in contrast to models which can be made robust to the presence of heteroscedasticity, the consistency of the Helpman, et al. (2008) model is only possible under the 'unrealistic' homoscedasticity assumption, which they identified as the most important drawback of the model as the assumption is too strong to make it applicable or practicable to trade data many of which the presence of heteroscedasticity is pervasive. They therefore posit that the presence of heteroscedasticity in the data "preclude the estimation of any model that purports to identify the effects of the covariates in the intensive and extensive margins, at least with the current econometric technology" (Santos Silva and Tenreyro, 2009, p. $15)$.

In summary, as noted in the review, each technique has its pros and cons and the 'workhorse' or best performing model for the estimation of the gravity equation still remains unclear as a consensus on a commonly accepted solution has not yet been reached. Therefore, given the pros and cons of each estimator, the determination of the best performing estimator (given our set of data application) remains an empirical issue.

\subsubsection{Empirical Literature on SPS and TBT measures and International Trade Flows}

With the increasing proliferation of SPS and TBT measures as important non-tariff trade barrier, several studies have empirically investigated the implications of these measures on international trade, more specifically on agricultural-food trade using both aggregated and disaggregated data. In most cases, gravity models are typically used in evaluating the empirical role that standards exert on trade flows. As previously identified, the estimated gravity model within the standard-

${ }^{16}$ The Helpman et al. (2008) model hinges heavily on both the homoscedasticity and normality assumptions to be consistent. 
trade literature might show scope for improvement especially in two areas: the econometric estimation technique and the proper specification of the model, especially given the peculiarities of the countries studied. Early studies on food standard-trade have estimated the standard log linear gravity model using OLS both with the occurrence and non-occurrence of zero trade flows. For instance, a study by Otsuki et al. (2001a) (which is perhaps the most cited literature) which investigates the impact of a proposed 1998 EU stricter SPS measure on the maximum level of allowable aflatoxin residue in food products on Africa's exports of groundnut products, employed OLS estimation techniques and took care of zero trade flow data by adding one to them. The study finds food safety standards to have a statistically significant negative impact on Africa's exports of groundnut. A significant negative trade impact was also found by Otsuki et al. (2001b) in their investigation of aflatoxin standards on world trade using OLS. This method is nonetheless said to suffer from deliberate measurement error (Winchester, et al., 2012). However, following the publication of these two earlier studies, there have been two main developments in the gravity modeling. The first is a theoretical paper by Anderson and van Wincoop (2003) which theoretically justified the representation of multilateral trade costs in addition to the bilateral trade cost that is usually included in a gravity model. The second and most important development is the issue of zero trade observations and the proper estimation techniques to tackle them coupled with the problem posed by the log linear transformation of the gravity equation (Santos Sliva and Tenreyro, 2006).

Various estimation techniques that incorporate zero trade records in the empirical analysis were consequently adopted. For instance, studies by de Frahan and Vancautereen (2006) and Fontagne et al. (2006) went beyond the OLS technique and instead used the censored Tobit model with random effects in order to tackle the zero trade observations. The former found positive trade effects of SPS and TBT measures on agricultural food products while the latter study found negative trade effects in agricultural products and positive trade effects in manufacturing and processed agricultural sectors. Besides, the Heckman model was employed by Chevassus-Lozza et al. (2008), Disdier and Marette (2010) and Vigani et al. (2010) to tackle the selection bias resulting from eliminating the non-random occurring zeros from the trade matrix. These studies found negative trade effects of SPS measures except for Vigani et al. (2010) which found a mixed effect. Other studies have taken advantages of the availability of panel data and employed either the random or fixed effect model or both (Disdier, et al., 2008; Melo et al., 2014; etcetera) where the model is log linearized, with the zero trade flows truncated or deliberately deleted.

Following the position of Santos Sliver and Tenreyro (2006) that the PPML model the best suited in dealing with the zeros and the heteroscedasticity inherent in trade data, studies by Disdier and Fontagne (2010), Wilson and Bray (2010) and Shepherd and Wilson (2013), have applied the PPML to examine the impact of standards on international trade and to deal specifically with the zeros that featured in the dependent variable. While the first two studies found a negative impact of SPS measures on trade using PPML, the last two found mixed effects depending on the standards considered. 
There are also a few studies which compared different estimation techniques with the occurrence of zero trade flows (Drogue and DeMaria, 2012; Xiong and Beghin, 2011) to determine the best performing estimator. However, these studies only compared a few of the estimators and chose the best performing model from the limited models considered. Drogue and DeMaria (2012) considered three estimation methods (OLS, PPML and ZINBPML) but relied on the ZINBPML model to provide the best fit and parsimonious specification among the models. Estimating their gravity models with both country pairs and time fixed effects, they find a negative impact of dissimilarity in standards on trade and vice versa. Similarly, including country-pairs and time fixed effects, Xiong and Beghin (2011) compared five estimation techniques to investigate the implication of SPS standards covering residues on pesticides on the extensive and intensive margins of trade across three groundnut products. Based on some diagnostic tests, their preferred models are the ZINBPML and Heckman models in order of preference. They find similar results for both the Helpman, et al. (2008) sample selection model and ZINBPML estimation technique. For these two models they find no significant impact of standards on shelled groundnut and groundnut oil exports but a positive impact on edible groundnut exports. Similarly, Drogue and DeMaria (2012) obtain similar results when different estimators (Hurdle, Heckman, and ZIPPML) were considered, indicating that the results are insensitive to the estimation used.

An important limitation of many of these studies lies in the invariability of their measure of standards, making the identification of the impact difficult. Drogue and DeMaria (2012) measured standards using the dis(similarity) between the maximum residual limits (MRL) of pesticides in force in importing country from 2000 to 2009; this is time invariant as they are reported to be the same over this period. Xiong and Beghin (2011) used MRL on aflatoxin B1 implemented by each EU. This measure is not bilateral in nature as it is the same measure faced by all trading partners without regard to the origin. However, Head and Mayer (2014) noted that factors which affect imports (exports) without regard to the country of originating country can no longer be identified ${ }^{17}$ in a gravity model setting estimated with exporting and importing countries fixed effects.

In this study, our approach to measuring standards will be devoid of this identified limitation as our measurement is constructed to ensure variability over time and between importing and exporting countries, as will be shown in the proceeding section. In addition, our study departs from previous studies which only consider a few estimation techniques and our analysis is wider and more encompassing in scope as we employed a wide selection of estimation techniques so as to objectively identify the most suitable estimator for our data.

\subsection{Data and Constructing Standards}

Standards are classified in line with the International Classification for Standards (ICS) code, which differs from how trade flows are normally classified. We therefore collated EU food standards focusing on both SPS standards and mandatory technical standards (technical

\footnotetext{
${ }^{17}$ As a solution, they proposed that the trade impact can be identified by eliminating some of the country dummies, or by creating new dyadic bilateral variables which have straightforward interpretation. See Head and Mayer (2014) for other factors that also cannot be identified, and possible solutions to this.
} 
regulations) by matching the total number of standards in each year against the appropriate standard international trade classification (SITC). A standard is pronounced to be active in a given year if it was enacted in that year or has been set in the previous year(s) and has never been withdrawn. We treated all corrigendum to the existing pool of standards as additional standards while all draft standards are excluded from our dataset (see also Shepherd and Wilson, 2013). Likewise, standards which denote 'terminology' or vocabulary' of a product are not deemed to be substantive and are also excluded. We have differentiated between two standards: the EU standards defined as those developed and adopted by all EU Member States, and international standards which we define as the ones from the Codex Alimentarius Commission, (hereafter Codex). The latter are those developed jointly by the Food and Agriculture Organisation (FAO) and World Health Organisation (WHO). Standards data on fish was obtained from the Perinorm ${ }^{18}$ database, a rich and subscription-based database that houses different types of standards collated over the years such as voluntary standards, SPS standards including government directives on mandatory technical regulations. We collate all EU standards in force over the period between 2007 and 2012 by mapping each standard to a standard trade classification.

\subsubsection{Constructing Protectionism Indices of Standards}

To avoid using standards as a protectionist tool, the WTO obliged its members to employ internationally scientific based standards such as Codex's standards whenever it is possible ${ }^{19}$. We define protectionism as the fraction of a country's standards that is more stringent than the standards internationally recognized by the WTO. Thus, our measure of protectionism is constructed by measuring the differences in each EU standard against an international benchmark. We employed Codex standards as the 'non-protectionist' scientifically based benchmark. Following Li and Beghin (2014), we developed a simple criterion of protectionism: EU standards that exceed those set by Codex are taken to be protectionist, while those that are laxer than Codex's are defined to be anti-protectionist. Our trade weighted product level protectionism index for fish standards is given as:

$$
P_{i j t}=\frac{\operatorname{Codex}_{s t d_{t}}-E U_{s t d_{t}}}{100} w_{i j t}
$$

Where $P_{i j t}$ measures the extent of protectionism of EU fish standards imposed by a given importer on country $i$ exports at time $t ; E U_{s t d_{t}}$ denotes the incidence of EU fish standards at time $t$; Codex $_{\text {std }}$ is the international equivalence of each EU standards and is measured as the number of Codex standard in fish at a given time $t ; w_{i j t}$ is the weight ${ }^{20}$ of the import values of fish (the product affected by standards) in world imports in fish. More specifically, $w_{i j t}$ is given as:

\footnotetext{
${ }^{18}$ Perinorm is a subscription-only database covering standards on 22 countries including those set by international bodies such as Codex and International Standard Organisation (ISO).

${ }^{19}$ However, the WTO also allows its members to use precautionary principles by setting their own appropriate level of protection different from the international one, as long as their national standards are non-discriminatory, have scientific backings and are the least trade restrictive (WTO SPS agreement).

${ }^{20}$ Ideally, for a given country, weights should mirror the dead-weight loss of the commodity aggregated over all commodities. Unfortunately, data on dead weight loss are unavailable, thus this is substituted instead with import values.
} 


$$
w_{i j t}=I M_{i j t} / I M_{t}
$$

$I M_{i j t}$ is the share of bilateral fish import values from country $j$ to $i$ in a given year, and $I M_{t}$ is world fish imports in the corresponding year. $w_{i j t}$ is also known as the import coverage ratio and is a popular way of calculating the trade weighted standard measure in literature (de Frahan and Vancauteren, 2006; Disdier, et al., 2008). While the first part of the measure (Codex std $_{t}-E U_{s t d_{t}}$ ) covers the stringency of the standard, the second part $\left(w_{i j t}\right)$ is similar to the coverage ratio of standards and measures the percentage of trade that is affected by standard. More specifically, the coverage ratio of a standard of country $i$ is the share of bilateral import values from country $j$ to $i$ of the affected product of a particular year in total world exports of the affected product of that same year. Thus, our measure of standards introduces variability across importers, exporters and time.

Equation (2.1) results in indices that are lower and upper bounded; negative values indicate protectionism while positive values are indicative of anti-protection, and zero values imply neutrality of standards between the EU and Codex. The higher the deviation of EU standards from international ones from Codex, the more negative the index becomes and vice versa. The lower the index is (i.e. the more negative it is), the higher its stringency, and the harder it becomes to comply with for exporters.

\subsection{Methodology}

Our objective is to investigate the implications of EU food safety standards and technical regulations on African exports. We did this by focusing on fish and fishery products. This is based on the premise that these products attract a relatively significant number of standards in comparison to other products due to their highly perishable nature. In addition, the available evidence shows that these products are the most often rejected export product from Africa at the EU border, resulting in an incidence of about $70 \%$ rejection as a percentage of all Africa's food exports refused entry into the EU due to not meeting the required EU food safety standards. Thus, we proceed by investigating if these EU standards are indeed overly stringent to the extent of being protectionist using a variety of estimation techniques.

\subsubsection{Model Specification and Estimation Techniques}

For the sake of comparison and completeness, we adopt the Anderson and van Wincoop (2003) as our preferred specification of the gravity equation, given in logarithmic form as:

$$
\begin{aligned}
& \ln y_{i j t}=\beta_{0}+\beta_{1} \ln G D P_{i t}+\beta_{2} \ln G D P_{j t}+\beta_{3} S_{j t}+\beta_{4} \ln D_{i s t_{i j}}+\beta_{5} \text { Lang }_{i j} \\
& +\beta_{6} \text { Col }_{i j}+\beta_{7} \ln \text { Llock }_{i j}+\beta_{8} R T A_{i j}+\varepsilon_{i j t}
\end{aligned}
$$


Where $l n$ denotes the natural logarithms of the variables; $i$ and $j$ are exporter and importer subscripts respectively, $t$ denotes the time period; $y_{i j t}$ is the export value from country $i$ to country $j$ in time $t$ in nominal US dollars, obtained from the United Nations Commodity Trade (UN COMTRADE) statistical database at the SITC Revision 1 product code ${ }^{21} ; G D P_{i t}$ and $G D P_{j t}$ are the gross domestic products (GDP) of countries $i$ and $j$ respectively in time $t$ in nominal US dollars, sourced from the World Bank. $S_{j t}$ denotes the European Union food standards on fish products which is a combination of SPS measures on fish safety and technical regulations governing fish products. This is the main parameter of interest in this study and was obtained from the Perinorm database. Dist $t_{i j}$ denotes the geographical distance between two major economic center of countries $i$ and $j$. Lang $_{i j} \operatorname{Col}_{i j}$ Llock $_{i j} R T A_{i j}$ are respective dummies that take the value of 1 if countries $i$ and $j$ speak similar official language; when countries $i$ had been colonized by country $j$ in the past; when at least one of the country-pairs is a landlocked country; when trading pairs belong to similar trade agreement; zero otherwise and $\varepsilon_{i j t}$ is the disturbance term. Data on distance, landlocked, language and colony status were collated from the Centre d'Etudes Prospectives et d'Informations Internationales (CEPII) database, while data used to construct the regional agreement dummy comes from the WTO. The countries included in our analysis are available in Table A2.2 in the appendix.

Our dataset covers bilateral trade on fish exports between the 27 European Union countries and 40 African countries between 2007 and 2012 and provides a balanced panel dataset of 6480 observations. The choice of our period of analysis hinges on third factors. First, analysis from 2007 enables us to include all the existing 27 EU countries who have adopted the harmonized EU standards. Second, this period is an important period in which food standards were standardized. Third, the period also captures the global financial crisis period during which the EU region is posited to have tightened its non-tariff barrier and restricted market access in response to the crisis (Bussière, et al., 2011). Our focus on this time period is further explained by the speculation that standards became more protectionist in nature during this time.

We controlled for multilateral trade resistance terms (MRT) using the Baier and Bergstrand (2010) Taylor series approach. The Baier and Bergstrand first-order Taylor series approximation of Anderson and van Wincoop's nonlinear systems of price equation also gave rise to theoretically consistent gravity model (Head and Mayer, 2014). We applied a first-order Taylor series expansion to all bilateral trade costs and thereafter used the newly transformed variables in the regression. Simple averages weights $(1 / n)$ are used in their construction as shown in Baier and Bergstrand (2010), where $n$ is the number of observations. With symmetric but non-zero trade costs, the first order Taylor series approximation of the gravity model for panel data in logarithm form is given as:

${ }^{21}$ SITC Revision 1 code 0444 is used as the product category for fish, crustacean, mollusc and other invertebrates. 


$$
\begin{aligned}
& \ln y_{i j t}=\ln G D P_{i t}+\ln G D P_{j t}-(\sigma-1) \ln t_{i j t}+(\sigma-1)\left[\frac{1}{n}\right] \sum_{j=1}^{n} \ln t_{i j t}-\frac{1}{2} \frac{1}{n^{2}} \sum_{i=1}^{n} \sum_{j=1}^{n} \ln t_{i j t} \\
& +(\sigma-1)\left[\frac{1}{n} \sum_{i=1}^{n} \ln t_{j i t}-\frac{1}{2} \frac{1}{n^{2}} \sum_{i=1}^{n} \sum_{j=1}^{n} \ln t_{j i t}\right]
\end{aligned}
$$

In equation (2.4), $t_{i j}$ refers to any of the bilateral trade cost variables associated with the coefficients of $\beta_{3}$ to $\beta_{8}$ in equation (2.3). These include our measure of food standards, distance, common language, landlocked, colony status and RTA. The first variable located on the righthand side represents an average of the total trade costs incurred by a given exporter from all importers. The second variable on the right-hand side denotes the average of all trade costs faced by the importer from all exporters. Following Egger and Nelson (2009), using the regional trade agreement variable as an example, each of the bilateral trade cost variable is transformed using the approximation given below:

$$
\ln R T A_{i j t M R T}=\ln R T A_{i j t}-\frac{1}{n} \sum_{j=1}^{n} \ln R T A_{i j t}-\frac{1}{2} \frac{1}{n^{2}} \sum_{i=1}^{n} \sum_{j=1}^{n} \ln R T A_{i j t}
$$

The transformed variable $\ln R T A_{i j M R T}$ is defined as the importer and exporter time fixed effects, and a similar definition holds for the other trade costs. Using the definition given by equation (2.5), the log linear model in equation (2.4) is transformed to one which fully accounts for the influence of MRT, and is given as:

$$
\begin{aligned}
& \ln y_{i j t}=\beta_{0}+\beta_{1} \ln G D P_{i t}+\beta_{2} \ln G D P_{j t}-(\sigma-1) \beta_{3} S_{j t M R T}-(\sigma-1) \beta_{4} \ln D i s t_{i j M R T}- \\
& (\sigma-1) \beta_{5} \text { Lang }_{i j M R T}-(\sigma-1) \beta_{6} \operatorname{Col}_{i j M R T}-(\sigma-1) \beta_{7} \text { Llock }_{i j M R T}-(\sigma-1) \beta_{8} R T A_{i j t M R T}+\varepsilon_{i j t}
\end{aligned}
$$

An overview of the variables considered in our analysis and the summary statistics is displayed in Table A2.3 of the appendix.

\subsubsection{Estimation Techniques}

There are some unique features of our data which are worth mentioning. About $63 \%$ of the bilateral trade flows in our data are zeros. While some of these zeros may be due to statistical zeros such as rounding up or incompleteness of the UN COMTRADE database, the majority of them are more likely to be a result of African exporters' inability to trade due to some prohibitive fixed costs they have to bear in establishing trade with EU countries. One of these prohibitive fixed costs is the compliance cost of meeting the food safety standards set by the EU. Due to firm heterogeneity, firms differ by their degree of productivity and those who are more productive would find it profitable to export to the EU after adding the huge cost of complying with EU standards to the cost of production. However, it is not every firms that will find trade profitable, and this gives rise to zero trade flows if two country-pairs do not trade in a given year or to positive trade flows when country-pairs trade in a given year. Thus, the high frequency of 
zeros in our dependent variable demands the use of an appropriate method that would allow for consistent estimates. To account for the occurrence of zeros, two major sets of estimation techniques have been widely used. These are the linear models and non-linear models. An overview of the major estimation techniques frequently employed is provided below.

\subsubsection{Log-Linear Models}

We employ six of the most important linear ${ }^{22}$ methods in estimating equation (2.6). The first method we employed is the truncated pooled OLS. Although the technique can sometimes be applied to panel data, it would only give precise estimators and strong test statistics if the relationship existing between the regressors and the dependent variable remained constant over time. Following the early practices in the literature, we took the logarithm of the dependent variable in which all zero observations are lost because taking the logarithm of zeros results into undefined values. In addition, with the advantage of the panel framework we are able to account for unobserved heterogeneity using panel estimator techniques, specifically using the two traditional panel data models - the fixed and random effects model. In addition, we have also employed the FGLS panel estimator technique. It corrects for the heteroscedastic error structure across panels and the presence of autocorrelation with panels as well as cross sectional correlations. Martinez-Zarzoso (2013) found this method to be an efficient estimator within the class of least squared estimators in the presence of unknown forms of heteroscedasticity. Similar to Porojan (2001), who attempted to deal separately with the heteroskedasticity problem, Martinez-Zarzoso (2013) posited that the FGLS method is also an appropriate way to discretely resolve the heteroscedasticity inherent in trade data. For instance, in a Monte Carlo simulation exercise, they showed that the estimates outperformed other linear and non-linear estimators in out of sample forecasts using datasets in which zeros are pervasive.

We also employed the two variants of the Tobit model which has been frequently used to deal with the zero trade problems that can result from having a level of trade below some threshold, or from actual zero trade between country pairs. The first is the Eaton and Tamura (1994) threshold Tobit model, termed the 'ET Tobit'. Following a common practice in the literature, we also replaced all the zero observations present in the dependent variable by the value of 1 before its logarithm is taken. The method defines an observable dependent variable $y_{i j t}$, a latent variable

$y_{i j t}^{*}$ that is positive including a threshold of zero: the observed dependent variable is then said to equal the latent variable when the latent variable is greater than zero, and zero, otherwise. The model which is expressed in terms of the latent variable is specified as follows.

$$
\begin{aligned}
& y_{i j t}=0 \text { if } y_{i j t}^{*} \leq 0 \quad \text { or } \\
& y_{i j t}=y_{i j t}^{*} \text { if } y_{i j t}^{*}>0
\end{aligned}
$$

\footnotetext{
22 Although the sample selection models are also used to deal with zeros, we did not consider them here. This is due to the fact that they are more appropriate in estimating an entirely different types of parameters in contrast to the other methods that give estimates that sum up both the intensive and extensive margins of trade (Head and Mayer, 2014).
} 
Secondly, we also employed an alternative Tobit procedure by Eaton and Kortum (2001) that was proposed by Head and Mayer (2014), termed the EK Tobit which avoids the problem of replacing the zero trade flows with a small constant without any criteria. In particular, following Eaton and Kortum (2001), we replaced the zeros by the minimum level of trade for a given importing country from all its destination countries. The new dependent variable was then plugged into the right-hand side of equation (2.6) which was thereafter estimated in Stata with the 'xtintreg' command (c.f. Head and Mayer, 2014).

\subsubsection{Non-linear Methods}

We also estimated equation (2.6) with the dependent variable in levels using 2 non-linear techniques. Firstly, following Santos Silva and Tenreyro (2006), we used the PPML model in dealing with the zero exports flows. Secondly, we utilized the MPML model to deal with the occurrence of zero or missing trade (Eaton et al., 2012; Head and Mayer, 2014). Assuming that market shares are the appropriate dependent variable in our gravity equation, for a finite number of firms the dependent variable then takes the form:

$$
\pi_{i j}=\frac{y_{i j}}{y_{j}}
$$

Where $\pi_{i j}$ represents country $i$ market share in $j ; x_{i j}$ are the fish exports to country $j$ from country $i$; $x_{j}$ are world fish exports to country $j$. Since the sum of $\pi_{i j}$ sums up to one across all destinations $i$ (for any $j$ ), the gravity variables can be estimated by employing the MPML model (c.f. Eaton et al. 2012; Head and Mayer, 2014).

\subsection{Results and Discussion}

To give more insight into the estimation techniques, we first start by checking their adequacy using some robustness tests before placing policy emphasis on them.

\subsubsection{Robustness Checks}

In order to consistently estimate the trade impacts of EU fish standards, our approach is to investigate how the performance of our estimators are affected by the occurrence of zeros in the dependent variable influences the performances of our models. The preferred estimator is contingent on the assumptions regarding how the relationship between the variance and the expected value of the dependent variable. In particular, we are interested in determining the efficient estimator which is able to accommodate a dependent variable in which zeros are frequent. Furthermore, we are also interested in investigating if the structure and assumption about the structure of the error term of each estimator holds with the occurrence of zeros among the trade flow observations. In other words, we are keen to see if the patterns of heteroscedasticity assumed by the various estimators are acceptable. Given the estimators considered in this study, the type of heteroscedasticity pattern taken up by the models is either the Constant Coefficient of Variance (CCV) assumption or the Constant Variance to Mean Ratio (CVMR) type of heteroscedasticity (Head and Mayer, 2014). On the one hand, the log linear 
model has log normal errors with constant variance (homoscedasticity assumption) and exhibits the CCV pattern of heteroscedasticity. That is, this assumption implies that the standard deviation of the dependent variable is proportional to its mean. On the other hand, the two nonlinear models considered in this study - PPML and MPML have the CVMR heteroscedasticity type of pattern where it is assumed that the means of their respective dependent variables are proportional to the variance of their respective dependent variables.

Following Santos Silva and Tenreyro (2006) and Martinez-Zarzoso (2013), our comparison of the performances of various estimation techniques would be based on the popular Park test. This Park test (Park, 1966) will be employed to ascertain the appropriateness of the log linear models against the GLM models as well as to ascertain the patterns of heteroscedasticity assumed by those estimators. In addition, the Ramsey reset test (Ramsey, 1969) will also be used in checking for the appropriateness and misspecification of all the estimators. Lastly, the performances among the estimators would be checked using AIC and BIC.

First, we proceed by determining if the patterns of heteroscedasticity assumed by the estimators are accepted. We did this by checking if the variance functions assumed by the estimators are consistent with their properties. The general form of the variance function of the GLM and loglinear model is given as:

$$
v(y \mid x)=(\mu(y \beta))^{\lambda}
$$

Here, $y$ is the dependent variable, $v$ and $\mu$ its variance and mean respectively and $x$ are vector of regressors, $\lambda$ is non-negative, finite and its values distinguishes the difference between loglinear and non-linear models. For instance, for values of $\lambda_{1}=1$, would yield the Poisson model; when $\lambda_{1}=2$, we would get the log-linear estimators. The more efficient estimator is now contingent on its assumption on how dependent variable's variance-mean relationship. On the one hand, the log linear model has a CCV pattern of heteroscedasticity with a data generating process that satisfies $\lambda_{1}=2$. This holds if its standard deviation is proportional to its mean. On the other hand, PPML and MPML have the CVMR type of heteroscedasticity pattern - i.e. heteroscedasticity à la Poisson, with $\lambda_{1}=1$ assumed.

With the variance function described above, Manning and, Mullahy (2001) suggest that the choice of the most reliable model could be determined using a Park type of regression - a test statistic used in analysing the error term so as to determine the pattern of heteroscedasticity assumed by the estimators. It is a reliable method of distinguishing between the log-normal data generating process and the CVMR data generating process (Head and Mayer, 2014). The test consists of estimating the following equation which can be directly derived from equation (2.10). This is specified as:

$$
\ln \left(y_{i}-\hat{y}_{i}\right)^{2}=\ln \left(\lambda_{0}\right)+\lambda_{1} \ln \hat{y}_{i}+\varepsilon_{i}
$$


Based on a non-robust covariance estimator, the null hypothesis is that Ho: $\lambda_{1}=2$ (that the model is a log-linear one) is tested against the alternative that it is not. The hypothesis is not rejected if the confidence interval of $\lambda_{1}$ contains a value of 2 . Acceptance of this null hypothesis would imply the log linear estimator is appropriate. However, because the logarithmic transformation of equation (2.11) is only valid under the assumption that the dependent variable is conditionally distributed, Manning and Mullahy (2001) therefore suggested to estimate the modified version of the Park regression as a more robust alternative. The alternative is described by:

$$
\left(y_{i}-\hat{y}_{i}\right)^{2}=\lambda_{0}\left(\hat{y}_{i}\right)^{\lambda_{i}}+\eta_{i}
$$

We estimated equation (2.12) by employing the appropriate non-linear estimator using a Eicker White heteroscedasticity robust estimator. The 'straightforward approach' of Manning and Mullahy (2001) gives a confidence interval for $\lambda_{1}$. The null hypothesis that $H_{o}: \lambda_{1}=1$ is tested against the alternative that it is not. The hypothesis is not rejected if the confidence interval of $\lambda_{1}$ contains a value of 1 and/or if the test statistics is statistically insignificantly different from zero.

The result from the Park test is presented in Table 2.1. We report both the confidence interval of the (park) test and the p-values produced by the test of the hypotheses, both of which check whether or not the pattern of heteroscedasticity assumed by each model is appropriate. Out of all the estimators, only the MPML model passed the test which suggests that the other models are inadequate given the dataset considered. Firstly, in the case of the MPML estimator, at the $5 \%$ conventional significance level, the p-value of the statistical test of our hypothesis indicates that the estimated coefficient on $\lambda_{1}=1$ are statistically insignificantly different from zero (see column 2 in Table 2.1).

Table 2.1: Testing for the Pattern of Heteroscedasticity

\begin{tabular}{lcrc}
\hline Estimator & $\begin{array}{c}\text { Park Test } \\
(\text { P-value })\end{array}$ & 95\% Confidence Interval \\
\hline Trun OLS & 0.000 & -0.198 & 0.178 \\
FGLS & 0.000 & -0.360 & 0.032 \\
FE & 0.000 & 2.773 & 6.169 \\
RE & 0.000 & -0.275 & 0.052 \\
ET Tobit & 0.000 & -0.642 & 0.877 \\
EK Tobit & 0.000 & -0.445 & -0.177 \\
PPML & 0.000 & 2.497 & 4.782 \\
MPML & 0.382 & -2.139 & 2.202 \\
\hline
\end{tabular}

Note: For the $\log$ linear estimator, the Park-type test of $\lambda_{i}=1$ was estimated using a non-robust covariance procedure; whereas both PPML and MPML, the modified park test testing of $\lambda_{i}=2$ was based on a robust covariance estimator. 
Second, as shown in column 3 of Table 2.1, the 95\% confidence interval of the coefficient on $\lambda_{1}$ of the MPML estimator contains the value of $1,(-2.139,2.202)$. As a result, the null hypothesis that $\lambda_{1}=1$ could not be rejected. This result is in favour of MPML as we cannot reject the null hypothesis of the Poisson proportionality assumption of the mean being equal to the conditional variance at the $5 \%$ conventional significance level, again reinforcing that the multinomial poisson distribution is appropriate. Our result confirms that of Head and Mayer (2014) whose finding reveals that the selection of the most appropriate estimator is dependent on the process relating to how the error term was generated and whose simulation results reveal that the MPML estimator is preferable under a Poisson type of error where a constant variancemean assumption is presumed to hold.

In contrast, in the case of the PPML model, the confidence interval of the Park test carried out did not contain one, and the p-value of the hypothesis of the test is statistically significant; thus, the null hypothesis that $\lambda_{1}=1$ is unequivocally rejected. This result shows that PPML is inefficient as the Poisson-like heteroscedasticity type was not satisfied for this estimator. Similarly, none of the confidence intervals of the entire log linear estimators contain the value of two. Furthermore, for all the log linear models, the p-values of the hypothesis of the tests are statistically significant, thus their null hypotheses that $\lambda_{1}=2$ were rejected outright. These results are indications that all the log linear estimators exhibit worse case performance.

We also used the heteroscedasticity-robust Ramsey reset test (Ramsey, 1969) to investigate if the models are adequate and appropriate given their underlying assumptions. In essence, it is a test of the functional form of the model and checks if the conditional expectations are correctly specified. The test is simply carried out by checking if the coefficient on an additionally constructed regressor specified as $\left(x^{\prime} \beta\right)^{2}$ is significant, where $\beta$ represents the vector of the parameters $(x)$ estimated. The null hypothesis is that the coefficient associated with the test statistics is insignificant or zero. The p-values of the test are provided in the second column of Table 2.2. The test reveals a statistically insignificant p-value for the MPML estimator, signifying that the estimator passed the functional form test; this points to the appropriateness of the MPML estimator for our dataset. Similar results are evidenced for truncated OLS, FGLS, fixed effects and PPML estimators. However, the random effects model alongside the ET Tobit and EK Tobit models did not pass the test as the test rejected the null hypothesis that the coefficients on their test statistics are statistically significantly different from zero.

Furthermore, the performance of the log linear estimators and GLM were also tested using the Akaike information criterion (AIC) and the Bayesian information criterion (BIC). However, the results of the non-linear estimators cannot be directly comparable to those of the log-linear estimators due to the differences in the number of observations and differences in the specification of the dependent variables of the estimators. The results are presented in the last two columns of Table 2.2. Among the log linear estimators, the FGLS model yields the smallest values of AIC and BIC, while the MPML model gives the smallest AIC and BIC results among the GLM estimators, once again reinforcing its appropriateness and adequacy. 
Table 2.2: Ramsey Reset and Information Criterion Test

\begin{tabular}{lccc}
\hline Estimators & Ramsey Reset Test & AIC & BIC \\
\hline Pooled OLS & 0.646 & 10551.544 & 10608.4511 \\
FGLS & 0.152 &.. &.. \\
Fixed Effects & 0.282 & 5433.016 & 5460.685 \\
Random Effects & 0.014 &.. &.. \\
ET Tobit & 0.012 & 12595.81 & 12670.35 \\
EK Tobit & 0.033 & 16010.19 & 16084.73 \\
PPML & 0.222 & $2.09 \mathrm{e}+06$ & $2.09 \mathrm{e}+06$ \\
MPML & 0.137 & 2709.765 & 2777.530 \\
\hline
\end{tabular}

Overall, for this particular African dataset, we find evidence that the underlying data generating process follows a CVMR heteroscedasticity type, indicating strong support for the MPML estimator. There is also no evidence of the estimator's functional form misspecification as evident by the Ramsey Reset test. Moreover, among its class of estimator, it presents lower AIC and BIC statistics. Consequently, as pointed out by these robust checks points, the prediction of the MPLM technique is rather good for our kind of dataset which is characterized by very low trade values and many zeros.

\subsubsection{Estimated Results}

The results determining if EU standards have the intent of protectionism are presented in Table 2.3. The dependent variable for the log linear models is the logarithm of exports and for the PPML and MPML models, the dependent variables are exports and export share in levels, respectively. As a first step, using the 'xtserial' command in Stata, we had checked and detected the presence of autocorrelation in our data as evident from the significant test statistics from the test result. We therefore estimated the fixed and random effects models with the 'xtregar' command in Stata. In addition, in the FGLS model we chose the options that correct for both panel heteroscedasticity and autocorrelation of order one within the panel. All other models were estimated using clustered robust standard errors.

First, we make a brief comparison of all models and thereafter emphasize the policy implications of our preferred model. For all models, the coefficients on the income elasticities of exporters' GDP are far below the theoretical value of one. A notable exception to this is the EK Tobit model whose coefficient is about 1.5. However, there have been justifications for the coefficients on exporter and importers' elasticities of income to fall below or above one in the literature. Furthermore, the coefficients are insignificant when the gravity equation is estimated by the PPML and fixed effect models. However, most of the coefficients on importers' income elasticities are in close range to the theoretical predicted value of one. All the coefficients are also statistically significant except for the PPML and the fixed effect models.

More importantly, with regard to EU fish standards, our protectionism indicator shows all models including our preferred estimator (MPML) have insignificant negative effects on 
Africa's exports at least at the conventional 5\% significance level. Exceptions to the above result are the ET and EK Tobit models whose coefficients turn out to be positively significant, indicating that EU fish regulations are less restrictive than those regulated by Codex. However, these latter results are unreliable as the preliminary robustness checks indicate that both models are inconsistent and therefore could not be relied on.

The insignificant result as shown by the MPML model is indicative of the fact that EU fish standards in relation to the ones imposed by Codex are not protectionist in nature. Although the EU has been constantly inhibiting some non-complying African fish exports from entering its borders, the insignificant coefficient indicates that EU regulation is in line with those specified by Codex, such that we can conclude that EU standards have no protectionist intent. This indicates that these regulations are aimed solely to address legitimate concerns for human health and safety and do not necessarily address protectionist concerns. Thus, the inability of African fish exporters to comply with EU standards and the consequent rejection of their exported products might instead indicate the inadequacy of their domestic standards regulations and their lack of the scientific and technological abilities to ensure compliance. This results tallies with the analytical position of Henson and Jaffee (2004) who claim that standards are not always problematic and are less pessimistic than the widely held view of the mainstream 'standards as a barrier' perspective. They argued that standards do not necessarily hurt Africa's exports as some of their export sectors and some African countries are successfully responding to stringent food safety standards imposed by developing countries by making the necessary investments in operations and are able to comply with importing countries' requirements and proliferate developed countries' markets.

Regarding the other costs variables, as expected, the results show geographical distance has a negative effect on fish export for all models; although all models are statistically insignificant with the exception of FGLS model which produces a significant trade effect. With respect to the common language variable, for all estimators except FGLS, sharing similar language between the two trading partners does not significantly impact Africa's fish trade, negating our a priori expectation of significant positive trade effect. These results indicate that sharing a similar language with the EU is not a stimulating factor in propelling Africa's fish exports to the EU. Furthermore, in conformity with our a priori expectations, all estimate models predict negative and statistically significant effects on exports for countries that are landlocked, except the ET and EK Tobit models which produced insignificant effects.

Contrary to our expectations, regional trade agreements between country-pairs do not have any effect on trade for all models except in the FGLS model where it has a large and positive significant effect on fish exports. Similar results have been pointed out by some studies which find that RTA has no effect or negative trade effect especially for developing countries (Ghosh and Yamarik, 2004; Francois et al., 2006; Martinez-Zarzoso et al., 2009; Greveda and MartinezZarzoso, 2015). In the case of many African countries, many of the RTAs between Africa and the EU have been non-reciprocal with the exception of the on-going negotiation known as the economic partnership agreement (EPA). Major reasons adduced for this result is the lack 
Chapter 2: Trade Effects of EU SPS and TBT measures When Zeros are Frequent: A Comparison of Estimation Techniques Using African Data

Table 2.3: Results from the Various Estimators

\begin{tabular}{|c|c|c|c|c|c|c|c|c|}
\hline & $\begin{array}{l}\text { TrunOLS } \\
\text { ln_export }\end{array}$ & $\begin{array}{c}\text { FGLS } \\
\text { ln_export }\end{array}$ & $\begin{array}{c}\text { Fixed } \\
\ln \_ \text {export }\end{array}$ & $\begin{array}{l}\text { Random } \\
\text { ln_export }\end{array}$ & $\begin{array}{l}\text { ET Tobit } \\
\text { ln_export }\end{array}$ & $\begin{array}{l}\text { EK Tobit } \\
\text { ln_export }\end{array}$ & $\begin{array}{l}\text { PPML } \\
\text { Export }\end{array}$ & $\begin{array}{c}\text { MPML } \\
\text { Export share }\end{array}$ \\
\hline \multirow[t]{2}{*}{ Log of Exporters' GDP } & $0.528^{* * *}$ & $0.634^{* * *}$ & -0.075 & $0.498^{* * *}$ & $1.027^{* * *}$ & $1.501^{* * *}$ & 0.139 & $0.469^{* * * *}$ \\
\hline & $(0.104)$ & $(0.035$ & $(0.210)$ & $(0.080)$ & $(0.131)$ & $(0.179)$ & $(0.161)$ & $(0.072)$ \\
\hline \multirow[t]{2}{*}{ Log of Importers' GDP } & $0.734^{* * *}$ & $0.669^{* * *}$ & 0.136 & $0.792^{* * *}$ & $1.745^{* * *}$ & $2.440^{* * *}$ & 0.143 & $0.189^{* *}$ \\
\hline & $(0.107)$ & $(0.037)$ & $(0.178)$ & $(0.083)$ & $(0.138)$ & $(0.176)$ & $(0.367)$ & $(0.080)$ \\
\hline \multirow[t]{2}{*}{ Fish Standards } & -0.007 & -0.001 & 0.002 & 0.001 & $0.004^{*}$ & $0.005^{*}$ & 0.001 & 0.000 \\
\hline & $(0.005)$ & $(0.001)$ & $(0.002)$ & $(0.002)$ & $(0.002)$ & $(0.003)$ & $(0.001)$ & $(0.001)$ \\
\hline \multirow[t]{2}{*}{ Log of Distance } & -0.813 & $-1.098^{* * * *}$ & & -0.811 & -1.526 & -1.782 & -1.111 & -0.235 \\
\hline & $(1.000)$ & $(0.384)$ & & $(0.871)$ & $1.874)$ & $(2.545)$ & $(1.176)$ & $(0.552)$ \\
\hline \multirow[t]{2}{*}{ Common Language } & -0.277 & $-0.578^{* *}$ & & -0.442 & $(0.888$ & 1.758 & $-1.541^{*}$ & -0.426 \\
\hline & $(0.745)$ & $(0.232)$ & & $(0.608)$ & $1.071)$ & $(1.583)$ & $(0.931)$ & $(0.670)$ \\
\hline \multirow[t]{2}{*}{ Colony } & 0.497 & $0.846^{* * *}$ & & $1.307^{*}$ & $3.082^{* *}$ & $3.703^{* *}$ & $2.454^{* *}$ & $2.285^{* *}$ \\
\hline & $(0.854)$ & $(0.269)$ & & $(0.761)$ & (1.346) & $(1.855)$ & $(0.990)$ & $(0.914)$ \\
\hline \multirow[t]{2}{*}{ Landlocked } & $-6.437^{* * *}$ & $-5.331^{* * *}$ & & $-3.129^{* * *}$ & -1.982 & -1.489 & $-10.023^{* * *}$ & $-2.516^{* * *}$ \\
\hline & $(1.756)$ & $(0.520)$ & & $(1.001)$ & (1.208) & (1.906) & $(2.558)$ & $(0.881)$ \\
\hline \multirow[t]{2}{*}{ RTA } & 0.535 & $0.433^{* * *}$ & -0.021 & 0.268 & 0.339 & 0.393 & 0.009 & -0.010 \\
\hline & $(0.503)$ & $(0.142)$ & $(0.396)$ & $(0.283)$ & $0.431)$ & $(0.687)$ & $(0.276)$ & $(0.354)$ \\
\hline \multirow[t]{2}{*}{ Constant } & $-18.467^{* * *}$ & $-18.824^{* * *}$ & $3.739^{* * *}$ & $-19.860^{* * *}$ & $-55.303^{* * *}$ & $-77.820^{* * *}$ & 2.274 & $-13.910^{* * *}$ \\
\hline & $(2.938)$ & (1.004) & $(0.536)$ & $(2.188)$ & (3.493) & $(4.325)$ & (7.432) & $(2.061)$ \\
\hline Observations & 2188 & 2345 & 1870 & 2412 & 6480 & 6480 & 6480 & 6480 \\
\hline$\overline{A I C}$ & 10551.544 & . & 5433.016 & . & 12595.81 & 16010.19 & $2.09 e+06$ & 2709.765 \\
\hline$B I C$ & 10608.4511 & . & 5460.685 & . & 12670.35 & 16084.73 & $2.09 e+06$ & 2777.530 \\
\hline Ramsey Test & 0.646 & 0.152 & 0.2819 & 0.014 & 0.012 & 0.033 & 0.222 & 0.137 \\
\hline
\end{tabular}

Note: $\ln$ denotes natural log. The dependent variable is measured in logarithm for every model with the exception of the Poisson and Multinomial Poisson models whose dependent variables are exports and export share in levels, respectively. In all models, we controlled for multilateral trade resistance using the Baier and Bergstrand (2010) approximation. Clustered robust standard errors, (clustered at the level of country-pairs) are in brackets and $* \mathrm{p}<0.10 ; * * \mathrm{p}<0.05 ; * * * \mathrm{p}<0.01$ 
of well-wither, corruption and the lack of sophisticated science and technology to increase the exports of quality export products to the EU, all of which deter Africa's ability to penetrate the EU markets. This result thus signifies that deeper agreements are needed to deeply integrate African countries and ensure their market access to the EU.

In general, the differences in the techniques shown in Table 2.3 are mostly seen in the magnitude of the standard errors and coefficients predicted and, in seldom cases, in the signs of the parameters of the gravity variables. However, the main difference between them lies in the standard error - the measure of precision. Table 2.4 summarizes the top two consecutive estimators with the lowest standard errors and the estimator with the highest standard error. We can see that, in most cases, FGLS and MPML exhibit the least standard errors depending on the variable considered, indicating more precision. Conversely, the EK Tobit and PPML models mostly exhibit the highest standard errors.

Table 2.4: Top Three Estimators with the Lower, Lowest and Highest Standard Errors

\begin{tabular}{lccc}
\hline Variable & $(1)$ & $(2)$ & $(3)$ \\
\hline Log of Exporters' GDP & Lower & Lowest & Highest \\
Log of Importers' GDP & FGLS & MPML & Random Effect \\
Fish Standards & FGLS & MPML & PPML \\
Log of Distance & PPML & MPML & Truncated OLS \\
Common Language & FGLS & MPML & EK Tobit \\
Colony & FGLS & MPML & EK Tobit \\
Landlocked & FGLS & Random Effects & EK Tobit \\
RTA & FGLS & MPML & PPML \\
\hline CalA & FGLS & ET Tobit & PPML \\
\hline
\end{tabular}

Calculated based on estimates in Table 2.3

\subsection{Conclusion}

The issues of zero trade observations and the potential departure from the usual homoscedasticity assumption when using the log linearized gravity equation have generated a number of debates in the literature with differing claims about the most suitable estimation technique. This necessitates a careful consideration of the methods in order to produce reliable policy estimates. Our aim is to consistently investigate if the EU TBT measures - specifically technical regulations governing fish products, and the EU SPS measures on food safety are overprotective in nature using an African dataset on fish exports to the EU. We provide an indepth review of methods that have been employed in solving these problems. Our survey of studies at the forefront of the current debate shows that each estimator is not without its pros and cons. To produce unbiased and consistent estimates for policy making, we undertake a careful consideration of the robustness of a number of widely used estimators; such consideration allows us to validate claims that EU fish standards are protectionist in nature given the high level of African fish exports rejected since 2008 at the EU border, primarily due to an inability to comply with the stringent EU standards. 
As an empirical analysis, we adapted Anderson and van Wincoop (2003) specification and controlled for multilateral trade using Baier and Bergstrand (2010) approximation. Given our dataset and the gravity equation specified, we assessed the performance of the log linear and generalized linear models in a dataset whose independent variable contains about $63 \%$ zero trade flow observations. Our results obtained from most of the estimators show that EU standards are not protectionist when compared to the international benchmark recommended by the FAO and WHO. These results indicate that the constant border rejection of Africa's exports by the EU cannot be attributed to the latter standards being protectionist compared to the recommended international standards. Plausible explanations for the results might be attributed to a variety of domestic factor restraining Africa's ability to penetrate the EU markets. Such factors could include the inadequate supply capacity, Africa's poor state of institutional and regulatory capacity, their weak supply capacity, among many other factors.

Notwithstanding, the results of the different robustness checks are evidently in favour of the MPML technique as the most consistent estimator in relation to the impacts of standards and other explanatory variables; its results are to be relied upon for more efficient and reliable policy outcomes. In other words, given this particular African dataset used in this study and the resulting data generating process underlying the structure of the error term, strong evidence is produced showing that the data generating process follows a constant variance mean ratio type of heteroscedasticity, indicating a strong support for the MPML.

Conclusively, the choice of the most appropriate estimator is dependent on the process that generated the error term and the dataset (Martinez Zarzoso, 2013; Head and Mayer, 2014). In addition, in recent time it has been acknowledged that "deciding which of the models is more appropriate is an empirical question that has to be answered for each specific dataset the researcher is considering" (Santos Silva et al., 2015, p. 2). Thus, a caveat is worth mentioning: though we found that all the estimators give similar results in regard to the impact of standards with the MPML model being the most appropriate estimation technique, we are not excluding the fact that the conclusions derived might be different when different datasets are used; for instance, those of Asia and Latin America. Nevertheless, it is somewhat interesting that we have used a dataset of poor and small countries which is characterized by many zeros and little trade values, so we believe that this finding can be generalized to other similar datasets with similar characteristics.

Our results have several policy implications for achieving increased export penetration to EU markets by African countries. Although our results point out that EU standards are not overly protectionist in nature, the persistent high number of fish exports rejected at the EU border indicates the need for assistance in order to comply with such standards. Thus, engaging in sophisticated scientific and technological transfer alongside the provision of financial assistance to African farmers and exporters are important policy imprints which need to be implemented to ensure positive change. For instance, trade agreement with the EU should include the provision of technological and scientific assistance to the agricultural sector, particularly small scale producers who dominate the scene in Africa in order to assist them in 
complying with EU food standards. At the home front, the issue of rejection of Africa's exports at the EU border can also be addressed through comprehensive reforms in the area of trade facilitation. Good customs and border management and the improvement of transit regimes would minimize delays that cause food contamination and border rejections, and would help move fish exports and other perishables more efficiently to the EU markets.

\section{References}

Anderson, J. (1979). A theoretical foundation for the gravity equation. The American Economic Review, 69(1), 106-116.

Anderson, J., and Marcouiller, D. (2002). insecurity and the pattern of trade: an empirical investigation. Review of Economics and Statistics, 84(2), 342-352.

Anderson, J., and Van Wincoop, E. (2003). Gravity with gravitas: A solution to the border puzzle. American Economic Review, 93(1), 170-192.

Baier, S. L., and Bergstrand, J. H. (2009). Estimating the effects of free trade agreements on international trade flows using matching econometrics. Journal of International Economics, 77(1), 63-76.

Baier, S. L., and Bergstrand, J. H. (2010). Approximating general equilibrium impacts of trade liberalization using the gravity equation. In P. A. G. van Bergeijk and S. Barkman (Eds.), The gravity model in international trade. advances and applications (1st ed., pp. 88-134). Cambridge: Cambridge University Press.

Baltagi, B. H. (2008). Econometric analysis of panel data (4th ed.). UK: John Wiley and Sons, Ltd.

Baltagi, B. H., Egger, P., and Pfaffermayr, M. (2003). A generalized design for bilateral trade flow models. Economics Letters, 80(3), 391-397.

Bergstrand, J. H. (1985). The gravity equation in international trade: some microeconomic foundations and empirical evidence. The Review of Economics and Statistics, 67(3), 474481.

Bergstrand, J. H. (1989). The generalized gravity equation, monopolistic competition, and the factor-proportions theory in international trade. The Review of Economics and Statistics, 71(1), 143-153.

Bernard, A. B., Eaton, J., Jensen, J. B., and Kortum, S. (2003). Trade, plants and productivity in international. The American Economic Review, 93(4), 1268-1290.

Blind, K. (2004). The economics of standards: theory, evidence and policy. Cheltenham: Edward Elgar.

Bosquet, C., and Boulhol, H. (2013). Applying the glm variance assumption to overcome the scale-dependence of the negative binomial qgpml estimator. Econometric Reviews, 33(7), 772-784.

Bouet, A., Mishra, S., and Roy, D. (2008). Does Africa trade less than it should, and if so, why? The role of market access and domestic factors. IFPRI Discussion Paper No. 00770. Washinton DC: International Food Policy Research Institute (IFPRI).

Burger, M., van Oort, F., and Linders, G.J. (2009). On the specification of the gravity model of 
trade: zeros, excess zeros and zero-inflated estimation. Spatial Economic Analysis, 4(2), 167-190.

Bussière, M., Callegari, G., Ghironi, F., Sestieri, G., and Yamano, N. (2013). Estimating trade elasticities: demand composition and the trade collapse of 2008-2009. American Economic Journal: Macroeconomics, 5(3), 118-151.

Carrère, C. (2006). Revisiting the effects of regional trade agreements on trade flows with proper specification of the gravity model. European Economic Review, 50(2), 223-247.

Chaney, T. (2008). Distorted gravity: The intensive and extensive margins of international trade. American Economic Review, 98(4), 1707-1721.

Chen, N., and Novy, D. (2011). Gravity, trade integration, and heterogeneity across industries. Journal of International Economics, 85(2), 206-221.

Chevassus-Lozza, E., and Latouche, K. (2008). The importance of EU-15 borders for CEECs agri-food exports: The role of tariffs and non-tariff measures in the pre-accession period. Food Policy, 33(6), 595-606.

De Frahan, B. H., and Vancauteren, M. (2006). Harmonisation of food regulations and trade in the Single Market: Evidence from disaggregated data. European Review of Agricultural Economics, 33(3), 337-360.

Deardorff, A. V. (1998). Determinants of bilateral trade: Does gravity work in a neoclassical world? In J. A. Frankel (Ed.), The Regionalization of the World Economy (pp. 7-32). Chicago: University of Chicago Press.

Disdier, A. C., and Marette, S. (2010). The combination of gravity and welfare approaches for evaluating non-tariff measures. American Journal of Agricultural Economics, 92(3), 713726.

Disdier, A., and Fontagné, L. (2010). Trade impact of European measures on GMOs condemned by the WTO panel. Review of World Economics, 146(3), 495-514.

Disdier, A. C., Fontagné, L., and Mimouni, M. (2008). The impact of regulations on agricultural trade: Evidence from the SPS and TBT agreements. American Journal of Agricultural Economics, 90(2), 336-350.

Drogué, S., and DeMaria, F. (2012). Pesticides residues and trade: the apple of discord? Food Policy, 37(6), 641-649

Eaton, J., and Kortum, S. (2001). Trade in capital goods. European Economic Review, 45(7), 1195-1235.

Eaton, J., Kortum, S., and Sotelo, S. (2012). International macro. NBER Working Paper Series No 7864. Cambridge, USA: National Bureau of Economic Research.

Eaton, J., and Tamura, A. (1994). Bilateralism and regionalism in Japanese and U.S. trade and direct foreign investment patterns. Journal of the Japanese and International Economies, 8(4), 478 - 510.

Egger, P. (2000). A note on the proper econometric specification of the gravity equation. Economics Letters, 66(1), 25-31.

Egger, P., and Pfaffermayr, M. (2003). The proper panel econometric specification of the 
gravity equation: A three-way model with bilateral interaction effects. Empirical Economics, 28(3), 571-580.

Egger, P., and Pfaffermayr, M. (2004). Distance, trade and FDI: A Hausman-Taylor SUR approach. Journal of Applied Econometrics, 19(2), 227-246.

Eichengreen, B., and Irwin, D. a. (1998). The role of history in bilateral trade flows. In J. A. Frankel (Ed.), The Regionalization of the world economy (pp. 33-62). Chicago: University of Chicago Press.

Felbermayr, G.J, and Jung, B. (2009). Sorting it out: technical barriers to trade and industry productivity. Open Economies, 22(1), 93-117

Fischer, R., and Serra, P. (2000). Standards and protection. Journal of International Economics, 52(2), 377-400.

Flam, H., and Nordstrom, H. (2011). Gravity estimation of the intensive and extensive margins of trade: an alternative procedure with alternative data. CESifo Working Paper Series No 3387. Munich: Center for Economic Studies and the Ifo Institute (CESifo).

Flowerdew, R., and Aitkin, M. (1982). A method of fitting the gravity model based on the Poisson distribution. Journal of Regional Science, 22(2), 191-202.

Fontagné, L., Mimouni, M., and Pasteels, J. (2005). Estimating the impact of environmental SPS and TBT on international trade. Integration and Trade Journal, 22(3), 7-38.

Frankel, J. A. (1997). Regional Trading Blocs in the World Economic System. Washington D.C: Institute for International Economics.

Frankel, J., and Wei, S. (1993). Is there a currency bloc in the Pacific? In A., Blundell-Wignall and S., Grenville (Eds.), Exchange rates, international trade and monetary policy (pp. 275-307). Sydney: Reserve Bank of Australia.

Gomez-Herrera, E. (2013). Comparing alternative methods to estimate gravity models of bilateral trade. Empirical Economics, 44(3), 1087-1111.

Gradeva, K., and Martínez-Zarzoso, I. (2015). Are trade preferences more effective than aid in supporting exports? evidence from the "everything but arms" preference scheme. The World Economy. Doi:10.1111/twec.12289

Haq, Z., Meilke, K., and Cranfield, J. (2013). Does the gravity model suffer from selection bias? European Review of Agricultural Economics, 40(2), 331-360.

Haworth, J., and Vincent, P. (1979). The stochastic disturbance specification and its implications for log-linear regression. Environment and Planning A., 11(7), 781-790.

Head, K., and Mayer, T. (2014). Gravity equations: workhorse, toolkit, and cookbook. Ch. 3 in Handbook of International Economics, G. Gopinath, E. Helpman and K. Roogoff (Eds), Vol. 4, 131-95. Amsterdam: Elsevier.

Heckman, J. J. (1979). Sample selection bias as a specification error. Econometrica, 47(1), 153 161.

Helpman, E., Melitz, M., and Rubinstein, Y. (2008). Estimating trade flows: trading partners and trading volumes. Quarterly Journal of Economics, 123(2), 441-487.

Jaffee, S. M., and Henson, S. (2004). Standards and agro-food exports from developing 
countries: rebalancing the debate. World Bank Policy Research Working Paper No. 3348. Washinton DC: The World Bank.

Johnson, N., and Kotz, S. (1969). Distributions in statistics - discrete distributions. New York: John Wiley and Sons.

Kareem, F. O., and Kareem, O. I. (2014). Specification and estimation of gravity models: a review of the issues in the literature. RSCAS Working Papers No. 74. Rome: Robert Schuman Centre for Advanced Studies (RSCAS), European University Institute.

Linders, G.J. M., and De Groot, H. L. F. (2006). Estimation of the gravity equation in the presence of zero flows. Mimeo, 1-26.

Manning, W. G., and Mullahy, J. (2001). Estimating log models: to transform or not to transform? Journal of Health Economics, 20, 461-494.

Martin, W., and Pham, C. S. (2008). Estimating the gravity model when zero trade flows are frequent. MPRA Working Paper.

Martínez-Zarzoso, I. (2013). The log of gravity revisited. Applied Economics, 45(3), 311-327.

Martinez-Zarzoso, I., Nowak-Lehmann, F. D., and Vollmer, S. (2007). The log of gravity revisited. CeGe Discussion Paper No. 64. Goettingen: Center for European, Governance and Economic Development Research (CeGe), Georg-August Universität Göttingen, Germany.

McCallum, J. (1995). National borders matter: Canada-US regional trade patterns. The American Economic Review, 85(3), 615-623.

Melitz, M. J. (2003). The impact of trade on intra-industry reallocation and aggregate industry productivity: a comment. Econometrica, 71(6), 1695-1725.

Melitz, M. J. (2007). North, South and distance in the gravity model. European Economic Review, 51(4), 971-991.

Melitz, M. J., and Ottaviano, G. I. P. (2008). Market size, trade, and productivity. Review of Economic Studies, 75(1), 295-316.

Melo, O., Engler, A., Nahuelhual, L., Cofre, G., and Barrena, J. (2012). Do sanitary, phytosanitary and quality related standards affect international trade? Evidence from Chilean fruit exports. World Development, 54, 350-359.

Munasib, A., and Roy, D. (2011). Sanitary and phytosanitary standards as bridge to cross. IFPRI Discussion Paper No. 01140. Washington DC: International Food and Policy Research Institute (IFPRI)

Otsuki, T., Wilson, J. S., and Sewadeh, M. (2001a). Saving two in a billion: quantifying the trade effect of European food safety standards on African exports. Food Policy, 26(5), 495-514.

(2000b). What price precaution? European harmonisation of aflatoxin regulations and African groundnut exports. European Review of Agricultural Economics, 28(2), 263-284.

Park, R. (1966). Estimation with heteroscedastic error terms. Econometrica, 34(4), 888.

Porojan, A. (2001). Trade flows and spatial effects: the gravity model revisited. Open Economies Review, 12(3), 265-280. 
Ramsey, J. B. (1969). Tests for specification errors in classical linear least-squares regression analysis. Journal of the Royal Statistical Society. Series B (Methodological), 31(2), 350371.

RASFF. (2014). The Rapid Alert System for Food and Feed 2014 Annual Report 2014. Retrieved from http://ec.europa.eu/food/safety/rasff/docs/rasff_annual_report_2014.pdf [Accessed September 15, 2015].

Ravenstein, E., G., (1885). The laws of migration. Journal of the Statistical Society of London, $48(2), 167-235$.

Rose, A. K. (2004). Do we really know that the WTO increases trade? The American Economic Review, 94(1), 98-114.

Rose, A. K., and van Wincoop, E. (2001). National money as a barrier to international trade: the real case for currency union. The American Economic Review, 91(2), 386-390.

Santos Silva, J., and Tenreyro, S. (2006). The log of gravity. The Review of Economics and Statistics, 88(4), 641-658.

Santos Silva J.M.C. and S. Tenreyro (2008). Comments on The Log of Gravity Revised. Retrieved from http://personal.lse.ac.uk/TENREYRO/mznlv.pdf [Accessed September 20, 2012].

Santos Silva, J., and Tenreyro, S. (2009). Trading partners and trading volumes: implementing the Helpman-Melitz-Rubinstein model empirically. CEP Discussion Paper No 935. UK: London School of Economics.

Santos Silva, J., and Tenreyro, S. (2011). Further simulation evidence on the performance of the Poisson pseudo-maximum likelihood estimator. Economics Letters, 112(2), 220-222.

Santos Silva, J., Tenreyro, S., and Windmeijer, F., (2015). Testing non-nested models for nonnegative data with many zeros. Journal of Econometric Methods, 4(1), 29-46.

Shepherd, B., and Wilson, N. L. W. (2013). Product standards and developing country agricultural exports: The case of the European Union. Food Policy, 42, 1-10.

Shepotylo, O. (2009). Gravity with zeros: estimating trade potential of CIS countries. Kyiv School of Economics Discussion Papers No 16. Ukraine.

Sören, P., and Brümmer, B. (2012). Bimodality and the performance of PPML (No. 1202). Institute for Agriceconomics Discussion paper. Göttingen: Georg-August Universität Göttingen, Germany.

Staub, K. E., and Winkelmann, R. (2012). Consistent estimation of zero-inflated count models. Health Economics, 22(6), 673-686.

Tinbergen, J. (1962). Shaping the world economy; suggestions for an International Economic Policy. New York: Twentieth Century Fund, New York.

Turkson, F. E. (2010). Logistics and bilateral exports in developing countries: a multiplicative form estimation of the logistics augmented gravity equation. CREDIT Research Paper No. 11/06. Nottingham: Centre for Research in Economic Development and International Trade, University of Nottingham.

Vigani, M., Raimondi, V., and Olper, A. (2010). GMO regulations, international trade and the 
imperialism of standards. LICOS Discussion Papers No. 25510. Leuven: Centre for Institutions and Economic Performance (LICOS), University of Leuven.

Wilson, N., and Bray, V. (2010). It happened all at once: switching regressions, gravity models and food safety. Selected Paper prepared for presentation at the Agricultural and Applied Economics Association 2010. Denver, Colorado.

Winchester, N., Rau, M. L., Goetz, C., Larue, B., Otsuki, T., Shutes, K., Nunes de Faria, R. (2012). The impact of regulatory heterogeneity on agri-food trade. World Economy, 35(8), 973-993.

Xiong, B., and Beghin, J. (2011). Does European aflatoxin regulation hurt groundnut exporters from Africa? European Review of Agricultural Economics, 39(4), 589-609.

Xiong, B., and Beghin, J. (2014). Disentangling demand-enhancing and trade-cost effects of maximum residue regulations. Economic Inquiry, 52(3), 1190-1203. 


\section{Appendix}

Table A2.1: List of Countries in the Dataset

\begin{tabular}{ll}
\hline Country Groups & \multicolumn{1}{c}{ Members } \\
\hline Importers (EU27) & Austria, Belgium, Bulgaria, Cyprus, Czech Republic, Denmark, Estonia \\
& Finland, France, Germany, Greece, Hungary, Ireland, Italy, Latvia, \\
& Lithuanian, Luxembourg, Malta, Netherlands, Poland, Romania, Slovakia, \\
& Slovenia, Spain, Sweden, United Kingdom \\
\hline Exporters & Algeria, Angola, Benin, Burundi, Cameroon, Cape Verde, Central African \\
& Republic, Democratic Republic of Congo, Republic of Congo, Côte d'Ivoire, \\
& Egypt, Eritrea, Gabon, The Gambia, Ghana, Guinea, Guinea-Bissau, Kenya, \\
& Lesotho, Madagascar, Mali, Mauritania, Mauritius, Morocco, Mozambique, \\
& Namibia, Niger, Nigeria, Rwanda, Sao Tome and Principe, Senegal, \\
& Seychelles, Sierra Leone, South Africa, Swaziland, Tanzania, Togo, Tunisia \\
& Uganda, Zambia, Zimbabwe.
\end{tabular}

Table A2.2: Summary Statistics

\begin{tabular}{lcccc}
\hline Variables & Untransformed & \multicolumn{2}{c}{$\begin{array}{c}\text { Demeaned as in Baier } \\
\text { and Bergstrand (2010) }\end{array}$} \\
& Mean & Std. Dev. & Mean & Std. Dev. \\
& 3054.829 & 20937.11 & & \\
Export & 4.902 & 3.648 & & \\
Log of Export & 0.104 & 0.449 & & \\
Export Share & 16.161 & 1.536 & & \\
Log of Exporters' GDP & 19.271 & 1.674 & & \\
Log of Importers' GDP & -5.541 & 18.725 & $-3.53 \mathrm{e}-08$ & 16.213 \\
Protectionism Index of Fish Standards & 8.582 & 0.439 & $1.20 \mathrm{e}-07$ & 0.132 \\
Log of Distance & 0.106 & 0.308 & $4.71 \mathrm{e}-09$ & 0.238 \\
Language Dummy & 0.040 & 0.196 & $-1.40 \mathrm{e}-09$ & 0.161 \\
Colonial Links Dummy & 0.389 & 0.488 & $1.12 \mathrm{e}-08$ & 0.168 \\
Landlocked Variable & 0.276 & 0.447 & $-3.27 \mathrm{e}-09$ & 0.247 \\
Trade Agreement Dummy & & & & \\
\hline
\end{tabular}

Source: Own computation 


\title{
Chapter 3
}

\section{Effect of Food Regulation on the Extensive and intensive Margins of Trade: Evidence from EU-African Trade}

\begin{abstract}
Attribution
Part of this essay has been published at The World Economy journal and is cited as: Kareem, F. O., Brümmer, B., and Martinez-Zarzoso, I. (2016). European Union Market Access Conditions and Africa's Extensive Margin of Food Trade. The World Economy. DOI: $10.1111 /$ twec. 12466
\end{abstract}

This Essay draws from the article by Kareem, F. O., Brümmer, B., and Martinez-Zarzoso, I. (2016). European Union Market Access Conditions and Africa's Extensive Margin of Food Trade. The World Economy. DOI: 10.1111/twec.12466

(C) 2016 John Wiley \& Sons Ltd.

The appropriate permission for re-use has been requested by me (Fatima Olanike Kareem) as the corresponding author of the article. A formal permission licence for re-use in this thesis/dissertation has been granted by John Wiley and Sons via the RightsLink service. 


\begin{abstract}
We examine the impact of two important non-tariff measures that affect firms' decisions to export food products to the European Union (EU). As a novelty to the literature, we analyse the implication of EU pesticide standards on African exports alongside another complementary non-tariff measure in the form of a minimum entry price control measure which aims to protect EU growers of certain fruits and vegetables against international competition. We represent these trade costs in the context of a Melitz firm heterogeneity framework using the Helpman, Melitz and Rubenstein (2008) method. The analysis was based on Africa's exports of tomatoes, oranges, and limes and lemons to the EU from 2008 to 2013, using the gravity model of trade.
\end{abstract}

Our results show that at the extensive margin of trade, the high stringency of EU pesticide standards prevents new entry into the EU market, drives less productive firms away, and discourages existing exporters from expanding their market base. However, the impacts vary widely at the intensive margin; the export of tomatoes is inhibited, with no effect on lime and lemon exports, but the African export of oranges is significantly promoted to the EU. This reveals that standards are not necessarily problematic as is widely viewed, and serve as catalyst or barrier to international trade. Furthermore, we find the EU entry price system to be of no relevance to African exports of oranges, and limes and lemons; however, it appears to act like an export tax, significantly impeding export of tomatoes to the EU.

Given the recent fall in tariffs, one of the keys to unlocking and stimulating African exports in these products lies in tackling both behind the border restrictions. Adequate measures must be secured to increase compliance with EU standards so as to enhance continuous market access for the continent, such that Africa would be able to make use of trade to alleviate its prevailing poverty as well as achieve a more balanced and equitable economic growth. Engaging in deeper trade integration and removal of domestic market restraints are some important policy imprints that could work to ensure sustainability practices and market access to the EU.

Keywords: Gravity model, African exports, Pesticide standards, Entry price control, Extensive margin, Intensive margin

JEL Classification: C13 C33 F10 F13

\title{
3.1 Introduction
}

The last decades have witnessed a structural shift from the exports of traditional agricultural food products such as cocoa and sugar by most developing countries to non-traditional high valued agricultural food products such as processed and fresh fruits and vegetables (Reardon et al., 2009). Consequently, trade is significantly playing a crucial role in the provision of food, export earnings and economic growth for many developing countries. However, this cannot be categorically said for African countries, many of which have gradually become predominant net food importers (World Bank, 2012). In addition, the continent continues to depend majorly 
on exports of traditional valued agricultural-food products despite the structural shift of most developing countries to non-traditional high value agricultural products. As a result, this may jeopardize the significant role played by food exports in stimulating economic growth and as a means of poverty reduction especially for sub-Saharan African countries, many of which rely heavily on agriculture for sustenance. This weak integration of many African countries into the global economy can be an impediment to the developmental progress of the continent, primarily because deep trade integration is widely viewed as the most promising avenue to achieving economic growth (Nicita and Rollo, 2015).

Numerous factors have been linked to the weak integration of African countries in global markets, including the high cost of exporting and poorly developed trade facilitation infrastructure (Djankov, et al., 2010; and Iwanow and Kirkpatrick, 2009; Portugal-Perez and Wilson, 2012), domestic supply constraints (Xiong and Beghin, 2011) and trade inhibiting nontariff barriers (NTBs) imposed on exports (Czubala, et al., 2009; Shephard and Wilson, 2013; Otsuki, et al., 2001). Of these obstacles, standards imposed on food products have been identified as the single most important market access condition for Africa's exports (Otsuki et al., 2001), thus necessitating a careful study. Consequently, a clearer understanding of the actual impacts of such NTBs on market access is of paramount importance for the population of this continent, the majority of whom depend on agricultural activities for their livelihood.

By definition, food safety standards are an integral part of sanitary and phytosanitary (SPS) measures levied on food products with the objective of ensuring food safety and ensuring consumers' health and safety, based on prior scientific evidence. Their usage has gained importance in recent years due to a number of food scares in developed countries (UnNeverhr, 2003). This makes standards to constitute one of the most paramount market access conditions imposed by the EU on food exports. Standards are of particular concern to exporters due to their dual ability to be used as a protectionist measure in preventing imports as well as the legitimate use of offering protection for consumers' health and safety. On the one hand, there is the 'standards as a barrier' perspective where standards have been viewed as a barrier to export penetration due to the related trade cost effects. It is posited that standards affect trade competitiveness due to the investment costs of complying with them which consequently may dampen the competitiveness of the exported good as well as reduce its profit margin, and thereby act as a trade barrier (Markus and Wilson, 2001). In addition, the increasing stringency of these standards implies a rising cost of compliance and this situation is aggravated for exporters from Africa due to their lack of necessary technology and infrastructure that inhibits their capability to comply with importing countries' standards (Jaffee and Henson, 2004).

However, standards can also be trade enhancing once the right environment is set up (ibid). Thus, on the one hand, standard can also serve as a catalyst in stimulating exports due to its import-demand enhancing effects. This is mainly because standards increase the face value of certified products and processes by providing consumers with vital information and assurance about their health and safety, consequently, compliance can generate increased import demand for the products (Blind, 2001; Moenius, 2004; Baller, 2007). Standards also removes 
information asymmetric from the producers and exporters by providing them guideline about the technicalities and specifications of the products, which consequently might increase technology innovation and or diffusion (Blind, 2001). Thus, this study aims to validate these theoretical stances by highlighting evidence-based trade impacts of EU food standards on Africa's food export.

This study is motivated by the recent literature on firm heterogeneity which reveals that the growth of developing countries' trade was predominantly as a result of the expansion of trade along the extensive margin (the creation of new trade relationship i.e. exports of existing products to new partners or markets, exports of new products or varieties to existing or new markets) rather than the expansion in the intensive margin - expansion in the volume trade to existing trading partners (Debaere and Mostashari, 2010; Reis and Farole, 2012; Nicita and Roll, 2015). In spite of this assertion, we argue that the ability of African countries to initiate or penetrate new markets might ultimately be constrained by stringent importing countries' market conditions. Thus, analysing the impacts of the aforementioned EU market conditions in the food sector on Africa's exports along the extensive margin is crucial to understanding the process of entries and exists in export markets and also identify if indeed it is a significant constraint to Africa's export competitiveness. For instance, studies that look at the impact of EU market conditions in the food sector on Africa's exports have predominantly focused on the intensive margin (Otsuki, et al., 2001; Grebrehewit, et al., 2007). However, the implications of EU food safety regulations on market access have received less attention on the extensive margin of trade. Having a better understanding of the effects of these two EU market access conditions in the food sector and their effect on both existing and potential exporters is therefore important from a policy perspective.

This study therefore makes two important contributions and novelties to the literature, particularly in respect to prior research on Africa. First, we expand the scope of existing empirical studies by examining the impact of EU food safety standards concerning pesticide residues in food on the two trade margins. Similar studies on Africa which look at the two margins of trade have rather focused on estimating the trade impacts of aflatoxin standards and not pesticides standards (Xiong and Beghin, 2011). Our present study builds on and extends previous empirical applications by investigating all existing EU pesticides regulations which address food safety concerns on permitted levels of pesticide residues which by definition fall under SPS measures. Thus, we are able to capture the relative importance of all pesticides standards affecting African exports of the selected products. This is in sharp contrast to previous studies which analysed the effects of only one pesticide standard on one product or a few pesticide and product pairs (Wilson and Otsuki, 2004; Scheeper, et al., 2007; Chen, et al., 2008). While these studies are important in their own right, however, they can only provide partial policy implications for policy makers and trade practitioners. Our argument is that each product attracts an array of pesticide standards, and investigating the trade impacts of only one of these standards is tantamount to subjective selection bias. A single pesticide standard is not representative but rather a mis-characterization of the set of standards regulating the quality of the product in a given market. To our knowledge, this represents the first study of its kind that 
investigates the impacts of all regulated pesticides on African exports. Previous empirical research that investigated all regulated pesticide standards were directed on non-African countries (Drogué and DeMaria, 2012; Ferro, al., 2015; Xiong and Beghin, 2014; Winchester et al., 2012). Similar studies on Africa are rare relative to the emergence of food safety standards and regulations and the implication for export from the continent.

Second, we introduced another measure of restrictiveness that exporters face when exporting fresh fruits and vegetable to the EU. This system of protection is referred as the EU entry price system (hereafter EPS) and is imposed complementarily to the EU safety standards. The EPS measure aims to protect EU growers of 15 fruits and vegetable products from international competition by the imposition of a minimum entry price requirement. This non-tariff measure acts to restrict the synthetic import prices below the predetermined entry price, leading to the imposition of a specific duty on exports when the import price falls below a predetermined minimum entry price. This erodes the export competitiveness while increasing EU growers' competitiveness relative to exporters'.

Alongside SPS measures on pesticide residue limits which might affect export prices, the EPS also ensure that certain fruits and vegetables are subjected to the imposition of a penalty factor so as to make cheap and competitive exports more expensive. However, this trade cost has never been represented in a gravity model when analysing EU bilateral trade on exports of fresh fruits and vegetables. By working like a tariff, EPS not only generates the usual trade distortion effects expected from tariff protection, but also generates another effect which a pure tariff regime would not generate. This is by inducing exporters to supply more expensive exports to the EU to avoid the additional duties (Geotz and Grethe, 2010). Indeed, such pricing behaviour might make the exporter to supply the product at a price which is greater than that which would be obtainable in EU domestic markets. Consequently, this erodes any competitive cost advantage, thereby jeopardizing trade liberalization efforts and eroding gains from trade. As a result, the EPS is of paramount importance to market access. Despite the importance, this measure has not been represented in previous research which investigated the impact of standards on fruits and vegetables. One reason is due to the difficulty in obtaining comprehensive data on the EPS. This is coupled with the fact that tariffication of the impact of the EPS is long and tedious. This study therefore represents an important landmark in the literature.

We proceed by investigating the impact within a gravity model using a panel dataset focusing on fresh fruit and vegetable exports - namely tomatoes, oranges, limes and lemons - between 2008 and 2013. The choice of the export products is due to the fact that they are simultaneously subjected to EU entry price control and also attract stringent pesticide regulations due to their perishable nature and susceptibility to food safety risks. In our analysis, we investigated the potential impacts of EU food safety standards concerning allowable pesticide residues on Africa's exports. Although EU food safety standard regulations encompass many requirements, all of which need to be satisfied, the focus of this study is on pesticide standards. Out of all EU food safety requirements, the violation of the acceptable maximum residual limit (MRL) of 
pesticides in food or feed products represents the second largest reason for border rejections of third country's exports to the EU; this consequently constitutes a loss of export revenue and products for the exporters. In fact, the violations of pesticide residue limits constitute about $70 \%$ of EU rejections of all Africa's fruit and vegetable exports between 2008 and 2013, thus indicating an important market access problem for the African continent (RASFF, 2014).

The rest of the study is organised as follows. The next section provides some background information on the selected food exports and an overview of the regulatory pesticide standards imposed on them. Section 3.3 reviews the previous literature. Section 3.4 discusses the methodological and empirical strategies, and also provides a description of the data. Section 3.5 discusses our empirical results. The final section concludes and proffers some policy recommendations.

\subsection{Background of the Study}

This section provides background information on two important and complementary non-tariff measures on fresh fruit and vegetables in the EU - pesticides standards and the EU EPS. We analyse EU enforcement of standards in terms of the border rejection of non-complying countries' exports and the reasons for such rejection in order to determine the implication of non-compliance on export success. Furthermore, we provide background information of Africa's export and output performance in the selected products, as well as an analysis of the trend of EU standards and Africa's exports. We end by providing information on the EPS which is an important non-tariff measures imposed on selected fruits and vegetable products in the EU.

\subsubsection{Pesticide Standards Regulations in the EU}

Pesticides are active substances used to protect crops from plant and pest diseases before and after harvest, with the aim of increasing the quantity and quality of the produce. However, their usage or misuse remains a concern for human health and the environment. Thus, stringent risk assessment is usually undertaken to determine the maximum acceptable daily intake of pesticides that would be well below the acute reference dose over a person's lifetime, without posing any adverse consequences. Pesticide standards are therefore used to address food safety concerns and falls under SPS measures. Pesticide standards are set using the maximum residue levels (MRLs) of a pesticide's concentration in or on food, based on good agricultural practices (GAP). MRLs usually include wide safety margins that are well below the level that could pose any adverse effect on consumers' health and safety. In the EU, pesticide regulations are governed by Directives (EC) No 396/2005, which establishes the MRLs of pesticides residues allowable in products of both plant and animal origin intended for consumption, based on scientific evidence from risk assessments. This directive came into force in September, 2008 and repealed the four previously existing fragmented regulations on pesticides. The directive harmonized all pesticide standards among EU member states and replaced all national pesticide standards with the new MRLs. 
Prior to this directive, pesticide regulations used to be fragmented, as members would usually come up with their own country level pesticide MRLs for active substances that were not yet covered by EU regulations. Despite the framework of the single common market operated by the EU, the lack of agreement of food standards created unnecessary trade distortion and legal uncertainties. This led to the subsequent harmonization of EU pesticide standards under the new law - directive 396/2005. With this directive, EU pesticide regulations become more encompassing as more than three times the previous number of pesticides were regulated. This directive has been amended several times as new scientific evidence on previously nonestablished substances was discovered and more and more pesticides were regulated.

The EU exercises a 'precautionary principle' by setting the most stringent default standard of $0.01 \mathrm{mg} / \mathrm{kg}$ on pesticides whose risk assessment has not been made or completed. The precautionary principle is applied to protect health when there are reasonable reasons for health concerns, but sufficient scientific information or evidence concerning food risks is lacking, incomplete or inconclusive. The frequent exercise of this precautionary principle perhaps makes EU pesticide standards some of the most stringent in the world.

In this study, we analyse the implications of the EU pesticide standards on three selected products at the HS6 disaggregated level: tomatoes, oranges, and limes and lemons. The choice of fresh fruit and vegetable products is due to the fact that they have the potential to retain high levels of pesticide residues and are prone to having a handful of different number of pesticides in them; as a result, they are frequently categorised among the so-called 'dirty dozen' products that usually retain a high content of pesticides in them. Table 3.1 displays the number of regulated pesticides for each product considered in this study. The EU imposes standards on a large range of pesticides for tomatoes, oranges and limes and lemons, amounting to 468 pesticides in 2008 which declined to about 462 in 2013. This reduction is due to a number of previously regulated pesticide standards, which are now exempted from regulation with no MRL required for them, as subsequent risk assessment has shown them to be safe for consumption. The EU coverage of regulated pesticides is higher in contrast to of Codex Alimentarious Commission (hereafter codex) which have standards on only a limited range of pesticides. For instance, in 2013, the EU set limits on 462 pesticides on tomatoes, while those of Codex were only 72. The EU is therefore much more restrictive in relation to the number of pesticide standards. That being said, Codex is significantly increasing the number of pesticide standards it regulates, increasing from 54 in 2008 to about 72 in 2013.

Table 3.1: EU Number of Pesticide Regulated in EU, 2005 to 2013

\begin{tabular}{lccccccc}
\hline & $\mathbf{2 0 0 5}$ & $\mathbf{2 0 0 8}$ & $\mathbf{2 0 0 9}$ & $\mathbf{2 0 1 0}$ & $\mathbf{2 0 1 1}$ & $\mathbf{2 0 1 2}$ & $\mathbf{2 0 1 3}$ \\
\hline EU - Tomatoes and Citrus & 167 & 468 & 467 & 467 & 467 & 467 & 462 \\
Codex - Tomatoes & & 54 & 60 & 66 & 68 & 69 & 72 \\
Codex - Citrus & & 27 & 29 & 31 & 37 & 39 & 60
\end{tabular}

Sources: Own compilation, European Pesticide and Codex Alimentarious Commission Databases 
While numbers tell us the extent of the standards, they do not provide information about their intensity or stringency; this is provided by the maximum residue limit (MRL) imposed on the pesticides. The stringency of pesticide standards is measured in parts per million (indexed as $\mathrm{mg} / \mathrm{kg}$ ). The higher the MRL, the lower the stringency of the pesticide standard, and a decrease in the MRL signals an increase in its stringency level. Figures 3.1 and 3.2 display the average stringency level of the subsets of pesticides regulated by the EU and Codex.

Figure 3.1: EU Pesticide Standards

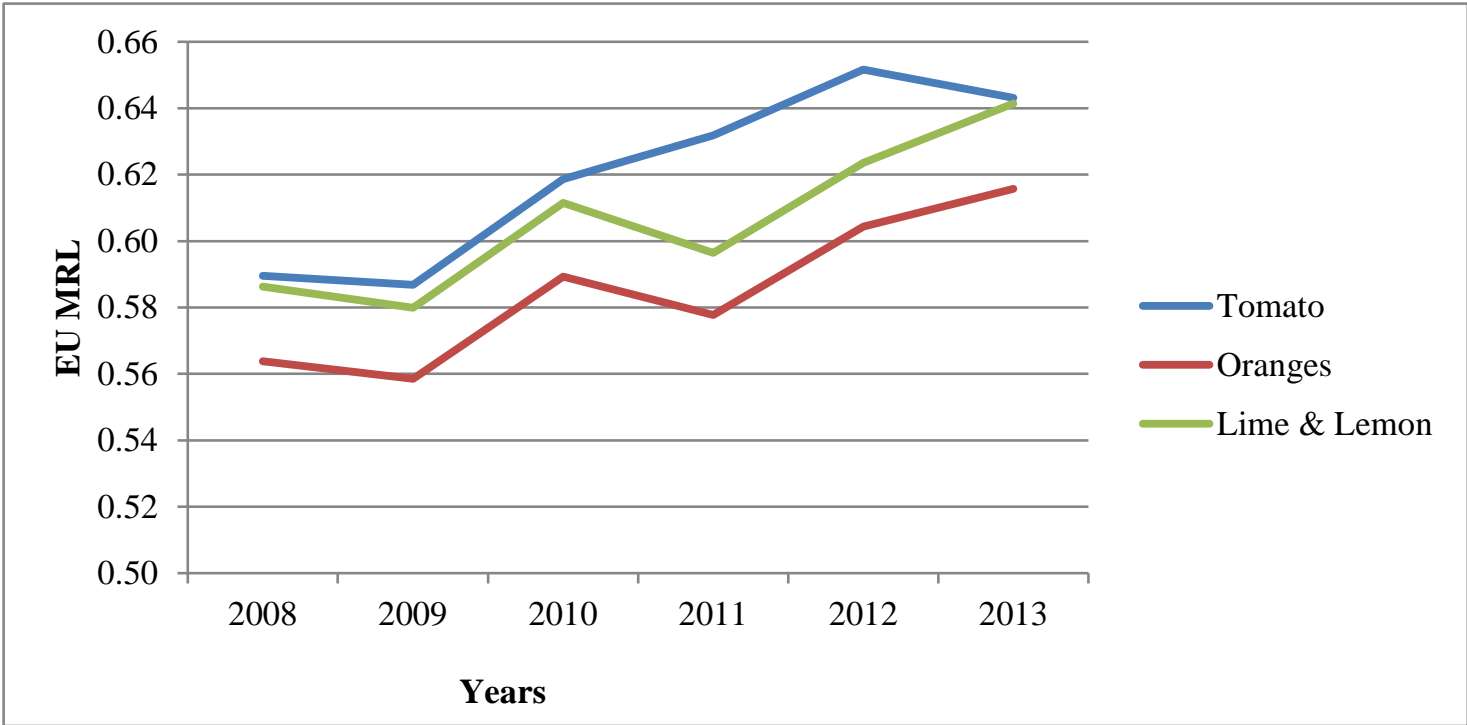

Source: Own Computation based on data from the European pesticide database

In the case of tomatoes, among the 462 pesticides regulated by the EU in 2013, the average MRL is $0.64 \mathrm{ppm}$, and the average MRL for Codex standards in the same period is $2.73 \mathrm{ppm}$. Similar results are obtained in the cases of oranges, and limes and lemons. This indicates that EU tomato standards are on average more stringent than those of Codex as the EU's maximum allowable residue levels are lower for all products considered.

Figure 3.2: Codex Pesticide Standards

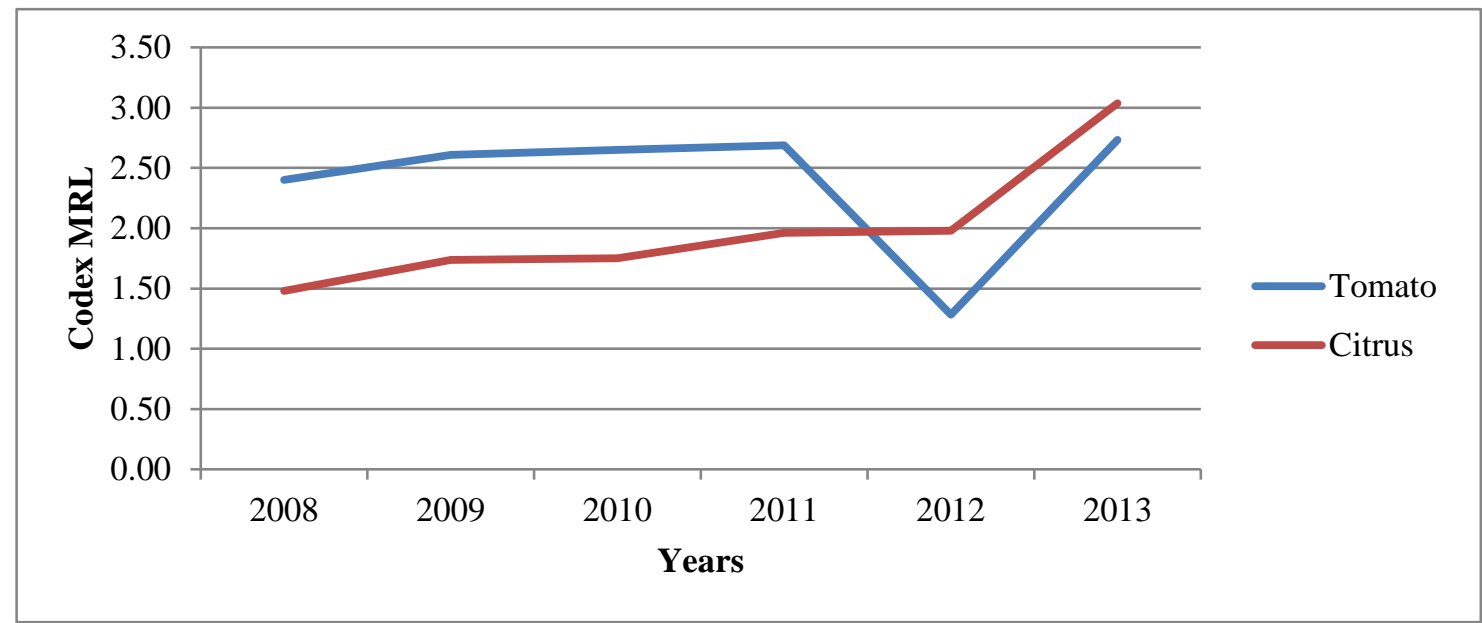

Source: Own Computation based on data from the Codex Alimentarious Commission Database 
In the EU, the stringency and restrictiveness of pesticide standards differ significantly among the three products considered (Figure 3.1). From a high stringency level in 2008, EU pesticide standards on these three products became more restrictive in 2009 (a lower trend signifies higher stringency and thus, more restrictiveness and vice versa). In addition, the stringency level of oranges, and limes and lemons are more restrictive in 2011 compared to 2010, while levels for tomatoes were more restrictive in 2013 compared to 2012. However, over the same period, Codex standards in all 3 products became relatively less stringent with the exception of the regulation on tomatoes which became very restrictive in 2012 (Figure 3.2).

Although these standards are of legitimate concerns by countries to safeguard health and safety, compliance may be both costly and trade distorting. This might be aggravated for developing countries due to their dearth of the necessary technical and scientific infrastructure, as well as the limited financial resources necessary to comply with these standards. The inability to comply with such standards can lead to trade restrictions such as border rejections or import detentions, import bans on particular products, and loss of a country's reputation which affects subsequent exports (Baylis, al., 2010). The consequences of these import bans and border restrictions can be enormous and extremely costly. While they result in an immediate reduction in export earnings, they might affect the exporting country's reputation and damage competitiveness of its exports in the long run, Maertens, and Swinnen, 2009; Baylis et al., 2010). On the flipside, complying with standards implies quality products and ensures market access to the EU. Therefore, in the next session, we will analyse the EU's enforcement of its standards and the implication on trade.

\subsubsection{EU Border Rejection of Feed and Food and the Reasons for the Rejection}

Standards are set with the aim of achieving high levels of sanitary and health protection for consumers; export products which do not meet the standards are not allowed a place on the markets. In the EU, enforcement of such standards is via three avenues: border rejection for export products coming in; an alert being circulated about the potential harm of the product; and information for goods already in circulation in one or more member countries, in which case products not complying with the set standards are withdrawn from the market (RASFF, 2014). Thus, non-compliance usually leads to import refusals at the border or import detention and destruction.

There have been a significant number of border refusals of food exports by the EU which amount to about 9233 between 2008 and 2013 (ibid). This is evident in Table 3.2 which shows the unit border rejection of the ten most rejected food exports from countries exporting to the EU. In particular, after nuts and nut products, fruits and vegetables is the second most important product category usually refused entry into EU markets due to exporters' inability to meet EU stipulated standards. Refusal of this category of products represents about $20 \%$ of all EU food export refusals between 2008 and 2013. 
Table 3.2: EU Border Refusal by 10 Most Affected Product 2008 to 2013

\begin{tabular}{lrrrrrr}
\hline Product & $\mathbf{2 0 0 8}$ & $\mathbf{2 0 1 0}$ & $\mathbf{2 0 1 2}$ & $\mathbf{2 0 1 3}$ & $\mathbf{2 0 0 8 - 2 0 1 3}$ & \%of Total \\
\hline Nuts, Nut Products and Seeds & 673 & 468 & 272 & 215 & 2557 & 27.69 \\
Fruits and Vegetables Products & 192 & 244 & 479 & 402 & 1874 & 20.30 \\
Fish and other Fish Products & 89 & 183 & 166 & 86 & 969 & 10.49 \\
Food Contact Material & 60 & 88 & 127 & 156 & 620 & 6.72 \\
Herb and Spices & 37 & 153 & 83 & 77 & 513 & 5.56 \\
Cereals and Bakery Products & 60 & 52 & 69 & 36 & 318 & 3.44 \\
Feed Materials & 0 & 38 & 103 & 65 & 339 & 3.67 \\
Crustaceans and Products Thereof & 49 & 31 & 36 & 30 & 270 & 2.92 \\
Meat \& Meat Products (other than Poultry) & 13 & 52 & 40 & 64 & 252 & 2.73 \\
Dietic \& Fortified Food, Food Supplements & 13 & 39 & 52 & 54 & 205 & 2.22 \\
Others & 181 & 196 & 288 & 258 & 1316 & 14.25 \\
Total & 1367 & 1544 & 1715 & 1443 & 9233 & 100.00 \\
\hline Sour Con
\end{tabular}

Source: Compilation from EU RASFF Publications, Various Years

Specifically, during this period, the distribution shows that standards are levied against different food safety hazards. This covers a variety of different standards requirements in the food sector such as the violation of the acceptable maximum residual limits of mycotin, pesticide residues, heavy metals, the migration of substances, the presence of pathogenic micro-organisms, etcetera. Out of these, pesticide standards remain the second largest reason for border rejections in the EU (Table 3.3). In this period, non-compliance with EU pesticide residue limits led to about 1102 cases of import rejections, which represents about $11.41 \%$ of all border rejections from all countries in the world. This indicates that the issue of pesticide residue is of paramount importance.

Table 3.3: Reasons for the EU Border Refusal of Third Countries' Food and Feed by Type of Hazard, 2008 to 2013

\begin{tabular}{lrrrrrr}
\hline Type of Hazard & $\mathbf{2 0 0 8}$ & $\mathbf{2 0 1 0}$ & $\mathbf{2 0 1 2}$ & $\mathbf{2 0 1 3}$ & $\mathbf{2 0 0 8 - 2 0 1 3}$ & \%of Total \\
\hline Mycotin & 28 & 49 & 425 & 269 & 1827 & 18.91 \\
Pesticide Residues & 31 & 143 & 320 & 337 & 1102 & 11.41 \\
Not Determined/Other & 802 & 84 & 1 & 3 & 987 & 10.22 \\
Migration & 12 & 586 & 51 & 42 & 773 & 8.00 \\
Pathogenic Micro-organisms & 15 & 126 & 159 & 279 & 693 & 7.17 \\
Poor or Insufficient Controls & 4 & 18 & 144 & 75 & 551 & 5.70 \\
Heavy Metals & 14 & 7 & 108 & 136 & 458 & 4.74 \\
Foreign Bodies & 73 & 26 & 61 & 22 & 362 & 3.75 \\
Organoleptic Aspects & 47 & 38 & 53 & 26 & 317 & 3.28 \\
Adulteration/Fraud & 0 & 72 & 74 & 79 & 292 & 3.02 \\
GMO/Novel Food & 32 & 90 & 52 & 37 & 260 & 2.69 \\
Food Additives and Flavourings & 1 & 49 & 59 & 29 & 257 & 2.66 \\
Composition & 6 & 1 & 60 & 60 & 255 & 2.64 \\
Parasitic Infestation & 10 & 111 & 13 & 4 & 243 & 2.52 \\
Non-Pathogenic Micro-Organisms & 28 & 7 & 50 & 33 & 194 & 2.01 \\
Others & 330 & 207 & 124 & 12 & 1089 & 11.27 \\
Total Hazard & 1433 & 1614 & 1754 & 1443 & 9660 & 100.0 \\
\hline
\end{tabular}

Source: Compilation from EU RASFF Publications, Various Years 
For each product, all the specified standard requirements (Column 1, Table 3.3) needed to be satisfied as a prerequisite for granting market access into the EU market. Each requirement is as important as every other one, otherwise, market access could be denied. However, the focus of this study is on pesticide standards due to two important reasons. First, it is easy to quantify unlike all other standards requirements. Second, it represents the second largest reason for rejecting and detention of food imports, which consequently constitutes a loss of export revenue and products for the exporters. Third, pesticide (mis)use exerts an important impact on climate change and also has other environmental and health impacts; its impact on trade flows is therefore important in its own right and should be studied in order to proffer evidenced based policies to encourage sustainable practices in countries violating the limit.

Africa's large share of refusal of its food exports to EU markets is primarily because of noncompliance with EU standards. Table 3.4 shows the evolution of EU border rejection of Africa's food exports for the most affected African countries and products. For Africa, fruit and vegetable exports remains the third most important product denied entry into the EU; it comprises about 7.21\% of all Africa's food exports rejected entry between 2008 and 2013. Out of the 1874 cases of fruits and vegetables rejected between 2008 and 2013 from all countries (Table 3.2), Africa accounts for about 203 cases of this (Column 9 of Table 3.4), which amounts to about $10 \%$ of all EU rejections of vegetables in this period. More so, as depicted in Table 3.4, among the most affected countries, Egypt, Nigeria, and Kenya recorded the highest number of rejected fruit and vegetable exports, amounting to 86 rejections for Egypt, 31 cases for Nigeria, and 23 for Kenya.

Table 3.4: EU Border Refusal of African Exports by Most Affected Countries and Products, 2008 to 2013

\begin{tabular}{|c|c|c|c|c|c|c|c|c|c|}
\hline Most Affected Products & $\underset{\overrightarrow{0}}{\overrightarrow{\sigma_{0}}}$ & 莺 & 苛 & 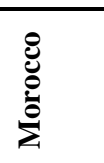 & 嵒 & $\stackrel{8}{3}$ & 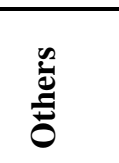 & స్ & 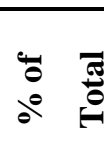 \\
\hline Fish \& Fish Products & 0 & 15 & 3 & 128 & 1 & 9 & 163 & 336 & 11.93 \\
\hline Nuts \& Nut Products & 89 & 18 & 0 & 1 & 52 & 39 & 16 & 219 & 7.78 \\
\hline Fruits \& Vegetables & 86 & 8 & 23 & 16 & 31 & 4 & 20 & 203 & 7.21 \\
\hline Crustaceans \& Products thereof & 0 & 0 & 0 & 3 & 1 & 0 & 43 & 57 & 2.02 \\
\hline Cephalopod & 1 & 1 & 1 & 20 & 0 & 0 & 9 & 40 & 1.42 \\
\hline Cocoa & 2 & 3 & 1 & 5 & 14 & 0 & 3 & 28 & 0.99 \\
\hline Fat and Oil & 1 & 5 & 0 & 1 & 5 & 0 & 10 & 22 & 0.78 \\
\hline Cereals and Bakery & 2 & 6 & 0 & 1 & 4 & 2 & 2 & 17 & 0.60 \\
\hline Other food product/Mixed & 0 & 1 & 0 & 1 & 1 & 0 & 0 & 4 & 0.14 \\
\hline Honey & 0 & 0 & 0 & 0 & 0 & 0 & 1 & 1 & 0.04 \\
\hline Other Products & 384 & 114 & 56 & 384 & 221 & 115 & 520 & 1889 & 67.08 \\
\hline Total & 565 & 171 & 84 & 560 & 330 & 169 & 787 & 2816 & 100.0 \\
\hline
\end{tabular}

Source: Compiled from RASFF Online Database 
The huge number of rejections implies non-compliance to EU standards, and represents an important market access problem for Africa. The volume of trade during this period would have been more than the figures recorded if only these countries had complied with the stipulated EU standards. The high rejection levels of Africa's fruits and vegetables and the implications for market access reinforce our choice of these products in this study.

The different reasons for rejecting African food and feed by the EU are presented in Table 3.5. These include exceeding the stipulated mycotin limit and poor and insufficient controls. Meanwhile, pesticide residue violation is listed as the third major reasons for denial of market access. In fact, out of all the 18 reasons for which Africa's food exports were usually rejected, exceeding the pesticide residue constitute about $15.57 \%$ of rejections between 2008 and 2009 . In addition, the most frequent countries violating EU pesticide residue limits are Egypt with 80 cases of border rejections, followed closely by Morocco which has 36 cases of rejection, Nigeria with 28 rejections, and Kenya with 23.

The data portraited in Table 3.5 clearly establish that fruits and vegetables remain one of the most important export product categories which face a significant number of rejections of export products from Africa and other continents, and that violation of pesticide standards also remains an important reason for such rejections.

Table 3.5: Reasons for the EU Refusal of Africa's Food and Feed by Hazard Category, 2008 to 2013

\begin{tabular}{|c|c|c|c|c|c|c|c|c|c|c|}
\hline & $\overrightarrow{0}$ & 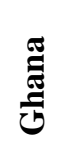 & 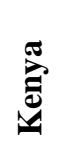 & 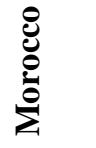 & 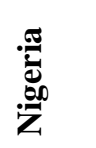 & 岳 & 葛 & $\stackrel{\mathscr{2}}{0}$ & $\stackrel{\pi}{0}$ & 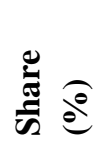 \\
\hline Mycotin & 84 & 28 & 1 & 0 & 56 & 53 & 4 & 29 & 255 & 22.43 \\
\hline Poor or Insufficient Controls & 3 & 15 & 1 & 56 & 6 & 5 & 15 & 130 & 231 & 20.32 \\
\hline Pesticide Residues & 80 & 1 & 23 & 36 & 28 & 3 & 3 & 3 & 177 & 15.57 \\
\hline Organoleptic Aspects & 3 & 8 & 1 & 15 & 6 & 2 & 10 & 54 & 99 & 8.71 \\
\hline Pathogenic Micro-organisms & 2 & 1 & 1 & 23 & 4 & 2 & 1 & 33 & 67 & 5.89 \\
\hline Parasitic Infestation & 0 & 1 & 0 & 48 & 0 & 2 & 6 & 5 & 62 & 5.45 \\
\hline Non-Pathogenic Micro-Organisms & 13 & 6 & 0 & 11 & 3 & 0 & 3 & 23 & 59 & 5.19 \\
\hline Packaging Defective/Incorrect & 3 & 2 & 0 & 17 & 1 & 0 & 3 & 7 & 33 & 2.90 \\
\hline Adulteration/Fraud & 3 & 5 & 0 & 6 & 3 & 1 & 4 & 9 & 31 & 2.73 \\
\hline Food Additives and Flavourings & 9 & 2 & 0 & 1 & 3 & 5 & 1 & 7 & 28 & 2.46 \\
\hline Heavy Metals & 0 & 0 & 0 & 9 & 1 & 1 & 0 & 12 & 23 & 2.02 \\
\hline Biocontaminants & 0 & 0 & 0 & 20 & 0 & 0 & 1 & 1 & 22 & 1.93 \\
\hline Foreign Bodies & 8 & 4 & 0 & 2 & 0 & 0 & 0 & 6 & 20 & 1.76 \\
\hline Labeling Absent/Incomplete/Incorrect & 2 & 2 & 0 & 8 & 0 & 0 & 2 & 1 & 15 & 1.32 \\
\hline Industrial Contaminants & 1 & 0 & 0 & 0 & 1 & 0 & 0 & 10 & 12 & 1.06 \\
\hline GMO/Novel Food & 0 & 0 & 0 & 0 & 1 & 0 & 0 & 0 & 1 & 0.09 \\
\hline Migration & 0 & 0 & 0 & 0 & 0 & 0 & 1 & 0 & 1 & 0.09 \\
\hline Not Determined/Other & 0 & 0 & 0 & 0 & 0 & 0 & 0 & 1 & 1 & 0.09 \\
\hline Total Hazard & 211 & 75 & 27 & 252 & 113 & 74 & 54 & 331 & 1137 & 100.0 \\
\hline
\end{tabular}

Source: Compiled from RASFF Online Database 
We further disaggregate the reasons for the border rejection of African fruit and vegetable exports so as to provide evidence as to what percentage could be attributed to the violation of EU pesticide standards. The disaggregation is provided in Table 3.6.

As shown in Table 3.6, the EU share of rejection of Africa's fruits and vegetables as a percentage of total rejection of all Africa's exports has been on the increase. It shot up from $12.7 \%$ in 2008 to as high as $32.17 \%$ and $61.98 \%$ in 2012 and 2013 respectively, signifying an increasing number of rejections in recent years. Of all the fruits and vegetables denied entry into the EU market, $12.5 \%$ were due to pesticide residue violations. This figure has subsequently increased over recent years, with about $94.67 \%$ of rejected African fruits and vegetables denied market access to the EU due to violation of pesticide residue standards. In fact, out of all the reasons why African food exports were usually rejected by the EU, exceeding the pesticide residue limit constitutes $70 \%$ of all Africa's fruit and vegetable export rejections between 2008 and 2013. This signifies that much effort is needed by Africa to ensure that they meet EU standards if trade is to serve as one of the means of generating income and alleviating poverty in the region.

Table 3.6: EU Refusal of African Fruits and Vegetable Exports by Pesticide Residue 2008 to 2013

\begin{tabular}{|c|c|c|c|c|c|c|c|}
\hline Border Rejection & 2008 & 2009 & 2010 & 2011 & 2012 & 2013 & Total \\
\hline Rejection of African Food Exports & 126 & 196 & 202 & 195 & 143 & 121 & 983 \\
\hline of which Fruit \& Vegetable Exports & 16 & 16 & 21 & 24 & 46 & 75 & 198 \\
\hline $\begin{array}{l}\text { Share in Total African Rejected Food } \\
\text { Exports }\end{array}$ & 12.70 & 8.16 & 10.40 & 12.31 & 32.17 & 61.98 & 20.14 \\
\hline Pesticide Residue in Fruits \& Vegetables & 2 & 5 & 9 & 15 & 37 & 71 & 139 \\
\hline $\begin{array}{l}\text { Share in Total Rejection of African Fruit } \\
\text { and Vegetable Exports }\end{array}$ & 12.5 & 31.25 & 42.86 & 62.50 & 80.43 & 94.67 & 70.20 \\
\hline \multicolumn{8}{|c|}{ Other Notification on Pesticide Residues in African Fruit and Vegetable Exports } \\
\hline Alerts & 1 & 3 & 2 & 2 & 2 & 2 & 12 \\
\hline Information & 5 & 9 & 19 & 1 & 0 & 0 & 34 \\
\hline
\end{tabular}

Source: Compiled from EU RASFF Online Database

In addition to border rejections which resulted from exceeding the maximum pesticide residue limit, there are also cases of fruits and vegetables being flagged for pesticide residue problems after being imported, resulting in the EU circulating alerts to Member States in the form of supermarkets 'alerts' or 'information for attention'. In such cases, distributed export products are usually recalled from the supermarkets and destroyed. This subsequently undermines consumers' trust in the products and diminishes the subsequent exports to the EU as previous reputation matters. The last two rows of Table 3.6 provide information on the number of fruits and vegetables subjected to alerts and information, the latter which can be information for attention or information to follow up on such affected products. For the whole period, the EU 
food authority issued a total of 12 alerts to EU food retailers and supermarkets advising them to be on the lookout for certain fruits and vegetables imported from Africa as they have exceeded their MRL. Meanwhile, information which called their attention to such products represented a total of 34 cases in the same period.

This precedent analysis of EU border rejection has several implications for market access of African exports. While the EU import refusal ensures the health and safety of the importing consumers, it can also signal two types of information to the exporting firm or the exporting country concerned. First, exporting countries might act on the information and undertake measures to comply in subsequent years so as to ensure market access to the EU. Second, the loss of export revenue from the border rejection can discourage subsequent export of the product if the exporter fails to meet the set standards, especially among risk averse exporters. Furthermore, Baylis, et al. (2010) noted that border rejection alters the reputation of the exporter not only in the eyes of its trading partners, but also among other potential importers, potentially leading to a significant loss of exports. The enforcement of regulatory standards usually gives rise to import rejection or detention following border inspection for products which do not meet the stipulated standards. This can be significant for concerned exporters as the costs involve not only the loss of export revenue from the detention, but also the cost of transportation and other export costs including the loss of reputation in the eyes of the trading partners, both current and potential.

\subsubsection{Africa's Export Performance}

Africa has a comparative advantage in the production of agricultural products, particularly tropical food products due to its favourable climatic conditions. Such a huge production volume has great potential for export, serving as a source of export earnings and boosting income by increasing economic growth. Thus, a competitive export performance is needed to realize this goal. Table 3.7 shows trends in Africa's production of the selected products alongside the corresponding volume exported to the world.

\section{Tomatoes}

Africa is one of the most important producers of tomatoes given its tropical region and the availability of all year-round sunshine which heavily favours production. This is evident in Table 3.7 as production of tomatoes increased from about 10 million tonnes in 1995 to an approximate value of 17.2 million tonnes in 2011. Significant positive rise in production was witnessed in most years, apart from the period between 2010 and 2011 in which negative growth was recorded. In spite of the recent fall in growth rate, Africa is still one of the world's major producers of tomatoes, producing between $11 \%$ and $13 \%$ of the world's tomatoes between 1995 and 2011 (Column 7, Table 3.7).

On the export side, Table 3.7 shows that Africa's tomato exports more than tripled, increasing from 174 thousand tonnes in 1995 to 540 thousand tonnes in 2011. In addition, after a negative growth of $9.2 \%$ in 1995, exports experienced a positive growth rate with the exception of 2010 when negative growth was witnessed. In spite of the rapid expansion in the production of 
tomatoes, it is surprising that only a small proportion is exported to the world at large. As evident in Table 7, the huge production of tomatoes and output expansion between 1995 and 2011 was not commensurate to the volume exported. For instance, in 1995, when tomato production was about 9.99 million tonnes, the volume exported was around 170 thousand tonnes, corresponding to a mere $1.8 \%$ of the tomatoes produced. This scenario is also true for subsequent years. In fact, most of the increased production of tomatoes in Africa has been domestically consumed as the continent only exported about $1.2 \%$ to the world in 2005 and around $3.1 \%$ in 2011 . This scenario depicts the continent's weak export capacity in tomatoes despite its capacity to produce enormous quantities. In addition, the continent still accounts for about 3.9\% to $7.18 \%$ of total world exports between 2005 and 2011, highlighting the slow expansion of exports in this period (Column 8, Table 3.7).

Table 3.7: African Exports and Production in Millions of US\$, 1995 to 2011

\begin{tabular}{|c|c|c|c|c|c|c|c|}
\hline \multirow{2}{*}{$\begin{array}{l}\text { Year } \\
\text { Tomato }\end{array}$} & \multicolumn{2}{|c|}{ Production } & \multicolumn{3}{|c|}{ Export } & \multicolumn{2}{|c|}{ Share in the world \% } \\
\hline & Tonne ${ }^{a}$ & $\begin{array}{c}\text { Growth } \\
\text { Rate }\end{array}$ & Tonne $^{b}$ & $\begin{array}{c}\text { Growth } \\
\text { Rate }\end{array}$ & Share $\mathbf{a} / \mathbf{c}$ & Production & Export \\
\hline 1995 & 9.99 & 2.48 & 0.17 & -9.24 & 1.84 & 11.73 & 5.57 \\
\hline 2005 & 16.25 & 1.68 & 0.20 & 48.38 & 1.21 & 12.56 & 3.94 \\
\hline 2006 & 16.92 & 4.11 & 0.22 & 10.10 & 1.28 & 12.88 & 3.79 \\
\hline 2007 & 17.12 & 3.21 & 0.39 & 11.20 & 2,22 & 12.52 & 5.55 \\
\hline 2008 & 17.67 & 3.21 & 0.39 & 11.20 & 2.22 & 12.52 & 6.03 \\
\hline 2009 & 19.10 & 8.11 & 0.47 & 20.51 & 2.48 & 12.37 & 6.86 \\
\hline 2010 & 18.18 & -4.83 & 0.45 & -5.21 & 2.47 & 11.96 & 6.33 \\
\hline 2011 & 17.22 & -5.24 & 0.54 & 19.26 & 3.11 & 10.90 & 7.19 \\
\hline \multicolumn{8}{|c|}{ Citrus: Oranges } \\
\hline 1995 & 4.17 & -9.31 & 0.818 & 12.52 & 19.61 & 7.13 & 18.09 \\
\hline 2005 & 5.90 & 6.75 & 1.47 & 14.10 & 24.98 & 9.35 & 29.76 \\
\hline 2006 & 6.24 & 5.66 & 1.63 & 10.82 & 26.20 & 9.44 & 30.82 \\
\hline 2007 & 6.16 & -1.18 & 1.62 & -0.82 & 26.29 & 9.39 & 31.96 \\
\hline 2008 & 6.46 & 4.84 & 1.81 & 11.43 & 27.94 & 9.29 & 31.96 \\
\hline 2009 & 6.61 & 2.39 & 2.03 & 12.57 & 30.72 & 9.76 & 32.44 \\
\hline 2010 & 6.89 & 4.15 & 2.02 & -0.81 & 29.26 & 9.98 & 30.88 \\
\hline 2011 & 7.50 & 8.85 & 2.27 & 12.70 & 30.29 & 10.75 & 32.88 \\
\hline \multicolumn{8}{|c|}{ Lemons \& Limes } \\
\hline 1995 & 0.57 & -1.32 & 0.42 & -3.91 & 7.34 & 6.59 & 3.36 \\
\hline 2005 & 0.92 & -2.80 & 0.15 & -1.54 & 16.34 & 7.45 & 6.95 \\
\hline 2006 & 1.02 & 10.93 & 0.149 & -0.80 & 14.61 & 7.46 & 6.80 \\
\hline 2007 & 0.99 & -2.42 & 0.13 & -11.6 & 13.23 & 7.41 & 5.78 \\
\hline 2008 & 1.05 & 5.13 & 0.17 & 25.40 & 15.79 & 6.10 & 7.08 \\
\hline 2009 & 1.52 & 45.03 & 1.60 & -2.99 & 10.56 & 8.80 & 6.67 \\
\hline 2010 & 1.04 & -31.29 & 0.20 & 27.98 & 19.67 & 6.93 & 8.40 \\
\hline 2011 & 1.10 & 5.55 & 0.19 & -8.21 & 17.10 & 7.25 & 7.45 \\
\hline
\end{tabular}

Source: FAOSTAT

Numerous factors have been attributed to the decline in the export of this produce and the weak exports depicted above. The proliferation of standards - both private and public, have been identified as one of the major obstacles to market access for developing countries' tropical export products (Disdier, et al., 2008). Remarkably, as evident in our descriptive analysis, most 
of the poor or declining export growth can be attributed to the non-expansion of Africa's production due to some domestic supply constraints, or some hidden market access problems which would be discussed more in later sessions.

\section{Oranges}

Oranges are an important citrus fruit for the African region. This can be seen in terms of production, which rose from 5.9 million tonnes in 2005 to about 7.5 million tonnes in 2011; positive increment in production was witnessed in most of this period except for a decline in the growth rate of orange production of about $1.18 \%$ in 2007 . There was however an increase of about $4.84 \%$ in 2008 , falling slightly again in 2009 , before rising tremendously to $8.85 \%$ in 2011.

Interestingly, the increase in production and growth of oranges commensurate with an increase in the exports of oranges. Exports of oranges almost tripled in size, from about 818 thousand tonnes in 1995 to about 2.3 million tonnes in 2011. In fact, most of the increased production of oranges in recent years has been exported as the continent increased its share of orange exports in total production from $19.6 \%$ in 1995 to as high as $30.3 \%$ in 2011, consuming the remaining $69.7 \%$ within the continent. In addition, the region has been demonstrated to be one of the major exporter of oranges in the world, accounting for about $18 \%$ of total world exports in 1995, which increased significantly to $32.9 \%$ in 2011 (column 7, Table 3.1). However, it is important to point out that the growth of oranges exports fell significantly in 2007 (Table 3.8, column 4). From a negative growth of $0.82 \%$ in 2007 , the annual growth of orange exports rose to about $11.4 \%$ in 2008; a negative growth of about $0.81 \%$ was witnessed again in 2010 after the financial crisis. The declining growth might be as a result of intense competition from other fresh fruits such as tangerines, satsumas, mandarins and apples, as well as consumer's preference for processed orange juice over fresh oranges especially in high income countries. The declining growth could also be attributed to high non-tariff barriers which include the increased in the emergency and stringency of food safety regulation. Such regulations increase the cost of the product, lowering demand and thus inhibiting export expansion.

Notwithstanding, many African countries are significant producers and exporters of oranges in the world; their share in world orange production increased from $7.13 \%$ in 1995 to about $10.8 \%$ in 2011. (Columns 6 and 7, Table 3.7). Africa's share of exports in total world exports also increased from 18.1\% in 1995 to around 32.9\% in 2011 (Columns 6 and 7, Table 3.7). This trend signifies the strength of orange as an economically important export product for the continent.

\section{Limes and Lemons}

In terms of limes and lemons, from Table 3.7, we can see that production has been rather stagnant with a lack of adequate expansion over the years. Initially, production increased steadily from 571 thousand tonnes in 1995 but has been stagnating around 1 million tonnes between 2005 and 2011. In fact, prior to 2008, the annual rate of growth was negative. After 
2008, these citrus fruits started to experience positive growth with the exception of 2010 due to the surge in food prices.

A look at the exports of these commodities shows that the stagnated production volume observed between 1995 and 2011 was pari passu with the continent's volume of exports. For instance, from a peak of 0.42 million tonnes in 1995, export volume rose slowly from 0.15 million tonnes in 2005 to about 0.19 million tonnes in 2011. Annual growth of exports has been negative in the whole period under consideration with the exception of 2008 and 2010 when exports recorded a tremendous positive growth of $25.4 \%$ and $27.98 \%$ respectively. From the perspective of the exporting countries, it is evident in Table 7 that the neglect and lack of expansion in the production of these products has led to a significant decrease in exports. However, from the perspective of the importing countries, major studies have attributed this negative growth to the inability of exporting African countries to penetrate their trading partners' markets due to the stringent non-tariff barriers imposed on trade, particularly food safety standards which many exporters found difficult to comply with (Czubala, et al., 2009; Shephard and Wilson, 2013). However, despite the neglect in expanding these export products, it is interesting to see that some of the increased production has been exported as the continent increased its share of lime and lemon exports as a percentage of its total production from $7.3 \%$ in 1995 to as high as $17.1 \%$ in 2011, with the remaining locally consumed within Africa (Table 3.7, column 6). However, the region remains a relatively important producer of these products in the world, contributing between $6.6 \%$ and $7.5 \%$ of total world production between 1995 and 2011. Indeed, the products are increasingly becoming important export products to the continent as the share of total world exports increased from about 3.4\% in 1995 to around $7.4 \%$ in 2011.

Table 3.8 shows the direction of trade of the three products considered in this study between 1995 and 2013. For the sake of this comparison, we broke the time period between 1995 and 2013 into two separate periods: The first describes the period of pre-harmonization of pesticide standards in the EU (1995 to 2007) where member states were not obliged to strictly adhere to standards set by the EU and can impose their own country specific standards on exports. The second period is between 2008 and 2013 and represents the time when EU standards are harmonized among member states such that only standards enacted by the EU parliament prevail in member states (Directive 396/2005).

In the case of tomatoes, a large proportion of tomato exports has been traded within Africa, amounting to as much as $86.5 \%$ between 1995 and 2013. 74.4\% constituted intra Africa trade during the pre-harmonization period, and this increased significantly to about $91.6 \%$ following the harmonization of standards in the EU. This shows clear signs of a lack of significant market access to developed countries. A further look at Table 2 signifies that the EU remains the major destination for tomato exports; aside from Africa, it accounts for about $9.4 \%$ of the continent's tomato exports between 1995 and 2007. However, this share fell drastically to about $2.9 \%$ in the harmonization period in the EU, not only due to the increased number of pesticides now 
Chapter 3: Effect of Food Regulations on the Extensive and Intensive Margins of Trade: Evidence from EU-African Trade

regulated in this period but also due to the very stringent standards set by the EU to guard against risks from pesticide overdose.

Table 3.8: Direction of Trade of Selected Africa's Fruit and Vegetable Exports, 1995 to 2013

\begin{tabular}{lccc|lccc|lccc}
\hline & Tomatoes & \multicolumn{3}{c|}{ Oranges } & \multicolumn{3}{c}{ Limes \& Lemons } \\
\hline & $1995-$ & $1995-$ & $2008-$ & & $1995-$ & $1995-$ & $2008-$ & & $1995-$ & $1995-$ & $2008-$ \\
& 2013 & 2007 & 2013 & & 2013 & 2007 & 2013 & & 2013 & 2007 & 2013 \\
\hline Africa & 86.5 & 74.4 & 91.6 & Africa & 80.1 & 80.6 & 79.8 & Africa & 67.1 & 68.1 & 66.7 \\
EU & 7.7 & 9.4 & 2.9 & EU & 16.8 & 13.0 & 18.9 & EU & 24.8 & 18.9 & 27.4 \\
Jordan & 2.9 & 0.04 & 4.1 & Israel & 0.8 & 1.6 & 0.4 & Argentina & 4.1 & 8.6 & 2.2 \\
Syria & 1.3 & 3.8 & 0.2 & Australia & 0.6 & 1.6 & 0.01 & Israel & 0.8 & 0.6 & 0.9 \\
Others & & & & Others & & 3.2 & 0.89 & Others & & \\
Total & 100.0 & 100.0 & 100.0 & Total & 100.0 & 100.0 & 100.0 & Total & 100.0 & 100.0 & 100.0 \\
\hline
\end{tabular}

Source: Calculations using data from UN COMTRADE statistical database

Despites stringent standards, the tomato is still termed one of the 'dirty dozen' products by the Environmental Working Group (EWG, 2013). The 'dirty dozen' are the top twelve fruits and vegetables that usually retain high levels of pesticide residue and have numerous different pesticides found on them. Thus, the EU is very vigilant about these products and exercises 'precautionary principles' such that a large number of pesticides for which risk assessment has not been undertaken or for which risk assessment is still ongoing are assigned a default and stringent value of 0.01 . Thus, the fall in African exports of this product could be attributed to the high cost of upgrading their supply facilities in order to comply with the new set of EU standards; the process of meeting these requirements is aggravated by the continent's inadequate technological and financial resources to successfully ensure the compliance to such stringent standards. Thus, the precedent fall in African tomato exports to the EU in this period has led to diversion of trade to other countries where standards are less stringent, particularly Jordan and some other African countries which are able to absorb the excess supply of the product.

The case of Africa's export of oranges is somewhat different. Intra Africa trade still constitutes the main avenue where these exports are absorbed, amounting to around $80 \%$ both in the pre and post harmonization periods; this high percentage indicates a lack of adequate market access to other markets. Furthermore, this also shows that the EU is the most important trading partner with Africa. Remarkably, African exports of oranges to the EU accelerated from about $13 \%$ in the pre-harmonization period (1995 to 2007) to about $18.9 \%$ in the post harmonization period despite the prevalence of more stringent standards and an increase in the number of regulated standards in this period. This might be indicative of the fact that these exporters were able to comply with the safety standards, which accelerated their increased penetration of EU markets.

Similar results exhibited by oranges were found for limes and lemons as the EU still remains the most important trading partner for these products, apart from intra trade within Africa which constitutes about $68.1 \%$ and $66.7 \%$ in the pre and post harmonization periods respectively. Africa's direction of trade to the EU improved from $18.9 \%$ to $27.4 \%$ following the 
harmonization of EU standards. In fact, Africa satisfied this increased export supply to the EU mainly by diversifying a significant percentage of its exports from Argentina and other countries to meet the increased import demand in the EU. This increase in exports is witnessed in spite of the fact that the period coincides with a time when the EU enacted more stringent food safety pesticide standards.

Thus, the direction of trade indicates that the EU remains Africa's largest and most important international trading partner for the three selected products. Furthermore, African tomato exports witnessed a significant decline during the EU's period of standards harmonization while exports of oranges, and limes and lemons accelerated in the same period.

\subsubsection{EU Pesticide Standards and Market Access of Africa's Exports - A Preliminary Analysis}

The EU has its own standards requirements and variations in the laxity and/or stringency of these might have different implications on exports. A detailed analysis of the performance of the selected export products and the associated food safety standards - as well as the likely implications on market access - is provided in this section to give us a preliminary view on the implications of EU pesticide standards on the selected African food exports. As highlighted previously, a decrease in the MRL of pesticides tends to signify an increase in the stringency in the EU's standards and vice versa.

\section{Tomatoes}

The trend of African tomato exports to the EU and the corresponding EU pesticide standards is shown in Table 3.9. Evidently, exports of tomatoes to the EU decreased from 1.6 million dollars in 2005 to about 303 thousand dollars following the harmonization of EU standards in 2008. This is can be attributed to a significant increase in the range of pesticides regulated by the EU, and more importantly due to the increase in the stringency of the MRL of tomato standards in 2008 relative to 2005 , which increased from an average of 0.75 in 2005 to 0.59 in 2008 . The high cost of complying with the EU's new regulations erodes export competitiveness for this product for those who choose to still export to the EU, as well as barring non-complying firms from market access to the EU. This is as expected as data from EU import rejections indicates that many African countries' fruit and vegetable exports were denied entry into the EU markets because they were unable to meet the stringent EU food standards in this period. This development is due to the EU Directive which harmonized all EU standards and set the most stringent default value for pesticides for which no scientific risk assessment has been made; it also resulted in an increase in the number of regulated pesticides.

However, by 2011, with a pesticide standards average of MRL 0.63 amounting to a decrease in the stringency of standards by $21 \%$ compared to 2010, exports rose to 608 thousand dollars. Interestingly, in 2013, the stringency of standards increased negligibly to 0.64, with African exports to the EU increasing to 743 thousand dollars, corresponding to a growth of $9.1 \%$ in spite of the relative tightening of standards. This demonstrates that some African countries responded to these evolving standards and successfully used high safety and quality standards 
to upgrade the structure of their supply chains, making the necessary adjustments and investments in operations. This in turn helps them to achieve a competitive advantage and to reposition themselves and penetrate the markets of developed countries. However, despite the increase in exports after the decline experienced in 2008, it is important to realize that the subsequent increase in tomato exports to the EU was still far below the figures from 2005 during the pre-harmonization period.

Table 3.9: EU Food Safety Standards and Imports from Africa, 2005 to 2013

\begin{tabular}{lrrrr}
\hline & $\mathbf{2 0 0 5}$ & $\mathbf{2 0 0 8}$ & $\mathbf{2 0 1 1}$ & $\mathbf{2 0 1 3}$ \\
\hline EU MRL of Pesticides (mg/kg) & & & & \\
Tomatoes & 0.36 & 0.59 & 0.632 & 0.643 \\
Oranges & 0.58 & 0.564 & 0.578 & 0.616 \\
Limes and Lemons & 0.59 & 0.586 & 0.596 & 0.641 \\
Yearly Change in Stringency Level (\%) & & & -2.1 & \\
Tomatoes & & & 1.9 & 1.4 \\
Oranges & & & 2.5 & -2 \\
Limes and Lemons & & & & -2.7 \\
Annual African Export to EU & 1608.5 & 302.7 & 580.8 & 742.5 \\
Tomatoes (US \$ ‘00) & 1372.8 & 4576.5 & 7041.1 & 20952.8 \\
Oranges (US \$ million) & 832.5 & 558.9 & 1496.4 & 3019.0 \\
Limes and Lemons (US \$ '000) & & & & \\
Annual Growth Rate of Exports (\%) & & 10.8 & -6.3 & 9.1 \\
Tomatoes & & 8.0 & -25.9 & 31.5 \\
Oranges & & 93.1 & 88.4 & 2.1 \\
\hline Limes and Lemons & & & \\
\hline
\end{tabular}

Sources: Own computation from EU Pesticide and World Integrated Trade Solution databases

\section{Oranges}

In regard to Africa's export of oranges to the EU, it is observed that exports of oranges significantly increased by more than threefold from 1.6 million dollars in 2005 to about 4.6 million dollars in 2008 when the average stringency of EU pesticide MRL was as high as 0.56. This scenario implies that standards do not necessarily hurt exports once exporting countries make the necessary investment and efforts to ensure compliance. However, by 2011, when EU MRL was 0.58 , which represents a $1.9 \%$ increase in stringency compared to the previous year of 2010, exports to the EU were around 7 million dollars, a $26 \%$ decrease from the previous year. This indicates that continuous investment needed to be made in order to keep up to date with standards and ensure compliance if market access is to be guaranteed. By 2013, exports grew by $32 \%$, amounting to about 21 million dollars when the EU average MRL was around 0.62 ; this represents a reduction in the stringency level by $2 \%$ to the levels which prevailed in 2012. This relative laxity in stringency was due to the subsequent results of numerous risk assessments which allowed the EU to establish new MRLs for pesticides which were previously given the most stringent default value of 0.01 . For instance, the Pyraclostrobin pesticide was previously assigned a default value of 0.01 . However, by 2013, following rigorous scientific evidence from risk assessments, a less stringent value of 2 MRL was imposed on it. This implies that untimely risk assessment might create unnecessary obstacles to trade. 


\section{Lime and Lemon}

Similar to the information obtained for tomatoes, Africa's lime and lemon exports to the EU also recorded a significant reduction in their value; figures decreased from 833 thousand dollars in 2005 to as low as 559 thousand dollars in 2008 when the EU harmonized its standards resulting in an average stringency of $0.59 \mathrm{MRL}$. These stringent standards diminished Africa's export success in this period. However, by 2011, exports had picked up tremendously, amounting to around 1.5 million dollars, with a growth of about $20 \%$ compared to figures from 2010. Nevertheless, this period also witnessed an increase in the stringency levels of standards amounting to $2.5 \%$ relative to 2010 , representing an average of $0.60 \mathrm{MRL}$. However, this trend is not surprising as the EU provided the necessary assistance for selected horticultural exporters in ACP countries which assisted them in meeting its standards. By 2013, exports had almost tripled in size, totaling around 3 million dollars, while EU standard in this period relaxed to 0.64 MRL representing a reduction of about $2.7 \%$ compared to the limits set in 2012 .

Indeed, our analysis of these three products has shown that there is no monotonic relationship between standards, as standards can either impede or promote trade, the net effect of which is ambiguous. Depending on the effect that dominates, standards may increase, decrease, or leave trade unaltered. Thus, the exact impact is an empirical one.

\subsubsection{EU Entry Price Procedure for Certain Fruits and Vegetable}

Although exporting to the EU requires that exporting countries' compliance to EU's quality standards requirements, in reality, the compliance to such stipulated standards does not guarantee unrestricted market access, particularly for some specified exporters of fruits and vegetables. In addition to satisfying the EU standards requirements, exporters must also satisfy a 'behind the border' minimum price requirement - the EU minimum entry price control.

The EU aim to protects Community producers of 15 fruit and vegetable products from intense international competition by means of its minimum entry price control. This is done by imposing a penalty factor in the form of specific duties on exports, when the daily import prices fall below a predetermined seasonally varying stipulated minimum price. This system of protection is referred to as the EU entry price system (thereafter EPS). The EPS is a non-tariff measure which aims to restrict import prices below the stipulated entry price and act to erode the competitiveness of exporters and increase the competitiveness of EU growers relative to exporters. For instance, if the exporter supplies the product at a price below the ceiling entry price due to the competitive edge of the exporter who incurs lower costs for production, then a predetermined specific duty is levied as a penalty factor. The specific duty imposed depends on how far the exporters' milling price is below the prevailing entry price. The EU EPS came into force on July 1, 1995, replacing the old reference price system.

To calculate the applicable duties, information is needed on the import price of the product as well as the predetermined entry price. However, a large proportion of EU fruit and vegetable imports are sold on commission, which means that the final import prices of the products are cannot be ascertained until the commodities are sold inside the EU markets. As a result of this 
fact, the European Commission (EC) calculates a 'synthetic' import price which the Commission refers to as the standard import values (SIVs). The applicable SIVs, published on a daily basis by the EC, are calculated from a survey of the prices of each fruit and vegetable product and exporting country of origin, collated from the designated wholesale fruits and vegetables markets in every EU country (Goetz and Grethe, 2008). An SIV ${ }^{23}$ is then calculated on a daily basis as a weighted mean of the wholesale prices that are collected from all representative markets, less the marketing and transportation costs and custom duties (EC Regulation 3223/94).

The EPS varies by season with lower entry prices imposed during the EU's off-season period for the applicable fruits and vegetables, and high entry prices imposed when the fruits and vegetables are in season in the EU. Although almost all African countries enjoy preferential market access to EU markets which is made possible by the "Every Thing But Arms" (EBA) agreement, only a selected few enjoy preferential EPS while the others have to comply with the EU's market access conditions regarding to the EPS.

Table 3.10 shows the schedule of minimum entry prices for the three products that are analysed in this study. For lemons and tomatoes, the entry price runs throughout the whole year from 01.01 to 31.12 as EU growers are not that competitive in producing these products. However, for oranges the entry price system runs between December and May, corresponding to the postharvest period for EU growers - a period in which oranges are out of season and the EU domestic prices are less competitive compared to the prices coming from African countries.

Table 3.10: Schedule of EU Entry Price Control and the Applicable Duties

\begin{tabular}{lllll}
\hline & Application Date & MFN Tariff $(\boldsymbol{\%})$ & $\begin{array}{r}\text { Ceiling EP } \\
(\boldsymbol{\epsilon} / \mathbf{1 0 0 k g})\end{array}$ & $\begin{array}{c}\text { Specific Duties } \\
(\boldsymbol{\epsilon} / \mathbf{1 0 0 k g})\end{array}$ \\
\hline Tomatoes & $01.01-31.12$ & $8.80-14.40$ & $52.60-112.60$ & $0-29.80$ \\
Oranges & $01.12-31.05$ & $3.20-16.00$ & 35.4 & $0-7.10$ \\
Lemons & $01.01-31.12$ & 6.4 & $46.20-55.8$ & $0-25.60$ \\
\hline
\end{tabular}

Source: European Commission, TARIC Database, 2014

Most exporting countries in Africa tend to have lower export prices, with a relative price competitiveness all year round due to the favourable tropical region and cheaper labour. In the case of tomatoes, the ceiling entry price (EP) varies between $52.60 € / 100 \mathrm{~kg}$ and 112.60 $€ / 100 \mathrm{~kg}$ ); for oranges, the ceiling EP is constant at $35.40 € / 100 \mathrm{~kg}$; for lemons, the ceiling EP varies between $46.20 € / 100 \mathrm{~kg}$ and $55.80 € / 100 \mathrm{~kg}$. The duties are then calculated as follows: if the synthetic import price (in this case SIV) is equal or greater to the ceiling EP in any given season, the usual ad valorem tariff applies, and no EP duty is levied. If the 'synthetic import

\footnotetext{
${ }^{23}$ The EU allows exporters three options in determining the applicable EPS duties: standard import values, using the free on board (FOB) prices, and the deductive price. By declaring the export value using the free FOB price, this is then then adjusted for the costs of freights and insurance, giving rise to a cost, insurance and freights (CIF) price. The deductive price option is based on the final selling price of the consignment as indicated by an invoice. Thus, when the final price of the good is far above the floor EP, this results in very high duties and the importer may resort to using these two methods, however, the duties still apply.
} 
price' is below the ceiling EP but above the floor EP, an ad valorem tariff applies plus a specific EP duty. If the synthetic import price is equal to or below the floor ceiling EP in any given season, an ad valorem tariff applies plus the highest EP duty.

In this period, exporters whose mill price falls below the ceiling entry price are penalized for bringing in products relatively cheaper than domestic ones through the imposition of a specific tariff. For tomatoes, the specific tax ranges from a minimum of $0 € / 100 \mathrm{~kg}$ to a maximum of $29.8 € / 100 \mathrm{~kg}$; the range for oranges and limes is between $0 € / 100 \mathrm{~kg}$ and $7.10 / € / 100 \mathrm{~kg}$, and 00 $€ / 100 \mathrm{~kg}$ and $25,60 € / 100 \mathrm{~kg}$ respectively.

We take an example from the EU integrated community tariff (TARIC) website to get a clearer picture of the EPS. Table 11 depicts the schedule of MFN EP levied on a typical country in Africa which has no preferential agreement on EP with the EU (with the exception of Morocco). Suppose that in a day in January, tomato exports from an Africa country (Ghana, for example) arrive at the EU border at a milling/CIF price of $112.6 € / 100 \mathrm{~kg}$. In this case, the import price calculated with the CIF (cost, insurance and freights) price is equivalent to the prevailing ceiling EP of $112.6 € / 100 \mathrm{~kg}$ (column 4). Thus, the normal custom tariff of $0 \%$ applies due to the preferential agreement Ghana has with the EU and no specific duty applies as the EU EPS requirement is perfectly satisfied.

Table 3.11: Detailed EPS Schedule for Tomato: 01.04 to 30.04

\begin{tabular}{|c|c|c|c|c|}
\hline Cases & EP Conditions & $\begin{array}{l}\text { MFN } \\
\text { Tariff }\end{array}$ & $\begin{array}{l}\text { Preferential } \\
\text { Tariff* }\end{array}$ & $\begin{array}{l}\text { Specific } \\
\text { Duties }\end{array}$ \\
\hline 1 & $\begin{array}{l}\text { If the import price is equal to or greater than } \\
\text { the entry price of } 112.60 \mathrm{EUR} / 100 \mathrm{~kg}\end{array}$ & 8.80 & 0 & - \\
\hline 2 & $\begin{array}{l}\text { If the import price is equal to or greater than } \\
\text { the entry price of } 110.30 \mathrm{EUR} / 100 \mathrm{~kg}\end{array}$ & 8.80 & 0 & $\begin{array}{l}2.30 \mathrm{EUR} \\
/ 100 \mathrm{~kg}\end{array}$ \\
\hline 3 & $\begin{array}{l}\text { If the import price is equal to or greater than } \\
\text { the entry price of } 108.10 \mathrm{EUR} / 100 \mathrm{~kg}\end{array}$ & 8.80 & 0 & $\begin{array}{l}\text { 4.50 EUR } \\
/ 100 \mathrm{~kg}\end{array}$ \\
\hline 4 & $\begin{array}{l}\text { If the import price is equal to or greater than } \\
\text { the entry price of } 105.80 \mathrm{EUR} / 100 \mathrm{~kg}\end{array}$ & 8.80 & 0 & $\begin{array}{l}6.80 \mathrm{EUR} \\
/ 100 \mathrm{~kg}\end{array}$ \\
\hline 5 & $\begin{array}{l}\text { If the import price is equal to or greater than } \\
\text { the entry price of } 103.60 \mathrm{EUR} / 100 \mathrm{~kg}\end{array}$ & 8.80 & 0 & $\begin{array}{l}9.00 \mathrm{EUR} \\
/ 100 \mathrm{~kg}\end{array}$ \\
\hline 6 & $\begin{array}{l}\text { If the import price is equal to or greater than } \\
\text { the entry price of } 0 \mathrm{EUR} / 100 \mathrm{~kg}\end{array}$ & 8.80 & 0 & $\begin{array}{l}29.80 \mathrm{EUR} \\
/ 100 \mathrm{~kg}\end{array}$ \\
\hline
\end{tabular}

Source: EC TARIC Database

*All the countries have preferential tariff of zero except Morocco whose tariff cut was not zero but well below the MFN rate.

However, if Ghana arrives with a CIF price of $100 € / 100 \mathrm{~kg}$, this implies that the CIF price falls below the floor EPS of $103.60 € / 100 \mathrm{~kg}$. In this case, the normal custom tariff of $0 \%$ applies, and a specific duty of $29.80 € / 100 \mathrm{~kg}$ is applied, implying that the import price of Ghana's tomatoes in the EU market is now $129.80 € / 100 \mathrm{~kg}(100+29.80)$. This can be seen in some real life examples: on the $1^{\text {st }}$ of April, 2013, the synthetic import price of tomatoes from Morocco, Tunisia, and all other African countries was $75.70,97.00$ and $98.90 € / 100 \mathrm{~kg}$ respectively. Using 
Table 3.11, this implies that all these African countries bring very competitive exports to the $\mathrm{EU}$, and these prices are well below the EU floor (minimum) entry price of $103.60 € / 100 \mathrm{~kg}$. Thus, to protect EU growers from this price competition, penalty factors were imposed on their exports in the form of an additional maximum duty of $29.80 € / 100 \mathrm{~kg}$. This resulted in a total import price of 105.50 for Morocco, 126.80 for Tunisia and128.7 $€ / 100 \mathrm{~kg}$ for all others. The addition of this additional duty clearly eroded the competitiveness of these exporters.

\subsection{Literature Review}

Due the increasing importance of food standard as a non-tariff measure (NTM), some studies have empirically measured the impacts on international trade. As in all NTMs, most of which are a mix of qualitative and quantitative requirements, one of the greatest challenges is to provide an acceptable measure of standards in order to obtain unbiased estimates. This has affected the ways standards are being represented in the literature. A review of these studies is therefore provided with a view to acquainting the reader with the various ways that standards have been measured and empirically represented in trade models as well as potential scope for their improvement. The literature has identified a number of ways to measure standards. These measures include: (1) Sanitary and phytosanitary (SPS) and technical barrier to trade (TBT) measures notified to the World Trade Organization (WTO) under the SPS and TBT agreements $^{24}$; (2) the Perinorm database; (3) food safety compliance measures; (4) regulations on the maximum allowable residue limits; (5) a miscellany of other measures. The first four of these measures will be reviewed here due to their frequency of use in the literature.

A frequent approach used in measuring standards is based on notifications of SPS and TBT measures to the WTO. By default, the WTO ensure transparency of measures by obliging members to notify all their new public standards to the WTO so as to prevent protectionism and provide time for countries to raise their concerns over the notified measures and engage in peaceful dialogue if necessary. SPS measures seek to ensure food safety, animal and plant health by protecting humans, animals and plants from diseases, pests and food hazards. Conversely, TBT measures are technical regulations and standards (which encompass SPS measures) along with regulations on compliance assessment procedures which include testing, certification, inspection and verification, including accreditation.

Three approaches are then used to quantify these notifications into measures of standards. The first one entails a simple count of the total number of notifications per country for each product in a given year. The second is the frequency index, which is the share of the HS6 products notified by the importer of the same four digit HS4 line of products. The major weakness of this index is that it only accounts for the occurrence or nonoccurrence of the standard; the index fails to reveal important information about the value of those product affected by the standards. The third is the coverage ratio index which is an improvement on the frequency index. Although this measure provides information on the value of the affected product, it suffers from the endogeneity problem. In addition, all three indices are unable to capture the relative stringency

\footnotetext{
${ }^{24}$ The general objective of these agreements is to achieve transparency in the levying of standards and at the same time protect human life and health, consumers' interests, plant and animal health, including the environment.
} 
of the standards because they simply add up the counts of standards, thereby giving equal importance to all standards (Li and Beghin, 2014).

Simple count, frequency and coverage indices have been employed in studies which quantify the trade effects of standards using SPS and TBT measures (Fontague, et al., 2005; Disdier, et al., 2008). A general consensus in this selection of literature is that the imposition of standards by developed countries diminish export success of developing countries as they act as a surmountable barrier to their market access penetration. Standards are shown to have differential effects on both developed and developing economies; the latter are shown to be more inhibited by the standards set by developed countries, while developed countries benefit more. For instance, Disdier, et al. (2008) investigated the implications of SPS and TBT regulations on 690 agricultural commodities and show that food safety standards significantly limit agricultural commodity exported by developing countries to the OECD with no inhibiting impact among OECD countries. Others have shown that standards, whether set by developed or developing countries, are barriers to export opportunities with negative impacts on developing countries.

Aside from this information, the theoretical ambiguity of standards has been empirically demonstrated; some studies find that certain standards can be trade facilitating while some are trade restricting or may even have no effect. For instance, Fontagne, et al. (2005) revealed that environmental standards on exports of OECD countries, developing, and least developing countries have positive trade effects in the manufacturing and processed agricultural sectors and a negative trade effect in the agricultural sector. Similar ambiguous results were also shown by Tapia, et al., (2011) who analyzed the trade impact of SPS regulations on Germany and Argentina's beef exports to their main importing market. Their result shows a mixed effect as they find that standards can be trade inhibiting or promoting: While foot and mouth disease standards have a positive impact on German beef exports, bovine spongiform encephalopathy and hormonal standards have no significant trade effects. However, they find an overall negative trade effect of all three of these standards on Argentina's beef exports.

The second approach used in measuring standards is based on measures collated from the Perinorm database. Perinorm is a subscription-only database that collates standards and regulations imposed by national and regional governments of 23 countries and international standards authorities, including the Codex Alimentarius Commission (CAC) and the International Standard Organisation (ISO). The database offers an inventory of standards and provides information on the number of standards accruable for each sector in each country, the date each standard came into force, and the date the existing standard was amended and/or when it was totally withdrawn. The database differentiates between voluntary and mandatory standards, and also between national standards and international standards (termed harmonized standards) such as those from the CAC and ISO.

Studies that constructed measures of standards using this very rich database did so by counting the total number of standards per country and sector of traded products. While these studies 
benefited from the inventory of a rich database, nonetheless, similar to the SPS and TBT notifications, such counts (incidence of occurrence of standards) are said to be prone to what is termed "the "mixed bag' problem" (Swann, 2010, p.10). This measure is a mixed bag problem in the sense that standards which differ in importance and also in type (quality versus quantity or measurement standards, etc) are just added up. Such count measures do not tell us the level of stringency or technical complexity of the different standards as standards of low and high importance and of different types are just muddled up together. This problem is not a new one as counts have widely been used in quantifying the impact of non-tariff measures; this is understandable given the extreme difficulty of quantifying non-tariff barriers. A good example of this is the construction of the WTO trade restrictive index.

Perinorm standards have previously been used in Swann, et al. (1996), Moenius (2004) and more recently by Czubala, et al. (2009) and Shepherd and Wilson (2013). In these studies, the constructed count measures from the Perinorm database are then used in representing standards in three ways. The first entails the total number of national standards unique to a country in a given year. The second describes the total number of national standards in a given country which are equivalent to international ones such as those of the ISO or Codex. Third is the total number of standards in a given country that are equivalent to those of its trading partner. Czubala et al. (2009) and Shepherd and Wilson (2013) exploited the Perinorm data and used count method to determine the trade impact of standards with the contention that EU countrywide standards are trade inhibiting but international standards such as those of Codex are the least trade distorting.

Beyond the well-established trade inhibiting effects of standards, trade promoting effects have also been identified by these studies, most often through harmonization ${ }^{25}$ of standards or through mutual recognition agreement on standards. These studies have differentiated between harmonized and country-specific standards, and have tested the theoretical assertions of Fisher and Serra (2000) and Grandal and Shy (2001) that country-specific standards are trade impeding while harmonized standards are trade promoting. In recent years, empirical studies by Czubala, et al. (2009), Mangelsdorf, et al. (2012), and Shepherd and Wilson (2013) find support for this theoretical assertion that harmonized standards are indeed trade promoting. Mangelsdorf et al. (2012) also confirm the export promoting effects of standards as they find China's stock of standards expands its food exports (meat, fish, vegetables, cereals, milk, tea, and sugar) with a larger effect when China's domestic standards are consistent with international ones. In addition, Shepherd and Wilson (2013) report that agricultural product standards specific to the EU act as impediment to its trading partners' exports, particularly perishable or lightly processed products, while EU standards harmonized to ISO norms are trade enhancing.

While the bone of contention of the above studies surrounds harmonised standards being trade enhancing and country specific standards trade inhibiting, another strand of the literature has

\footnotetext{
${ }^{25}$ Harmonized standards are also known as international standards while non-harmonised standards are known as national or country-specific standards. However, the literature does not have a consensus on the precise definition of harmonisation; it has been defined as the adoption of a common standard in a region, or standards adopted by the whole world, or as bilaterally shared standards (Swann et al., 1996; Moenius, 2004, 2006).
} 
contradicted the proposition that country specific standards hinder trade and that it is only international standards that promote trade. Early studies in this direction by Swan et al. (1996) found evidence that United Kingdom national standards increase both its imports and exports, with international standards having a weaker and negligible impacts on its imports and exports respectively. Moenius (2006) also finds evidence that harmonised standards of the EU reduce exports of both EU and non-EU countries to the EU in approximately 80 agricultural products that were considered. They attributed their result to the fact that harmonisation reduces product variety, and therefore trade. However, they find that EU 'country' specific standards have no trade impeding effect among the EU countries, although they reduce agricultural imports from non-EU countries.

An influx of other studies also measured standards in a number of ways. Some studies measure the adoption or diffusion of standards across countries and thereafter investigate their impact on trade. In most cases, count measures are also employed. Herzfeld, Drescher and Grebitus (2011) and Masood and Brümmer (2014) count the number of certificates and/or producers certified with private standards in different countries. Clougherty and Grajek (2009) used the proportion of a country with ISO 9000 certification to its population, while Kim and Reinert (2009) used the share of firms in countries that have ISO 9000 certificates. While this measure of adoption or diffusion of standards might not capture the stringency of the standard, these measures can however stimulate trade by signalling products' quality and safety (Chen and Novy, 2012).

The last measure of standards reviewed in this study is more quantitative and represents a more accurate measure of the stringency for standards. Here, standards are quantifiable measures regulated by the importing countries and are more often presented in the form of the MRL of a substance or contaminant that is scientifically permitted for consumption. Such regulatory standards are measures on the MRL of veterinary medicinal products, MRL of mycotoxins, biological and chemical contaminants, biotoxins, feed additives, food additives and flavourings, and lastly, MRL of pesticides which is the main focus of this study. Most of these studies focus on analysing the trade effects of only one standard. Empirical studies on Africa using this measure provide evidence-based results that standards act as surmountable barriers to Africa's food exports. They find that the continent's exports were restricted to its trading partners' markets because of its non-compliance with the standards imposed by them. A number of approaches were then used to represent the MRLs; these are reviewed below.

The first study that employed this approach was that of Otsuki, et al. (2001); this study uses EU SPS measures on the maximum residual limit on aflatoxin, a mycotoxin which is a toxic fungus, and investigated its trade effects focusing on exports of dried nuts and fruits to the EU from nine African countries. Otsuki, et al. (2001) also provide evidence-based results that EU standards hurt African groundnut exports and restrict its export from nine major exporters to the EU due to their inability to meet stringent EU aflatoxin standards. Similarly, Grebrehiwet et al. (2007) also find aflatoxin standards set by five OECD countries to be highly inimical to South Africa's food exports between 1995 and 1999. On the contrary, Xiong and Beghin (2011) 
conducted an econometric replication of the Otsuki et al. (2001) study and did not find any support for the theory that standards hurt African exports. They pointed out that the impact is in thousands of dollars and not millions of dollars as posited by Otsuki et al. (2001). Furthermore, Jaffee and Henson (2004) found the data used by the authors to be erroneous while Xiong and Beghin (2011) found faults with the methodology used by them and concluded that Africa's groundnut exports are rather constrained by supply conditions as opposed to limited market access as originally proclaimed by Otsuki et al. (2001).

Similarly, a number of case studies have given contradictory views on the standards-as-barrier perspective, demonstrating that standards can but do not always impede developing countries' trade (Jaffee and Henson, 2004; World Bank, 2005; etcetera). These studies focused on the fisheries and horticultural export sectors, mainly concentrating on Kenya and a few other East African countries. They acknowledge that standards can be an impediment to export success, through import bans on particular products(s) non-complying products or through the huge cost of complying with stringent standards which diminishes the competitiveness of exports. Nevertheless, they show that this is not always the case as increasing and tightening of standards could also serve as catalyst to participate in international trade.

Jaffee and Henson (2004) proclaim that standards are not always problematic and are less pessimistic than portrayed by the generally held notion of the mainstream 'standards as a barrier' perspective; standards are indeed helping developing countries to propel the strength of their supply chain. They argued that standards do not necessarily hurt African exports, on the contrary - they will actually promote exports once the right technology is set up. Thus, in the short run standards may be unintentionally trade inhibiting, but in the long run standards can stimulate trade as consumers gain and show confidence in the quality export products. Jaffee and Henson (2004) also noted that some developing countries and/or industries are responding to these evolving standards and are successfully using high safety and quality standards to upgrade their capacities; at the same time, they are making the necessary adjustments and investments in operations and in the structure of their supply chains to achieve a competitive advantage, repositioning themselves in competitive international markets.

Aside from this, other studies have analysed the impact of MRL of pesticides standards on trade. Empirical studies which used this approach provide evidence-based results that standards act as a surmountable barrier to developing countries' food exports. For instance, Wilson and Otsuki (2004) report that the chlorpyrifos pesticide is regulated by 11 OECD countries and significantly limits the export prospects of 19 countries from Latin America and Africa which rely heavily on banana exports. Scheeper et al. (2007) also confirms that standards hurt Africa's exports after investigating the trade impact of the MRL of the Prochlarz pesticide standards on South Africa's avocado exports. In addition, Chen, et al. (2008) provide evidence that both the MRLs of the chlorpyrifos pesticide and oxytetracycline drug standards imposed by the US, EU, Japan, Australia, New Zealand and eight other Asian countries diminishes China's exports of aquatic and vegetable products to these developing countries. It is, however, pertinent to know that all these studies investigated the trade effects of only a single pesticide standard. 
A recent approach in the literature use the similarity, dissimilarity, or heterogeneity index among countries and products and applies it to pesticide standards. The major conclusion of this approach is that dissimilarity in pesticide standards across trading pairs diminishes exports, while countries are less negatively affected by a similarity in regulations. Rau, et al. (2010) proposed a heterogeneity index of trade which measures the bilateral (uni-directional) dissimilarity of standards. Indeed, countries could exhibit dissimilarity in their standards when their standards are relatively more or less stringent. However, a drawback of this approach is that the index provides no information about the exact relative stringency of the standards $(\mathrm{Li}$ and Beghin, 2014). The study by Winchester et al. (2012) extends the index to one which captures the differences in stringency between countries and used the index to investigate the impact of pesticides MRLs on agricultural trade. Although, this latter analysis represents an improvement over that of Rau et al., (2010) the aforementioned drawback remains unaddressed. Drogué and DeMaria (2012) also introduced another alternative measure of a (di)similarity index for pesticide standards and applied it to investigate the export of fresh produce to the EU; nevertheless, their index still presents the same drawback (Li and Beghin, 2014). The intuition behind this drawback is that dissimilarity or similarity of standards between any two countries would not tell us about the exact level of the relative stringency of these countries' standards. For instance, as noted by Li and Beghin (2014), dissimilarity in MRL of about 5 ppm in a 50 ppm MRL of a particular pesticide is different from dissimilarity in MRL of 5ppm in a $10 \mathrm{ppm}$ MRL of a similar substance.

In general, although the MRL measure of standards is widely accepted in empirical analysis as it overcomes the shortcomings of all other previously discussed methods, previous studies that employ this approach suffer from some general weaknesses, particularly the way in which standards are represented empirically. Most of them focus on estimating the impact of only one type of pesticide standard and are thus unable to capture the relative importance of all standards affecting trade flows (Otsuki, and Wilson, 2004; Chen, et al, 2008; etc). There are a huge number of pesticide standards which regulate the quality of a product in a given market. However, analysing the trade impacts of a single pesticide standard is not representative; in fact, it is a misrepresentation which may be likened to subjective selection bias. Our argument is that each product attracts an array of pesticide standards, and investigating the trade impacts of only one such standard is tantamount to subjective selection bias, as a single pesticide standard is not representative, but rather a mis-characterization of the set of standards regulating the quality of a product in a given market. As a consequence, the researcher runs the risk of omitting potentially important trade costs.

Our own study is an improvement on previous studies in some varieties of ways: First, we use a newly available time series of the EU database of MRL to estimate the impact on African exports. To our knowledge, this represents the first study of its kind on African exports. In addition, the empirics on Africa are very scanty relative to the emergence and importance of food safety standards as a vital market access condition in many importing developed countries. In our empirical application, we first calculate the impact of the stringency of EU and Codex pesticide standards on African food exports. Second, we analyse the implications of over 460 
pesticides on three fresh fruit and vegetable exports at the 6th digit Harmonised System (HS) level. We are therefore able to capture the relative importance of all pesticide standards affecting African exports in the selected products. This is in sharp contrast to previous studies which analyse the effects of only one pesticide standard on one product or a few pesticide and product pairs. Third, we introduce another measure of restrictiveness that exporters to the EU face when exporting fruits and vegetables to the EU - the EU entry price control. Previous studies that investigated the impacts of EU standards on fresh fruit and vegetable products exported to the EU fail to take this variable into account. Yet, in the EU, the export of some fruits and vegetables are subject to the imposition of a price control measure termed the EPS. This variable is important to market access; however, it has never been represented in previous studies which examined the effects of standards on fruits and vegetables. Thus, the combination of two complementary and important non-tariff measures affecting fruits and vegetables represents an important landmark in the literature.

\subsection{Methodology}

In line with previous studies, we also employ the gravity model in analysing the impact of standards. The formal usage of the model in analyzing trade flows could be traced to Tinbergen (1962) and Pöyhönen (1963). The simplest form of a gravity model predicts that bilateral export between country pair is explained by exporters' and importers' economic masses; these are proxy for their income and geographical distance between the country pairs. One of the major reasons for its continued use is due to the rigorous theoretical foundation given to it and its empirical success in predicting bilateral trade flows of different commodities under different situations (Deardorff, 1984).

\subsubsection{Methodological Framework}

The framework of our analysis is the Helpman, Melitz and Rubinstein (2008) (thereafter HMR) model which provides a both theoretical and empirical framework for the heterogeneous behaviour of firms. Firm heterogeneity occurs as only a small fraction of firms find it profitable to export, while others choose not to as they are less productive or efficient. This explains the occurrence of zero trade flows which largely characterize our data. HMR noted that the estimation of bilateral trade flows using a gravity equation may not only be subjected to sample selection bias (if the non-zero exports do not occur randomly), but that estimates may also be vulnerable to omitted variable bias if the number of exporting firms within an industry (extensive margin of trade) is unaccounted for. The idea is that due to trade costs, firms differ in productivity (firm heterogeneity) and only firms with productivity levels beyond a threshold end up exporting.

HMR therefore extended the Heckman (1979) procedure by controlling for sample selection and firm heterogeneity biases and approached zero issue by proposing a two-step estimation method which exploits the non-random occurrence of zeros in bilateral trade data. The first step involves estimating an equation (Probit regression) for the probability of exporting contingent on the decisions of the firms to export or not; this then gives information on the extensive margin of trade. The second step is a trade equation estimated in its logarithmic form, and 
involves using the probabilities that were predicted in the first step to estimate the effects on the intensive margin of trade (i.e. the number of firms which are actively engaged in trade). More formally, the extensive margin of trade involves the initiation of new trade relationship and could take the forms of exporting exiting products to new partners or markets, exporting new products or new varieties to existing markets or new markets (Hummels and Klenow, 2005). However, the intensive margin is the maintenance or deepening of trade to existing markets or trading partners and so, analyses is based on the volume of trade for existing trade relationships (ibid).

Our choice of the HMR model is based on some important premises. First, the standard practice of excluding zero bilateral trade observations can potentially result in sample selection bias, especially if there are non-random elimination of the zeros; estimating non-randomly selected samples is a specification error and can potentially bias the results. The HMR sample selection model is advantageous as it corrects for this sample selection bias resulting from eliminating zero trade flows when estimating the logarithmic form of a gravity model. This procedure is therefore frequently employed in the gravity model literature to correct for problems related to zero trade flows (HMR, 2008). In addition, the model uses the information provided by the zero trade observations; it therefore provides important information about the underlying decision process regarding the zero trade flows (Linders and de Groot, 2006). The model's approach is theoretically sound and offers a sophisticated econometric solution to estimate the gravity equation that includes zero trade flows (HMR, 2008). Lastly and most importantly, unlike previous models the HMR model eliminates the bias caused by unobserved firm heterogeneity. This also captures the effect of the number of exporters (productive firms).

\subsubsection{Model Specification}

Define a latent variable $z_{i j t}$ such that firms' selection into export markets is a monotonic

function so exports are zero when $z_{i j t}=0$ and exports are positive when $z_{i j t}>0$. Although $z_{i j t}$ is unobserved, it can however be observed when trade is positive; the probability of exporting is conditional on the observed variable and can then be obtained. Since $z_{i j t}$ affects the export volume and probability of exporting, the HMR two-step estimation procedure thus consists of two separate equations - the probability of exporting and the export volume. It can then be specified in log-linear form as follows:

$$
\begin{aligned}
& \rho_{i j t}=P\left(T_{i j t}=1 \mid x_{i j t}\right)=\Phi\left(\alpha_{0}+\alpha_{1} \ln Y_{i t}+\alpha_{2} \ln Y_{j t}+\alpha_{3} P R I_{i j t}+\alpha_{4} E_{i j t}+\alpha_{5} \ln (1+e p s \tau)_{i j t}\right. \\
& \left.+\alpha_{6} \operatorname{Gap}_{i j t}+\alpha_{7} \ln D_{i j}+\varepsilon_{8} \operatorname{Lang}_{i j}+\alpha_{9} \operatorname{Col}_{i j}+\alpha_{10} R T A_{i j t}+\varepsilon_{i j t}\right) \\
& \ln \operatorname{Exp}_{i j t}=\beta_{0}+\beta_{1} \ln Y_{i t}+\beta_{2} \ln Y_{j t}+\beta_{3} P R I_{i j t}+\beta_{4} E_{i j t}+\beta_{5} \ln (1+e p s \tau)_{i j t}+\beta_{6} \operatorname{Gap}_{i j}+\beta_{7} \ln D_{i j}+ \\
& \beta_{8} \operatorname{Col}_{i j}+\beta_{9} R T A_{i j}+\sigma_{1} \eta_{i j t}+\hat{\bar{w}}_{i j t}^{*}+\dddot{\varepsilon}_{i j t}
\end{aligned}
$$

Equation (3.1) is the selection equation given as a probit maximum likelihood regression model that determines firms' binary decisions to trade or not. However, equation (3.2) is the trade 
flows equation which is conditioned on positive trade flows. The subscripts $i, j, t$ denotes exporter, importer, and time, respectively and $\ln$ implies the variable is measured in logarithm form. In equation (3.1), the dependent variable is $\rho_{i j}$ which give the probability that a given country $i$ engage in bilateral exports with country $j$, conditional on the observed variables; $T_{i j t}$ denotes a binary variable which equals $1\left(T_{i j t}=1\right)$ when exporting country $i$ exports its products to country $j$, and zero otherwise $\left(T_{i j t}=0\right) ; \Phi($. $)$ denotes the cumulative distributive function for the bivariate normal distribution. $Y_{i t}$ and $Y_{j t}$ are, respectively, the exporting and importing countries' nominal GDP which is measured in US dollars, whose effect is expected to be positive on exports. $P R I_{i j t}$ is the pesticide restrictiveness indices on the regulated pesticides. $e p s \tau_{i j t}$ and $G_{a p} p_{i j t}$ are the two measures of EU entry price controls, respectively measuring the ad valorem tariff and Africa's price competitiveness relative to the EU's as a result of the implementation of the price control. Dist $t_{i j}$ captures the geographical distance between countries $i$ and $j$. Lang (common language), $\mathrm{Col}$ (colonial ties), and RTA (regional trade agreements) are dummy variables that assume the value of 1 when the exporting and importing countries have a common language, have colonial ties, and engage in bilateral trade agreement, respectively, and zero otherwise. $\varepsilon_{i j t}$ denotes the idiosyncratic error term which is expected to be well behaved.

In the trade flow equation, $\operatorname{Exp}_{i j t}$ describes the exports from country $i$ to country $j$ in logarithmic form, conditioned that the observed export flows $T_{i j t}$ are positive. We included similar set of regressants contained in the selection equation (1), minus an exclusion restriction variable which is excluded from the second stage regression; $\hat{\bar{W}}_{i j t}^{*}$ controls for firm heterogeneity - the number of firms that actively exporting, which may also be zero; and $\hat{\bar{\eta}}_{i j t}^{*}$ denotes the inverse Mills ratio - which is similar to Heckman's term for correcting sample selection bias.

Following HMR, we drop their Pareto distribution assumption regarding the distribution of firm heterogeneity which produces a non-linear constant used in controlling for firm heterogeneity and which necessitates them to employ a non-linear least square estimator (NLS) in estimating the trade equation. They find that expanding $\hat{\bar{z}}_{i j t}^{*}$ around a polynomial of the third order approximating a monotonic increasing distribution of $z_{i j t}$ yields the same result. Thus, we also implement a simple linear control for the firm heterogeneity variable $w_{i j t}$ by expanding $\hat{\bar{z}}_{i j t}^{*}$ around a cubic polynomial using a transformed variable $\hat{\bar{z}}_{i j t}^{*}$ which was obtained by $\hat{\bar{z}}_{i j t}^{*} \Phi^{+1}\left(\hat{\rho}_{i j t}\right)$. $z_{i j t}^{*}=z_{i j t} / \sigma_{i j t}$ and $\hat{\rho}_{i j t}$ is the predicted values of the probit equation which is used to obtain the predicted values of the latent variable. Using this transformation, the inverse Mills ratio has a 
unit normal distribution and is given as $\hat{\bar{\eta}}_{i j t}^{*}=\phi\left(\hat{z}_{i j t}^{*}\right) / \Phi\left(\hat{z}_{i j t}^{*}\right)$, while firm heterogeneity is obtained as a polynomial in $\hat{\bar{z}}_{i j t}^{*}$, where $\hat{\bar{z}}_{i j t}^{*}=\hat{z}_{i j t}^{*}+\hat{\bar{\eta}}_{i j t}^{*}$

To obtain consistent estimates, we also account for the impacts of multilateral trade resistance terms (MRT). A common way of proxying the MRT in panel data uses time varying exporters and importers fixed effects (Fenstra, 2004). As an alternative, we employed the Baier and Bergstrand (2010) first order Taylor series approximation of bilateral trade costs using simple averages. The major advantage of this approach is that it is computationally simple and has been shown to produce estimates to the Anderson and van Wincoop (2003) structurally iterated least squares method (see Baier and Bergstrand 2009, 2010; Egger and Nelson, 2011).

To account for the influence of MRT as theoretically modeled by Anderson and van Wincoop (2003), we applied a first order Taylor series expansion to all bilateral trade cost variables. For each trade cost variable, the first order Taylor series is expanded and all the newly generated (demeaned) trade cost variables are then used in the regression. Simple mean weight $(1 / \mathrm{n})$ are used in constructing the new series as shown in Baier and Bergstrand (2010). Following Egger and Nelson (2011), (using the RTA variable as an example), each bilateral trade cost variable was then transformed using the approximation given below:

$$
R T A_{i j t M R T}=R T A_{i j T}-\frac{1}{n} \sum_{j=1}^{N} R T A_{i j t}-\frac{1}{2} \frac{1}{n^{2}} \sum_{i=1}^{n} \sum_{j=1}^{n} R T A_{i j t}
$$

The transformed variable $R T A_{i j t M R T}$ is defined as exporter and importer time fixed effects, and a similar definition holds for the other bilateral trade costs such that the approximation which include the influence of multilateral resistance terms in a panel setting becomes:

$$
\begin{aligned}
& \ln \operatorname{Exp}_{i j t}=\beta_{0}+\ln Y_{i t}+\ln Y_{j t}-(\sigma-1) \ln t_{i j t}+(\sigma-1)\left[\frac{1}{n}\right] \sum_{j=1}^{n} \ln t_{i j t}-\frac{1}{2} \frac{1}{n^{2}} \sum_{i=1}^{n} \sum_{j=1}^{n} \ln t_{i j t} \\
& +(\sigma-1)\left[\frac{1}{n} \sum_{i=1}^{n} \ln t_{j i t}-\frac{1}{2} \frac{1}{n^{2}} \sum_{i=1}^{n} \sum_{j=1}^{n} \ln t_{j i t}\right]
\end{aligned}
$$

In equation (3.4), $t_{i j t}$ refers to any of the bilateral trade cost variables associated with the coefficients of $\beta_{3}$ to $\beta_{10}$ in equations (3.1 and 3.2). In our case, these are the two measures of food safety standards, entry price tariff, the variable measuring price competitiveness due to the EPS, distance, common language, colonial ties, and RTA. The first variable located on the righthand side of equation 3.4 represents an average of the total trade costs incurred by a given exporter from all importers. The second variable on the right-hand side denotes the average of all trade costs faced by the importer from all exporters. 
Using the definition given by (3.4) and expanding the series around equations (3.1) and (3.2) gives the transformed two-step HMR model which fully accounts for the influence of MRT in the gravity model in a framework of panel data and in log form as given below:

$$
\begin{aligned}
& \left.\rho_{i j t}=\Phi\right)\left[\alpha_{0}+\alpha_{1} \ln Y_{i t}+\alpha_{2} \ln Y_{j t}-(\sigma-1) \alpha_{3} P R I_{i j M R R T}-(\sigma-1) \alpha_{4} E_{i j \mathrm{ijRT}}-(\sigma-1) \alpha_{5} \ln (1+e p s)_{i j \mathrm{ijMR} T}-(\sigma-)\right. \\
& \left.\alpha_{6} \operatorname{Gap}_{i j \mathrm{j} M R T}-(\sigma-1) \alpha_{7} \ln D_{i j M R t}-(\sigma-1) \alpha_{8} \operatorname{lang}_{i j M R T}-(\sigma-1) \alpha_{9} \operatorname{Col}_{i j M R T}-(\sigma-1) \alpha_{10} R T A_{i j \mathrm{j} M R T}+\varepsilon_{i j t}\right]
\end{aligned}
$$

$$
\begin{aligned}
& \ln \operatorname{Exp}_{i j t}=\beta_{0}+\beta_{1} \ln Y_{i t}+\beta_{2} \ln Y_{j t}-(\sigma-1) \beta_{3} P R I_{i j t M R T}-(\sigma-1) \beta_{4} E_{i j t M R T}-(\sigma-1) \beta_{5} \ln (1+e p s)_{i j \mathrm{j} M R T} \\
& -(\sigma-1) \beta_{6} G p a_{i j t M R T}-(\sigma-1) \beta_{7} \ln D_{i j M R t}-(\sigma-1) \beta_{8} \operatorname{Col}_{i j M R T}-(\sigma-1) \beta_{9} R T A_{i j \mathrm{ijMR} T}+\alpha_{1} \eta_{i j t}+\hat{\bar{w}}_{i j t}^{*}+\dddot{\varepsilon}_{i j t}
\end{aligned}
$$

Equations 3.5 and 3.6 are then the theoretically consistent HMR two-step model which accounts for the influence of multilateral resistant terms which, if omitted, would lead to the 'gold medal error' and bias our estimates (Baldwin and Tagloni, 2006). Equation (3.5) is the extensive margin of trade while equation (3.6) gives estimates of the intensive trade margin.

\subsubsection{Data Description}

Our dataset covers bilateral trade on exports between EU countries and selected African countries between 2008 and 2013. An overview of the countries included in the analysis is available in the appendix. The choice of our period of analysis hinges on two factors: First, access and availability of EU pesticide data starts from 2008. Second, this period is an important period in which pesticide standards were harmonized in the EU (EC 396/2005) and the application of pesticide standards became more transparent. This is in contrast to the pre 2008 period when countries were at free will to use either the EU standards or their own stock of standards, making the application of standards less transparent.

Bilateral export data was sourced from United Nations Commodity Trade (UN COMTRADE) via the World Integrated Trade Solution (WITS) database at the 6th digit of the Harmonised System (HS6) level. This covers three unique datasets on African exports of tomatoes (070200), oranges (080510), and limes and lemons (080550) to the EU. There are several unique features of our data which are worth mentioning. Our dataset on exports of tomatoes, oranges, and limes and lemons contains about $86 \%, 79 \%$ and $82 \%$ zero trade observations between the trading countries, respectively. While some of these zeros may be due to statistical zeros such from rounding up or incompleteness of UN COMTRADE statistical database, a higher share of the zeros is more likely to be a result of African exporters' inability to trade due to some prohibitive fixed cost they have to bear in establishing a trade partnership with EU countries. One of these prohibitive fixed costs is the compliance cost of meeting the restrictive pesticide standards set by the EU. Thus, it is important to know the extent to which such standards can explain both positive and zero trade.

Data on language, distance and colony were collected from the Centre d'Etudes Prospectives et d'Informations Internationales (CEPII) database, GDP data comes from the World Bank's World Development Indicators (WDI), while those used in constructing the regional agreement 
dummy was from the WTO. Data on pesticide standards was manually collated online from the EUROPA database which houses a rich database of all pesticide standards developed and adopted by all EU Member States since 2008. We collated all pesticide standards in force over the period between 2008 and 2013 by mapping each standard to a standard trade classification at the HS6 level. We used the SIVs as a proxy for the commodity's import price, which is the milling price of the commodity, less the marketing and transportation costs and custom duties. Data on EU entry price measures and duties in Euros were manually collated from the TARIC website and converted to US dollars based on exchange rate data from the WDI database. The ad valorem equivalent of the entry price duties was calculated using the WTO Agricultural method based on trade data from UN COMTRADE. Daily data on country specific standard import values on each product set by the EC were obtained from the European Union's designated daily publications.

\subsubsection{EU Entry Price Data}

We constructed two distinct indicators at the bilateral level to capture the impact of EPS on Africa's exports. The first indicator that we constructed was for the corresponding duties imposed by the EU as a result of the EPS. In this study, we omitted tariffs as most African countries enjoy preferential tariff rates under the non-reciprocal EU's EBA and other similar agreements such as the Generalised System of Preference (GSP). In most cases, this results in a $0 \%$ tariff, with the exception of Morocco, Algeria, and South Africa, whose preferential tariffs on these products come in the form of a reduction in the EPS duties. The second indicator that was constructed produced variables which measure the difference between the EP and the synthetic import price.

The first indicator produces a calculation of the EP duties arising from the enforcement of the EPS by the EU on the three African export products considered in this study. For each product, the effectively applied daily EP duties (measured in EUR per 100kg) were manually calculated by us. This sums up to about 365 data points in a year, resulting in a total of 2192 data points per product, between 2008 and 2013. We transformed the daily EP duties into tariff-based measures with daily ad valorem tariff equivalents of these duties calculated using the 'WTO agricultural method'. A simple yearly average of the daily ad valorem tariff is then calculated from the daily ad valorem tariff and used in our analysis. A priori, we expect that the EP tariff will have the normal negative impact that tariffs usually have on trade flows.

However, based on anecdotal evidence and producer pricing behaviour, the rational exporter may supply export products at the maximum possible price to the EU when complying with the EP, so as to avoid the EP duties (Groetz and Grethe, 2009). This is because no additional duties are incurred on exports supplied at prices corresponding to, or slightly higher than, the maximum EP. In this case, all or most of the observations of our first indicator would be zero. Indeed, such pricing behaviour might encourage the exporter to supply the product at a price which is greater than that which is obtainable in the EU's domestic markets; this would consequently erode the exporters' competitive cost advantage. Thus, we introduced another variable to capture this pricing behaviour. The second indicator (termed Gap) captures the 
difference between the synthetic import price of the commodity (measured by the commodity's SIV) and the corresponding maximum EP which always attracts zero tariffs. This indicator is then given as:

$$
\operatorname{Gap}_{i j t}=S I V_{i t j}-E P_{i t j}^{c}
$$

Where $i, j$, and $t$ are the importer, exporter and time subscripts, respectively. SIV is the synthetic import price measured in dollars per $100 / \mathrm{kg}$ and $\mathrm{EP}^{\mathrm{M}}$ is the annual maximum entry price measured in dollars per 100/kg. This indicator is somewhat similar to that used by Goetz and Grethe (2009) with the exception that theirs is a relative indicator, as the right-hand side of equation (3.7) is divided by the EP, while ours is an absolute one. Using equation (3.7), observations on GAP can exhibit two distinct trends: they can either be less than zero, or greater or equal to zero. First, we deduce that if $G A P_{i j t}<0$, the import price is below the maximum EP; thus, an increase of the import price above the entry price brings about the imposition of additional duties which erodes the price competitiveness of the export goods. Consequently, for observations in which $G A P_{i j t}<0$, export competition is eroded. Second, for observations with $G A P_{i j t} \geq 0$, the import price is equal to or greater than the maximum EP, and no specific duty is levied.

Cases of the synthetic import price being above the EP lead to a decrease in export price competitiveness, as the final price of the exports becomes more expensive relative to similar domestic goods, discouraging export purchases and thus decreasing exports to the EU. However, cases in which the import price is below the EP also mean that additional duties would be incurred as a penalty factor (additional duties). Thus, the final price of the exports becomes more expensive due to the additional duties incurred. Adding in the additional duties to the synthetic import price (measured as SIV) may increase export prices above the prevailing domestic price, thereby discouraging exports; either way, the coefficient will be negative. This will hold unless the additional duties are such that when added to the SIV, they are so small that its final export price it will fall below the prevailing domestic prices, such that exports are still relatively cheaper than domestic goods. Alternatively, it would also hold if the prevailing synthetic import price plus duties is such that it is still higher than the home price for the good (such that the home market is a dumping ground for the product). If these last two scenarios are the case, then the coefficient of this variable will be positive a priori. Thus, the coefficient of this indicator can be negative, positive, or insignificant and the exact impact is an empirical one.

\subsubsection{Stringency of Standards}

We construct a simple standard restrictiveness index which is formulated by combining information on the total number of regulated pesticides and the level of stringency of the pesticides. On average, stringency of standards is expected to increase as more pesticides are regulated, and the higher the level of pesticide standards, the lower their stringency level. Using this definition, our restrictiveness index is then given as: 


$$
P R I_{i j k t}=\frac{1}{n} \sum_{k=1}^{n} M R L_{i j k t}
$$

Where PRI is the pesticide restrictive index imposed by importer $j$ on $i$ 's exports on pesticide $k$ over time $t ; n$ denotes the number of regulated pesticides while MRL is the yearly averaged MRL of all pesticide standards $k$ imposed on exports by the EU in time $t$. The MRL is indicated in part per million and measured in $\mathrm{mg} / \mathrm{kg}$. Equation (3.8) is then used to construct the two variables on the regulated pesticide restrictive index and the exempted pesticide restrictive index. The construction of the regulated pesticide restrictive index was such that the lower the value of this standard restrictiveness index, the higher the stringency of the pesticide standards. The regulated pesticide restrictive index can then either have a direct or inverse relationship with exports. A positive coefficient implies that the standard is trade prohibiting, as standard is directly related to exports, such that a decrease in the value of the standard restrictiveness index (increase in stringency) decreases exports. However, a negative value denotes that standards are trade promoting as standards have an inverse relationship with exports, such that a decline in its stringency (increase in standard) generate an increase in exports. Thus, the coefficient on the restrictive index would be positive if the pesticide standard limits trade and vice versa.

Some issues are encountered when working with the EU pesticide standards. The foremost issue is that of unestablished pesticide standards. Appendix III of the EU Directive 396/2005 stipulates that a default MRL of 0.01 should be applied to products for which no pesticide standards are established. So, we substitute this default MRL for non-established pesticide standards in the EU. A second issue is that in the EU, there are a few cases where some pesticides are banned or exempted, such that no MRL is required or set for them. While no MRL is set for banned pesticides, no MRL is required for exempted ones. Exempted pesticides are previously regulated pesticides for which subsequent improvement in scientific knowledge proves that no amount of their consumption can jeopardize health and safety, thus rendering such pesticides exempt from regulation. Fortunately, compared to the US database used by Li and Beghin (2014), the EU rich database provides information which helps to distinguish between circumstances when an unestablished MRL means default or exempted. Data on banned pesticides are, however, not included in the database as the EU database only includes pesticides that have been positively listed by the EU.

There are a few cases where some previously regulated pesticides have been exempted from having MRLs. Contemplating the appropriate MRL to place on an exempted pesticide remains a problem. We cannot assign a value of zero to it as an MRL analytically set to zero means that the pesticide is totally banned; this would therefore distort our stringency index by giving more weight to such pesticides. Thus, we proffer a solution to this by treating these kinds of pesticides separately in our analysis. Pesticides such as Heptamaloxyloglucan have been regulated in previous years with an MRL of 0.01 in 2008, but were exempted in subsequent years; instead, we assign a value of zero to such pesticides. We also calculated an index of standard restrictiveness on this set of exempted pesticides but give the index a new interpretation which 
is different from those pesticide standards which were regularly established before. Thus, for this set of exempted pesticides, the higher the MRLs, the more stringent the standard is; an MRL of zero would then be equivalent to no stringency. Thus, the lower (higher) the index of the pesticide standards, the laxer (stringent) the index of the pesticide residue standard is. Consequently, the coefficient on the stringency index of the exempted pesticide residue is expected to be negative if exempted standards limit trade.

\subsection{Results and Discussion}

The results of the HMR model is presented in this section. We estimated equations 3.5 and 3.6 separately for the three unique datasets of tomato, lime and lemon, and orange. Our exclusion variable for the orange dataset is common language, while colonial ties is the variable used for both the tomato and lime and lemon dataset. These selection variables are assumed to be correlated with the fixed costs of exporting, but weakly or negligibly correlated with variable trade costs. Examples of exclusion variables used in other studies are religion and language variables (HMR, 2008), governance indicators (Shepotylo, 2009) and previous occurrence of non-zero trade between country pairs (Linders and de Groot, 2006).

We estimated the selection equation using probit method because the dependent variable is a binary one, representing the decision to export or otherwise. However, the trade equation is estimated using a linear estimator since the distribution of the firm heterogeneity is now relaxed to allow it to follow a linear distribution, allowing us to estimate the model using a linear estimator. We employed the feasible generalized least squares method as it does not impose any prior restrictions on the model and also helps to control for heteroscedasticity. The method can be applied when unknown types of heteroscedasticity are present, and it is an efficient estimator among the class of least square estimators.

\subsubsection{Main Result: Impacts of EU Standards on African Exports}

Table 3.12 presents the main results of the study. Estimates of the selection equation (extensive margin of trade) are presented first, while those of the selection equation (intensive margin of trade) are presented thereafter.

\section{Tomatoes - Extensive Margin}

The extensive margin estimates have several implications for three types of exporters. First on the list are new firms or exporters that are seeking to enter the export market, which we term 'potentially new firms'. Second are existing firms that are currently established, but which seek to expand their export base and/or market base; these are termed 'expanding exporters'. Third, existing firms which are not profiting and are gradually abandoning trade, known as 'disappearing exporters'.

The estimates in the outcome equation show that Africa's GDP, albeit small, and its past colonial ties are the major factors fuelling African exporters' prospects to establish new trade relationships with the EU. Africa's economic mass stimulates the probability of penetrating the EU market, such that a one percent increment in their GDP increases the chances of 
disappearing exporters, new exporters and those who want to expand their export base by $0.168 \%$. However, the consumption expenditure of importers on African tomatoes, measured by EU GDP, is not statistically significant for this set of exporters. This can be attributed to the changing tastes and preferences of EU consumers for organic tomatoes which negatively affect their marginal propensity to import these tomatoes from Africa.

Table 3.12: Effect of EU Standards on African Exports

\begin{tabular}{|c|c|c|c|c|c|c|}
\hline \multirow[b]{2}{*}{ Variables } & \multicolumn{2}{|c|}{ Tomatoes } & \multicolumn{2}{|c|}{ Oranges } & \multicolumn{2}{|c|}{ Lime and Lemon } \\
\hline & (1) & (2) & (3) & (4) & $(5)$ & (6) \\
\hline & Extensive & Intensive & Extensive & Intensive & Extensive & Intensive \\
\hline \multirow[t]{2}{*}{ Exporter GDP } & $0.168^{* *}$ & $0.457^{* * *}$ & 0.063 & $0.278^{* * *}$ & $0.210^{*}$ & 0.006 \\
\hline & $(0.086)$ & $(0.073)$ & $(0.089)$ & $(0.088)$ & $(0.114)$ & $(0.069)$ \\
\hline \multirow[t]{2}{*}{ Importer GDP } & 0.100 & $-0.251^{* *}$ & $0.500^{* * *}$ & $0.359^{* *}$ & $0.603^{* * *}$ & 0.046 \\
\hline & $(0.119)$ & $(0.105)$ & $(0.114)$ & $(0.172)$ & $(0.203)$ & $(0.088)$ \\
\hline \multirow[t]{2}{*}{ Standards } & $6.997^{* * *}$ & $7.265^{*}$ & $5.709^{* * *}$ & -3.061 & $14.258^{* * *}$ & 1.264 \\
\hline & $(2.019)$ & $(3.821)$ & $(2.098)$ & $(2.540)$ & $(3.000)$ & $(2.517)$ \\
\hline \multirow[t]{2}{*}{ Entry Price Duties } & 0.021 & $-1.371^{* *}$ & 0.218 & 0.044 & 17.378 & -3.846 \\
\hline & $(0.347)$ & $(0.612)$ & $(0.467)$ & $(0.377)$ & (22.080) & $(32.086)$ \\
\hline \multirow[t]{2}{*}{ EPS GAP } & -0.006 & $-0.068^{* *}$ & 0.003 & 0.004 & -0.005 & -0.002 \\
\hline & $(0.017)$ & $(0.030)$ & $(0.012)$ & $(0.010)$ & $(0.004)$ & $(0.004)$ \\
\hline \multirow[t]{2}{*}{ Distance } & $-2.576^{*}$ & -3.476 & $-2.331^{* * *}$ & $-3.072^{* *}$ & $-3.228^{*}$ & $-4.132^{* * *}$ \\
\hline & $(1.507)$ & $(2.191)$ & $(0.807)$ & $(1.414)$ & $(1.939)$ & $(1.199)$ \\
\hline \multirow[t]{2}{*}{ Colonial Ties } & $3.259^{* * *}$ & & $2.247^{* * *}$ & $-2.595^{* *}$ & $3.148^{* * *}$ & \\
\hline & $(0.841)$ & & $(0.823)$ & $(1.193)$ & $(1.201)$ & \\
\hline \multirow[t]{2}{*}{ Language } & 0.312 & $1.511^{* * *}$ & $2.199^{* * *}$ & & 1.333 & $1.512^{* * *}$ \\
\hline & $(0.649)$ & $(0.552)$ & $(0.626)$ & & $(0.812)$ & $(0.395)$ \\
\hline \multirow[t]{2}{*}{ RTA } & 0.305 & $-9.417^{* *}$ & 0.579 & 0.798 & -0.209 & 0.056 \\
\hline & $(0.432)$ & $(4.666)$ & $(0.448)$ & $(0.549)$ & $(1.275)$ & $(2.302)$ \\
\hline \multirow[t]{2}{*}{$+\hat{\bar{\eta}}_{i j t}^{*}$} & & $8.687^{* * * *}$ & & $-1.316^{*}$ & & $1.567^{* * *}$ \\
\hline & & $(2.566)$ & & $(0.788)$ & & $(0.387)$ \\
\hline \multirow[t]{2}{*}{$\hat{\bar{z}}_{i j t}^{*}$} & & $159.313^{* * * *}$ & & $-17.906^{* *}$ & & $23.111^{* * *}$ \\
\hline & & $(50.997)$ & & $(7.200)$ & & $(7.628)$ \\
\hline \multirow[t]{2}{*}{$\hat{z}_{i j t}^{* 2}$} & & $-150.245^{\text {**** }}$ & & $13.607^{* * *}$ & & $-16.563^{* *}$ \\
\hline & & $(52.822)$ & & $(4.282)$ & & $(7.135)$ \\
\hline \multirow[t]{2}{*}{$\hat{\bar{z}}_{i j t}^{* 3}$} & & $48.973^{* *}$ & & $-2.915^{* * *}$ & & $3.712^{*}$ \\
\hline & & $(19.201)$ & & $(0.831)$ & & $(2.082)$ \\
\hline \multirow[t]{2}{*}{ Constant } & $-9.483^{* * *}$ & $-65.655^{* * *}$ & $-16.822^{* * *}$ & 1.353 & $-24.564^{* * *}$ & $-10.475^{* *}$ \\
\hline & $(3.170)$ & (18.554) & $(3.877)$ & $(6.653)$ & $(5.942)$ & $(4.382)$ \\
\hline Observations & 1392 & 137 & 1092 & 224 & 1092 & 154 \\
\hline
\end{tabular}

Now, before we proceed to our variable of interest measured by the pesticide restrictive index, we would recall that our MRL of regulated standards were constructed such that a positive 
coefficient implies that a particular standard is trade prohibiting, as standards have a direct relationship with exports: a decrease in the value of the standard restrictiveness index (increase in stringency) decreases exports. However, a negative value denotes that a standard is trade promoting as standards have an inverse relationship with exports: a decrease in the stringency (increase in standard) increases exports. Conversely, the coefficient of exempted pesticides was constructed to be interpreted in the conventional way such that a positive sign implies that exempted pesticide standards are trade enhancing and vice versa. We now proceed with our interpretation having these definitions in mind.

One of our major variables of interest - the regulated pesticide restrictive index - is significantly positive. This result indicates that standards imposed by the EU are inimical to Africa's tomato export performance at the extensive margin, such that a decrease in the standard (increase in the stringency of the pesticide standards) decreases tomato exports by $6.997 \%$. This result is as expected: in fact, our result for tomatoes confirm those of Chen et al. (2008) and Otsuki, et al. (2001), both of which found that EU standards were inimical to export success.

The coefficient for the ad valorem duties incurred from exceeding the EU ceiling entry price is insignificant, implying that the entry price is of no relevance to establishing new trade. Likewise, the variable which measures the competitiveness of the milling price of Africa's tomato exports relative to those of the domestic growers' in the EU is indistinguishable from zero due to the imposition of the entry price barrier.

In terms of other trade costs proxied by distance, we find that African tomato exports decrease with increasing distance, and the effect is as large as a $2.576 \%$ decrease in exports with a $1 \%$ increase in distance (kilometre). This is expected due to the transportation risks perceived from exporting highly perishable tomatoes over a long distance. Entering a regional trade agreement relationship with the EU does not significantly impact on African trade at the extensive margin. In addition, a common language between the two trading partners does not significantly propel tomato exports. Meanwhile, colonial ties between countries are a significant determinant of establishing new trade or expanding existing trade. The significance of this latter variable justifies its use as a plausible excluded variable in the trade equation (intensive margin model).

\section{Tomatoes - Intensive Margin}

At the intensive margin, estimates show that the relative large GDP of Africa and sharing a similar language with trading partners are both major determinants of the export success of existing tomato exporters. African productive capacity for this product is such that a one percent rise in GDP increases exports to the EU by $0.457 \%$ by existing firms who choose to remain in the export market. This is not surprising as the increase in economic growth is used to promote this export product through the provision of enabling an investment-friendly environment which supports the growth and facilitates the export of this product. However, the consumption expenditure of EU consumers is not significant, implying that their current income does not encourage their propensity to import or consume tomatoes from Africa. This is 
probably because as income increases, so does their unwillingness to consume conventional tomatoes; instead, this is substituted by an increased preference for organic products.

Regulated standards have direct impact on African tomato exports, signifying that a decrease in standards (increase in stringency) decreases tomato exports to the EU by $7.265 \%$ - a very high and prohibitive figure. This is not unexpected as tomatoes constitute one of the 'dirty dozen' exports. The dirty dozen products constitute a list of the most pesticide-contaminated fruits and vegetables that usually retain the highest levels of pesticide residues and are more likely to test positive for multiple pesticides (EWG, 2013). Thus, these products attract the most stringent standards to protect consumers, so stringent that they might mean additional fixed costs to comply with them. Such costs may prove too much to bear for small scale producers, most of which are exporters of the product in Africa. This has led to significant trade diversion to other countries. For example, prior to the harmonization of EU pesticide standards in 2008, Africa exported about $9 \%$ of its tomatoes to the EU. However, new EU regulations and the associated increase in the stringency of standards forced exports to the EU to fall to $2.9 \%$ with Africa redirecting its exports to countries in the Middle East, particularly Jordan (c.f. section 2).

Meanwhile, the entry price system of the EU which penalizes exporters whose milling price (standard import price) is below a specified minimum entry price, is significantly inimical to tomato exports from Africa. In essence, an increase in the import price above the entry price brings about the imposition of additional duties which significantly decrease exports by as much as $1.371 \%$. This is largely expected as a case in which the standard import value is below the minimum entry price would imply that additional duty would be incurred as a penalty factor. Thus, the final price of the export good becomes more expensive due to the additional duties incurred. Adding in the additional duties to the CIF increases the final import price above the prevailing domestic price in the EU, thereby discouraging exports. This may have implications for cases of disappearing exporters in the tomato export market, as the EU entry price system inhibits trade twice more than regulated EU pesticide standards.

On a related note, the variable which measures the competitiveness of Africa's tomato exports' import price relative to the domestic growers' price (due to the imposition of the entry price barrier) is also significantly negative. This signifies that the imposition of the entry price nontariff barrier erodes Africa's price competitiveness. In fact, a dollar increase in Africa's price of importing tomatoes over the EU ceiling entry price reduces exports by $0.068 \%$. The increase of the import price above the entry price brings about the imposition of additional duties which erode the price competitiveness of tomato exports. Thus, this scenario leads to a decrease in export volume. As the final price of the exports becomes more expensive relative to EU domestic prices, export purchases are discouraged resulting in a decrease in exports to the EU. Similar results were found by Chemnitz and Grethe (2005) on the issue of Morocco tomato exports to the EU and by Goetz and Grethe (2010) on China's exports of pears and apples to the EU. 
Diverging from the results obtained in the extensive margin of trade, distance is not significantly for already established tomato exporters. This signifies a reluctance to export tomatoes as a highly perishable product over such large distances. Having a trade agreement relationship with the EU is found to be inimical to African tomato exports. Although countries enter into trade agreements to stimulate more trade, this is not the case for many African countries for which existing RTAs are not significant in driving trade. Many of the RTAs between Africa and the EU have been non-reciprocal, with the exception of the ongoing negotiations known as the Economic Partnership Agreement (EPA). Major reasons adduced for this is a lack of potential to harness the benefit for the use of such an agreement, due primarily to the numerous constraints of Africa's domestic market. Notable examples of these constraints include corruption, the lack of financial resources, a lack of adequate education, and a lack of sophisticated science and technology to improve export products to the EU. Other factors fall under the category of hidden constraints or conditions in the RTAs, including the rule of origin and the EU minimum entry price control, all of which deter Africa's ability to penetrate the EU market. This signifies that deeper agreements are needed to truly integrate African countries and ensure their market access to the EU. Similar negative effects of RTA particularly on developing countries have been obtained by Ghosh and Yamarik (2004); Francois et al. (2006); Martinez-Zarzoso et al. (2009); Greveda and Martinez-Zarzoso (2015). Nevertheless, having similar languages has significantly increased tomato exports to the EU market. The inverse Mills ratio and variables which act as a proxy for firm heterogeneity are all statistically significant, confirming the presence of both sample selection and firm heterogeneity biases which the HMR helps in controlling for, thus justifying the use of the HMR model which helps in eliminating these two biases.

\section{Oranges - Extensive Margin}

Exporters' GDP is insignificant, signifying that the exporting African countries income base has not been significant in luring new exporters into this trade and is also a discouraging factor when it comes to expanding existing trade relationships. This might explain why some African exporters are gradually disappearing, resulting in some exporting in some years and not in others (zero trade flows). However, the importing countries demonstrated a relatively average propensity to export oranges from African countries based on the significant GDP. This positive absorptive capacity of the importing countries in contrast with the weak productive capacity of the exporting countries indicates that a continuous production of this product is needed so as to meet the high import demand and harness immense benefits from trade. The regulated pesticide restrictiveness index indicates a direct relationship with orange exports; this implies that a decrease in the standard (increase in the stringency) results in a decrease in orange exports. Consequently, this indicates that expansion in output must be done pari passu with an improvement in pesticide safety standards, if new exporters are to be able to penetrate the EU market.

Neither of the two variables which capture the EU minimum price control (known as the 'entry price system') are statistically distinguishable from zero. This implies that the EU entry price system is not relevant in the decision to enter into a new trade relationship with the EU, while 
EU stringent pesticide standards are a more determinant and problematic factor for potential exporters seeking to penetrate this market. Similar results were reported by Goetz and Grethe (2007) who found the EPS to be of low importance for exports of oranges from the Mediterranean countries into the EU.

Turning to the other trade costs, we find that orange exports to the EU decrease with increasing distance, signifying that an improvement in both domestic and international logistic trade facilitation infrastructure might improve trade. The EU regional trade agreements with African countries have not been able to boost the continent's orange exports to the EU. This is expected as regional trade agreements would not increase trade unless exporting countries comply EU pesticide standards which are applied on an MFN basis with no preferential treatment, even for countries with regional trade agreement relationships with the EU. Sharing a similar language with the EU is a stimulating factor for potential African exporters in establishing possible new trade relationships and expanding existing ones. Likewise, having colonial ties with the EU has a similar effect. The significance of the last two variables (which are fixed costs of trading) results in them being potentially used as excluded variables in the intensive margin model.

\section{Oranges - Intensive Margin}

Both trading partners' economic masses (EU and Africa's GDP) contributes to the existing export success of Africa's orange exports to the EU. However, these values are below average, signalling the fact that there is still a9 need for improvement in both the exporters' productive capacity and the absorption capacity of the importer in order to increase both the export supply of oranges and its import demand respectively.

In particular, EU pesticide standards for oranges have an inverse relationship with orange exports, signifying that a decrease in standards (increase in its stringency) increases African orange exports to the EU. In other words, although these particular standards discourage the formation of potential new trade relationships in the extensive margin model (column 3 in Table 12), they actually promote trade for existing African exporters who are already in trade relationships with the EU. These particular exporters have normally already upgraded their supply capacity to meet the EU standards; such fixed costs incurred in upgrading their supply side are now paying off. This shows that standard does not all the time constitute barrier to trade, and may also serve as a catalyst for trade. This result coincides with those of Swann et al. (1996), Jaffee and Henson (2004, 2008), Moenius (2006) and Maertens and Swinnen (2009), who affirm that standards are not always problematic: While they can decrease the export success of existing trade in the short run, in the long term they can encourage exporting countries to upgrade their supply capacities to meet the standards of importing countries and enhance market access.

We also posit that standards are not necessarily problematic. The reality is likely to be less pessimistic than portrayed by the widely-held view of the mainstream 'standards as a barrier' perspective. Indeed, EU pesticide standards are helping African countries to strengthen supply chains for oranges. These standards do not necessarily hurt African exports but actually promote 
exports once the right technology to ensure standards compliance has been invested in. This facilitates trade as consumers gain and show confidence in a quality export product. We agree with Jaffee and Henson (2004) that some African countries and/or firms are responding to these evolving circumstances and are successfully using the high EU quality and safety standards to upgrade their capacities. By making the necessary adjustments and investments in operations and in the structure of their supply chains, firms are able to achieve a competitive advantage and reposition themselves in competitive international markets to proliferate the EU markets. This trade promoting effect of pesticide standards might also be attributed to the numerous assisted programmes provided by the EU and United Nations Industrial Development Organization (UNIDO); such programmes have been extended to selected African exporters and seek to assist them in complying with stringent standards and prepare them for export markets.

Similar to what was obtained at the extensive trade margin, the trade impact of the two variables capturing the EU minimum entry price system is insignificantly different from zero, implying that EU EPS might not be relevant for these exporters in their existing trade relationship with the EU. The first variable is a penalty factor which imposes a specific duty on exporters whose standard import price is below a specified minimum entry price; this variable is found to be insignificant and thus irrelevant to export penetration and Africa's export success and market access to the EU. This shows that in most cases exporters are already producing at a competitive price at home; they have a relative advantage in the production of the commodity due to all year-round sunshine and a tropical climate which fosters production. This indicates that the EU entry price does not erode price competitiveness as the import price of the African countries in this product are competitive; indeed, no stipulated amount of additional ad valorem tariff is able to erode this competitiveness.

Complementarily, the second variable, which measures how competitive Africa's orange import price is relative to the prevailing entry price barrier, is also not statistically significant. One possible explanation of the irrelevance of the EPS for these exporters is that plausibly the exporters already have a competitive cost advantage over EU growers; they are therefore supplying oranges at the minimum possible price when complying to the EU requirements relating to the EP such that they are able to avoid paying any extra duties. Thus, the minimum price control is of no relevance to orange exporters at both margins of trade. This result tallies with that of Goetz and Grethe (2007) who find that the EU entry price control is of no relevance to some selected Middle Eastern exporters.

Distance significantly hinders these exports to the EU, while signing RTAs with the EU has no effect on the export of the product. The decaying state of infrastructure, rule of law, and corruption doesn't allow the impact of an RTA to materialize. Countries who have colonial ties with the EU experience lower exports to the EU, most likely because those without colonial ties have a relative advantage in producing this commodity for export, particularly North African countries such as Algeria, Egypt, and Morocco. All in all, both the inverse Mills ratio and the polynomial terms approximating the firm heterogeneity bias are statistically significant 
in the model. This signifies that selection bias from omitting zero trade flows (non-profiting or non-productive firms) from the trade matrix, and the bias caused by unobserved firm heterogeneity (which accounts for the fraction of firms exporting i.e. profiting from exporting), have both been adequately taken care of in the model.

\section{Lemon and Lime - Extensive Margin}

The income or productive capacity of African countries has been sufficient to enhance the exportation of lemons and limes to the EU, such that an additional accrued income has increased exports to the EU by $0.210 \%$. However, this productive capability is still low relative to the income growth the continent has been experiencing in recent years. Conversely, the absorptive capacity of EU consumers for these products is very high; new trade relationships could be stimulated if exporters were able to meet the tastes and preferences of EU consumers, and expand the supply of these commodities beyond their present level. Thus, target policies are needed to improve the quality of these products and drive higher export quantities to the EU.

Once again standards exhibit a direct impact on exports so much that a decrease in standards (increase in stringency) decreases exports by $14.258 \%$. This signifies that EU standards significantly crowded out both the formation of new trade relations and the expansion of old ones; as a result, the exit of gradually disappearing exporters from the EU market risks being hastened. The exempted pesticides which were previously regulated in some years and not in others have no impact on exports as consumers are relieved from bearing the costs of complying with them.

Similarly, the coefficients on the two measures of the EU entry price system are insignificantly different from zero, signifying that the prevailing entry price control is not a deterring factor for the formation of new trade relations with the EU or expansion of old ones. This confirms the findings of Cioffi and dell' Aquila (2004) regarding southern exporters to the EU. These results are largely expected as most Africa has comparative advantage in producing lemons and limes given their tropical environment which favours production all year round. Thus, most of the countries produce the products at relatively lower costs in comparison to EU growers. Thus, no amount of extra duties incurred could discourage them from exporting to the EU. In fact, the entry price is of no relevance to them in their decision whether or not to export to the EU.

Nevertheless, trade cost as measured by distance hinders the export of these products to the EU. The regional trade agreement between the trading partners is not significant in propelling lime and lemon exports to the EU, which signifies that negotiation of RTAs should be conducted product by product and not at the aggregated level. Meanwhile, sharing a similar language exerts no influence on these export products, while having colonial ties with the EU contributes significantly to the import demand by the EU. The significance of this latter variable qualifies it as a potentially valid excluded variable in the trade equation model. 


\section{Lemon and Lime - Intensive Margin}

The economic masses of African countries do not significantly encourage the export of these products. In essence, the economic growth recently enjoyed by the continent has not been used in encouraging lime and lemon exports, probably because of the misconception that the commodities are of little relevance to foreign exchange earnings. This is in spite of the fact that Africa produces between 6 and 9 percent of world export of these products in the last few years as shown in sub-section 3.2.3. Similar results were obtained by Xiong and Beghin (2011) who confirmed that domestic market constraints such as low GDP are the major limitation to Africa's export penetration. On the demand side, the EU's expenditure on these products is also very low as the marginal trade intensity effect of an additional dollar income on lime and lemon exports from Africa is indistinguishable from zero. An increase in importers' income decreases the import demand of these products probably because the marginal consumer prefers to consume it in an organic form; this is primarily due to the changing preferences of consumers who shy away from consuming conventional products which they perceive to be laden with pesticides. Thus, Africa's productive capacity and EU marginal expenditure on these products actually discourage existing African exporters from expanding, and also explain the reason for the gradual disappearance of exporters from the EU market.

Regulated pesticide standards have no significant impact on lime and lemon exports to the EU. This might be because exporters of these products have upgraded their supply capacity to meet the speculated standards. In addition, the EU have rendered some technical and financial aid to selected African horticultural exporters to assist them in meeting such standards. Thus, this result shows that standards are not always as problematic as they are usually perceived to be. This finding aligns with those of Artecona and Grundke (2010) for Latin America and the Caribbean countries and Xiong and Beghin (2011) for African countries; that standards are an insignificant determining factor when it comes to export penetration. In fact, the insignificant coefficients on both Africa's GDP and pesticide standards strongly confirm the results of Xiong and Beghin (2011) which find that Africa's prevailing domestic situations are the major constraint to Africa's export success rather than standards.

The cost of trading these export products proxied by distance is significantly very high, signifying that improvements in both domestic logistic measures and international trade facilitation measures are needed to ensure and facilitate increased export flow to the EU. As in the extensive trade margin, regional trade agreements are of no relevance to trade in these exports. However, sharing the same language significantly propels trade between trading partners. The results show that both selection bias and firm heterogeneity bias have been adequately corrected for using the HMR model, given the significance of the inverse Mills ratio and the polynomial variables correcting for firm heterogeneity.

\subsubsection{Robustness Checks}

We engaged in a number of sensitivity analysis to assure the reliability of our results. Our first paramount concern is whether the results were driven by economically small export flows. To proceed, all countries with value of less than five thousand US dollars' worth of bilateral exports 
to the EU are excluded from our analysis to allow us check if these outliers are the ones driving the results obtained. These correspond roughly to the $10 \%$ tail end of each dataset. The results of this check are presented in Table 3.13. These results further highlight our previous conclusion since they are similar to those obtained in Table 3.12, although the coefficients of the target variable are slightly lower in magnitude. Nevertheless, the basic message of this study in relation to the impact of standards on the selected products remains largely unchanged.

Table 3.13: Robustness Checks with an Alternative Sample: Eliminating Economically Small Export Flows

\begin{tabular}{|c|c|c|c|c|c|c|}
\hline \multirow[b]{2}{*}{ Variables } & \multicolumn{2}{|c|}{ Tomatoes } & \multicolumn{2}{|c|}{ Oranges } & \multicolumn{2}{|c|}{ Lime and Lemon } \\
\hline & $(1)$ & $(2)$ & (3) & $(4)$ & (5) & (6) \\
\hline & Extensive & Intensive & Extensive & Intensive & Extensive & Intensive \\
\hline \multirow[t]{2}{*}{ Exporter GDP } & $0.168^{* *}$ & $0.457^{* * *}$ & 0.098 & $0.194^{* * *}$ & $0.361^{* * *}$ & 0.024 \\
\hline & $(0.086)$ & $(0.073)$ & $(0.095)$ & $(0.075)$ & $(0.120)$ & $(0.064)$ \\
\hline \multirow[t]{2}{*}{ Importer GDP } & 0.100 & $-0.251^{* *}$ & $0.567^{* * *}$ & -0.157 & $0.648^{* * *}$ & -0.000 \\
\hline & $(0.119)$ & $(0.105)$ & $(0.131)$ & $(0.182)$ & $(0.219)$ & $(0.081)$ \\
\hline \multirow[t]{2}{*}{ Standards } & $6.997^{* * *}$ & $7.265^{*}$ & $5.087^{* *}$ & $-3.984^{*}$ & $13.814^{* * *}$ & 0.596 \\
\hline & $(2.019)$ & $(3.821)$ & $(2.260)$ & $(2.209)$ & $(3.517)$ & (2.662) \\
\hline \multirow[t]{2}{*}{ Entry Price Duties } & 0.021 & $-1.371^{* *}$ & 0.055 & 0.248 & -8.133 & -3.620 \\
\hline & $(0.347)$ & $(0.612)$ & $(0.512)$ & $(0.355)$ & $(26.491)$ & $(26.966)$ \\
\hline \multirow[t]{2}{*}{ EPS GAP } & -0.006 & $-0.068^{* *}$ & 0.000 & 0.005 & $-0.007^{*}$ & 0.001 \\
\hline & $(0.017)$ & $(0.030)$ & $(0.013)$ & $(0.009)$ & $(0.004)$ & $(0.004)$ \\
\hline \multirow[t]{2}{*}{ Distance } & $-2.576^{*}$ & -3.476 & $-2.761^{* * *}$ & -1.303 & -3.254 & $-2.931^{* * *}$ \\
\hline & $(1.507)$ & $(2.191)$ & $(0.898)$ & $(1.254)$ & $(2.322)$ & $(1.123)$ \\
\hline \multirow[t]{2}{*}{ Colonial Ties } & $3.259^{* * *}$ & & $2.220^{* *}$ & $-3.929^{* * *}$ & $3.350^{* *}$ & \\
\hline & $(0.841)$ & & $(0.912)$ & $(1.133)$ & $(1.384)$ & \\
\hline \multirow[t]{2}{*}{ Language } & 0.312 & $1.511^{* * *}$ & $2.559^{* * * *}$ & & 0.994 & $1.316^{* * *}$ \\
\hline & $(0.649)$ & $(0.552)$ & $(0.728)$ & & $(0.868)$ & $(0.414)$ \\
\hline \multirow[t]{2}{*}{ RTA } & 0.305 & $-9.417^{* *}$ & 0.740 & 0.184 & -0.488 & $-13.297^{* * *}$ \\
\hline & $(0.432)$ & $(4.666)$ & $(0.474)$ & $(0.531)$ & $(1.452)$ & $(4.469)$ \\
\hline \multirow[t]{2}{*}{$+\hat{\eta}_{i j t}^{*}$} & & $8.687^{* * *}$ & & $-2.617^{* * *}$ & & $1.852^{* * *}$ \\
\hline & & $(2.566)$ & & $(0.592)$ & & $(0.630)$ \\
\hline \multirow[t]{2}{*}{$\hat{\bar{z}}_{i j t}^{*}$} & & $159.313^{* * *}$ & & $-25.702^{* * *}$ & & $43.355^{* *}$ \\
\hline & & $(50.997)$ & & $(5.595)$ & & (19.665) \\
\hline \multirow[t]{2}{*}{$\hat{\bar{z}}_{i j t}^{* 2}$} & & $-150.245^{* * * *}$ & & $18.597^{* * * *}$ & & $-39.473^{*}$ \\
\hline & & $(52.822)$ & & $(3.344)$ & & (23.773) \\
\hline \multirow[t]{2}{*}{$\hat{z}_{i j t}^{* 3}$} & & $48.973^{* *}$ & & $-3.912^{* * *}$ & & 11.337 \\
\hline & & $(19.201)$ & & $(0.655)$ & & $(9.284)$ \\
\hline \multirow[t]{2}{*}{ Constant } & $-9.483^{* * *}$ & $-65.655^{* * *}$ & $-19.744^{* * *}$ & $23.110^{* * * *}$ & $-30.034^{* * *}$ & $-14.528^{* *}$ \\
\hline & $(3.170)$ & $(18.554)$ & $(4.398)$ & $(6.450)$ & $(6.833)$ & $(6.929)$ \\
\hline Observations & 1392 & 137 & 1071 & 207 & 1069 & 133 \\
\hline
\end{tabular}


A second concern is whether the results are driven by the characteristics ${ }^{26}$ of the exporting countries such as 'outlier countries' with huge GDP. To address this concern, we have excluded Nigeria, South Africa and Egypt ${ }^{27}$ from our datasets as they are the three most important countries with huge economic growth in our dataset. The results reported in Table 3.14 are similar to the ones displayed in Table 3.12 and so, our major conclusion remain the same, meaning that our results are robust to the exclusion of those three outlier African countries.

Table 3.14: Robustness Checks: Sensitivity to Outliers

\begin{tabular}{|c|c|c|c|c|c|c|}
\hline \multirow[b]{2}{*}{ Variables } & \multicolumn{2}{|c|}{ Tomatoes } & \multicolumn{2}{|c|}{ Oranges } & \multicolumn{2}{|c|}{ Lime and Lemon } \\
\hline & $(1)$ & (2) & (3) & (4) & (5) & (6) \\
\hline & Extensive & Intensive & Extensive & Intensive & Extensive & Intensive \\
\hline \multirow[t]{2}{*}{ Exporter GDP } & 0.124 & 0.221 & 0.116 & $0.224^{* *}$ & 0.190 & $0.436^{* * *}$ \\
\hline & $(0.095)$ & $(0.165)$ & $(0.112)$ & $(0.106)$ & $(0.128)$ & $(0.090)$ \\
\hline \multirow[t]{2}{*}{ Importer GDP } & 0.098 & $-0.440^{* * *}$ & $0.591^{* * *}$ & $-0.497^{*}$ & $0.798^{* * *}$ & $0.841^{* * *}$ \\
\hline & $(0.125)$ & $(0.145)$ & $(0.126)$ & $(0.287)$ & $(0.248)$ & $(0.248)$ \\
\hline \multirow[t]{2}{*}{ Standards } & $7.271^{* * *}$ & 7.688 & $5.692^{* *}$ & $-6.912^{* *}$ & $13.625^{* * *}$ & -5.595 \\
\hline & $(2.229)$ & $(4.721)$ & (2.449) & $(2.866)$ & $(3.048)$ & $(4.266)$ \\
\hline \multirow[t]{2}{*}{ Entry Price Duties } & 0.323 & $-1.563^{* *}$ & -0.181 & 0.380 & 13.106 & -44.731 \\
\hline & $(0.446)$ & $(0.749)$ & $(0.606)$ & $(0.447)$ & $(22.012)$ & $(38.215)$ \\
\hline \multirow[t]{2}{*}{ EPS GAP } & 0.007 & $-0.078^{* *}$ & -0.001 & 0.006 & -0.006 & 0.000 \\
\hline & $(0.022)$ & $(0.037)$ & $(0.013)$ & $(0.010)$ & (0.004) & $(0.005)$ \\
\hline \multirow[t]{2}{*}{ Distance } & -2.464 & $-4.557^{* *}$ & $-2.263^{* * *}$ & $-4.450^{* * *}$ & $-3.057^{*}$ & $-2.573^{* *}$ \\
\hline & $(1.708)$ & $(2.270)$ & $(0.850)$ & $(1.308)$ & $(1.844)$ & $(1.304)$ \\
\hline \multirow[t]{2}{*}{ Colonial Ties } & $3.558^{* * *}$ & & $2.690^{* * *}$ & $-5.099^{* * *}$ & $2.800^{* *}$ & \\
\hline & $(0.904)$ & & $(0.892)$ & $(1.446)$ & (1.194) & \\
\hline \multirow[t]{2}{*}{ Language } & 0.248 & 1.006 & $1.970^{* * *}$ & & $1.614^{*}$ & 1.492 \\
\hline & $(0.685)$ & $(0.642)$ & $(0.679)$ & & $(0.881)$ & $(0.969)$ \\
\hline \multirow[t]{2}{*}{ RTA } & 0.386 & $-14.379^{* * *}$ & 0.618 & 0.312 & -0.153 & $4.043^{* * *}$ \\
\hline & $(0.441)$ & $(5.286)$ & $(0.451)$ & $(0.585)$ & (1.292) & $(1.061)$ \\
\hline \multirow[t]{2}{*}{$+\hat{\eta}_{i j t}^{*}$} & & $6.229^{* *}$ & & $-1.943^{* * *}$ & & $2.099^{* * *}$ \\
\hline & & $(2.738)$ & & $(0.638)$ & & $(0.597)$ \\
\hline \multirow[t]{2}{*}{$\hat{\bar{z}}_{i j t}^{*}$} & & $107.382^{* * *}$ & & $-13.532^{* * *}$ & & $30.594^{* * * *}$ \\
\hline & & $(49.986)$ & & $(3.895)$ & & $(8.643)$ \\
\hline \multirow[t]{2}{*}{$\hat{z}_{i j t}^{* 2}$} & & $-93.926^{*}$ & & $9.644^{* * * *}$ & & $-22.348^{* * * *}$ \\
\hline & & $(48.573)$ & & $(1.889)$ & & $(7.206)$ \\
\hline \multirow[t]{2}{*}{$\hat{z}_{i j t}^{* 3}$} & & $28.132^{*}$ & & $-1.819^{* * *}$ & & $5.267^{* * *}$ \\
\hline & & (16.384) & & $(0.296)$ & & $(1.904)$ \\
\hline \multirow[t]{2}{*}{ Constant } & $-8.457^{* *}$ & $-36.689^{*}$ & $-20.485^{* * *}$ & $26.171^{* * * *}$ & $-29.336^{* * *}$ & $-46.764^{* * * *}$ \\
\hline & $(3.350)$ & $(21.255)$ & $(4.366)$ & $(9.118)$ & $(7.406)$ & (8.980) \\
\hline Observations & 1248 & 120 & 966 & 208 & 1008 & 140 \\
\hline
\end{tabular}

*** $\mathrm{p}<0.01, * * \mathrm{p}<0.05, * \mathrm{p}<0.1$ clustered robust standard errors in brackets, clustered by importers, exporters and year

${ }^{26}$ If the result is driven by the characteristics of the high-income countries, then this would explain in part why pesticide standards are insignificant for both oranges, and lime and lemon.

${ }^{27}$ Egypt was not in the initial lime and lemon dataset. So, only Nigeria and South Africa were excluded in that dataset. 


\subsection{Conclusion and Policy Recommendations}

As tariffs have been negotiated down, an array of non-tariff barriers - particularly food safety standards - are increasingly becoming important in agricultural food trade. Standards increase the value of certified products and processes by providing consumers vital information and assurance about their health and safety (Blind, 2001; Baller, 2007). Compliance can therefore ensure increased market access. Standards can, however, constitute barriers to trade as complying them implies huge costs for the exporters and producers which can be aggravated for those from developing countries; this is particularly applicable to Africa which is largely characterized as an imperfect market. However, the satisfaction of such stipulated standards does not guarantee unrestricted market access, particularly for fruits and vegetables exports to the EU. In addition to complying with EU pesticide standards, concurrently, exporters must also comply with the its minimum entry price requirements for certain fruits and vegetables; this requirement protects EU growers from intense competition and, if violated, attracts specific duties. The implications of these two NTMs can be enormous, especially for small scale exporters. This study investigates the impact of these two non-tariff measures on selected fruits and vegetables exports from Africa to the EU. Each one of the food exports selected enjoy relative productive strength in Africa; these include tomatoes, oranges, and limes and lemons.

A preliminary analysis shows that there has been an unprecedented lack of expansion in tomatoes and lime and lemon production in spite of the recent economic growth recorded. This is in part attributed to the shift in demand and preference for high quality products in the EU, which African producers could not meet, thereby dampening the incentive to produce for export. However, these standards underline legitimate concern for public health and safety; non-compliance can thus lead to significant export loss through the EU's refusal to import such products. EU rejection of exports from African countries and the potential food hazards responsible for such rejection were evaluated to get a clearer picture of the export loss from non-compliance. We established that fruits and vegetables remain one of the most important exports which face a significant number of rejections from Africa and other continents; more importantly, violation of pesticide standards remains one of the more important reasons for such rejections by the EU. The countries most affected in Africa are Egypt, Morocco, Nigeria, and Kenya. These rejections amount to significant export loss, and signify that much effort is needed by Africa to comply with EU standards if trade is to serve as one of the means to generate income and alleviate poverty in the continent. A preliminary analysis of the restrictiveness of EU pesticide standards indicates that EU standards were trade promoting in some years, and not in others, leaving the net effect to be empirically determined.

The results obtained for most margins of these products indicates government neglect in promoting and expanding production of these export products; this signifies that the recent increase in the continent's economic growth has been marginally used to propel these export products, given the low magnitude and/or insignificant values on the GDP obtained in most cases. Environmentally friendly investment policies that would serve to promote and increase the production of these export products should be undertaken to ensure increased export penetration to the EU market. Trade agreements are undertaken so as to strengthen trade 
relations between participating countries, remove unnecessary bottlenecks and increase trade volume. However, regional trade agreements between African countries and the EU have not been fully utilized by African countries, as our results point to the evidence that RTA has not enhanced exports to the EU. Over the past 40 years, export products from Africa have been granted generous market access to EU countries via various non-reciprocal RTAs established with African countries following the 1975 Lomé Convention. However, these preferential trade agreements have neither been successful in boosting local economies nor did they stimulate economic growth, as evident in our results. Thus, RTAs between the two trading partners should be negotiated product by product and not at the aggregated level. In particular, provisions should be made to enable Africa countries to strengthen their supply side capacity so as to be able to comply with the stipulated EU standards.

Furthermore, this study finds that standards can indeed act as an impediment to export success either through explicit import bans on particular products(s) or through the huge cost of complying with stringent standards which diminishes the competitiveness of exports. However, this is not always the case as increased and tightening of standards can also be catalyst for Africa to participate in international trade if they countries adhere to the standards set by importing countries. For instance, existing orange exporters in Africa are responding to these evolving standards and are successfully using high safety and quality standards to upgrade their capacities; at the same time, they are making the necessary adjustments and investments in operations and in the structure of their supply chains to achieve a competitive advantage. This allows firms to reposition themselves in competitive international markets and work toward penetrating EU markets. However, standards seem to significantly hurt export success of African tomato exporters at both margins of trade. Thus, adequate measures must be initiated to facilitate compliance with EU standards so as to enhance continuous market access for the continent; this will then permit Africa to be able to make use of trade to alleviate its prevailing poverty as well as achieve a more balanced and equitable economic growth.

Our results point to the need for several policy interventions. Engaging in sophisticated scientific and technological transfers and providing both financial and human development assistance to producers and exporters are both important policy imprints that should be implemented to ensure positive change. Deeper trade integration agreements with the EU should include the provision for technological and scientific assistance to the agricultural sector, particularly small-scale producers who dominate the scene in Africa, so as to assist them in complying with EU standards and ensure sustainable practices. At the home front, the removal of domestic market restraints such as an improvement in trade facilitation, provision of enabling regulatory framework, and institutional development will work not only to increase aggregate agricultural output, but also increase production for export. All these blueprints need to be faithfully implemented if immense gains are to be realized from trade. 


\section{References}

Anderson, E. J., and van Wincoop, E. (2003). Gravity with Gravitas: A solution to the border puzzle. American Economic Review, 93(1), 170 - 192.

Artecona, R., and Grundke, R. (2010). Estimating the effects of food safety and agricultural health standard on agro-food exports from Latin America and the Caribbean. Washington DC: ECLAC Studies and Perspectives Series No. 11. Economic Commission for Latin America and the Caribbean (ECLAC).

Baier, S. L., and Bergstrand, J. H. (2009). Estimating the effects of free trade agreements on international trade flows using matching econometrics. Journal of International Economics, 77(1), 63-76.

Baier, S. L., and Bergstrand, J. H. (2010). Approximating general equilibrium impacts of trade liberalizations using the gravity equation. In P. A. G. van Bergeijk and S. Barkman (Eds.), The gravity model in international trade. advances and applications (1st ed., pp. 88-134). Cambridge: Cambridge University Press.

Baldwin, R., and Taglioni, D. (2006). Gravity for dummies and dummies for gravity equations NBER Working Paper No. 12516. Cambridge, USA: National Bureau of Economic Research.

Baller, S. (2007). Trade effects of regional standards: a heterogeneous firms approach. World Bank Policy Research Working Paper 4124. Washington DC: The World Bank.

Bao, X., and Chen, W.C. (2013). The impacts of technical barriers to trade on different components of international trade. Review of Development Economics, 17(3), 447-460.

Baylis, K., Nogueira, L., and Pace, K. (2010). Food import refusals: Evidence from the European Union. American Journal of Agricultural Economics, 93(2), 566-572.

Blind, K. (2004). The economics of standards: theory, evidence and policy. Cheltenham: Edward Elgar.

Chemnitz, C., and Grethe, H. (2005). EU trade preferences for Moroccan tomato exports - who benefits? Contributed Paper, XI Congress of European Association of Agricultural Economists, Copenhagen. August 24-27.

Chen, C., Yang, J., and Findlay, C. (2008). Measuring the effect of food safety standards on China's agricultural exports. Review of World Economics, 144(1), 83-106.

Chen, N., and Novy, D. (2011). Gravity, trade integration, and heterogeneity across industries. Journal of International Economics, 85(2), 206-221.

Cioffi, A., and Dell'Aquila, C. (2004). The effects of trade policies for fresh fruit and vegetables of the European Union. Food Policy, 29(2), 169-185.

Clougherty, J. A., and Grajek, M. (2008). The impact of ISO 9000 diffusion on trade and FDI: A new institutional analysis. Journal of International Business Studies, 39(4), 613-633.

Czubala, W., Shepherd, B., and Wilson, J. S. (2009). Help or hindrance? The impact of harmonised standards on African exports. Journal of African Economies, 18(5), 711-744.

Deardorff, A. V. (1984). Testing trade theories and predicting trade flows. In R. Jones and P.B. Kenen (Eds.). Handbook of International Economics (Vol. 1, pp. 467-517). Elsevier. 
Debaere, P., and Mostashari, S. (2010). Do tariffs matter for the extensive margin of international trade? An empirical analysis. Journal of International Economics, 81(2), 163-169.

Disdier, A. C., Fontagné, L., and Mimouni, M. (2008). The impact of regulations on agricultural trade: Evidence from the SPS and TBT agreements. American Journal of Agricultural Economics, 90(2), 336-350.

Djankov, S., Freund, C., and Pham, C. S. (2010). Trading on time. Review of Economics and Statistics, 92(1), 166-173.

Drogué, S., and DeMaria, F. (2012). Pesticide residues and trade, the apple of discord? Food Policy, 37(6), 641-649. Gain (2015). EU-28 Citrus Semi-annual.

EC (2014). Analysis of the EU fruit and vegetables sector. Retrieved from http://ec.europa.eu/agriculture/russian-import-ban/pdf/fv-production_en.pdf [Accessed 14th January, 2016]

Egger, P., and Nelson, D. (2011). How bad is antidumping? Evidence from panel data. Review of Economics and Statistics, 93(4), 1374-1390.

EWG. (2013). Environmental working group annual report. Retrieved from http://www.ewg.org/about-us/annual-reports [Accessed December 1, 2014]

Feenstra, R. C. (2004). Advanced international trade. theory and evidence. Princeton and Oxford: Princeton University Press.

Ferro, E., Otsuki, T., and Wilson, J. S. (2015). The effect of product standards on agricultural exports. Food Policy, 50, 68-79.

Fischer, R., and Serra, P. (2000). Standards and protection. Journal of International Economics, 52(2), 377-400.

Fontagné, L., Mimouni, M., and Pasteels, J. (2005). Estimating the impact of environmental SPS and TBT on international trade. Integration and Trade Journal, 22, 7-38.

Francois, J., Hoekman, B., Manchin, M., (2006). Preference erosion and multilateral trade liberalization. The World Bank Economic Review, 20(2), 197-216.

Gain (2015). EU-28 Citrus Semi-annual. Gain report No. SP 1511. Retrieved from http://gain.fas.usda.gov/Recent\%20GAIN\%20Publications/Citrus\%20Semiannual_Madrid_EU-28_6-17-2015.pdf [Accessed 10 February, 2016].

Gandal, N., and Shy, O. (2001). Standardization policy and international trade. Journal of International Economics, 53(2), 363-383.

Gebrehiwet, Y., Ngqangweni, S., and Kirsten, J. F. (2007). Quantifying the trade effect of sanitary and phytosanitary regulations of OECD Countries on South African food exports. Agrekon, 46(1), 1-17.

Ghosh, S., and Yamarik, S. (2004). Are regional trading arrangements trade creating? An application of extreme bounds analysis. Journal of International Economics, 63(2), 369395.

Goetz, L., and Grethe, H. (2007). The EU import regime for oranges - much ado about nothing. Journal of International Agricultural Trade and Development, 3(1). 
Goetz, L., and Grethe, H. (2009). The EU entry price system for fresh fruits and vegetables Paper tiger or powerful market barrier? Food Policy, 34(1), 81-93.

Goetz, L., and Grethe, H. (2010). The entry price system for fresh fruit and vegetable exports from China to the EU - Breaking a fly on the wheel? China Economic Review, 21(3), 377393.

Graveda, K., Martinez-Zarzoso, I., (2015). Are trade preferences more effective than aid in supporting exports? Evidence from the 'Everything but Arms' preference scheme. World Economy. Doi:10.1111/twec.12289.

Heckman, J. J. (1979). Sample selection bias as a specification error. Econometrica, 47(1), 153 161.

Helpman, E., Melitz, M. J., and Rubinstein, Y. (2008). Estimating trade flows: trading partners and trading volumes. Quarterly Journal of Economics, 123(2), 441 - 487.

Herzfeld, T., Drescher, L. S., and Grebitus, C. (2011). Cross-national adoption of private food quality standards. Food Policy, 36(3), 401-411.

Hummels, D., and Klenow, P. J. (2005). The variety and quality of a nation's exports. American Economic Review, 95(3), 704-723.

Iwanow, T., and Kirkpatrick, C. (2009). Trade facilitation and manufactured exports: Is Africa different? World Development, 37(6), 1039-1050.

Jaffee, S. M., and Henson, S. (2004). Standards and agro-food exports from developing countries: rebalancing the debate. World Bank Policy Research Working Paper (3348). Washington DC: The World Bank.

Kareem, F. O., Brümmer, B., and Martinez-Zarzoso, I. (2016). European Union Market Access Conditions and Africa's Extensive Margin of Food Trade. The World Economy. DOI: $10.1111 /$ twec. 12466

Kareem, F. O., Brümmer, B., and Martinez-Zarzoso, I. (2016). European Union Market Access Conditions and Africa's Extensive Margin of Food Trade. The World Economy. DOI: $10.1111 /$ twec. 12466

Kim, S. J., and Reinert, K. a. (2009). Standards and institutional capacity: an examination of trade in food and agricultural products. The International Trade Journal, 23(1), 54-77.

Li, Y., and Beghin, J. C. (2014). Protectionism indices for non-tariff measures: an application to maximum residue levels. Food Policy, 45, 57-68.

Linders, G.J. M., and De Groot, H. L. F. (2006). Estimation of the gravity equation in the presence of zero flows. Mimeo, 1-26.

Maertens, M., and Swinnen, J. F. M. (2009). Trade, standards, and poverty: evidence from Senegal. World Development, 37(1), 161-178.

Mangelsdorf, A., Portugal-Perez, A., and Wilson, J. S. (2012). Food standards and exports: evidence for China. World Trade Review, 11(03), 507-526.

Martínez-Zarzoso, I., Nowak-Lehmann, D.F, Horsewood, N., (2009). Are regional trading agreements beneficial? Static and dynamic panel gravity models. North American Journal of Economics and Finance, 20(1), 46-65. 
Maskus, K. E., Wilson, J. S., and Otsuki, T. (2001). An empirical framework for analyzing technical regulations and trade. In K. E. Maskus and J. S. Wilson (Eds.), Quantifying the impact of technical barriers to trade: can it be done? Ann Arbor: University of Michigan Press.

Masood, A., and Brümmer, B. (2014). Impact of GlobalGAP certification on EU Banana Imports: A gravity modeling approach. GlobalFood Discussion Papers No. 49. Goettingen: Georg-August Universität Göttingen, Germany.

Moenius, J. (2004). Information versus product adaptation: the role of standards in trade. International Business and Markets Research Center Working Paper. USA: Northwestern University.

Moenius, J. (2006). The Good, the bad and the ambiguous: standards and trade in agricultural products. IARTC Summer Symposium, 5, 28-30. Turkey: International Agricultural Research and Training Center (IARTC).

Nicita, A., and Rollo, V. (2015). Market access conditions and Sub-Saharan Africa's exports diversification. World Development, 68, 254-263.

Otsuki, T., Wilson, J. S., and Sewadeh, M. (2001a). Saving two in a billion: quantifying the trade effect of European food safety standards on African exports. Food Policy, 26(5), 495-514.

Portugal-Perez, A., and Wilson, J. S. (2012). Export performance and trade facilitation reform: hard and soft infrastructure. World Development, 40(7), 1295-1307.

Pöyhönen, P. (1963). A tentative model for the volume of trade between countries. Weltwirtschaftliches Archiv, 90, 93-100.

RASFF. (2014). The Rapid Alert System for Food and Feed 2014 Annual Report. Retrieved from http://ec.europa.eu/food/safety/rasff/docs/rasff_annual_report_2014.pdf [Accessed September 15, 2015].

Rau, M.L., Shutes, K., and Schlueter, S. (2010). Index of heterogeneity of requirements in international agri-food trade. NTM-Impact Working Paper No 10/01.

Reardon, T., Barrett, C. B., Berdegué, J. A., and Swinnen, J. F. M. (2009). Agrifood industry transformation and small farmers in developing countries. World Development, 37(11), $1717-1727$.

Reis, J. G., and Farole, T. (2012). Trade competitiveness diagnostic toolkit. Washington, DC: World Bank. Retrieved from https://openknowledge.worldbank.org/handle/10986/2248 [Accessed September, 2015].

Scheepers, S., Jooste, A., and Alemu, Z. G. (2007). Quantifying the impact of phytosanitry standards with specific reference to MRLs on the trade flow of South African avocados to the EU. Agrekon, 46(2), 260-273.

Shepherd, B., and Wilson, N. L. W. (2013). Product standards and developing country agricultural exports: The case of the European Union. Food Policy, 42, 1-10.

Shepotylo, O. (2009). Gravity with zeros: estimating trade potential of CIS countries. Kyiv School of Economics Discussion Papers No 16. Ukraine.

Swann, P., Temple, P., Shurmer, M., (1996). Standards and trade performance: the UK 
experience. The Economic Journal, 106(438), 1297-1313.

Swann, G. P., (2010). International standards and trade: A review of the empirical literature. OECD Trade Policy Working Paper No. 97. Paris: Organization of Economic Cooperation and Development (OECD). DOI: 10.1787/5kmdbg9xktwgen

Tapia, C., Iglesias, D., Lema, D., and Ghezan, G. (2011). Assessment of sanitary NTM upon beef trade flows for the UE, Germany, and Argentine. NTM-Impact Working Paper No. $11 / 08$.

Tinbergen, J. (1962). Shaping the world economy; suggestions for an international economic policy. New York: Twentieth Century Fund, New York.

Unnevehr, L. J. (Ed.). (2003). Food safety in food security and food trade. IFPRI Vision 2020 Focus Briefs 10. Washington DC: International Food Policy Research Institute (IFPRI).

Wilson, J. S., and Otsuki, T. (2004). To spray or not to spray: pesticides, banana exports, and food safety. Food Policy, 29(2), 131-146.

Winchester, N., Rau, M. L., Goetz, C., Larue, B., Otsuki, T., Shutes, K., and Nunes de Faria, R. (2012). The impact of regulatory heterogeneity on agri-food trade. The World Economy, 35(8), 973-993.

World Bank. (2005). Food safety and agricultural health standards: challenges and opportunities for developing country exports. Washington, DC: The World Bank.

Xiong, B., and Beghin, J. (2011). Does European aflatoxin regulation hurt groundnut exporters from Africa? European Review of Agricultural Economics, 39(4), 589-609.

Xiong, B., and Beghin, J. (2014). Disentangling demand-enhancing and trade-cost effects of maximum residue regulations. Economic Inquiry, 52(3), 1190-1203. 


\section{Appendix}

Table A3.1: List of Countries in the Tomato Dataset

\begin{tabular}{ll}
\hline Country Groups & \multicolumn{1}{c}{ Members } \\
\hline Importers (EU) & Belgium, France, Germany, Luxembourg, Netherlands, Portugal, Spain \\
\hline Exporters (Africa) & Algeria, Angola, Cape Verde, Comoros, Democratic Republic of Congo, Côte \\
& d'Ivoire, Egypt Arab Republic, Equatorial Guinea, Gabon, The Gambia, \\
& Ghana, Guinea-Bissau, Kenya, Liberia, Mauritania, Morocco, Nigeria, Sao \\
& Tome and Principe, Senegal, Sierra Leone, South Africa, Togo.
\end{tabular}

Table A3.2: List of Countries in the Lime and Lemon Dataset

\begin{tabular}{ll}
\hline Country Groups & \multicolumn{1}{c}{ Members } \\
\hline Importers (EU) & France, Italy, Luxembourg, Netherlands, Poland, Portugal, Spain \\
\hline Exporters (Africa) & Algeria, Angola, Benin, Cape Verde, Congo Republic, Côte d'Ivoire, \\
& Djibouti, Equatorial Guinea, Gabon, Ghana, Liberia, Madagascar, \\
& Mauritania, Morocco, Nigeria, Sao Tome and Principe, Senegal, Sierra \\
& Leone, South Africa
\end{tabular}

Table A3.3: List of Countries in the Oranges Dataset

\begin{tabular}{ll}
\hline Country Groups & \multicolumn{1}{c}{ Members } \\
\hline Importers (EU) & Belgium, France, Italy, Malta, Netherlands, Portugal, Spain \\
\hline Exporters (Africa) & Algeria, Angola, Benin, Cape Verde, Chad, Democratic Republic of Congo, \\
& Congo Republic, Côte d'Ivoire, Egypt Arab Republic, Equatorial Guinea, \\
& Gabon, The Gambia, Ghana, Guinea-Bissau, Liberia, Madagascar, Mali, \\
& Mauritania, Morocco, Nigeria, Sao Tome and Principe, Senegal, Sierra Leone, \\
& South Africa, Togo. \\
\hline
\end{tabular}




\title{
Chapter 4
}

\section{Protecting Health or Protecting Imports? Evidence from EU Sanitary and Phytosanitary Measures}

\begin{abstract}
Non-tariff measures such as sanitary and phytosanitary measures are used in achieving the nontrade objective of protecting consumers' health and safety. However, such measures may also be used as trade protection tool to drive a price wedge between domestic and foreign producers. This study investigates the protectionist intent of European Union (EU) sanitary and phytosanitary measures on food safety using a sample of EU food imported from African countries with a specific focus on tomatoes and citrus fruits. We formalize what protectionism is by comparing EU food safety standards to the internationally scientific referenced benchmarks regulated by both the Food and Agricultural Organisation and the World Health Organisation. Our results show that the EU tomato food sub-sector is less dependent on imports and is overprotected by more stringent standards relative to the international benchmarks. Conversely, we find that the EU orange and lime and lemon food sub-sectors are heavily import dependent and are under-protected relative to the international standards. These results largely support the hypothesis that heavily import dependent food sub-sectors are less protected. Further analysis shows no substantial rise in the usage of these measures as protectionism tool during the financial crisis but points to a wave of protectionism after the crisis.
\end{abstract}

Keywords: Trade Protectionism, Non-tariff Measure, Food Safety Standards, Food exports

JEL Classifications: F13 F14 L15 P16 Q17 Q18

\subsection{Introduction}

Trade protectionism involving the deliberate use of government regulations to limit the importation of goods and services from third countries has been a popular facet of international trade. Prior to the General Agreement on Tariffs and Trade (GATT) and its subsequent revisions, extensions, and rounds, protectionism has been attained with the use of overly high tariffs on exported goods. However, as a result of the GATT $^{28}$ agreement, this kind of protectionism has lost its ground following a decrease in the use of tariffs and the consequent rise of non-tariff measures (NTMs) by many countries who shift towards using them as trade barriers (Baldwin, 1970). NTMs take many different forms, ranging from traditional barriers, such as quotas and subsidies, to more sophisticated and complex ones, including technical

\footnotetext{
${ }^{28}$ GATT agreements and the subsequent post-war GATT rounds (such as the Uruguay and Tokyo rounds) and the need to substantially reduce the pervasive protectionism of the 1930's and expand world trade resulted into increased success in the reduction of visible tariff Rivera-Batiz and Danyang (1992).
} 
barriers to trade (TBT), sanitary and phytosanitary ${ }^{29}$ (SPS) measures, entry price controls, among many others. However, protectionist intent is not usually glaring in NTMs as it often is with tariffs since they are frequently less transparent than tariffs and are mostly linked to nontrade policy objectives ${ }^{30}$ such as consumer protection such as food safety standards. Consequently, protectionist intent is more difficult to detect. Such non-trade objectives include the legitimate concern for the welfare of the citizenry, in which case the government is mandated to protect consumers' health and the environment by ascertaining that the NTMs guarantying a certain health and safety concern is imposed.

However, such NTMs could also be employed as a tool in protecting domestic producers and driving out foreign producers; this is done by using stringent trade protectionism measures to drive a wedge between foreign and domestic producers (Baldwin, 1970, 2000). This may occur with many food products in which the government seeks to achieve a non-trade objective of maximizing consumers' health and safety, but at the same time sets much more stringent food safety standards than would be required by international benchmarks. Indeed, the proliferation and continuous use of some SPS measures on food - food safety standards - as protectionist tools has been found to inhibit the expansion of exports in global markets for many developing countries, particularly the African continent (Otsuki et al., 2001; Shepherd and Wilson, 2013). Consequently, this may jeopardize the developmental progress of the continent since deep trade integration is widely viewed as the most promising avenue to achieving economic growth (Nicita and Rollo, 2015).

The protectionist use of NTMs and their implication for exporting countries is not yet completely understood. Studies investigating if the use of NTMs has protectionist intent are rare; this can be largely attributed to the difficulty of differentiating their non-trade policy objectives from their trade policy objectives and a lack of a globally accepted benchmark for doing this (Xiong and Beghin, 2014). This research therefore contributes to the literature by ascertaining the protectionist intent of NTMs with a specific focus on SPS standards. We posit that standards are a good case study given the fact that they are primarily enacted due to a legitimate concern for consumers' health and safety (the non-trade objective). However, they can also be used as a protectionist tool by importing countries that set overly restrictive standards so as to attain a certain level of protectionism (the trade objective). This provides a basis for determining whether or not the chosen level of standards is indeed protective. Moreover, out of all NTMs, our interest in standards stems from the fact that a significant share of traded food products is subject to standards regulated by many importing countries, and thus provide an important NTM to be studied.

While the World Trade Organisation (WTO) agreements on TBT and SPS measures specify that the measures should not be used to create unnecessarily trade barriers and recommend that international standards should be used, the agreements also recognize that countries could resort

\footnotetext{
${ }^{29}$ SPS are measures aimed safeguarding human, plants and animals' health and safety by protecting them from food hazards, pest and diseases and other related risks (WTO, 2015).

${ }^{30}$ Such non-trade objective includes achieving certain minimum health and safety level.
} 
to the usage of more stringent domestic standards provided they have scientific justification. This clause has been extensively exploited to the advantage of many developed standard-setting countries to the extent that some standards have generated a number of disputes, due to the accusation that they are being used as disguised protectionism. For instance, there have been a significant number of disputes among several OECD countries and a number of these have been brought to the WTO after its dispute settling procedure was established in 1995 (Dee and Ferrantino, 2005).

Given that countries have a free hand to make standards that deviate from the international norm, one may pronounce domestic standards that exceed the international socially optimal benchmark with a non-trade objective as being overly stringent, suboptimal, perhaps protectionist in nature, and therefore more trade distorting (Fisher and Serra, 2000; Grandal and Shy, 2001; Marette and Beghin, 2010). Likewise, domestic standards that are lower than the international socially optimal benchmark can be said to be less trade distorting or perhaps trade enhancing, but also suboptimal and non-protectionist. However, empirical investigation of the trade effect of such suboptimal standards is rare due to the difficulty of distinguishing standards with legitimate intent from those with protectionist intent ( $\mathrm{Li}$ and Beghin, 2014). Thus, this study fills this research gap by estimating the protectionism extent of EU standards relative to their globally acceptable benchmarks and how this affects the potential of African food exporters to establish trade relations with the European Union (EU). The closest measure in this sense is that of Li and Beghin (2014), albeit still with significant differences. Firstly, the focus of their study was on the United States rather than the EU. Secondly, their study utilized a crosssection of minimum residual limits (MRLs) of pesticides and veterinary drug standards to panels of trade flows. As a result, this study misses an important part of heterogeneity in standards. We use the newly available time series from the EU database of MRLs to estimate the impact on Africa's exports. Our study is an improvement on previous literature one of which is the usage of panel data which allows unobserved heterogeneity to be controlled for. Furthermore, to our knowledge, this represents the first study of its kind on Africa's exports.

We investigate the protectionist intent of EU food safety standards using a sample of EU food imports from African countries with a specific focus on tomatoes and citrus fruits. These products provide a good case study to analyse standard protectionism with an explicit focus on African countries due to a number of reasons. First, the EU is the largest importer of these products. As a consequence, this may spur interest groups to lobby the EU food standard setting process so as to protect domestic consumers and their economies of scale, being a marginal producer of tropical fruits. Second, the EU remains the top destination for many African countries; top exporters of these products tend to originate from African countries due to the favourable climatic conditions which give them a comparative advantage in the production of these agricultural produce. This has therefore necessitated our focus on African exporters. Third, these products are an easy target for protectionist non-tariff barriers relating to standards concerns due to their perishable nature and suitability for direct consumption. 
This study is motivated by recent literature on firm heterogeneity which reveals that the growth of developing countries' trade was predominantly as a result of the expansion of trade along the extensive margin (the establishment of new trade partners or new products to new or existing markets) rather than due to the growth in the intensive margin i.e. expansion in the volume of trade to already established partners (Debaere and Mostashari, 2010; Reis and Farole, 2012; Nicita and Roll, 2015). In spite of this assertion, we argue that the ability of developing countries to initiate or penetrate new markets might be ultimately constrained by the stringent market conditions of importing countries. Thus, analysing the impact of the aforementioned EU market conditions in the food sector on Africa's extensive margin is crucial to understanding the process of entries and exits in the export markets and identifying which factor may be the biggest constraint to Africa's export competitiveness. For instance, studies that analysed the impacts of EU market conditions in the food sector on Africa's exports have predominantly focused on the intensive margin (Otsuki, et al., 2001; Grebrehewit et al., 2007). However, the implications of EU food regulations have received less attention when it comes to market access at the extensive margin of trade. Thus, understanding the effects of this EU market access conditions in the food sector and their effect on potential exporters is important from a policy perspective.

The rest of the study is organized as follows: Section 4.2 briefly reviews the literature and also presents a simple model of trade protectionism. In section 4.3, we describe the data and develop a protectionist index of standards. Section 4.4 provides the empirical analysis. Section 4.5 discusses the results, and the final section concludes.

\subsection{Literature Review}

The literature on standards and international trade flows have primarily focused on examining the effect of minimum quality standards and compatibility standards on trade flows (Grandal and Shy, 2001; Otsuki et al., 2001; Disdier et al., 2008; Ferro et al., 2015; Fontagne' et al., 2015; etc). However, recent contributions have examined how standards can be used as a tool of regulatory protectionism. While the literature on the protectionist use of food safety standards is scarce, there are a few theoretical works available in contrast to the very limited empirical literature. On the theoretical side, early studies in this area have qualified protectionism to occur when the welfare maximizing standards of the domestic country are higher than those of the social planner, and vice versa for anti-protectionism. They demonstrated that domestic policy makers set a number of standards in order to maximize both producer and consumer welfare along with the welfare of some interest groups. These domestic standards are then compared to the globally acceptable international standards that a social planner would have implemented, seeking only to maximize social welfare inclusive of foreign profits (Fisher and Serra, 2000; Marette and Beghin, 2010).

The major conclusion that emerges from these theoretical literature is that standards are being used as tools of disguised protectionism to protect domestic producers from competition (Fischer and Serra, 2000; Anderson et al., 2004; Sturm, 2006; Sheldon, 2012). Nevertheless, extensive theoretical underpinning of some other authors has pointed to the fact that standards 
are not necessarily protectionist, and might at times be anti-protectionist (Tian, 2003; Maertens and Swinnen, 2007; Marette and Beghin, 2010; Swinnen and Vandemoortele, 2011). However, the empirical validation of these theoretical predictions are rare, a gap which this study attempts to fill. The divergent nature of these theoretical assertions indicates the need for standards to be empirically analysed product by product before ultimately categorizing them as protectionist tools - an indication that empirical analyses are of paramount importance.

\subsubsection{The Political Economy of Government Standards}

Theoretical studies on this issue usually rely on the famous protection for sales model that was first developed by Grossman and Helpman (1994) to analyse the political economy of trade protection. This political economy model allows for interest groups to influence government's decisions and is essential to understanding the process of standard setting. Thus, to explain standard protectionism, we also rely on a simple model of protection for sales to compare government public standards with international standards.

\subsubsection{The Protection for Sales Model}

We draw from the Grossman and Helpman (1994) protection for sales model ${ }^{31}$ of trade to provide a political economy explanation for standard protectionism by the government. In the protection for sales model (summarized here for expository purposes), we assume a twocountry world with agricultural trade interactions between a large food importing country (domestic) and a small food exporting country (foreign). We assume that the latter is a price taker and also standards taker as the country has limited resources to initiate the setting of standards. However, the former is a standard setter and imposes its standards on the small country's food exports; this same set of standards is also applied on domestic producers. Following Grossman and Helpman (1994), we make the assumption that standard is the only type of trade policy measure available to the government. By setting the standards, it is assumed that government care about protecting consumers' health and safety, and so the government's main objective is to maximize social welfare.

Although by setting standards, government aims to maximize social welfare, but, this objective is also being influenced by lobbyists (both producers and consumers) who seek to influence government's policies. Producer lobbyists look to achieve a desired level of protection for domestic producers against international competition and consumer lobbyists aim to influence government policy to receive higher quality or safety. As such, it is assumed that the government cares about social welfare and wants to maximize social welfare but nevertheless also cares about political contributions from these interest groups and consequently seeks to maximize their welfare. Since government values both the weighted sum of the total level of political contributions from the interest group and also the social well-being of the people, the total government objective function is given as the summation of social welfare and contributions from each of these lobbyist groups. The government objective function with political economy concerns for the domestic interest groups is given below.

\footnotetext{
${ }^{31}$ The protection for sale model has also been used in Swinnen and Vandemoortele $(2011,2012)$ to study the political economy of standards.
} 


$$
G(s)=a_{1} W^{G}(s)+\sum_{p \in L} a_{2} C_{p}(s) \quad a_{1}, a_{2} \geq 0
$$

Here, $a_{1}$ is the strength of the political effectiveness of the interest group(s) on a specific food product $p$ which they seek to lobby the government about; $\mathrm{L}$ is the set of the politically organized sectors, $S$ is the standard, $a_{2}$ is the weight the government attaches to general welfare $W^{G} \cdot C_{p}(s)$ is the political contribution by the organized food sector $p$. It is further assumed that there is truthfulness in the contribution such that the government is given higher contributions if the standards stimulate higher producers' surpluses, and vice versa. Maximizing the government welfare function, the first order condition with respect to the standard gives the politically optimal standards ( $\left.\mathrm{s}^{\prime}\right)$ :

$$
a_{1} \frac{\partial W^{G}\left(s^{\prime}\right)}{\partial s}+\sum_{p \in L} a_{2} \frac{\partial C_{p}\left(s^{\prime}\right)}{\partial s}=0
$$

The politically optimal condition in equation (4.2) is posited to depend on the political effectiveness of the lobby groups and the associated relative benefits of the standards for the groups, the producers' compliance costs, and consumers' preferences. According to Swinnen and Vandemoortele (2012), these factors might increase or decrease the optimal standards as exposited below. Firstly, ceteris paribus, a higher effectiveness leads to a higher standard if the lobby group stands to gain from the imposition of a higher standard, and vice versa. Secondly, higher compliance costs for domestic producers lead to lobbying for lower standards as producers have incentives to give less lobby contributions to the government. Higher compliance costs also imply larger prices which result in a lower consumer surplus and increases lobbying for a lower standard. Higher compliance costs for foreign producers relative to domestic producers may motivate producers to give more lobby contributions to the government so as to achieve increased competition and economies of scale. Thirdly, a shift in the consumers' preferences for quality and safety can also lead to an implementation of a higher standard by the government, and vice versa, assuming that the consumers are well-organised.

Alongside the government, we assume that a social planner exists whose objective is solely to maximize global social welfare. This, for instance, can be the case with international organisations such as the Food and Agriculture Organisation (FAO) and the World Health Organisation (WHO) who jointly make standards with the sole aim of maximizing international social welfare and whose agenda is void of any protective motive. Likewise, the socially optimal standards are obtained by the first order condition that maximizes social welfare.

$$
a_{1} \frac{\partial W\left(s^{*}\right)}{\partial s}=0 \quad \text { subject to } s^{*} \geq 0
$$

Equation (4.3) thus gives a socially optimal standard(s*), which is the globally acceptable benchmark. Similar to the analysis of tariff in the traditional trade model, the politically chosen 
trade policy is also compared to the socially optimal trade policy in order to clarify what protectionism is (Swinnen and Vandemoortele, 2011). The comparison is made on the basis of equations (4.2) and (4.3). Here, the chosen government's standard is pronounced as suboptimal if the politically optimal standard is different from the socially optimal standards set by the social planner in the international context. The divergence between these two standards is said to depend on some factors such as the political effectiveness of the lobby groups, producers' implementation costs, and consumers' preference (Swinnen and Vandemoortele, 2011, 2012).

Interest groups may lobby either in favour of or against standards, subsequently increasing or decreasing the politically optimal standard. In the $\mathrm{EU}$, this is the case for organized retailers who seek to influence the standard setting process. In recent times, Non-Governmental Organisations (NGOs) such as the Greenpeace, Friends of the Earth Europe, Compassion in World Farming, Ecoropa, and Green League have taken an interest in standard setting and implementation and, more generally, in the politics of food; their influence is especially pervasive in the area of anti-genetically modified organism and pro-organic food campaigns. Thus, on the one hand, lobby groups can lobby for the increase in stringency and proliferation of standards, thereby making the politically optimal standards rise above the socially optimal standards that would be implemented by a social planner - the case of over-standardization. However, producers can also lobby for negative protection and the reduction of standards such that the politically optimal standards might fall below the socially optimal standards - a case of under-standardization. In other words, two suboptimal cases may occur when the socially optimal is less than or greater than the politically optimal standards, which describes over- and under- standardization respectively (Swinnen and Vandemoortele, 2011, 2012).

On the one hand, interest groups (producers) might lobby for over-standardization if their cost of complying with the standards is relatively low, and they want to enjoy economies of scale and increase the foreign producers' cost of complying with standards, thereby giving them diseconomies of scale. A higher effectiveness of consumer's interest groups might also result in over-standardization if they value the quality of the product. On the other hand, domestic producers might lobby for under-standardization or a reduction in standardization if the standards are too costly to comply with for them. In addition, for net importers and heavily depend on foreign exported goods for production inputs, their relative preference to the producer lobbyist groups to lobby the government for a higher standard might be weaker, depending on the consumers' preference for safety and quality.

The protection for sales model thus yields three straightforward implications. (1) The politically optimal standards might coincide with the socially optimal standards when all lobby groups can attain their maximum surplus income at the social optimum. In this case, optimality implies that exporters would not be hurt when politically optimal standards are equal to socially optimal standards, even if the latter are trade enhancing or trade inhibiting. (2) Under-standardization: for cases in which the politically optimal standards are lower than the socially optimal set, both domestic and foreign producers benefit from this under-standardization. The negative impacts of standards on trade are reduced such that the level of protection will be directly related to 
export value. Thus, although under-standardization is suboptimal, it is not protectionist from this point of view. (3) Over-standardization: for cases in which the politically optimal standards are higher than the socially optimal set. The higher the level of over-standardization, the harder it becomes for exporters particularly those from "small countries" to comply with the importing country's standards. Thus, in the case of a small country, over-standardization will distort trade and give rise to a higher surplus income for domestic producers while foreign producers lose out. As a result, for protected industries (if the sector or good is protected), then the level of protection will be inversely related to the export value.

\subsection{Data and Descriptive Statistics}

In this section, we present a protectionism index of EU standards alongside some descriptive statistics of EU pesticide standards vis à vis those set by the Codex Alimentarius Commission. In addition, we provide an insight into the structure of EU production and trade for each of the three products considered in this study with a view to understanding the need to protect or not protect the sector.

\subsubsection{Measuring Protectionism - a Protectionism Index of Standards}

In this paper, our measure of standards is based on quantifiable pesticide standards regulated by the importing countries. Pesticide standards are SPS standards imposed on food and feed products to ensure animal, plant and human safety as well as the safety of the environment. The standards are represented in the form of a maximum residual level (MRL) of pesticides that is scientifically permitted for consumption. To avoid using standards as a protectionist tool, the World Trade Organisation (WTO) obliged its members to employ internationally scientific based standards, such as the Codex ${ }^{32}$ Alimentarious Commission (hereafter Codex) standards, wherever possible. We define protectionism as the fraction of a country's standards that are more stringent than the standards internationally recognized by the WTO. Following Li and Beghin (2014), using MRLs of pesticides standards, we formalize what protectionism is by developing an index of protectionism which we define as the differences in the stringency of a country's standards to internationally acceptable science based standards. Thus, our measure of protectionism is constructed by measuring the differences in EU standards against an international benchmark. One may pronounce standards that exceed the internationally accepted set as being overly stringent, 'excessive standards', and protectionist in nature and therefore more trade distorting.

Since our focus is on food safety, we used Codex standards - which set international food safety standards - as the 'socially optimal' scientifically based benchmark. We developed a simple criterion for protectionism: EU pesticide standards that exceed those set by Codex are taken to be protectionist, while those that are laxer than those set by Codex are defined to be antiprotectionist. Our product level protectionism index for pesticide standards is given as:

\footnotetext{
32. This is joint FAO and WHO commission. Codex is established to develop internationally standards using scientific knowledge, with the aim of protecting consumers' health and the environment as well as avoiding unnecessary obstacle to trade.
} 


$$
P_{i j k t}=\frac{1}{n}\left(\sum_{k=1}^{n} \exp \left(\frac{\operatorname{Codex}_{M R L_{i k t}}-E U_{M R L_{i k t}}}{\operatorname{Codex}_{M R L_{i k t}}}\right)\right)
$$

Here, $P_{i j k r}$ measures the extent of protectionism of pesticide standards aggregated over pesticide $k$, imposed on country $j$ exports at time $t ; E U_{M R L_{i k t}}$ denotes the maximum residual limits of EU pesticide standards at time $t$; $\operatorname{Codex}_{M R L_{i k t}}$ is the maximum residual limit of the international scientific reference pesticide standard at time $t$. The upper part of the index, Codex $_{M R L_{i k t}}-E U_{M R L_{k t}}$, measures the protectionism of the standard; it was thereafter scaled by Codex standards so as to make the index invariant to differences in pesticide limits between the EU and Codex.

Equation (4.4) results in an index that is lower and upper bounded by zero and $e \approx 2.718$, respectively, with the index normalized at one when both EU and Codex standards are the same. The lower the EU MRL standards (and the higher the stringency) are relative to the international Codex standards, the higher the index. The higher the EU standards (and the lower the stringency) are relative to the international Codex standards, the lower the index. In other words, the index is normalized at one when both EU and Codex standards are the same, describing the equilibrium condition; an index above one indicates more stringent EU standards relative to those of Codex and describes protectionism; finally, an index below one indicates lower stringency of EU standards relative to those of Codex - anti-protectionism. Thus, the higher the index is, the higher its stringency, and the harder it becomes for exporters to comply with EU standards relative to Codex standards; this consequently implies lower exports and vice versa. Thus, the coefficient on the protectionism index is expected to be negative if the EU pesticide standards are protectionist relative to those of Codex, and vice versa.

There are some issues that were encountered when working with both the EU and Codex pesticide standards. The foremost issue is that of unestablished pesticide standards. Appendix III of EU Directive 396/2005 stipulates that a default MRL of 0.01 should be applied to products for which no pesticide standards are established. So, we substituted this default MRL value for non-established pesticide standards in the EU. Codex also has some rare cases where certain pesticides who were not initially given an MRL value were later assigned one in later years. As a result, we were faced with the problem of missing MRLs; this is exacerbated by the fact that Codex does not use a default MRL value. In order to solve this issue, we posited that African countries exporting to the EU still have to face EU default standards even when the EU uses standards set by Codex. We therefore substituted these missing values with default EU values. Fortunately, such cases are rare and we concurred that they will not significantly distort our results.

A second issue is that Codex has only established rules on a subset of standards that are regulated by the EU. For example, in 2013 it established about 72 pesticide standards on 
tomatoes which is in stark contrast to the EU which established around 462 standards in the same period. To solve this issue when calculating the protectionism index, we were forced to consider only pesticide standards that are regulated by both the EU and Codex. This is done to allow us produce a consistent list of pesticides regulated by both bodies and allow for the ease of comparison of the pesticides' MRLs. When interpreting our results, this caveat should be kept in mind.

\subsubsection{Overview of EU and FAO/WHO Pesticide Safety Standards}

Standards on pesticides are provided by the specified MRL of the pesticide. In addition, the stringency of pesticide standards is measured in parts per million (indexed as $\mathrm{mg} / \mathrm{kg}$ ). The higher the MRL, the lower the stringency of the pesticide standard, and a decrease in the MRL signals an increase in its stringency level. The EU's coverage of regulated pesticides is high in contrast to Codex who only establish rules on a subset of standards regulated by the EU. So, for ease of comparison, we limited ourselves to only the pesticide standards that are regulated by both the EU and Codex. Figures 4.1, 4.2, and 4.3 display the average stringency levels of the subsets of pesticides regulated by the EU and Codex between 2008 and 2013 based on the index formulated in equation (4.4).

\section{Figure 4.1: Tomatoes MRLs}

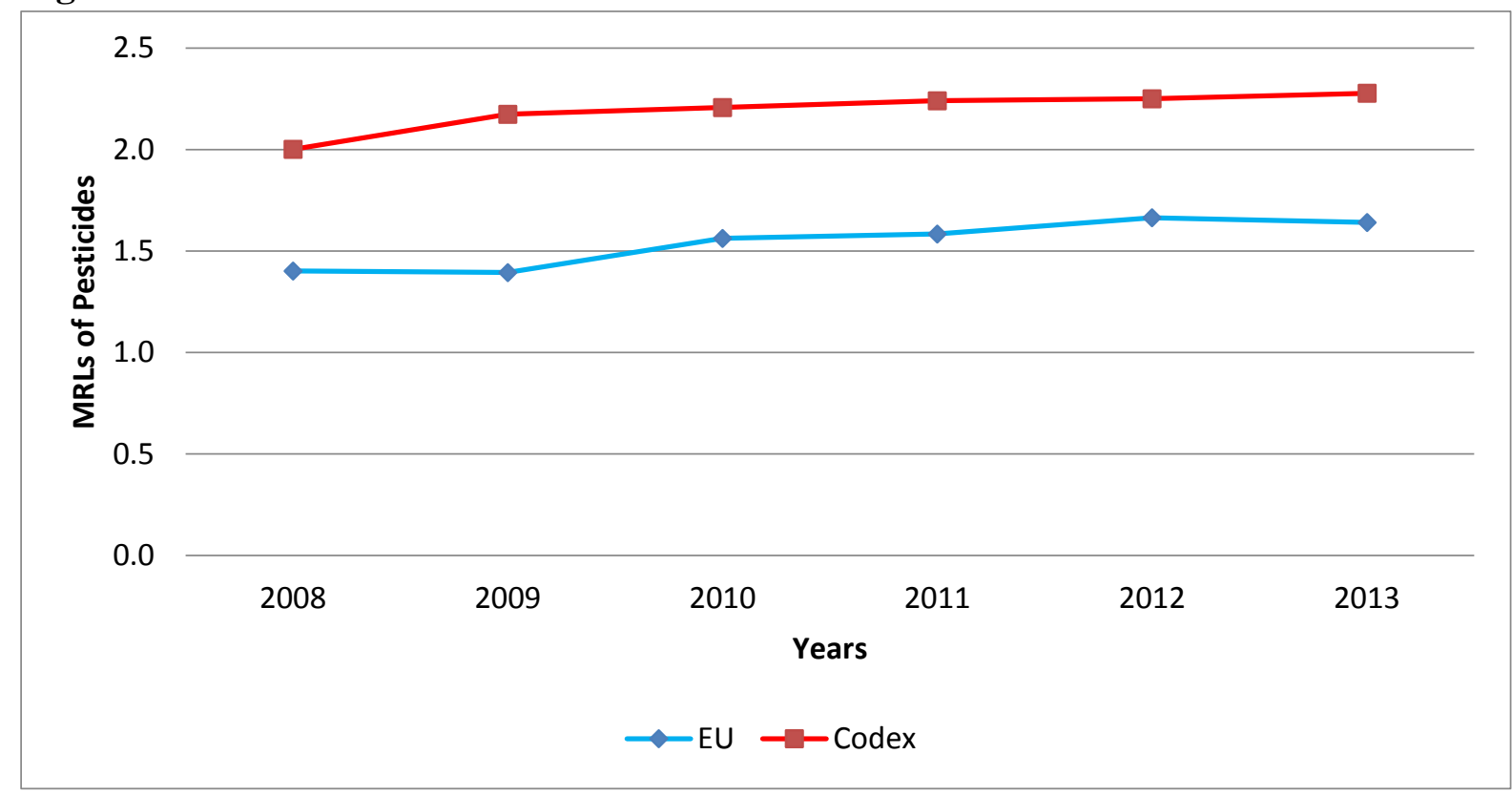

Source: Author's computation from the EU and Codex Pesticides Databases 
Figure 4.2: Oranges MRLs

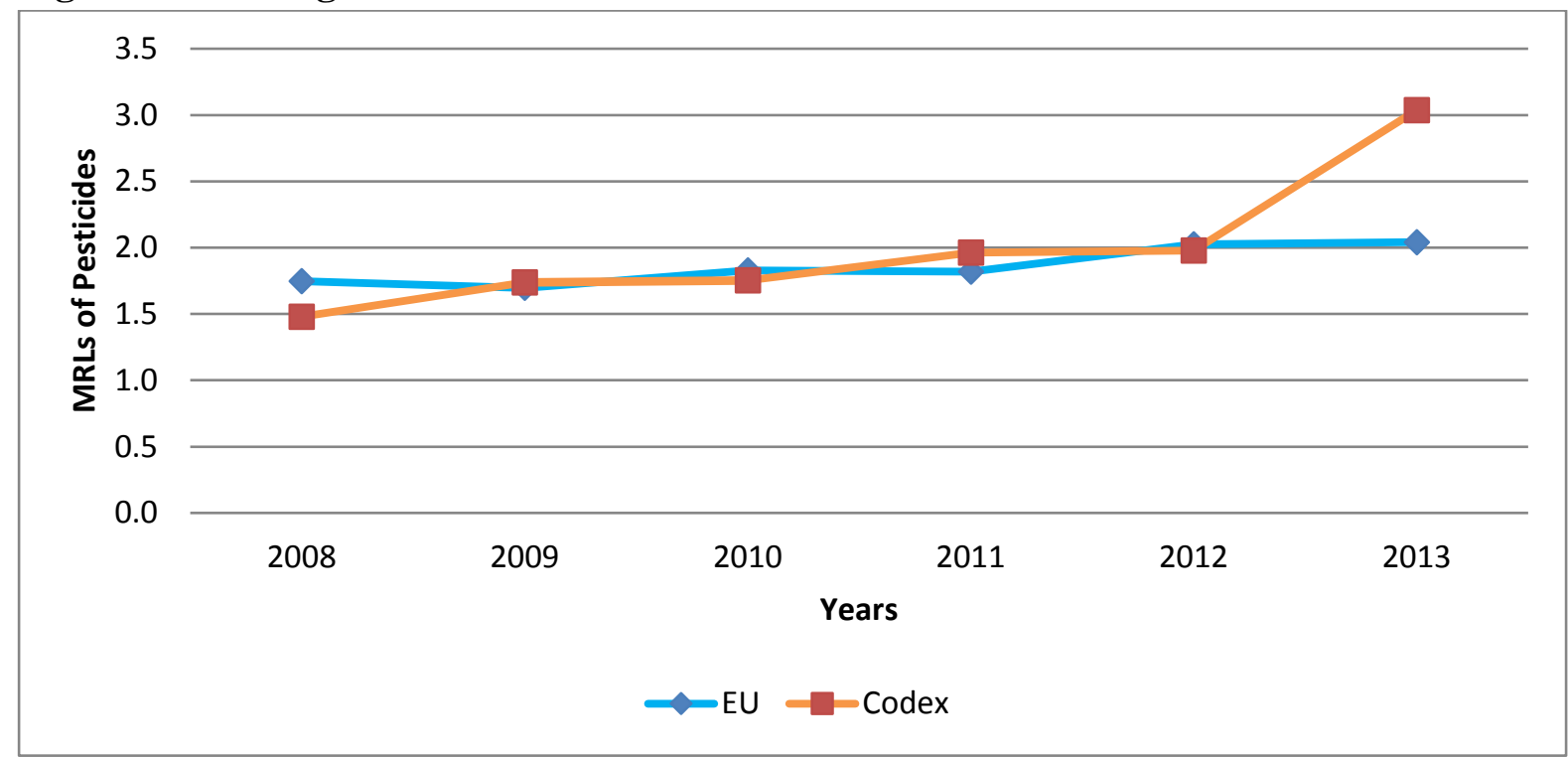

Source: Author's computation from the EU and Codex Pesticides Databases

In the case of tomatoes, Figure 4.1 shows that the regulated MRL of EU standards is consistently below those of Codex for all years, indicating that the EU set lower (stricter) pesticide standards on tomatoes relative to the international benchmark set by Codex. This is an indication of over-standardization and protective standards relative to the international standards. However, in the case of oranges, and limes and lemons, as shown in Figures 4.2 and 4.3, the EU standards are only more stringent than those of Codex in 2011 and 2013. There is a significant presence of under-standardization as the stringency is below that of Codex in the other years. In other words, there are indications of protectionism in 2011 and 2013 and antiprotectionism in other years. Thus, the overall impact is an empirical one.

\section{Figure 4.3: Lime and Lemon MRLs}

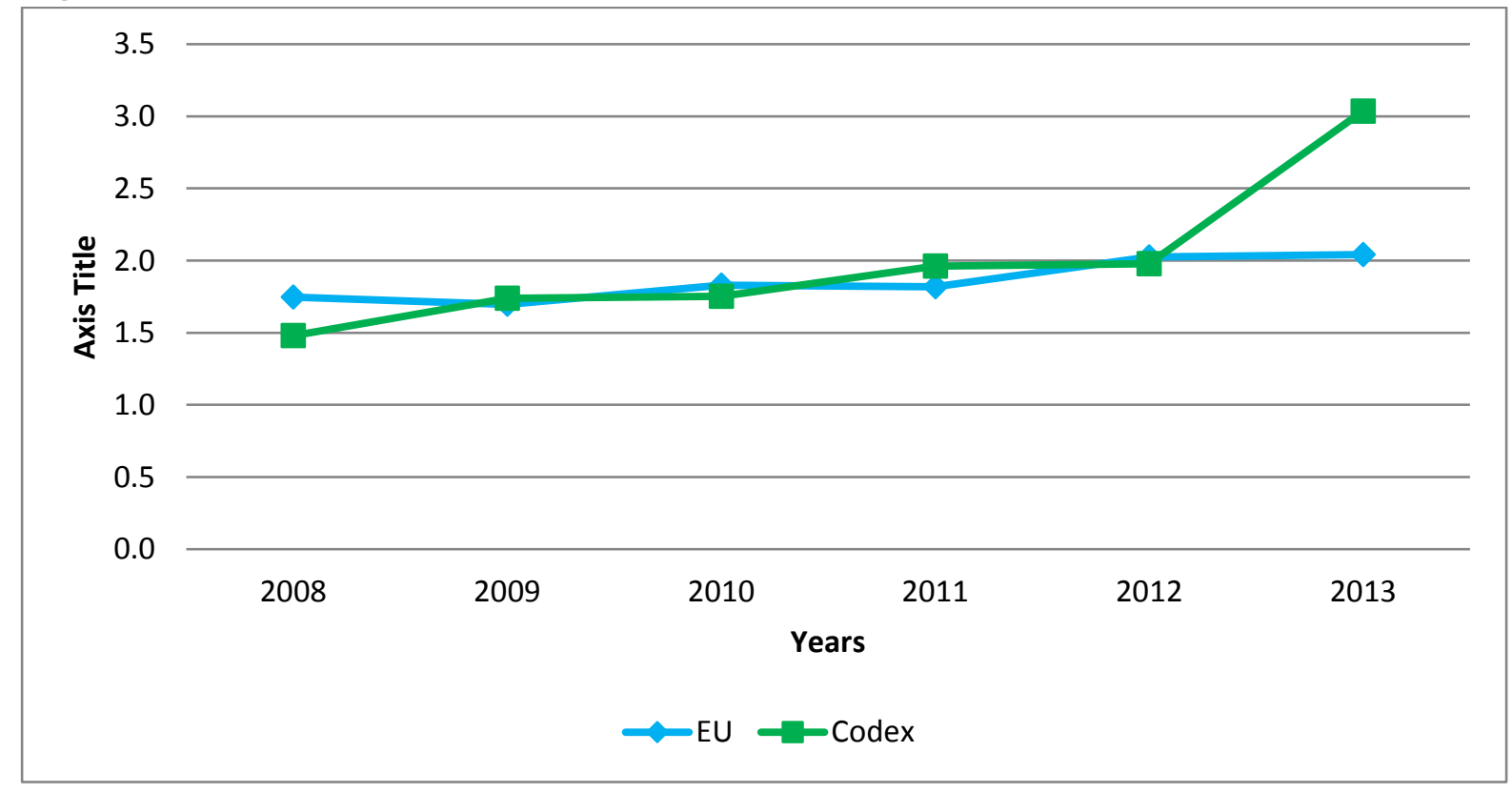

Source: Author's computation from the EU and Codex Databases 
Finally, in Figure 4.4, we depict the protectionism index as formulated in equation (4.1). As noted earlier, an index above one indicating more stringent EU standards relative to those of Codex; an index below one indicates lower stringency of EU standards relative to those of Codex. Clearly, for both oranges, and limes and lemons, the index always lies below one with the exception of 2013, indicating evidence of anti-protectionism for all years apart from 2013. However, in the case of tomatoes, the index lies above the one for all years which might be an indication of protectionism. Whether or not these assertions are true will be empirically ascertained in the next sections.

Figure 4.4: Trend in Protectionism Index

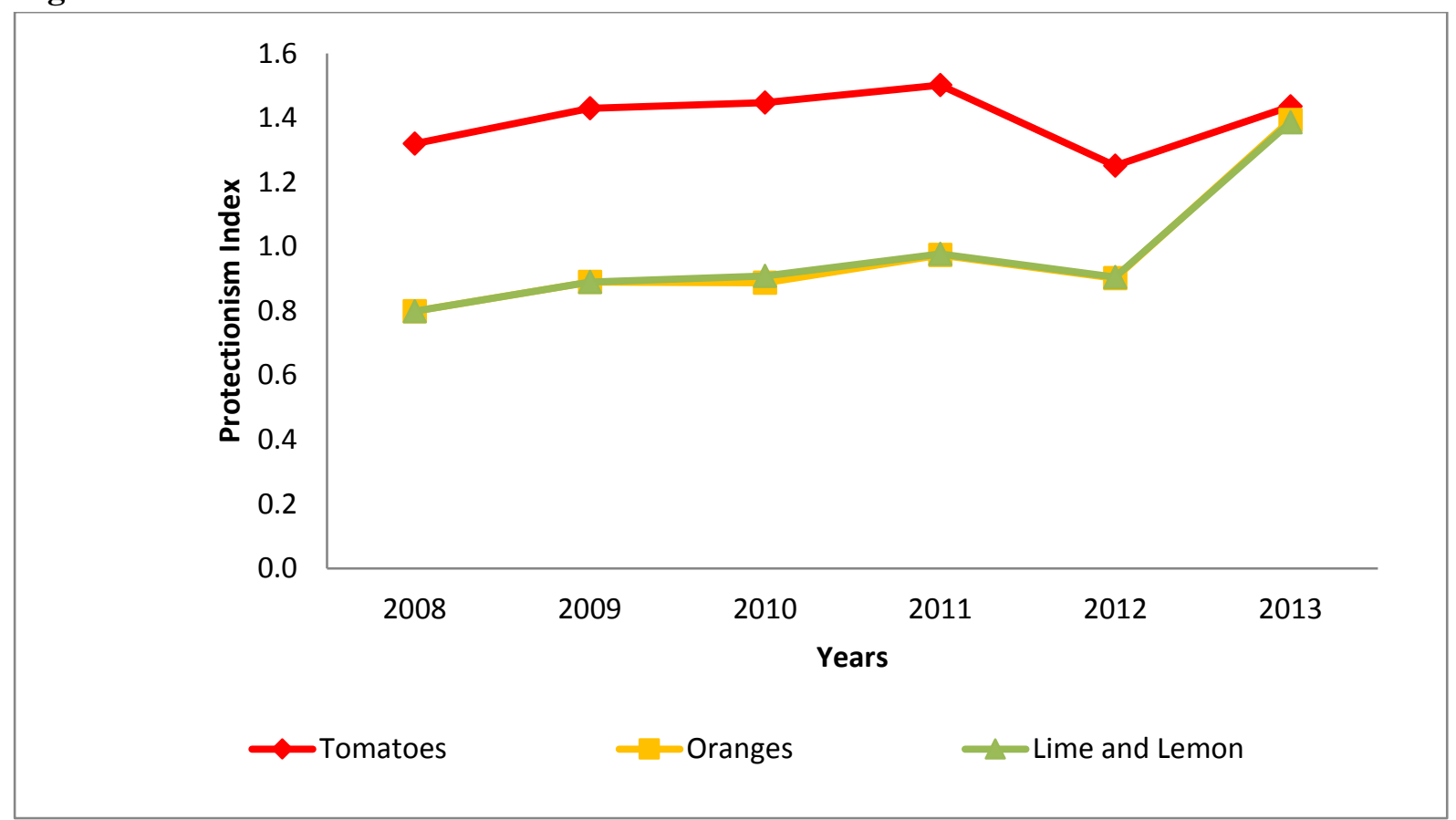

Source: Author's computation

\subsubsection{Structure of EU Production and Trade in the Selected Products.}

The EU is an important importer of fresh fruits and vegetables. It is a net exporter, recording a constant trade deficit in fresh and processed fruits and vegetables since 1999 with the deficit increasing from a value of 8.7 billion euros in 1999 to 11.9 billion in 2011 (EC, 2014). However, trade balance is revealed to be worsening in the fruit sector while it is more or less constant and, at times, slightly improving in the vegetable and processed fruit sectors. This deficit is due to the growth of imports which are uncompensated by EU exports due to the fact that the EU is a marginal producer of tropical fruits and vegetables.

Tables 4.1 and 4.2 show the trend in the production and trade of the products focused on in this study. With regard to citrus, there is a high reliance on imports due to the fact that citrus fruit production in the EU is restricted by unfavourable climatic conditions. A high percentage of citrus fruit production originates in Spain, amounting to around 59.8\% (EC, 2014). In terms of composition, citrus, particularly oranges constitute a top import product for the EU with the top exporters being South Africa, Egypt, and Morocco. South Africa is one of the major 
suppliers of oranges to the EU, supplying the EU market from June until October when the harvest starts in the Northern Hemisphere (Gain, 2015). However, in 2014, there was an 11.5\% decrease in imports from South Africa since May 27, 2014. This followed the European Commission's (EC) increased control measures on South Africa's citrus imports due to the perceived health risks relating to black spot diseases by the European EC. This resulted in decreased orange imports from South Africa.

Table 4.1: Structure of Production of the Selected EU Products, averaged 2008 to 2013

\begin{tabular}{|c|c|c|c|c|c|c|}
\hline & \multirow[b]{2}{*}{$\begin{array}{l}\text { Tonnes } \\
\left({ }^{\circ} 000\right)\end{array}$} & Oranges & \multicolumn{2}{|c|}{ Limes and Lemons } & \multirow[b]{2}{*}{$\begin{array}{l}\text { Tonnes } \\
\left({ }^{6} 000\right)\end{array}$} & \multirow{2}{*}{$\begin{array}{r}\text { Tomatoes } \\
\text { Share in } \\
\text { EU }(\%)\end{array}$} \\
\hline & & $\begin{array}{l}\text { Share in } \\
\text { EU }(\%)\end{array}$ & $\begin{array}{l}\text { Tonnes } \\
\left({ }^{6} 000\right)\end{array}$ & $\begin{array}{l}\text { Share in } \\
\text { EU }(\%)\end{array}$ & & \\
\hline Belgium & 0.0 & 0.0 & 0.0 & 0.0 & 231.0 & 1.5 \\
\hline Bulgaria & 0.0 & 0.0 & 0.0 & 0.0 & 111.3 & 0.7 \\
\hline Czech Republic & 0.0 & 0.0 & 0.0 & 0.0 & 11.5 & 0.1 \\
\hline Denmark & 0.0 & 0.0 & 0.0 & 0.0 & 9.0 & 0.1 \\
\hline Germany & 0.0 & 0.0 & 0.0 & 0.0 & 68.7 & 0.5 \\
\hline Estonia & 0.0 & 0.0 & 0.0 & 0.0 & 1.2 & 0.0 \\
\hline Ireland & 0.0 & 0.0 & 0.0 & 0.0 & 3.1 & 0.0 \\
\hline Greece & 878.4 & 13.2 & 48.3 & 3.9 & 1275.0 & 8.5 \\
\hline Spain & 3098.2 & 46.7 & 712.2 & 57.0 & 4099.5 & 27.3 \\
\hline France & 3.3 & 0.1 & 2.8 & 0.2 & 651.2 & 4.3 \\
\hline Croatia & 0.3 & 0.0 & 0.0 & 0.0 & 20.7 & 0.1 \\
\hline Italy & 2410.6 & 36.4 & 458.7 & 36.7 & 5800.7 & 38.6 \\
\hline Cyprus & 35.9 & 0.5 & 12.9 & 1.0 & 18.1 & 0.1 \\
\hline Latvia & 0.0 & 0.0 & 0.0 & 0.0 & 3.6 & 0.0 \\
\hline Lithuania & 0.0 & 0.0 & 0.0 & 0.0 & 9.0 & 0.1 \\
\hline Luxembourg & 0.0 & 0.0 & 0.0 & 0.0 & 0.1 & 0.0 \\
\hline Hungary & 0.0 & 0.0 & 0.0 & 0.0 & 156.8 & 1.0 \\
\hline Malta & 1.2 & 0.0 & 0.5 & 0.0 & 13.2 & 0.1 \\
\hline Netherlands & 0.0 & 0.0 & 0.0 & 0.0 & 795.0 & 5.3 \\
\hline Austria & 0.0 & 0.0 & 0.0 & 0.0 & 47.3 & 0.3 \\
\hline Poland & 0.0 & 0.0 & 0.0 & 0.0 & 500.9 & 3.3 \\
\hline Portugal & 201.8 & 3.0 & 12.9 & 1.0 & 638.1 & 4.2 \\
\hline Romania & 0.0 & 0.0 & 0.0 & 0.0 & 495.7 & 3.3 \\
\hline Slovenia & 0.0 & 0.0 & 0.0 & 0.0 & 4.3 & 0.0 \\
\hline Slovakia & 0.0 & 0.0 & 0.0 & 0.0 & 18.3 & 0.1 \\
\hline Finland & 0.0 & 0.0 & 0.0 & 0.0 & 39.2 & 0.3 \\
\hline Sweden & 0.0 & 0.0 & 0.0 & 0.0 & 7.5 & 0.0 \\
\hline United Kingdom & 0.0 & 0.0 & 0.0 & 0.0 & 0.0 & 0.0 \\
\hline EU 28 & 6629.8 & 100.0 & 1248.4 & 100.0 & 15030.0 & 100.0 \\
\hline
\end{tabular}

Source: Eurostat 
On the side of production, Table 4.2 shows that between 2008 and 2013, a yearly average of around 6629.8 thousand tonnes of oranges were produced, with Spain, Italy, and Greece accounting for about $96 \%$ of the total production with a share of $46.7,36.4 \%$ and $13.2 \%$ respectively (Table 4.1). During this period, $4 \%$ of production was exported to third countries amounting to around 933 million euros; meanwhile the total import cumulated to a value of about 3007.1 million Euros.

Similar trends also occur for limes and lemons. Between 2008 and 2013, yearly production of limes and lemons totalled an average of 1248.4 thousand tonnes (Table 4.2 ) with $96 \%$ of total production concentrated in Spain (57\%), Italy (36.7\%) and Greece (3.9\%). 5.7\% of the total production of limes and lemons were exported to extra EU countries, representing a yearly value of 59.7 million Euros. Meanwhile, imports were relatively higher at a yearly average value of 380.3 million Euros, amounting to an average yearly trade deficit of 320.6 million Euros. The scenarios for both limes and lemons, and oranges depict the EU as a net importer with a significant trade deficit in each product as the EU relies extensively on imports to satisfy domestic demand. Thus, our hypothesis is that the sector might be less protected. In other words, the EU's heavy dependence on third countries for domestic consumption might undermine the relative influence of lobbyists on the government, and or prompt the government to lower its standards and allow more imports.

Table 4.2: Structure of Trade with Extra EU countries, 2008 to 2013

\begin{tabular}{lll|ll|ll}
\hline & \multicolumn{2}{c|}{ Oranges } & \multicolumn{2}{l|l}{$\begin{array}{l}\text { Limes } \\
\text { Lemons }\end{array}$} & and & \multicolumn{2}{l}{ Tomatoes } \\
& Sum & Average & Sum & Average & Sum & Average \\
\hline Production ('000 tons) & 39778.7 & 6629.8 & 7490.2 & 1248.4 & 90179. & 15,030 \\
& & & & & 8 & \\
Volume Exported ('000 tons) & 1590.1 & 256.0 & 426.1 & 71.0 & 1364.1 & 227.3 \\
\% of Production Exported & 4.0 & 4.0 & 5.69 & 5.69 & 1.5 & 1.5 \\
Imports (Value million EUR) & 3007.1 & 501.2 & 2282.1 & 380.3 & 2247.3 & 374.5 \\
Exports (Value million EUR) & 933.0 & 155.5 & 358.4 & 59.7 & 1668.3 & 278.0 \\
Trade Balance (Value million & -2074.1 & -345.7 & -1923.7 & -320.6 & -579 & -96.5 \\
EUR) & & & & & & \\
\hline
\end{tabular}

Source: Eurostat

The case of tomatoes is somewhat different. It remains the EU's top imported vegetable, constituting the highest share of its fresh vegetables imports, amounting to around one fifth of its vegetable imports (EC, 2014). The EU exports of fresh vegetables is also dominated by tomatoes; however, this is not enough to achieve a trade balance. According to the Eurostat data, major exporters to the EU are Morocco and Egypt, with Morocco supplying about 80\% of EU imports of the product. Unlike citrus products which are mainly tropical fruits, tomatoes are cultivated en masse by some Southern EU countries due to favourable weather conditions. This is complemented by production from all season greenhouses in countries such as Belgium and the Netherlands, reducing an overreliance on imports in contrast to what that seen in the 
cases of oranges, and limes and lemons. The total production between 2008 and 2013 amounts to 90179 thousand tones with major producers accounting for $91 \%$ of production; major producing countries include Italy (38.6\%), Spain (27.3), Greece (8.5\%), France (4.3\%), the Netherlands (5.3\%), Portugal (4.2\%), and Romania (3.3\%). Tomato production is more than twice as large as both orange production, and lime and lemon production with only $1.5 \%$ of it being exported and the rest being consumed domestically. The huge domestic production of tomatoes relative to the other citrus products reduces the need for excessive imports and might explain why the sectors' total trade deficit between 2008 and 2013 of 579 million Euros is far below the deficits for oranges and limes and lemons of 2074 and 1923 million Euros, respectively.

Thus, unlike citrus, the EU is not overdependent on imports to satisfy tomato consumption; as a result, they may yield more to lobbyists who seeks to influence the EC to set stringent standards so as to increase exporters' implementation costs and therefore erode their market competitiveness. However, it is not clear if stringent MRLs set by the EU since 2008 are influenced by lobbyists due to the difficulty of differentiating standards' trade and non-trade objectives. Thus, a testable hypothesis in this study is that protectionism decreases or vanishes altogether with overdependence on imports and vice versa. In other words, for products where the EU heavily (lightly) depends on foreign exported goods for its domestic consumption, under-standardization (over-standardization) can result as the relative influence of lobbyist groups may be weaker (stronger). Thus, we hypothesized that the two selected citrus fruit sectors are under protected due to the heavy import dependence; the tomato sector is hypothesized to be over-protected due to relatively less reliance on imports.

\subsection{Empirical Analysis}

To investigate the protectionist intent of EU food safety standards, we employ the gravity model which predicts that bilateral export between country pairs is explained by exporters' and importers' economic masses; which are a proxy for their income and geographical distance between the country pair as well as some trade factors that increase or inhibit trade (Pöyhönen, 1962; Anderson, 1979; Anderson and Wincoop, 2003).

\subsubsection{Model Specification}

Our empirical strategy is to determine if standards are used as a protectionist tool in restricting trade by focusing on the extensive margin of African exports to the EU. The theoretical model for our analysis is based on firm heterogeneity behaviour; this shows that due to the heterogeneous behaviour of firms, a small fraction of firms finds it profitable to export while others choose not to as they are less productive (Melitz, 2003; Helpman et al., 2008). This thus gives rise to positive and zero trade flows. This is because EU market conditions on food might affect African countries' probability of exporting to the EU, with productive firms exporting and non-productive firms choosing not to export. Our empirical strategy is therefore to measure the effect of EU food regulations on Africa's probability to export. Our model is similar to that of Nicita and Rollo (2015) which analysed the impacts of tariffs on the extensive margin of trade for sub-Saharan exports. Extensive margin is the establishment of new trade relationship 
and can be in forms of exporting to new partners or markets, exporting new products or new varieties to existing markets or new markets (Hummels and Klenow, 2005). Similar to Helpman et al. (2008), our analyses of the extensive margin of trade would be based on the probability of exporting. We employed a probabilistic model to explore the implications of the EU entry price system and food safety standards on the probability of exporting. Moreover, our bilateral export data contain many zeros, thus allowing us to exploit the information contained in the zero trade flows along the extensive margin. Following Helpman et al. 2008, to quantify the trade impacts at the extensive margin, a log-linear probit model is as follows:

$$
\begin{aligned}
& \rho_{i j t}=P\left(E_{i j t}=1 \mid x_{i j t}\right)=\Phi\left(\alpha_{0}+\alpha_{1} \ln Y_{i t}+\alpha_{2} \ln Y_{j t}+\alpha_{3} \text { Initial_Status }_{i j t}\right. \\
& \left.+\alpha_{4} P M_{i j t}+\alpha_{5} \ln \text { Dist }_{i j}+\alpha_{6} \text { Lamg }_{i j}+\alpha_{7} R_{\text {RTA }}+\varepsilon_{i j t}\right)
\end{aligned}
$$

Equation (5) is a probabilistic model which determines the binary decision of whether to trade or not. The subscripts $i, j, t$ denote exporter, importer and time respectively, while $\ln$ is the logarithm. The dependent variable $\rho_{i j t}$ is the probability that country $i$ exports to country $j$ at time $t$, conditional on the observed variables; $E_{i j t}$ is a binary variable which equals one $\left(E_{i j t}=1\right)$ when country $i$ exports to country $j$ and zero when it $\operatorname{does} \operatorname{not}\left(E_{i j t}=0\right)$, where $Y_{i t}$ and $Y_{j t}$ are the importing and exporting countries' GDP respectively, measured in US dollars and sourced from the World Bank's World Development Indicators (WDI). $P M_{i j t}$ describes the average MRLs capturing the extent of protectionism of EU standards relative to Codex standards; this information was obtained from the Europa and Codex Alimentarius Commission websites which estimate separately for tomato, lime and lemon, and orange exports at the sixth digit Harmonized System (HS) product code. Dist $t_{i j}$ denotes the geographical distance between countries $i$ and $j$, obtained from the Centre d'Etudes Prospectives et d'Informations Internationales (CEPII) database. Lang, Col, and RTA are dummy variables that assume the of 1 when the exporting and importing countries share similar language, have colonial ties, or belong to similar trade agreement arrangements, respectively, they take a value of zero otherwise; $\varepsilon_{i j t}$ is the error term. Similar to Nicita and Rollo (2015), we include a proxy of initial export status of the product (initial_status) which is a dummy given the value of one when the export product was successfully exported in the initial period of 2008 (the start of the harmonization of EU food regulations), and zero otherwise. The intuition is that products already exported in the year 2008 have a high probability of being exported in subsequent years. The list of the countries included in the analysis is provided in the appendix

To obtain consistent estimates, we have controlled for multilateral trade resistance, theoretically modelled by Anderson and van Wincoop (2003), using the Baier and Bergstrand ${ }^{33}$ (2010) first order Taylor series approximation of bilateral trade costs using simple averages. For each trade

${ }^{33}$ Their approach also produces estimates that are close to those obtained in the Anderson and van Wincoop (2003) structurally iterated least squares method. 
cost variable, the first order Taylor series is expanded and all the newly demeaned bilateral trade cost variables are transformed using the following approximation:

$$
\left(x_{i j t}\right)_{P_{i} P_{j}}=x_{i j t}-\frac{1}{n} \sum_{j=1}^{n} x_{i j t}-\frac{1}{2} \frac{1}{n^{2}} \sum_{i=1}^{n} \sum_{j=1}^{n} x_{i j t}
$$

Where $P_{i} P_{j}$ is the MRT, $x P_{i} P_{j}$ is the contribution of $x$ to $P_{i} P_{j}, n$ is the number of bilateral observations on exports, and $x$ stands for any of the variables associated with coefficients $\alpha_{3}$ to $\alpha_{7}$ in equation (4.5). The first variable located on the right-hand side of equation (4.6) is the average of all total trade costs incurred by a given exporter from all importers. The second variable on the right-hand side denotes the average of all trade costs faced by the importer from all exporters.

\subsection{Results and Discussion}

Table 4.3 presents the estimates of the extensive margin of EU-African trade. For all products, each gravity variable has the expected signs with the exception of language which is statistically insignificant for tomato exports. Sharing the same language and membership in regional trade agreements with the EU increases Africa's exports at the extensive margin; while physical distance - a proxy of trade costs - inhibits export potential. In addition, for all products, our results point out that the decision whether or not to export to the EU largely depends on whether or not the product was already exported in the initial period (initial_status). In other words, products already exported in 2008 have a high probability of being exported in subsequent years, whether or not the standards are overprotective.

Our variable of interest - which measures the protectionism of pesticide standards, is differently signed across products indicating that the decision to protect a product can be product specific. In the case of tomato exports, the estimated coefficient on the protectionism index is negative and statistically significant; this points to the evidence that EU pesticide standards on tomatoes are actually protectionist as they are more stringent than the international benchmark stipulated by Codex. In essence, the negative coefficient reinforces the fact that they have demand inhibiting effects on potential African exporters, preventing them from establishing trade relationships with the EU and from taking advantage of the preferential access the EU is usually granted to Africa's exports. Thus, the EU might have set very stringent and low pesticide residue limits on tomatoes due to lobbying from consumer groups in a bid to safeguard consumers who do not want to buy organic varieties.

While the tomato sector is relatively less import dependent and is revealed to be over-protected, the case for oranges and limes and lemons is somewhat different. The estimated coefficients on their protectionism index are positive and significant, denoting that EU standards do not have protectionist intent. These EU standards have a demand enhancing effect; they are capable of stimulating new trade relations with the potential to enhance trade for new and potential African exporters targeting EU markets. Given the set of Codex standards considered in this study, the 
corresponding EU standards seem to be less stringent relative to those regulated by Codex. Thus, for these two products, EU pesticide regulations represent legitimate concerns for consumers' health and safety and do not necessarily imply protectionism against imports. Similar results were reported by Xiong and Beghin (2014) for US standards.

\section{Table 4.3: Protectionist Extent of EU Standards Relative to International Benchmarks}

\begin{tabular}{lccc}
\hline & $\mathbf{( 1 )}$ & $\mathbf{( 2 )}$ & $\mathbf{( 3 )}$ \\
VARIABLES & Tomatoes & Limes and Lemons & Oranges \\
\hline Exporter GDP & $0.179^{*}$ & $0.282^{* * *}$ & 0.112 \\
Importer GDP & 0.101 & 0.110 & 0.091 \\
& $0.270^{* *}$ & $0.660^{* * * *}$ & $0.621^{* * *}$ \\
Protectionism Measure & 0.131 & 0.203 & 0.128 \\
& $-1.720^{* * *}$ & $0.750^{* * *}$ & $0.464^{* *}$ \\
Initial_Status & 0.545 & 0.188 & 0.181 \\
& $1.004^{* * *}$ & $0.514^{* * *}$ & $0.556^{* * *}$ \\
Distance & 0.247 & 0.252 & 0.185 \\
& $-3.881^{* *}$ & $-2.980^{* *}$ & $-3.219^{* * *}$ \\
Language & 1.593 & 1.395 & 0.908 \\
& $2.207^{* * *}$ & $2.354^{* * *}$ & $3.689^{* * *}$ \\
RTA & 0.717 & 0.804 & 0.632 \\
& $6.434^{* * *}$ & 0.966 & $1.509^{* *}$ \\
Constant & 2.351 & 1.208 & 0.593 \\
& $-14.525^{* * *}$ & $-27.756^{* * *}$ & $-21.369^{* * *}$ \\
AIC & 4.010 & 5.669 & 4.438 \\
BIC & 585.955 & 551.224 & 668.921 \\
Observations & 631.584 & 597.388 & 713.529 \\
\hline
\end{tabular}

*** $\mathrm{p}<0.01, * * \mathrm{p}<0.05, * \mathrm{p}<0.1$; clustered robust standard errors in parentheses, clustered by importer, exporter and year

One important explanation for aforementioned result was provided by Marette and Beghin (2010) who posited that such anti-protectionism behaviour might occur if producers and exporters from exporting countries are more cost efficient in complying with standards than domestic producers. However, in the case of African countries, this explanation is less tenable as many of them cannot meet selected standards set by the EU due to a lack of financial, technical and qualified labour (Jaffee and Henson, 2004; Henson and Wilson, 2005). A much more reasonable explanation for this result is that domestic policymakers in the EU may choose a relatively lower standard than an international social planner; this could serve to explain in part the observed results. For instance, compared to tomatoes, the EU are heavily dependent on third countries' citrus fruits for domestic consumption and processing. Due to the large numbers of imports and heavy dependence on foreign exported citrus for domestic juice production, the relative influence of lobbyists might be weaker on the government such that the government might be prompted to lower standards to allow more imports. 
Thus, our results support the hypothesis that protectionism decreases or altogether vanishes with overdependence on imports and vice versa. In other words, unlike tomatoes, the EU has no comparative advantage in the producing citrus due to unfavourable weather conditions; instead they depend heavily on imports to satisfy the domestic consumption of these fruits and thus, might be less yielding to lobbyists who seek to influence the EC to set stringent standards. This might even give rise to under-standardization in order to allow more imports.

As a further step, we investigate the assertions that many developed countries resorted to the usage of protectionist NTMs both during and after the financial crisis (Bown, 2011; Datt et al., 2011; OECD, 2010). Thus, to ascertain if this occurred in the case of standards, we have divided our dataset into the crisis period (2008 to 2009) and the post-crisis period (2010 to 2013). Table 4.4 presents the estimates from both the financial and post-financial crisis periods.

Table 4.4: Extent of Protectionism during and after the 2008/2009 Financial Crisis.

\begin{tabular}{|c|c|c|c|c|c|c|}
\hline & \multicolumn{3}{|c|}{ Crisis Period } & \multicolumn{3}{|c|}{ Post Crisis Period } \\
\hline & Tomatoes & $\begin{array}{l}\text { Limes } \\
\text { and } \\
\text { Lemons }\end{array}$ & Oranges & Tomatoes & $\begin{array}{l}\text { Limes } \\
\text { and } \\
\text { Lemons }\end{array}$ & Oranges \\
\hline & (1) & $(2)$ & (3) & (5) & (6) & (7) \\
\hline \multirow[t]{2}{*}{ Exporter GDP } & 0.051 & $0.508^{*}$ & -0.028 & 0.118 & $0.269^{* *}$ & 0.076 \\
\hline & $(0.294)$ & $(0.268)$ & $(0.137)$ & $(0.101)$ & $(0.117)$ & $(0.097)$ \\
\hline \multirow[t]{2}{*}{ Importer GDP } & -0.067 & $1.179^{* * *}$ & $0.680^{* * *}$ & $0.298^{* *}$ & $0.786^{* * *}$ & $0.668^{* * *}$ \\
\hline & $(0.248)$ & $(0.455)$ & $(0.256)$ & $(0.141)$ & $(0.268)$ & $(0.150)$ \\
\hline \multirow{2}{*}{$\begin{array}{l}\text { Protectionism } \\
\text { Measure }\end{array}$} & 4.165 & $11.153^{* * *}$ & $4.636^{*}$ & $-1.741^{* * *}$ & $0.563^{* * *}$ & 0.173 \\
\hline & $(2.769)$ & $(3.395)$ & $(2.480)$ & $(0.533)$ & $(0.218)$ & $(0.196)$ \\
\hline \multirow[t]{2}{*}{ Initial_Status } & $4.769^{* * *}$ & $3.981^{* * *}$ & $2.996^{* * *}$ & 0.443 & -0.237 & -0.103 \\
\hline & $(1.463)$ & $(0.361)$ & $(0.647)$ & $(0.289)$ & $(0.352)$ & $(0.254)$ \\
\hline \multirow[t]{2}{*}{ Distance } & -7.726 & $-4.856^{* *}$ & $-3.886^{* *}$ & $-4.352^{* *}$ & $-4.749^{*}$ & $-3.490^{* * *}$ \\
\hline & (4.954) & $(2.021)$ & $(1.658)$ & $(1.720)$ & $(2.737)$ & $(0.935)$ \\
\hline \multirow[t]{2}{*}{ Language } & 7.103 & $2.931^{*}$ & $4.683^{* * *}$ & $2.024^{* * *}$ & $2.925^{* * *}$ & $3.851^{* * *}$ \\
\hline & $(4.625)$ & $(1.599)$ & $(1.286)$ & $(0.708)$ & $(1.105)$ & $(0.721)$ \\
\hline \multirow[t]{2}{*}{ RTA } & 0.104 & -0.053 & -0.011 & -4.277 & $3.277^{*}$ & 4.507 \\
\hline & $(0.640)$ & $(1.601)$ & $(0.575)$ & $(3.892)$ & $(1.934)$ & $(6.451)$ \\
\hline \multirow[t]{2}{*}{ Constant } & -5.694 & $-47.358^{* * *}$ & $-19.974^{* *}$ & $-13.354^{* * *}$ & $-31.530^{* * *}$ & $-21.724^{* * *}$ \\
\hline & $(5.764)$ & $(11.127)$ & $(8.052)$ & $(4.000)$ & $(7.852)$ & (4.992) \\
\hline AIC & 157.364 & 160.647 & 208.740 & 472.893 & 424.425 & 504.660 \\
\hline $\mathrm{BIC}$ & 193.105 & 196.924 & 243.462 & 514.873 & 466.939 & 545.620 \\
\hline Observations & 392 & 416 & 350 & 784 & 832 & 700 \\
\hline
\end{tabular}


For the financial period, our estimated results as reported in the first three columns of Table 4.4 refute the claim that standards on tomatoes and two selected citrus fruits were used as protectionist tools during the financial crisis. Indeed, the positive coefficients on the protectionism index indicate that more of these export products have been allowed access into the EU market during the financial crisis. This result supports that of the WTO report of 2009 which finds that none of its Member states have resorted into a widespread usage of trade protectionism or trade restrictions; furthermore, there was no evidence of any significant occurrences of trade retaliation (WTO, 2009) during the global financial crisis. Similar result was obtained by Hoekman (2012) who also affirm that there was no substantial rise in the level of trade protection during the financial crisis. However, during the period of the post-financial crisis, the last three columns of Table 4.4 show the estimated coefficients of the protectionism measure to be statistically significant and negatively signed for all the products, inferring that food safety standards were more protective in the post financial period. These results confirm those of Hoekman (2012) who find that there has been a strong wave of trade protectionism in many developed countries after the crisis.

\subsubsection{Robustness Check}

We checked the robustness of our results to an alternative estimation technique. We have previously employed a probabilistic model to investigate the extent of protection on Africa's binary export decision of whether to trade with the EU or not. However, while it is true that the decision not to export (and the consequential occurrence of zeros in export flows to the EU) by many of these exporting countries might be in part attributable to over-protective standards, it may also be due to the statistical recording format. For instance, we have used the United Nations Commodity Trade (UN COMTRADE) statistical database of the United Nations Conference on Trade and Development (UNCTAD); some literature has reported that export values that are below a certain threshold are rounded down and are thus recorded as zeros (Frankel, 1997). If some of the zeros in our data are due to this statistical recording format, this implies that some of the export data has been censored below zero.

Being censored below zero might imply that some of the actual trade flow observations were not included in the trade matrix or have been recorded as zeros as they fell below a minimum predetermined threshold. In the case of predetermined thresholds, this implies that any trade flow value that is less than a certain predetermined threshold might have been recorded as zero, while other observations that are equal to or greater than the threshold might have been recorded as their actual values.

Thus, as a robustness check, we used the Tobit model which is well suited to deal with such situations. The results using the Tobit model are presented for the three datasets as shown in Table 4.5. The new results are in conformity to our previous results. Remarkably, as shown by the results, even if some of the zeros in the data are as a result of statistical zeros and not because of the inability to meet the standards (true zeros), the basic conclusions of the results that were obtained in Table 4.3 remain the same, indicating that the previous results are robust even with the presence of statistical zeros. 
Table 4.5: Robustness to a Different Estimation Technique - using Tobit Model

\begin{tabular}{lccc}
\hline & $(1)$ & $(2)$ & $(3)$ \\
& Tomatoes & $\begin{array}{c}\text { Limes and } \\
\text { Lemons }\end{array}$ & Oranges \\
\hline Importer GDP & $0.130^{*}$ & $0.167^{* * *}$ & 0.080 \\
Importer GDP & $(0.076)$ & $(0.064)$ & $(0.049)$ \\
& $0.217^{*}$ & $0.412^{* * *}$ & $0.345^{* * *}$ \\
Protectionism Measure & $(0.113)$ & $(0.140)$ & $(0.075)$ \\
& $-1.080^{* * *}$ & $0.410^{* * *}$ & $0.245^{* *}$ \\
Initial_Status & $(0.351)$ & $(0.126)$ & $(0.107)$ \\
& $0.544^{* * *}$ & $0.289^{* *}$ & $0.249^{* * *}$ \\
Distance & $(0.127)$ & $(0.125)$ & $(0.092)$ \\
& $-2.619^{*}$ & -1.835 & $-1.748^{* * *}$ \\
Language & $(1.374)$ & $(1.184)$ & $(0.664)$ \\
& $1.375^{* * *}$ & $1.427^{* * *}$ & $1.875^{* * *}$ \\
RTA & $(0.457)$ & $(0.516)$ & $(0.239)$ \\
& $5.732^{* * *}$ & 0.590 & 0.560 \\
Constant & $(1.720)$ & $(1.812)$ & $(1.345)$ \\
& $-10.970^{* * * *}$ & $-17.087^{* * *}$ & $-12.275^{* * *}$ \\
AIC & $(3.455)$ & $(3.553)$ & $(2.416)$ \\
BIC & 855.295 & 816.519 & 1050.102 \\
Observations & 905.994 & 867.812 & 1099.668 \\
\hline
\end{tabular}

Clustered robust standard errors are in brackets and $* \mathrm{p}<0.10 ; * * \mathrm{p}<0.05 ; * * * \mathrm{p}<0$.

Remarkably, even if some of the zeros in the data are as a result of statistical zeros and not because of the inability to meet the standards (true zeros), the basic conclusions of the results that were obtained in Table 4.3 remain the same, indicating that the previous results are robust even with the presence of statistical zeros.

\subsection{Conclusion}

This study provides some first empirics on the extent of protectionist intent of EU standards relative to those of Codex which serve as the international benchmark recommended by the WHO and FAO. Using a sample of African countries, EU tomato standards are found to exhibit protectionist tendencies as they are more stringent than their Codex counterpart. However, in the case of oranges, and limes and lemons, these fruits exhibit anti-protectionist tendencies on firms' decisions to export; this points to the indication that EU pesticide regulations may be aimed solely at addressing legitimate concerns for human health and safety and do not necessarily address protectionist concerns. Our results show that tomatoes represent a relatively less import dependent sub-sector which is over-protected; meanwhile oranges and limes and lemons represent heavily import dependent food sub-sectors and are under-protected. Thus, our results support the hypothesis that protectionism vanishes with overdependence on imports and vice versa. The implication of our findings highlights the fact that importing countries' 
standards are not always protectionist and can at times be anti-protectionist relative to internationally acceptable standards. In other words, standards are not necessarily always problematic or protectionist as widely portrayed in the literature. The protectionist intent of a standard is product specific, indicating that the decision to either protect health or not to protect it is product specific.

Despite the fact that the EU sets one of the strictest collection of standards in the world and international standards like Codex have been posited as those that maximize global social welfare, EU standards are not always the more stringent of the two nor is it always the case that they are trade inhibiting. Thus, a caveat is worth mentioning: although we found international standards to at times have a weaker trade enhancing effect than domestic standards, this is not to say that countries should refrain from the usage of globally acceptable standards as recommended by the WTO. Clearly more research is needed in this direction with extensions to other product lines and importing countries.

Conclusively, from a policy point of view, an important policy implication of our findings is that overly protective standards can have huge trade inhibiting effects on developing countries. Although many African countries are in RTAs with the EU, standards make market access penetration conditional, as most of the existing RTAs are negotiated on the basis of reduced tariffs and not on the transfer of technical or financial resources to increase conformity to standards. Thus, increased capacity building and transfer of technology would be a welcome policy if the numerous RTAs that the EU has with Africa are to help in achieving the continent's developmental goals. Consequently, even if standards are used as a protectionist tool, the effect might be dampened for these countries.

\section{References}

Anderson, J. (1979). A theoretical foundation for the gravity equation. The American Economic Review, 69(1), 106-116.

Anderson, J., and Van Wincoop, E. (2003). Gravity with gravitas: A solution to the border puzzle. American Economic Review, 93(1), 170 - 192.

Anderson, K., Damania, R., and Jackson, L. (2004). Trade, standards, and the political economy of genetically modified food. World Bank Policy Research Working Paper 3395. Washington DC: The World Bank.

Baier, S. L., and Bergstrand, J. H. (2010). Approximating general equilibrium impacts of trade liberalizations using the gravity equation. In P. A. G. van Bergeijk and S. Barkman (Eds.), The gravity model in international trade. advances and applications (1st ed., pp. 88-134). Cambridge: Cambridge University Press.

Baldwin, R. (1970). Nontariff distortions of international trade. Washington, DC: Brookings Institution.

Baldwin, R. (2000). Regulatory protectionism, developing nations and a two-tier world trading system. In S. Collins and D. Rodrik (Eds.) Brookings Trade Forum. Washington, DC: Brookings Institution.

Bown, C. P. (2011). The great recession and import protection: the role of temporary trade 
barriers. London: Centre for Economic Policy Research and the World Bank.

Datt, M., Hoekman, B., and Malouche, M. (2011). Taking stock of trade protectionism since 2008. Economic Premise, 72, 1-9

Dee, P. S., and Ferrantino, M. J. (eds.) (2005). Quantitative methods for assessing the effects of non-tariff measures and trade facilitation. Singapore: Asia-Pacific Economic Cooperation (APEC) and World Scientific. Introductory chapter, pp. 13-41

Disdier, A.C., Fontagné, L., and Mimouni, M. (2008). The impact of regulations on agricultural trade: Evidence from the SPS and TBT agreements. American Journal of Agricultural Economics, 90(2), 336-350.

Ferro, E., Otsuki, T., and Wilson, J. S. (2015). The effect of product standards on agricultural exports. Food Policy, 50, 68-79.

Fischer, R., and Serra, P. (2000). Standards and protection. Journal of International Economics, 52(2), 377-400.

Fontagné, L., Orefice, G., Piermartini, R., and Rocha, N. (2015). Product standards and margins of trade: Firm-level evidence. Journal of International Economics, 97(1), 29-44.

Frankel, J. A. (1997). Regional trading blocs in the world economic system. Washington DC: Institute for International Economics.

Gandal, N., and Shy, O. (2001). Standardization policy and international trade. Journal of International Economics, 53(2), 363-383.

Gebrehiwet, Y., Ngqangweni, S., and Kirsten, J. F. (2007). Quantifying the trade effect of sanitary and phytosanitary regulations of OECD Countries on South African food exports. Agrekon, 46(1), 1-17.

Grossman, G. M., and Helpman, E. (1994). Protection for sale. American Economic Review, 84(4), 833-850.

Helpman, E., Melitz, M., and Rubinstein, Y. (2008). Estimating trade flows: trading partners and trading volumes. Quarterly Journal of Economics, 123(2), 441-487.

Henson, S., and Wilson, J. S. (2005). The WTO and technical barriers to trade. Cheltenham: Edward Elgar Publishing Inc.

Hoekman, B. (2012). Trade Policy: So Far So Good? There was no widespread resort to protectionism during the global crisis but there have been recent moves in that direction. Finance and Development, 49(2), 17.

Hummels, D., and Klenow, P. J. (2005). The variety and quality of a nation's exports. American Economic Review, 95(3), 704-723.

Jaffee, S. M., and Henson, S. (2004). Standards and agro-food exports from developing countries: rebalancing the debate. World Bank Policy Research Working Paper 3348. Washinton DC: The World Bank

Li, Y., and Beghin, J. C. (2014). Protectionism indices for non-tariff measures: An application to maximum residue levels. Food Policy, 45, 57-68.

Linders, G.J. M., and De Groot, H. L. F. (2006). Estimation of the gravity equation in the presence of zero flows. Mimeo, 1-26.

Maertens, M., and Swinnen, J. (2007). Standards as barriers and catalysts for trade, growth, and poverty reduction. Journal of International Agricultural Trade and Development, 4(1), 47-61. 
Marette, S., and Beghin, J. (2010). Are standards always protectionist? Review of International Economics, 18(1), 179-192.

Melitz, M. J. (2003). The impact of trade on intra-industry reallocation and aggregate industry productivity: A comment. Econometrica, 71(6), 1695-1725.

Nicita, A., and Rollo, V. (2015). Market access conditions and sub-Saharan Africa's exports diversification. World Development, 68, 254-263.

Otsuki, T., Wilson, J. S., and Sewadeh, M. (2001). Saving two in a billion: quantifying the trade effect of European food safety standards on African exports. Food Policy, 26(5), 495 514.

Pöyhönen, P. (1963). A Tentative Model for the Volume of Trade between Countries. Weltwirtschaftliches Archiv, 90, 93-100.

Reis, J. G., and Farole, T. (2012). Trade competitiveness diagnostic toolkit. Washington, DC: World Bank. Retrieved from https://openknowledge.worldbank.org/handle/10986/2248 [Accessed September, 2015].

Sheldon, I. M. (2013). North-South trade and standards: What can general equilibrium analysis tell us? World Trade Review 11(3), 376-89.

Shepherd, B., and Wilson, N. L. W. (2013). Product standards and developing country agricultural exports: The case of the European Union. Food Policy, 42, 1-10.

Sturm, D. M. (2006). Product standards, trade disputes, and protectionism. Canadian Journal of Economics, 39(2), 564-581.

Swinnen, J. F. M., and Vandemoortele, T. (2011). Trade and the political economy of food standards. Journal of Agricultural Economics, 62(2), 259-280. (2012). Trade and the political economy of standards. World Trade Review, 11(3), 390400.

Tian, H. (2003). Eco-labelling scheme, environmental protection, and protectionism. Canadian Journal of Economics/Revue Canadienne d Economique, 36(3), 608-633.

WTO. (2009). Report on G20 trade and investment measures. Geneva: World Trade Organization (WTO). Retrieved from http://www.oecd.org/daf/inv/investmentpolicy/43689944.pdf [Accessed 14 December, 2015)

Xiong, B., and Beghin, J. (2014). Disentangling demand-enhancing and trade-cost effects of maximum residue regulations. Economic Inquiry, 52(3), 1190-1203. 


\section{Appendix}

Table A4.1: List of Countries in the Tomato Dataset

\begin{tabular}{ll}
\hline Country Groups & \multicolumn{1}{c}{ Members } \\
\hline Importers (EU) & Belgium, France, Germany, Luxembourg, Netherlands, Portugal, Spain \\
\hline Exporters (Africa) & Algeria, Angola, Cape Verde, Comoros, Democratic Republic of Congo, Côte \\
& d'Ivoire, Egypt Arab Republic, Equatorial Guinea, Gabon, The Gambia, \\
& Ghana, Guinea-Bissau, Kenya, Liberia, Mauritania, Morocco, Nigeria, Sao \\
& Tome and Principe, Senegal, Sierra Leone, South Africa, Togo. \\
\hline
\end{tabular}

Table A4.2: List of Countries in the Lime and Lemon Dataset

\begin{tabular}{ll}
\hline Country Groups & \multicolumn{2}{c}{ Members } \\
\hline Importers (EU) & France, Italy, Luxembourg, Netherlands, Poland, Portugal, Spain \\
\hline Exporters (Africa) & Algeria, Angola, Benin, Cape Verde, Congo Republic, Côte d'Ivoire, \\
& Djibouti, Equatorial Guinea, Gabon, Ghana, Liberia, Madagascar, \\
& Mauritania, Morocco, Nigeria, Sao Tome and Principe, Senegal, Sierra \\
& Leone, South Africa \\
\hline
\end{tabular}

Table A4.3: List of Countries in the Oranges Dataset

\begin{tabular}{|c|c|}
\hline Country Groups & Members \\
\hline Importers (EU) & Belgium, France, Italy, Malta, Netherlands, Portugal, Spain \\
\hline Exporters (Africa) & $\begin{array}{l}\text { Algeria, Angola, Benin, Cape Verde, Chad, Democratic Republic of Congo, } \\
\text { Congo Republic, Côte d'Ivoire, Egypt Arab Republic, Equatorial Guinea, } \\
\text { Gabon, The Gambia, Ghana, Guinea-Bissau, Liberia, Madagascar, Mali, } \\
\text { Mauritania, Morocco, Nigeria, Sao Tome and Principe, Senegal, Sierra Leone, } \\
\text { South Africa, Togo. }\end{array}$ \\
\hline
\end{tabular}




\title{
Chapter 5
}

\section{What drive Africa's Inability to Comply with Standards? Evidence from the EU Border Rejection Data}

\begin{abstract}
African exports have been rejected a number of times at the European Union (EU) borders because of their non-compliance with EU food safety standards. This paper therefore investigates the causes of the rejections of African exports at the EU borders. Our results indicate that natural geographical hurdle, poor trade-related infrastructure, inefficient border procedures and a lack of technical personnel increase the incidences of rejection at the EU border and add to Africa's challenges in accessing EU markets. In addition, in line with the growing literature, this study finds empirical support for the proposition that institutions, infrastructure and logistic quality matters for increased market penetration and continuous integration into the global trading system. Thus, the barrier created by EU rejection of Africa's exports can be addressed through the strengthening of African's institutions and trade facilitations measures particularly her custom and border management including transit regimes.
\end{abstract}

Keywords: Entry barrier, Food safety measure, SPS conformity assessment, Export rejections, Institution, Trade and border procedures, Africa, European Union

JEL Classification: F13 F14 L15 017 C33

\subsection{Introduction}

Since the Doha round ${ }^{34}$, there has been a continuous drop in tariffs. This is supposed to result in increased trade for African countries, many of whom enjoy preferential access to their trading partners such as the Everything but Arm (EBA) in the European Union and Africa Growth and Opportunity Act (AGOA) in the United States, among several other arrangements. However, with the fall in tariffs comes the shift of many countries from tariff to non-tariff barriers which prove to be more inhibitive than tariff and can also be used as a disguised form of protectionism, thereby constituting an unnecessary barrier to Africa's trade. Indeed, these non-tariff barriers (NTBs) might offset any potential benefits of enhanced market access given by the EU to most African countries, especially the preferential tariffs, by significantly damp ening gains from trade.

\footnotetext{
${ }^{34}$ This is one of the most recent rounds of trade negotiations among WTO member states. The round was launched in 2001 with the major aim of improving the trade prospects of developing countries through the lowering of trade barriers and revisions to trade rules.
} 
In particular, among the NTBs, food safety standards have been found to constitute a more significant barrier to developing countries export especially because of the high costs of complying with them (Unnevehr, 2003; Gourdon and Nicita, 2013; Shepherd and Wilson, 2013). These measures are aimed at achieving health and safety in food for the consumers, thus conformity assessments are usually undertaken to determine if exporting countries comply to such food safety requirements. Such conformity assessment procedures include certification and accreditation of the product, testing a sample of the product to ascertain if it conforms to specified requirements, pre-inspection of the product at the home country, and lastly, inspection of the product at the border. Thus, compliance to such measures is required for both domestic products and third countries' exports, since the measures are applied on an MFN basis, and guarantees market access. However, non-compliance can lead to serious actions being taken against defaulting exporting countries such as outright banning or import rejections. For instance, in the European Union (EU), there has been a significant number of border refusals of food imports by the EU due to non-compliance of exporting countries with EU food safety standards, amounting to about 9233 rejections between 2008 and 2013 (RASFF, 2014).

Violation of the food safety requirements is the primary reason for border rejections of third countries' exports to the EU. More so, violation is usually committed by developing countries who have limited institutional and technical capacity to comply with EU standards. Africa accounts for about $30 \%$ of the total violations of EU food standards, with about 600 cases of African shipments being refused entry into the EU at the border between 2008 and 2013. The huge number of import rejections implies that non-compliance to EU standards represents an important market access problem for Africa. The consequences of these import bans and border restrictions can be enormous and extremely costly. The costs of rejections at the border includes loss of the exported goods which are usually destroyed by the importing country, loss of transportation costs, loss of costs due to freight and insurance, and other related costs. In addition to the immediate reduction in earnings from exports, rejections also damage the affected country's reputation and reduce its export competitiveness in the long-run (Baylis, et al., 2009).

Numerous authors have pointed out that the reasons for the inability of African countries to benefit from trade cannot be totally attributed to the trade inhibiting effects of such standards. Major contributory factors for the continent's trade performance have been linked to their domestic supply constraints resulting from their limited productive capacity to produce (Xiong and Beghin, 2011) and the lack of the institution needed to ensure compliance with importing countries' standards (Kim and Reinert, 2009). However, others have attributed it to Africa's poorly developed trade facilitation ${ }^{35}$, particularly in the key areas of infrastructure, customs and border procedures, as well as transportation and communication. These factors have been said to constitute much more of a barrier to Africa's integration in the global trading system (Iwanow and Kirkpatrick, 2009; Djankov, et al., 2010; Freud and Rocha, 2011; and Portugal-Perez and

\footnotetext{
${ }^{35}$ According to the WTO's definition, trade facilitation is defined as "the simplification, modernisation and harmonization of export and import processes" (WTO, 2015, p. 33) and "addresses the logistics of moving goods through ports or more efficiently moving customs documentation associated with cross-border trade" (Wilson et al., 2005, p. 842).
} 
Wilson, 2012). In fact, Africa's competitive advantage in terms of its abundance of agricultural resources and relatively low labour costs could easily be lost through inefficient logistics and poorly developed trade facilitations. In addition, these barriers might offset any potential benefits of the enhanced market access given by the EU to most African countries, especially the preferential tariff and quota, thereby significantly dampening gains from trade. Empirical evidence and detailed specificity about these factors are therefore needed to build a strong case for comprehensive long term reform. It is on the basis of this that this paper is motivated.

Our paper contributes to the literature on non-tariff measures (NTMs), an area that is currently under-researched in Africa. While most of the existing literature have analysed the implications of food safety standards on trade flows (Otsuki et al., 2001; Xiong and Beghin, 2014; Disdier, et al., 2015; Ferro, et al., 2015), fewer studies have examined at the impact of enforcement of food safety regulations on trade flows (Baylis et al., 2010; Grundke and Moser, 2014). The literature has, however, overlooked the factors triggering non-compliance with importing countries' standards which results in their inability to export safe and healthy products. This study uses the number of rejections of unsafe food exports from Africa at the EU border as a measure of EU enforcement of its food safety regulations and as a measure of the assessment (non)conformity with its food safety standards. We also investigate the extent to which domestic factors are contributing to such non-compliance. A similar approach of measuring compliance to importing countries' food safety standards was employed by Baylis et al. (2009) who used the incidences of EU border rejection to measure compliance. More recently, Jouanjean, et al. (2012) used data on US border rejections ${ }^{36}$. However, these studies did not explicitly focus on Africa which is the focal point of this study. We use a similar approach to these studies by measuring compliance to food safety standards using border rejections, but instead focus on the most often rejected categories of African exports, namely fish and fish products, fruits and vegetables, and nuts and nut products. These products represent about $70 \%$ of all products rejected at the EU border.

Our objective is to investigate the extent to which domestic factors in each African country are inhibiting their ability to comply with EU food safety standards. To achieve this objective, firstly, we investigate the impact played by economic and geographical factors in affecting border rejection. Secondly, we proceed by also considering the impact of trade related infrastructure, trade procedures and institutions which might also be responsible for the incidences of border rejections. Most African countries have poorly developed institutions and infrastructures, so this might be a triggering factor responsible for such rejections. While there is an extensive body of studies which support the notion that institution and the strengthening of trade facilitation infrastructure are a catalyst for trade, to what extent such factors help in attenuating the trade inhibiting effects of food safety standards has rarely been investigated in the literature. One exception is that of Kim and Reinert (2009), who focused explicitly on

\footnotetext{
${ }^{36}$ Baylis et al. (2009) investigated the factors that drive the refusals of third countries' exports by the USA using products and country-pairs that have recently been a target of refusal by the EU. They find that increased EU rejections of third countries' exports are associated with trade protection concerns within the importing country, perceived risk level of the export product, and countries with a long-standing reputation of violating US food safety standards. More recently, Jouanjean et al. (2012) investigate the importance of reputation in driving border rejections using US import refusal data. They find that exporter, sector or product, and nearest neighbours with a previous reputation of noncompliance with US food regulation increases the chances of being refused entry into the US market.
} 
institutions. Our study therefore makes two unprecedented contributions to the literature. First, this represents the first study to link the factors responsible for the EU's rejection of African exports to trade facilitation measures and existing domestic institutions such as country level corruption and domestic regulatory policies. Secondly, to the best of our knowledge, this work remains the first among its kind to empirically investigate the factors responsible for the noncompliance to EU standards and border rejection of African exports by the EU. Thus, its importance in aiding informed policies on enhancement of market access for the continent cannot be overlooked.

We proceed by estimating count data models with panel data to examine the determinants of compliance to EU standards by African countries between 2008 and 2013. Our major findings are that border rejections are affected not only by geographical distance, but more importantly by Africa's dilapidating trade infrastructure, cumbersome customs procedures and weak domestic institutional conditions.

The rest of the study is organised as follows. Section 5.2 provides the background on compliance with EU food safety standards by African countries. Section 5.3 provides the methodology of the study and the empirical results are presented in Section 5.4. The last section concludes with our findings.

\subsection{EU Food Safety Standards and Its Conformity Assessment}

In this section, we analyse EU assessment of compliance to its safety standards in terms of the border rejection of non-complying countries' exports along with the reasons for such rejections in order to determine the implications of non-compliance on export success.

\subsubsection{Reasons behind EU Border Rejection of Feed and Food}

Standards are set with the aim of achieving high levels of sanitary and health protection for consumers. Compliance with such standards are usually strictly monitored, particularly by developed countries. In the EU, conformity assessment of exports takes place also at its border through border inspections and food products that do not meet its stipulated food and feed standards are usually refused entry into its borders. Thus, the EU typically enforces its standards on third countries through its rejection of non-complying countries' exports. The EU food standards enforcement was made possible by the EU's Rapid Alert System for Food and Feed (RASFF) in which the EU maintains notifications about violations and potential violations of feed and food products by both EU and third countries. Established in 1979 and subsequently given a legal basis by EC regulation 178/2002, this system enables a swift reaction to food of potential risk to public health that is detected in the food chain. The ultimate aim of the system is to ensure that food products are safe for the consumers. The system enables the maintenance of one of the highest standards in the world, by serving as a tool in enabling food and feed control authorities to efficiently exchange information about potential food risks and measures that were taken in response to the risks. This is done through its 24-hour services which ensure that all urgent notifications about food safety risks are sent out, received, rapidly coordinated and acted on by Members states in a coordinated way, thereby averting many food risks for European consumers. 
In the EU, depending on the perceived risks, enforcement of such standards is via three avenues: alerts, information and border rejection. There are alerts being circulated about the potential risks of the feed or food products that are already in circulation in one or more member countries, in which case the products not complying with the set standards are withdrawn from the market. Information is given about the potential risks from products which are not yet in a members' market at the time of notification, or whose risks are not considered very serious. High risk export products coming into member markets are subjected to border rejection. Other food and feed safety information that are cannot be notified border rejections, alert or as information are presented as news. Border rejection notifications are the focus of this paper, as they are usually issued when food products are perceived to represent the greatest food safety risks. Border rejection notifications "concern[s] consignment of food, feed or food contact material that was refused entry into the Community for reason of a risk to human health and also to animal health or to the environment if it concerns feed" (RASFF, 2014, p. 37). Thus, non-compliance usually leads to import refusals at the border or import detention and destruction.

Major reasons for EU border rejections of third countries' exports between 2008 and 2013 in order of importance are given in Table 5.1. These span the violation of various standards requirements in the food sector such as the violation of the acceptable maximum residual limits of mycotin and pesticides residues regulations, migration of substances, presence of pathogenic micro-organisms, etcetera.

Table 5.1: Reasons for EU Rejection of Food and Feed, 2008 to 2013

\begin{tabular}{lcc}
\hline Hazard & $\mathbf{2 0 0 8 - 2 0 1 3}$ & Share in Total (\%) \\
\hline Mycotin & 1827 & 18.91 \\
Pesticide Residues & 1102 & 11.41 \\
Not Determined/Other & 987 & 10.22 \\
Migration & 773 & 8.00 \\
Pathogenic Micro-organisms & 693 & 7.17 \\
Poor or Insufficient Controls & 551 & 5.70 \\
Heavy Metals & 458 & 4.74 \\
Foreign Bodies & 362 & 3.75 \\
Organoleptic Aspects & 317 & 3.28 \\
Adulteration/Fraud & 292 & 3.02 \\
Genetically Modified Organism/Novel Food & 260 & 2.69 \\
Food Additives and Flavourings & 257 & 2.66 \\
Composition & 255 & 2.64 \\
Parasitic Infestation & 243 & 2.52 \\
Non-Pathogenic Micro-Organisms & 194 & 2.01 \\
Others & 1089 & 11.27 \\
Total Hazard & 9660 & 100.0 \\
\hline
\end{tabular}

Source: Compilation from EU RASFF Reports, Various Years 
Most surprising, the reasons for refusing all third countries' exports to the EU amounts to as many as 9,660 violations of different EU food safety regulations. Inspectors at the border must be satisfied that each export product is free from the aforementioned food hazards as a prerequisite for granting market access into the EU market. Each requirement is as important as every other one, otherwise, market access could be denied. However, many countries have demonstrated their inability to satisfy EU standards. Thus, there have been a significant number of border rejections of food exports by the EU, amounting to about 9,233 notifications ${ }^{37}$ between 2008 and 2013 (RASFF, online database). This is evident in Figure 5.1, which depicts the unit border rejection of the most frequently rejected food exports from countries exporting to the EU. In particular, nuts and nuts products,

Figure 5.1: EU Border Rejection of Third Countries Exports by Most Affected Product, 2008 to 2013

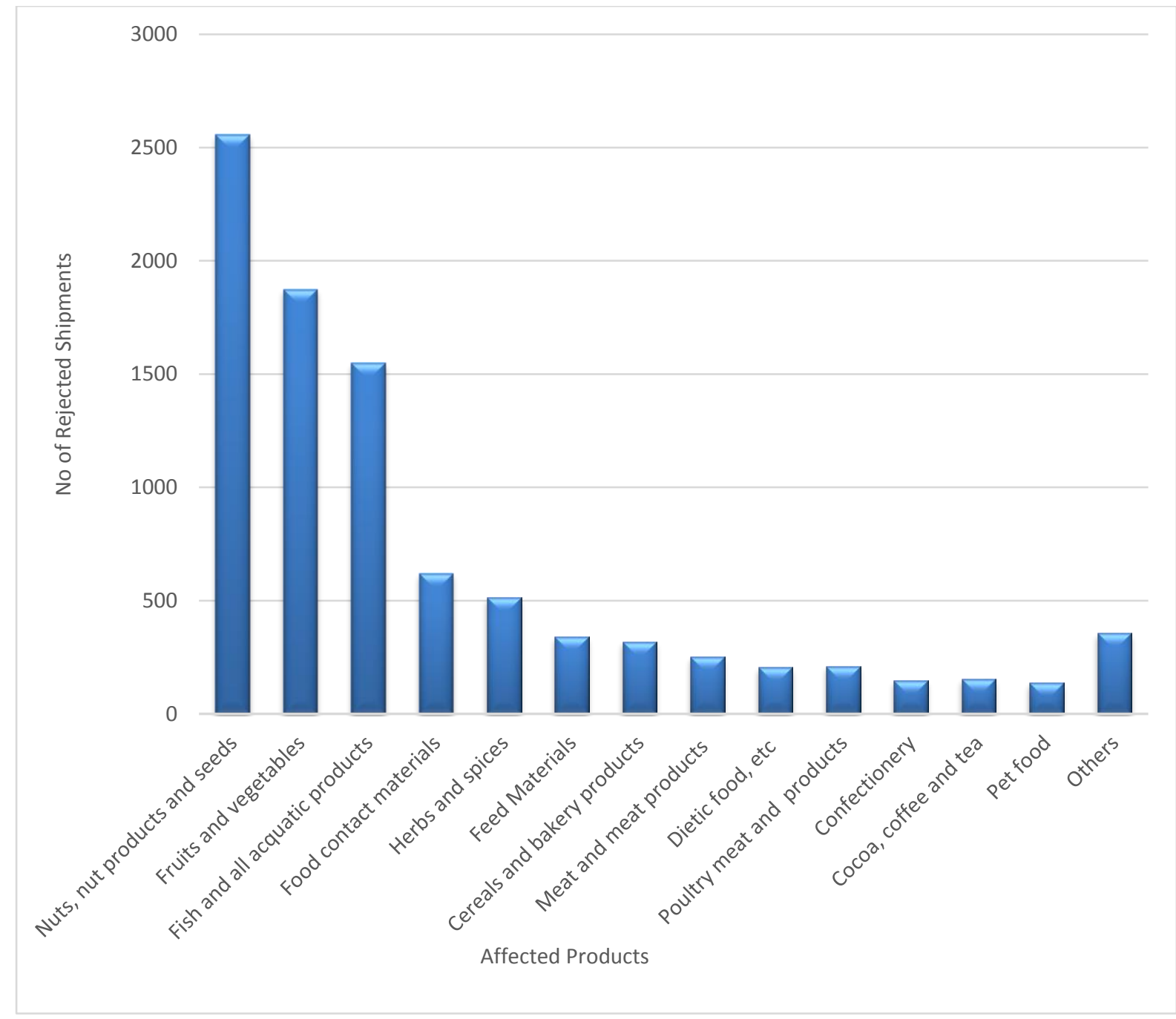

Source: Compilation from EU RASFF Reports, Various Years

\footnotetext{
37 The total number of violations $(9,960)$ reported in Table 1 is more than the total number of notifications, which was 9,233 in Figure 5.1. This was because some notifications can be reported to have more than one food hazard.
} 
fruits and vegetables, and fish and other aquatic products ${ }^{38}$ are the three most important product categories in order of importance that are usually refused entry into EU markets as a result of exporters failing to meet stipulated EU standards. Refusals of these three products categories represent over 64\% of all EU food export refusals between 2008 and 2013 (Figure 5.2).

Figure 5.2: Proportion of EU Export Rejection in Total Rejection (\%)

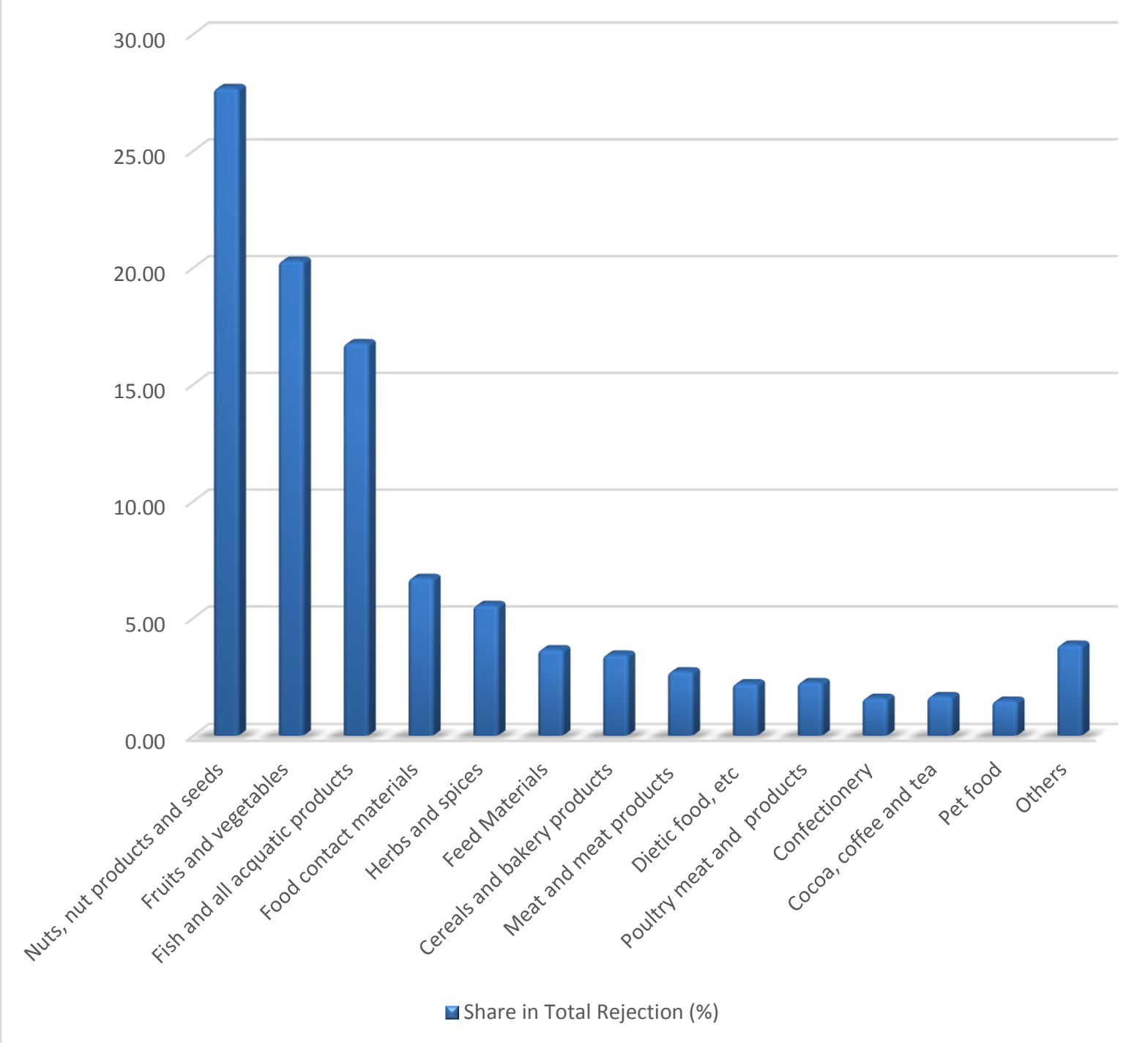

Source: Compilation from EU RASFF Reports, Various Years

Table 5.2 shows the evolution of rejections of Africa's exports at the EU borders for the most affected African countries and most affected products. For Africa, the most frequently rejected category of export product is fish, crustacean, mollusc and other aquatic products, representing about $40.56 \%$ of all Africa's rejected exports between 2008 and 2013. This comprises about 447 of a total of 1548 EU rejections in the products reported in Table 5.1. This is closely followed by nuts and nuts products which constitute about $19.87 \%$ of all Africa's food rejections from the EU between 2008 and 2013. Fruits and vegetable products is the third most

\footnotetext{
38 Products under these categories in the RASFF database are fish and fish products, crustacean, cephalopods and bivalve molluscs. These were reported separately but summed up by us as they can be classified as aquatic products.
} 
important category of rejected products, accounting for about $18.42 \%$ of total rejections of Africa exports. In addition, out of the 1874 cases of fruits and vegetables rejected between 2008 and 2013 from all countries, Africa accounts for about 203 of these cases, which amounts to about $10 \%$ of all EU rejections of vegetables in this period. The huge number of rejections implies non-compliance to EU standards represent an important market access problem for Africa. In fact, Africa's fish and fish products, nuts and nuts products, as well as fruits and vegetable - the three classes of export products often refused entry into the EU market, account for about $70 \%$ of all food and feed exports rejected from African countries.

Table 5.2: EU Rejection of African Exports from the Most Affected Products and Countries, 2008 to 2013

\begin{tabular}{|c|c|c|c|c|c|c|c|c|c|c|c|}
\hline Most Affected Products & $\underset{\substack{60 \\
\text { [I }}}{\overrightarrow{2}}$ & $\underset{\tilde{\Xi}}{\tilde{\Xi}}$ & $\underset{\overparen{D}}{\stackrel{0}{d}}$ & $\begin{array}{l}\stackrel{0}{0} \\
0 \\
\dot{0} \\
\sum\end{array}$ & 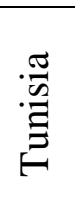 & 吾 & 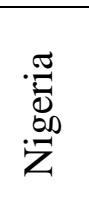 & 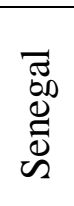 & $\frac{n}{\tilde{\omega}}$ & $\stackrel{\pi}{0}$ & 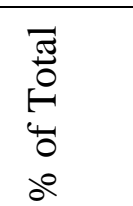 \\
\hline $\begin{array}{l}\text { Fish, Crustacean, Mollusc \& } \\
\text { other Aquatic Invertebrate }\end{array}$ & 1 & 17 & 4 & 154 & 38 & 9 & 8 & 57 & 159 & 447 & 40.56 \\
\hline Nuts & 89 & 18 & 0 & 1 & 4 & 39 & 52 & 5 & 11 & 219 & 19.87 \\
\hline Fruits and Vegetables & 86 & 8 & 23 & 16 & 15 & 4 & 31 & 5 & 15 & 203 & 18.42 \\
\hline Feed Material & 1 & 3 & 0 & 27 & 0 & 3 & 1 & 2 & 28 & 65 & 5.90 \\
\hline Herbs and Spices & 12 & 5 & 1 & 26 & 1 & 2 & 3 & 0 & 9 & 59 & 5.35 \\
\hline Cocoa & 2 & 3 & 1 & 5 & 0 & 0 & 14 & 0 & 3 & 28 & 2.54 \\
\hline Fat and Oil & 1 & 5 & 0 & 1 & 0 & 0 & 5 & 3 & 7 & 22 & 2.00 \\
\hline Cereals and Bakery & 2 & 6 & 0 & 1 & 0 & 2 & 4 & 0 & 2 & 17 & 1.54 \\
\hline Meat & 2 & 0 & 0 & 0 & 0 & 0 & 0 & 0 & 8 & 10 & 0.91 \\
\hline Non-Alcoholic Beverages & 7 & 0 & 0 & 0 & 0 & 0 & 1 & 0 & 0 & 8 & 0.73 \\
\hline Others & 4 & 4 & 0 & 3 & 1 & 4 & 4 & 2 & 2 & 24 & 2.18 \\
\hline Total by country & 207 & 69 & 29 & 234 & 59 & 63 & 123 & 74 & 233 & 1102 & 100.00 \\
\hline
\end{tabular}

Source: Compiled from RASFF Online Database

The reasons for the EU rejecting African food and feed are presented in Table 5.3. Major reasons adduced for the rejection of these African products are exceeding the stipulated EU mycotin limit, poor and insufficient controls, adulteration and fraudulent practices. By far, the most significant reason given was the violation of mycotin limits, accounting for as much as $22.43 \%$ of rejections from Africa's food exports between 2008 and 2013. The countries who most frequently violated EU food standards are Morocco with 252 cases of border rejections, closely followed by Egypt which has 211 cases of rejection, Nigeria with 113 rejections, and Ghana and South Africa with 75 and 74 incidences of rejection respectively.

This precedent analysis of EU border rejection might be indicative of the inability of African countries to meet EU standards. This in part might point out their lack of the necessary regulatory institutions to facilitate standards compliance, the lack of minimum country-level standards in African countries, or a case of a regulatory gap ${ }^{39}$.

${ }^{39}$ In this case, the existing standards are sub-optimal and sub-standard to the level required by the EU. 
Table 5.3: Reasons for EU Rejecting Africa's Food and Feeds, 2008 to 2013

\begin{tabular}{|c|c|c|c|c|c|c|c|c|c|c|}
\hline & $\overrightarrow{\sum_{0 \rightarrow 0}^{\circ}}$ & 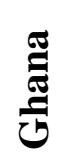 & 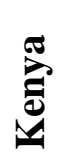 & 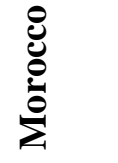 & 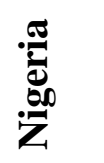 & 产 & 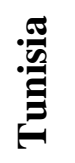 & 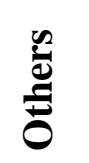 & 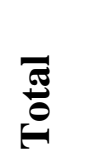 & $\stackrel{\frac{\pi}{\pi}}{\overparen{\theta}}$ \\
\hline Mycotin & 84 & 28 & 1 & 0 & 56 & 53 & 4 & 29 & 255 & 22.43 \\
\hline Poor or Insufficient Controls & 3 & 15 & 1 & 56 & 6 & 5 & 15 & 130 & 231 & 20.32 \\
\hline Pesticide Residues & 80 & 1 & 23 & 36 & 28 & 3 & 3 & 3 & 177 & 15.57 \\
\hline Organoleptic Aspects & 3 & 8 & 1 & 15 & 6 & 2 & 10 & 54 & 99 & 8.71 \\
\hline Pathogenic Micro-organisms & 2 & 1 & 1 & 23 & 4 & 2 & 1 & 33 & 67 & 5.89 \\
\hline Parasitic Infestation & 0 & 1 & 0 & 48 & 0 & 2 & 6 & 5 & 62 & 5.45 \\
\hline $\begin{array}{l}\text { Non-Pathogenic Micro- } \\
\text { Organisms }\end{array}$ & 13 & 6 & 0 & 11 & 3 & 0 & 3 & 23 & 59 & 5.19 \\
\hline Packaging & 3 & 2 & 0 & 17 & 1 & 0 & 3 & 7 & 33 & 2.90 \\
\hline Defective/Incorrect & & & & & & & & & & \\
\hline Adulteration/Fraud & 3 & 5 & 0 & 6 & 3 & 1 & 4 & 9 & 31 & 2.73 \\
\hline $\begin{array}{l}\text { Food Additives and } \\
\text { Flavourings }\end{array}$ & 9 & 2 & 0 & 1 & 3 & 5 & 1 & 7 & 28 & 2.46 \\
\hline Heavy Metals & 0 & 0 & 0 & 9 & 1 & 1 & 0 & 12 & 23 & 2.02 \\
\hline Bio-contaminants & 0 & 0 & 0 & 20 & 0 & 0 & 1 & 1 & 22 & 1.93 \\
\hline Foreign Bodies & 8 & 4 & 0 & 2 & 0 & 0 & 0 & 6 & 20 & 1.76 \\
\hline Labelling & 2 & 2 & 0 & 8 & 0 & 0 & 2 & 1 & 15 & 1.32 \\
\hline Absent/Incomplete/Incorrect & & & & & & & & & & \\
\hline Industrial Contaminants & 1 & 0 & 0 & 0 & 1 & 0 & 0 & 10 & 12 & 1.06 \\
\hline GMO/Novel Food & 0 & 0 & 0 & 0 & 1 & 0 & 0 & 0 & 1 & 0.09 \\
\hline Migration & 0 & 0 & 0 & 0 & 0 & 0 & 1 & 0 & 1 & 0.09 \\
\hline Not Determined/Other & 0 & 0 & 0 & 0 & 0 & 0 & 0 & 1 & 1 & 0.09 \\
\hline Total Hazard & 211 & 75 & 27 & 252 & 113 & 74 & 54 & 331 & 1137 & 100.0 \\
\hline
\end{tabular}

Source: Compiled from RASFF Online Database

Other factors can also be attributed to the inadequacy of Africa's trade facilitating measures caused by cumbersome trade procedures which prevent the efficient movement of commodities in cross-border trade. For instance, while it usually takes a day for the Netherlands to export goods via an airport supply chain, export times could be as high as 18 days in Cameroon and about 25 days for Chad (Arvis, et al., 2012). This is attributed to inefficient border procedures and inadequate trade infrastructure which bring about border rejections especially for highly perishable goods such as fish products, fruits and vegetables. Poor storage infrastructure in ship or consignments, especially for perishable goods, can also result in problems such as migration, infestation with a foreign body, bio-contaminants, parasitic infestation, and the emergence of pathogenic organisms in the exported products. For instance, according to a 2014 report from the EU, tomato exports originating from three production units in Morocco might have resulted in several cases of food poisoning due to a cooling liquid used in the chiller cabinets where the tomatoes were stored (RASFF, 2014). All these issues signify the role of inefficient trade procedures and of poor trade infrastructure in increasing the incidences of border rejections. 


\subsection{Methodology}

The total number of border rejections per exporting country is strictly a non-negative count variable. More so, some of the exporting African countries have had no border rejections in some years, giving rise to the presence of a number of zeros. The occurrence of zero rejections might be due to specific reasons. Firstly, it might be that these groups of countries did not export any of the agricultural export products considered in this study to the EU. Secondly, these countries may have met EU standards, and successfully exported to the EU, and thus recorded zero rejections of their export products. Thus, this type of data generating process gives rise to a class count data model (Cameron and Trivedi, 1998; Winkelmann, 2008).

\subsubsection{Model Specifications}

To investigate the factors influencing border rejections of African exports by the EU, we rely on a standard count data model which is represented in a general form of a conditional probability function:

$$
\operatorname{Pr}\left(Y_{i j p t}=y_{i j t} \mid x_{i}\right)=\frac{\exp \left(-\exp \left(x_{i j t}^{\prime} \beta\right)\right) \exp \left(y_{i t j} x_{i j t}^{\prime} \beta\right)}{y_{i j t} !}
$$

where subscripts $i, j, p$ and $t$ denote exporter, importer, product and time respectively; $y$ is the count variable, in this case, the total number of border rejections of African exports by the EU in the selected products over years; $x$ symbolizes the vector of the independent variables of the model, while $\beta$ is the vector of the associated coefficients. Two generalized linear models (GLM) which are the Poisson and Negative Binomial Poisson estimation techniques are employed in estimating equation (5.1).

\section{(a) The Poisson Model}

The Poisson specification estimates $\beta$ by solving a first order condition given as:

$$
\sum_{i=1}^{n}\left[y_{i j t}-\exp \left(x_{i j t} \beta\right)\right] x_{i j t}=0
$$

The estimator is consistent under the estimator's equi-dispersion assumption about the dependent variable that the conditional mean, given as $\exp \left(x_{i j t} \beta\right)$, is proportional to the conditional variance $V\left[y_{i j t} \mid x\right]$ (Winkelmann 2008). However, the equi-dispersion assumption ${ }^{40}$ is unlikely to hold (Burger et al., 2009; Martinez-Zarzaso, 2013) because the estimator does not fully account for the presence of unobserved heterogeneity, thus, making the conditional variance greater than the conditional mean.

\footnotetext{
${ }^{40}$ Although the Poisson model hinges on the assumption of equi-dispersion of the dependent variable, however, Santos Silva and Tenreyro (2009) establish that the model still remain consistent and well-behaved with departure from this assumption.
} 


\section{(b) Negative Binomial Pseudo Maximum Likelihood Model}

In cases of overdispersion - which occurs when the variance of the dependent variable is more than its mean - a more suitable model is the negative binomial pseudo maximum likelihood (NBPML) model. The NBPML estimator is a count data model that does not rely on the assumption of an underlying Poisson process and is able to efficiently deal with the presence of both overdispersion and unobserved heterogeneity in the variation of the dependent variable (c.f. Burger et al., 2009).

Following Winkelmann (2008), the NBPML model is specified as:

$$
\operatorname{Pr}\left[y_{i j t} \mid x_{i j t}, \alpha\right]=\frac{\Gamma\left(\alpha+y_{i j t}\right)}{\Gamma(\alpha) \Gamma\left(y_{i j t}+1\right)}\left(\frac{\alpha}{\alpha+\exp \left(x_{i j t} \beta\right)}\right)^{\alpha}\left(\frac{\exp \left(x_{i j t} \beta\right)}{\alpha+\exp \left(x_{i j t} \beta\right)}\right)^{y_{i j t}}
$$

In equation (5.3), $\alpha$ is the dispersion term which shows the degree to which the variance of the dependent variable disperses from its mean; the term assumed to be greater than one; $\Gamma$ is the gamma function and all other variables are as earlier defined. Given the estimator's overdispersion assumption, its variance function is specified as:

$$
\operatorname{Var}\left[y_{i j t} \mid x\right]=\left(1+\alpha^{-1}\right) \exp \left(x_{i j t} \beta\right)
$$

Here, the NBPML model's expected value is given as that of the Poisson's. However, the variance is expressed as a function of a mean that is expressed as $\exp \left(x_{i j t} \beta\right)$ and an unobserved heterogeneity given as a dispersion parameter $\alpha$ which allows unobserved heterogeneity to be incorporated into the model. In addition, the dispersion parameter ${ }^{41}$ is allowed to take on values greater than 1, thereby explicitly taking care of overdispersion. The larger $\alpha$ is, the higher the magnitude of the overdispersion of the dependent variable.

\subsubsection{Data and Variables Included}

Our objective is to investigate the potential factors that are responsible for noncompliance with EU standards, and the consequential rejection of African exports. Specifically, we first investigate the impact of geographical, economic and trade factors on border rejections and thereafter went ahead and investigated the contributory impact of both institutional and trade procedures. To investigate the determining factors of border rejection of African countries, we set up a standard random effects model. Our model specification follows that of Baylis et al. (2009) with some modifications in terms of the variables included. Our main dependent variable is the total number of border rejections of non-conforming food products exported to the EU by African countries. Our explanatory variables are countries and exporters' characteristics that are associated with the risks of being rejected and are divided into three groups. These are country area characteristics, country trade and economic characteristics, as well as countrylevel trade and institutional infrastructure.

${ }^{41}$ This dispersion parameter serves as a formal test of overdispersion for the dependent variable. 


\subsubsection{Description of Variables}

\section{Country-level Geographical Characteristics}

Distance, being a landlocked or island country and language are important geographical characteristics that might make exports more susceptible to contamination and food hazards. Distance between trading partners represents an important trade cost that might increase cases of import rejections, particularly for poor countries with inadequate facilities to preserve export products during long distance journeys. Inadequate facilities during long distance trade could result in common reasons for rejecting imports; examples of such reasons include parasitic infestation, the presence of pathogenic and non-pathogenic micro-organisms in or on export products, contaminations, the presence of foreign bodies, poor organoleptic properties of the export product, etcetera. Thus, import rejections tend to increase with increasing distance to the EU. Firms operating in landlocked countries are less competitive, and tend to export less due to higher transport costs relative to countries that are not landlocked, and might record fewer import rejections from the EU. However, due to their disadvantaged position, they usually have higher export times thereby rendering highly perishable goods to be susceptible to the violation of technical regulations and sanitary and phytosanitary (SPS) requirements. In the same vein, countries sharing a similar language with the EU might find it easier to understand EU food safety requirements, thereby increasing their compliance level and reducing import rejections by the EU.

\section{Country-level trade and economic characteristics}

In relation to the explanatory variables included in our model, following Baylis et al. (2009) and Jouanjean et al. (2012), we have included some indicators to capture the reputation of the exporting countries into our model. We have used two variables in measuring reputation. The first one was a dummy variable indicating if the product was rejected in the previous year which we termed 'product reputation'. Product reputation matters because products high risks products especially perishables exported by frequently violating countries usually attract higher vigilance. Furthermore, they will elicit a great number of inspections in subsequent years which might increase the likelihood of finding evidence of non-compliance.

The second is a dummy variable indicating if at least one export product was rejected in the previous year from a given country, termed 'country reputation'. Country reputation is also important due to the premise that, on the one hand, countries with a history of past rejections in any one product may be subjected to increased vigilance and inspections in all its products. This clearly increases the chances of having products rejected in subsequent years. On the other hand, past rejections of products coming from a heavy violating country can allow the affected country to gather experience about its weak food safety enforcement. They are then more likely to invest in supply upgrading to conform to EU standards, and such experience might decrease import rejections. In fact, in relation to country reputation, the EU have in some cases rejected (or banned) all products coming from export countries which persistently violate standards due to concerns about the countries' levels of sanitary and phytosanitary (SPS) standards. 
We also introduce a variable to capture past EU imports from African countries. We control for this due to concerns that increased border rejections might have appeared following an import surge. Under pressure from lobby groups, the EU might have increase border vigilance to deliberately limit import flow in a particular sector. There may have been economic or political pressure for increased import inspections. Finally, we included a measure of the exporting countries' economic growth, captured by their gross domestic product. Due to the huge cost of complying with food safety standards, we consider that low income countries' exports are at a higher risk of being subjected to rejection due to having higher risks of exporting sub-standard products as a result of their limited financial resources to ensure compliance.

Lastly, we included country, product and time fixed effects to account for unobserved heterogeneity. Based on the above definitions, the regression model is given as:

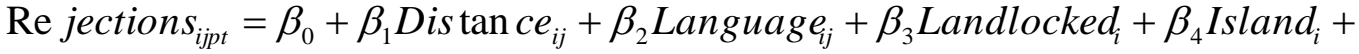

$$
\begin{aligned}
& \beta_{5} C_{-} \operatorname{Re} \text { putation }_{i j t-1}+\beta_{6} P_{-} \operatorname{Re} \text { putation }_{i j t-1}+\beta_{7} \operatorname{Pr} \text { evious_Im ports } \text { Ijpt }_{i}+\beta_{8} G D P_{i t}+ \\
& \left.\delta_{i}+\delta_{p}+\delta_{t}+\mu_{i j p t}\right)
\end{aligned}
$$

Where $i, j, p$ and $t$ are the exporting countries, importing countries, product and time respectively, as defined earlier. Rejections - our dependent variable is the total number of rejections of non-conforming food products exported to the EU by each African country between 2008 and 2013 for the three most frequently rejected products identified earlier in the previous section. These are fish, crustaceans, mollusc, and other aquatic vertebrates; nuts and nut products; and fruits and vegetables. Distance is the geographical distance between the major economic centres of each exporting African country and the EU. Language is a dummy variable which is coded as one if the exporting countries share a similar language with at least one country in the EU, and zero otherwise. Landlocked and island are dummy variables that assume the values of one if the African country is a landlocked or island country, and zero otherwise. $P \_$Reputation and $C_{-}$Reputation are product and country reputation respectively as discussed previously. Previous_Imports denotes a year's lag values of EU import from African countries; and GDP is the income level of the exporting countries as given by their gross domestic product. $\delta_{i}, \delta_{p}$ and $\delta_{t}$ are the dummy variables controlling for country, product and time-fixed effects respectively, while $\mu_{i j p t}$ is the error term. The summary statistics of all the above variables are reported in Table 5.4. 
Table 5.4: Summary Statistics I

\begin{tabular}{lllll}
\hline Variables & Mean & $\begin{array}{l}\text { Standard } \\
\text { Deviation }\end{array}$ & Minimum & Maximum \\
\hline Rejections & 1.45 & 4.47 & 0 & 41 \\
Distance & 5820.31 & 2087.59 & 1733.39 & 9693.59 \\
Island & 0.12 & 0.32 & 0 & 1 \\
Landlocked & 0.16 & 0.36 & 0 & 1 \\
Language & 0.04 & 0.19 & 0 & 1 \\
Product_Reputation & 0.26 & 0.44 & 0 & 1 \\
Country_Reputation & 0.61 & 0.49 & 0 & 1 \\
Past Imports ('000 dollars) & 76116.95 & 255665 & 0 & 2182462 \\
Log of exporter GDP(million dollars) & 23.61 & 1.57 & 20.56 & 26.98 \\
\hline Sol Cor & & & & \\
\hline
\end{tabular}

Source: Computed

Our second objective is to investigate the impact of trade related infrastructure, procedures, and institutions on border rejection. The important variables of institutional and trade procedures are discussed below.

\section{Country-level institutional capacity}

A growing body of literature has identified good institution as a necessary condition for the developmental process. Thus, we also identify missing institutions as factors which can hinder developing countries' ability to comply with developed countries' standards. The most significant aspects of institutions relevant to compliance with standards are: high levels of corruption and poor government regulatory quality. In fact, in relation to corruption, about 3\% of Africa's export products have been refused entry to the EU due to adulteration and fraudulent practices, making it a potentially important variable considered in our analysis. A limited number of studies suggested that corruption impact on export quality and trade (Faruq, 2011; Goel and Korhonen, 2011). For instance, corruption can impact on export quality and trade by weakening long term investment incentives, thereby decreasing productivity and quality improvement (Faruq, 2011). Hence, it may be that more corrupt countries will see their export rejected at the EU border due to their fraudulent practices

On a related note, the literature has pointed out that the impact of developed countries' standards on developing countries have been aggravated for developing countries for the latter due to their weak domestic regulatory quality which leads to weak standards and quality regulation in the domestic economy. As a consequence, this hinders their capacity to implement testing and certification processes (Essaji, 2008; Kim and Reinert, 2009). Given this information, the measure of African countries' institutional capacity to satisfy EU food safety standards therefore includes the quality of their domestic level regulatory capacity. We use 'regulatory quality' sourced from the World Bank World Governance Indicators - a measure of governance indicators as a proxy each country's capacity to formulate and implement food safety regulations, testing and certification procedures. This measure reflects government's abilities to formulate and implement high quality regulatory policies, the quality of its public service 
delivery and its commitment to such policies. The intuition is that countries that score high in this indicator would definitely have high regulatory quality, including adequate food regulatory mechanisms and, thus, a low probability of having border rejections when exporting to the EU. This is based on the perceived positive influence of institutional quality and governance on trade performance (Kucharčuková, et al., 2012).

\section{Country-level core trade facilitation measures}

Trade facilitation describes trade procedures or activities which are channelled towards ensuring the efficient logistics of moving goods during international trade through ports and all procedures associated with cross-border trade. This includes export and import formalities, customs and regulatory environments, as well as conformity to regional or international standards and regulations (OECD, 2005). Trade facilitation can thus be used to achieve an improvement in compliance with SPS measures depending on how weak or strong they are in a country. Such measures include trade-related infrastructure and customs and border procedures. For instance, both soft infrastructure like information and communication technology (ICT) and hard infrastructure such as road, rail, sea and air ports are essential in transporting export goods in a timely manner, especially in the case of perishable goods. Thus, weak or missing infrastructure can also aggravate rejections of exported goods. In addition, cumbersome border and customs procedures and the associated lack of adequately trained technical staff, especially those related to SPS control and health and safety issues, can escalate incidences of import rejections by the importing countries.

Thus, we also investigate Africa's state of trade procedures as factors which can hinder their ability to comply with developed countries' standards. Major factors which are of high relevance to explaining specific hurdles in international trade are infrastructural quality (Portugal-Perez, 2012), and trade procedures - which are essentially border and customs procedures (UNECA, 2013). Trade procedures are measured using improved data that was sourced from the World Bank Doing Business database on domestic logistic performances. These span data on the quality of customs procedures and infrastructural quality.

Therefore, we model the impact of institution and trade infrastructure as well as trade procedures on border rejections as follows:

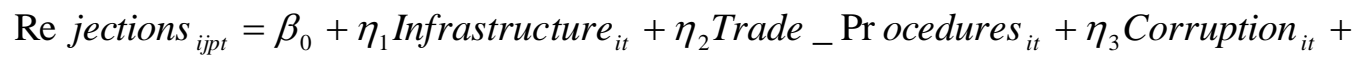

$$
\begin{aligned}
& \eta_{4} \text { Re } \text { gulatory _Quality }_{i t}+\eta_{i}+\eta_{p}+\eta_{t}+\varepsilon_{i j p t}
\end{aligned}
$$

where Trade_Procedures is a vector of variables which measures the efficiency of customs clearance process, border controls, as well as the quality of logistics services. These include documents required to export, number of border agencies, percentage of shipments meeting quality criteria, rate of physical inspection of exports, customs clearance times without physical inspection, and customs clearance times with physical inspections. Infrastructure is the trade related infrastructure in the domestic country which spans air and seaports, rails, road, and 
Information and communications technology. Corruption is the level of control of corruption in the domestic economy while regulatory quality is the quality of each African government regulations and laws as well as the extent of the government's commitment to its enforcement. $\eta_{i}, \eta_{p}$ and $\eta_{t}$ are the dummy variables controlling for country, product and time fixed effects, respectively, while $\varepsilon_{i j p t}$ is the residual term of the model. Table 5.5 reports the summary statistics of all the variables included in our analyses and their sources.

Table 5.5: Summary Statistics II

\begin{tabular}{lllll}
\hline Variables & Mean & $\begin{array}{l}\text { Standard } \\
\text { Deviation }\end{array}$ & Minimum & Maximum \\
\hline Infrastructure quality & 2.24 & 0.42 & 1.27 & 3.79 \\
Control of corruption & -0.47 & 0.52 & -1.24 & 0.87 \\
Regulatory quality & -0.48 & 0.47 & -1.47 & 0.52 \\
Documents to export & 7.16 & 1.74 & 4 & 11 \\
Number of border agencies & 3.77 & 1.80 & 1 & 11 \\
Percentage of shipments meeting quality & 68.76 & 20.43 & 7 & 100 \\
Criteria & & & & \\
Custom clearance day with physical & 4.25 & 3.36 & 0.79 & 20 \\
inspection & & & & \\
Custom clearance days without physical & 3.18 & 3.07 & 0.4 & 18 \\
Inspection & & & & 100 \\
Rate of physical inspection of import (\%) & 32.23 & 26.89 & 1 & \\
\hline
\end{tabular}

Source: Computed

\subsubsection{Sources of Data}

To estimate the different count models previously specified, we focus on EU import rejection data for 26 African countries ${ }^{42}$ reported between 2008 and 2013. Data on EU rejection of these African export products were sourced from the EU rapid alert system for food and feed (RASFF) database from 2008 to 2013. Although the RASFF was created in 1979, public access to the summary information on the incidence of border rejections only started in 2008. Hence, our analysis starts from this period. The EU classification of import refusal data is reported at a more aggregated level. Thus, to allow a meaningful analysis, we map each notification to the respective Harmonised System (HS) product classification. Analysis was based on three products rejected by the EU at the border identified in the previous section, namely fish, crustaceans, molluscs and other aquatic invertebrates (HS code 03), Fruits and Vegetables (HS code 07 plus HS 08) and Nuts and nut products. Nuts and nut products were later split into groundnuts, not roasted or otherwise cooked (HS code 1202) and edible groundnuts, otherwise prepared or preserved (HS code 200811), bringing the number of products considered in the analysis to four. However, we choose not to disaggregate fruits and vegetable products due to the ambiguity in the way in which they were notified in some cases. For instance, for some

\footnotetext{
${ }^{42}$ The included countries are Algeria, Benin, Cameroon, Cape Verde, Congo Republic, Cote d'Ivoire, Egypt Arab Republic, Ethiopia, Gabon, Ghana, Kenya, Madagascar, Malawi, Morocco, Mozambique, Namibia, Nigeria, Rwanda, Senegal, Seychelles, South Africa, Tanzania, The Gambia, Togo, Tunisia and Uganda.
} 
notifications, we do not have enough information to enable us to distinguish if the refusal relates to a vegetable or fruit product.

For simplicity, we restrict our data to just the countries that have had at least one EU rejection between 2008 and 2013; this reduced our sample countries from 54 African countries to 26 countries for the four products over the 6 years. Data on EU rejection of these African export products amounts to a total of 484 refusals. In relation to other data, import and export data are from the UN COMTRADE database. Data on language, landlocked, distance are from the Centre d'Etudes Prospectives et d'Informations Internationales (CEPII), GDP data are from the World Bank's World Development Indicator (WDI), governance indicators on corruption and regulatory quality are from the World Bank's Worldwide Governance Indicators (WGI) while data on infrastructure, customs and logistic quality are from the World Bank's Doing Business database.

\subsection{Empirical Analysis and Results}

In this section, we first present a descriptive analysis of our independent variable. Thereafter, we move on to the count models where we show the results of the factors affecting import rejections.

\subsubsection{Descriptive Analysis}

In terms of the features of our dependent variable, a simple chart of distribution of the dependent variable shows our data is skewed to the right for most of the years under consideration. Clearly employing non-count data estimation techniques for analyzing such count data would be grossly inappropriate.

Figure 5.3: The Distribution of Border Rejection of the Selected African Exports, 2008 to 2013

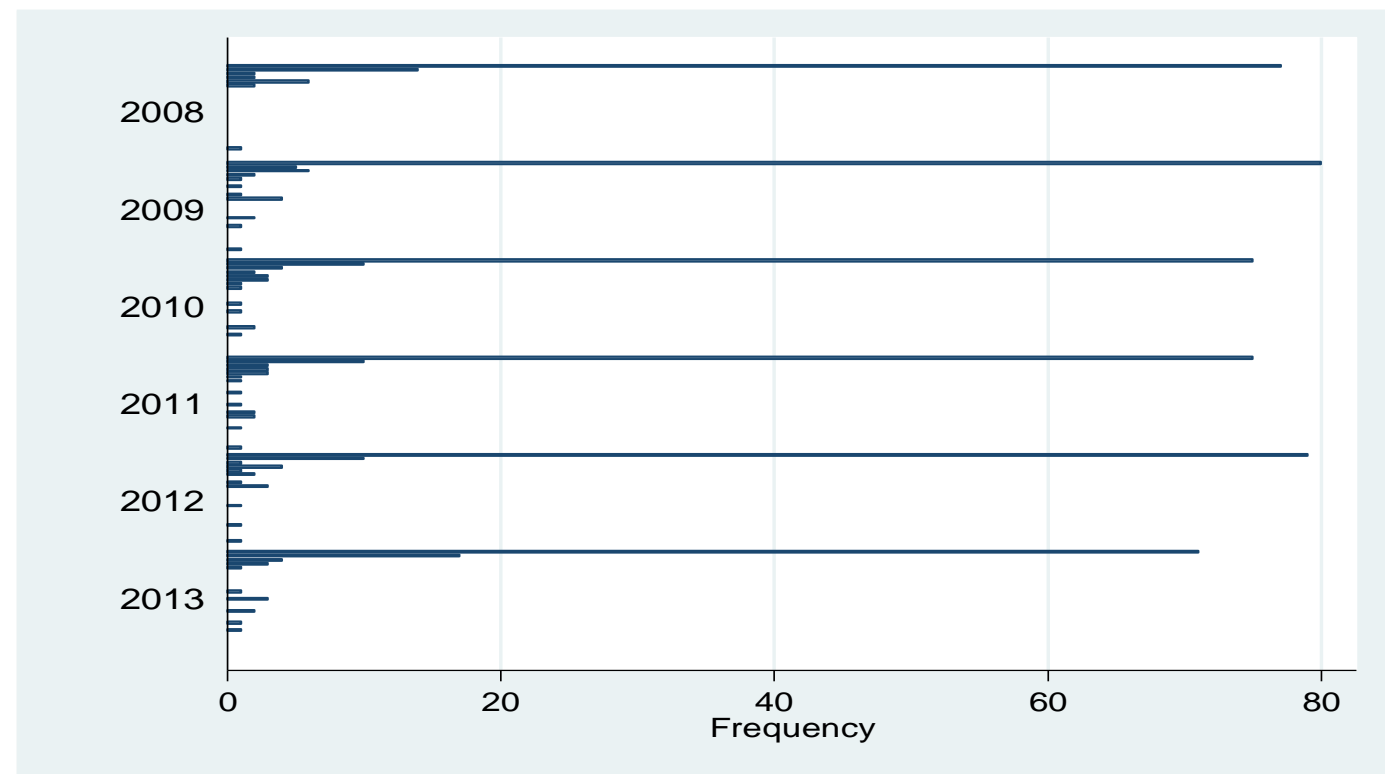

Source: Author's Computation based on data from the EU RASFF. 


\subsubsection{Econometric Analysis}

Before we go on to interpret our results, we begin by reporting various specification tests to ascertain the most efficient of the count data models previously discussed. The main statistics tests employed are the Park (1996) test and the Ramsey reset test. All the goodness of fits employed are discussed below.

\subsubsection{Robustness Checks I}

Firstly, we used the Ramsey reset test (Ramsey, 1969) to determine the appropriateness of all the models estimated. It is a test of specification error and checks the functional form of the models to determine whether the models are correctly specified. The test is carried out by checking the significant level of an additionally constructed dependent variable specified as $\left(x^{\prime} \beta\right)^{2}$, where $\beta$ is as earlier is the vector of the estimated parameters. The test's null uhypothesis is that the coefficient of the test variable is zero or insignificant. The test results are displayed in Table 5.6

Table 5.6: Comparison of the Estimation Techniques

\begin{tabular}{l|cccc}
\hline Various Tests & $\begin{array}{c}(1) \\
\text { Poisson } \\
(p . a)\end{array}$ & $\begin{array}{c}(2) \\
\text { Poisson } \\
(\text { r.e. })\end{array}$ & $\begin{array}{c}(3) \\
\text { NBPML } \\
(p . a .)\end{array}$ & $\begin{array}{c}\text { NBPML } \\
(\text { r.e. })\end{array}$ \\
\hline Ramsey Reset Test & -0.03 & 0.003 & $-0.11^{* *}$ & $0.31^{* * *}$ \\
\hline Park TEST: $v(y \mid x)=\left(\mu(y \mid x)^{\alpha}\right.$ & & & & - \\
$\alpha_{1}$ & 1.13 & 0.30 & - & - \\
P Value & 0.31 & 0.00 & - & - \\
95\% Confidence Interval & $0.88-1.39$ & $-0.08-0.69$ & - & - \\
\hline
\end{tabular}

Note: p.a. and r.e. are population average and random effects, respectively. "_" not available after population average effects models.

As reported in Table 5.6, for both the population average (p.a) and random effects (r.e) Poisson regressions, the coefficients on the test statistics for the two variants of Poisson models are statistically insignificantly different from zero, suggesting that both Poisson models are appropriate. However, for the each of the two NBPML models, the test rejects the null hypothesis that the coefficient of the test statistics for each of the NBPML model is statistically insignificantly different from zero, implying that the negative binomial specifications are inappropriate.

Secondly, we also employ a Park-like test to ascertain if the Poisson assumption is satisfied. We are interested in whether the equi-dispersion property (that the mean of the dependent variable is proportional to the variance) assumed by the Poisson estimator is satisfied. The general form of this property is given as $v(y \mid x)=\left(\mu(y \mid x)^{\alpha}\right.$. Here, $\alpha$ is the dispersion term, it is non-negative and finite and its value determines the difference between the Poisson 
and negative binomial models. For instance, when $\alpha=1$, the Poisson model is obtained; an NBPML model is obtained if $\alpha>1$. The more efficient estimator now depends on the assumption of how its variance relates to its mean. For instance, when $\alpha=1$, the Poisson model is obtained; an NBPML model is obtained if $\alpha>1$.

Following Manning and, Mullaby (2001), a Park type of regression could be used to decide the appropriate model. We therefore rely the Park test (Park, 1966) which checks for the adequacy of the models by estimating the following equation:

$$
\left(y_{i t}-\hat{y}_{i t}\right)^{2}=\alpha_{0}+\alpha_{1}\left(\hat{y}_{i t}\right)+\varepsilon_{i t}
$$

Equation (5.7) is estimated using the appropriate GLM estimator based on the White's robust estimator (see Manning and Mullahy 2001; Martinez-Zarzoso 2013; Santos Silva and Trenyro 2006). The null hypothesis that $H_{o}: \alpha_{1}=1$ is tested against the alternative that it is not. In addition, the approach of Manning and Mullahy (2001) gives a confidence interval for $\alpha_{1}$ and the null hypothesis is not rejected when the resulting confidence interval of the estimated $\alpha_{1}$ includes the value of 1 or when the (p-value) of the test is not statistically different from zero. Acceptance of this null hypothesis would be an indicator that the Poisson model is appropriate as there is no departure from its underlying assumptions.

The lower part of Table 5.6 reports the results of the modified Park test using a robust covariance matrix. The tests are reported after the population average and the random effects Poisson models. For the population average Poisson model, the point estimate for $\alpha_{1}$ is 1.13 , which is close to the value of 1 and is therefore a confirmation of the Poisson's equi-dispersion assumption of variance of the dependent variable being proportional to its mean. Its reported pvalue also shows that the estimated value of $\alpha_{1}$ is not significantly different from 1 . In addition, the $95 \%$ confidence intervals of $\alpha_{1}$ presented in Table 5.5 also reveal that the estimated confidence intervals for $\alpha_{1}$ which is $(0.88-1.39)$ contains the value of 1 , which confirms the satisfaction of the equi-dispersion assumption. Thus, the Poisson assumption cannot be rejected. Conversely, for the random effects estimator, the point estimate given as 0.30 is statistically significantly different from 1 as shown by the reported p-value described below the point estimates. In addition, the estimated confidence interval for $\alpha_{1}$ does not contain 1 . Therefore, the random effects Poisson specification is unequivocally rejected while the population average Poisson specification cannot be rejected.

While most of the test results are in favour of the population average effects Poisson, the results from the Poisson and NBPML models show similar conclusions about the impacts of the variables affecting border rejections, although their coefficients are slightly different. Based on this, we present the results of the Poisson and NBPML estimations techniques but place emphasis on the population average effects Poisson model. 


\section{A. Impact of Geographical and Economic Factors}

Table 5.7 present the results of both the population average and random effects Poisson and NBPML models. A clear look at the results indicates that both the Poisson and NBPML models have the same signs but differ relatively in the magnitudes of the coefficients, apart from the coefficient of GDP which turns out to be statistically insignificant in the NBPML random effects model.

Table 5.7: Economic and Geographical Factors influencing Rejections of Africa's Exports at the EU Border

\begin{tabular}{lcccc}
\hline & $(1)$ & $(2)$ & $(3)$ & $(4)$ \\
& Poisson & Poisson & NBPML & NBPML \\
Independent Variables & $p . a$. & r.e. & p.a. & r.e. \\
\hline \multirow{2}{*}{ Distance } & & & & \\
& $0.167^{* * *}$ & $0.168^{* * *}$ & $0.191^{* * *}$ & $0.077^{*}$ \\
Landlocked & $(0.036)$ & $(0.042)$ & $(0.033)$ & $(0.046)$ \\
& $-762.946^{* * *}$ & $-768.525^{* * *}$ & $-873.517^{* * *}$ & $-351.464^{*}$ \\
Same Language & $(161.858)$ & $(192.170)$ & $(152.102)$ & $(208.808)$ \\
& $-255.734^{* * *}$ & $-257.852^{* * *}$ & $-292.567^{* * *}$ & $-116.792^{*}$ \\
Product's Reputation & $(55.367)$ & $(65.789)$ & $(51.968)$ & $(70.655)$ \\
& $1.872^{* * * *}$ & $1.844^{* * *}$ & $1.585^{* * *}$ & $1.603^{* * *}$ \\
Country's Reputation & $(0.342)$ & $(0.349)$ & $(0.341)$ & $(0.217)$ \\
& $-1.115^{* * *}$ & $-1.115^{* *}$ & $-1.482^{* * *}$ & $-0.877^{* * *}$ \\
Previous Imports & $(0.495)$ & $(0.514)$ & $(0.462)$ & $(0.326)$ \\
& -0.000 & -0.000 & -0.000 & $0.000^{*}$ \\
Log of exporters' GDP & $(0.000)$ & $(0.000)$ & $(0.000)$ & $(0.000)$ \\
& $2.373^{* * *}$ & $2.501^{* * *}$ & $2.755^{* * *}$ & 1.060 \\
Exporters Effects & $(0.782)$ & $(0.948)$ & $(0.733)$ & $(0.828)$ \\
Products Effects & Yes & Yes & Yes & Yes \\
Time Effects & Yes & Yes & Yes & Yes \\
No of Observations & Yes & Yes & Yes & Yes \\
\hline No & 520 & 520 & 520 & 520 \\
\hline
\end{tabular}

Note: p.a. and r.e. are population average and random effects models, respectively. Clustered robust standard errors are in brackets and $*$ $\mathrm{p}<0.10 ; * * \mathrm{p}<0.05 ; * * * \mathrm{p}<0.01$.

As shown in Table 5.7, factors relating to geographical, cultural and economic characteristics turn out to be important in explaining import rejections. Distance between each African country and the EU is positive and statistically significant, denoting that rejection of the selected African products increases with increasing distance. In fact, a 100 kilometre increase in distance between the EU and African countries increases border rejection of their products by approximately 18 shipments $\left\{\right.$ that is $\left.e^{0.167}-1 * 100\right\}$, which is a very large distance effect. Although fresh products are transported in refrigerated containers, contamination might still occur during storage especially when stored in contaminated containers, during loading and unloading of products into the container and when transporting over long distance even when adequate sanitary measures have been taken earlier in the food chain (Keener, 2003; Ackerley, 2010). During transportation, contamination may result from poor road conditions, high transit temperature, rough handling, chilling or freezing damage, moisture damage, heat damage, insect damage, chemical contamination from preservatives, cross contaminations, bruises and 
cuts in produce, all resulting in rapid decay etc. These all lead to undesirable microbial growth, spoilage and the rapid decay of the products, resulting in high spoilage levels and increased import rejections.

Common language exerts a significantly negative effect on border rejections. This highlights that exporting countries that have a similar language with the EU have lower rates of rejections, compared to those that do not share a similar language with the EU. Intuitively, one would expect that it is relatively easier for them to understand and thus adapt to EU standards requirements. This result contradicts that of Baylis, et al. (2009) who found countries sharing similar languages with the EU have higher rejection rates.

In relation to the other variables capturing geographical characteristics of the exporter, landlocked is negative and statistically significant, signifying that landlocked countries are not so disadvantageously prone to border rejection. In fact, landlocked countries have lower incidences of border rejections than countries that are not landlocked. In the literature, much attention had been drawn to the relative disadvantage of landlocked developing countries in trade and transport facilitation, as their lack of access to the sea hinders their ability to integrate better in the global trading system and also poses considerable challenges to their growth and development. This is because landlocked countries have to transit their exports and imports through neighbouring countries leading to high trade costs and a reduction in their international competitiveness and level of trade. This shows why landlocked countries export less due to their relative disadvantage and thus their exports are less prone to being rejected in comparison to countries that are not landlocked. Island countries are subject to similar problems and have an analogous chance of being rejected at the border as the coefficient is negative and statistically significant.

Past rejections turn out to be a significant factor in explaining border rejections. We have used two variables in measuring reputation. The first one is the lag values of a dummy variable indicating if the product was rejected in the previous year - product reputation. The second is the lag values of a dummy variable indicating if at least one export product was rejected from the exporter in the preceding period - 'country reputation'. The coefficient on the product reputation is significantly positive, indicating that the likelihood of experiencing a border rejection in the current year increases if the product has already faced at least one border rejection in the previous year. This scenario implies that the reputation of the product matters in the enforcement of food safety standards. Products from countries which are rejected in previous years face more scrutiny when inspected at the EU border as the EU keep track of prior rejections. This is in line with Baylis, et al. (2009) and Jouanjean, et al. (2012) who obtained similar results for products rejected at the US border. However, the country reputation variable is statistically significant and has a negative sign. As expected, an EU border rejection which affects a country's reputation - to the point where other products exported by it are also heavily scrutinised - decreases the chances of being rejected in subsequent years. This is because a heavy violator of EU food safety standards would soon be put on the EU ban list. However, being on the ban list represents a learning process for the exporter who subsequent 
pays more attention to the SPS requirements of its export products in the future so as to avoid EU rejection.

In addition, the level of economic and financial capability of the exporting countries proxy by GDP, turns out to be a significant driver of border rejection. GDP is an indicator of a country's financial ability to comply with importing countries' standards. However counterintuitively, our results point out that richer countries have higher border rejections, which might be indicative of their financial unwillingness to comply. This is not surprising as the increase in economic growth witnessed by many of the richer African countries has not been efficiently utilised to upgrade their production and supply chain and ensure compliance with international standards. Thus, given that richer countries in Africa trade more than poorer countries, they are prone to more border rejections, given their financial unwillingness to comply with international standards. Our result confirms those of Kim and Reinert (2009) who find that many developing countries, including those in Africa, have weak financial capability to comply with international standards. However, previous imports by the EU are statistically insignificant when explaining the incidences of border rejection. This indicates that the incidence of rejections does not occur following the surge in imports in the previous years. This points out that these rejections are purely a result of the countries not meeting the stipulated EU standards and not due to some hidden protectionist intent of the EU or some lobby groups aiming to reduce the flow of Africa's exports to the EU.

\section{B. Impact of Infrastructure, Border Procedure and Institution}

In the preceding discussions, the magnitude of the distance coefficient turns out to be very high, illustrating the increasing importance of transportation costs and trade facilitation and infrastructure in explaining the rejection of Africa's exports. Consequently, we further examine their significance in reducing or increasing the incidence of rejections of Africa's exports at the EU border using detailed data from the World Bank's yearly 'doing business' report. These data are only available consecutively for 22 African countries ${ }^{43}$, therefore limiting our analysis to this subset of countries for which the data are available. In addition, we also consider how important institutional factors are in driving border rejection using two measures of the exporting countries: regulatory quality and control of corruption.

\subsubsection{Robustness Checks II}

Before we report our main estimated results, the adequacies of the estimated models are first checked. As a robustness check, we perform a similar specification tests to the ones used before when comparing the models. The results of the various checks are reported in Table 5.7. The results show that the p-values of the Ramsey reset test are in favour of all models except the population average effects NBPML model. The NBPML model thus shows evidence of

\footnotetext{
43 Cape Verde, Congo Republic, Rwanda and Tunisia have no data regarding trade and trade procedure data sourced from the World Bank's Worldwide Governance Indicators. In addition, some of the variables used for the analyses were started to be collated in 2010 (for example, variable relating to percentage of shipments meeting quality criteria), thus limiting our analysis from 2010 to 2013.
} 
misspecification as the test results reject the null hypothesis that the estimated test statistics is statistically insignificantly different from zero.

Table 5.8: Robustness Checks on the Estimation Techniques

\begin{tabular}{l|cccc}
\hline Various Tests & $\begin{array}{c}(1) \\
\text { Poisson } \\
(p . a)\end{array}$ & $\begin{array}{c}(2) \\
\text { Poisson } \\
(\text { r.e. })\end{array}$ & $\begin{array}{c}(3) \\
\text { NBPML } \\
(p . a .)\end{array}$ & $\begin{array}{c}(4) \\
\text { NBPML } \\
(p . a .)\end{array}$ \\
\hline Ramsey Reset Test & -0.23 & 0.01 & $-0.12^{* * *}$ & 0.06 \\
\hline Park TEST: $v(y \mid x)=\left(\mu(y \mid x)^{\alpha}\right.$ & & & & - \\
$\alpha_{1}$ & 1.58 & 1.07 & - & - \\
P Value & 0.00 & 0.78 & - & - \\
95\% Confidence Interval & $1.22-1.95$ & $-0.60-1.54$ & - & - \\
\hline
\end{tabular}

Note: p.a. and r.e. are population average and random effects, respectively. "-" not available after population average effects models.

Finally, the modified Park test reported at the end of Table 5.8 indicates that the estimate on the parameter $\alpha_{1}$ is not significantly different from 1 for the random effects Poisson model. This indicates that we cannot reject the Poisson equi-dispersion assumption when the random effects Poisson model is employed. Thus, based on these tests, the random effects Poisson model is our preferred model, contingent on our dataset.

The results of the population average and random effects Poisson and NBPML models are presented in Table 5.9. As shown, most of the variables turn out to be statistically significant at $1 \%$ but display considerable variations in their sign. Documents required to export are the number of documents that customs authorities, container and port authorities, government ministries and parastatals, banks and health and safety control agencies, and other related agencies require in order to clear a good when exporting it. The coefficient turns out to be positive, significantly increasing import rejections. This is because obtaining the documents needed by the importing countries, particular those relating to health certification are usually costly, especially for small scale exporters. In addition, such documents are usually cumbersome to obtain as they tend to involve third party certification and accreditation. As such, exporters who don't have all the documents would have their exports refused entry at the EU border. In addition, the excessive number of documents needed to export - such as sanitary and phytosanitary documents - might cause unnecessary delays, while a lack of the recognised documents and certificates documenting conformity with importing countries' standards might also lead to rejections. Indeed, a number of Africa's exports have been rejected on the grounds of lacking the required health certificate and fraudulent practices relating to the health certificate (RASFF, online database). Freud and Rocha (2011) have also affirmed that the huge number of documents required to export is one of the factors constraining Africa's export success. 
We also examine the number of border agencies encountered when exporting. Our results show the coefficient to be highly significant and negative. Apart from customs agencies, other agencies such as transport, veterinary, and health or sanitary and phytosanitary (SPS) are also encountered when exporting. Intuitively, our results imply that a reduction in the number of border agencies in the exporting countries, especially those agencies involved in health and food safety checks, increases the incidence of border rejections of African exports. Indeed, a reduction of border agencies by 1 can lead to about 2 cases of border rejections. Like most developing countries, African countries are usually short of staff and lack the necessary technical staff at the country's border to detect export goods that do not meet EU requirements (Essaji, 2008). Sub-standard export products therefore usually pass the border agencies of the exporting countries and are consequently rejected at the EU border. This is so because the EU is well equipped with the required number of trained border agencies and staff to undertake technical and physical detection of food safety violation.

Table 5.9: Impact of Trade Procedures, Infrastructure and Institution on Border Rejection

\begin{tabular}{|c|c|c|c|c|}
\hline Independent Variables & $\begin{array}{c}(1) \\
\text { Poisson } \\
(p . a)\end{array}$ & $\begin{array}{c}(2) \\
\text { Poisson } \\
(\text { r.e. })\end{array}$ & $\begin{array}{c}(3) \\
\text { NBPML } \\
\text { (p.a.) }\end{array}$ & $\begin{array}{c}(4) \\
\text { NBPML } \\
(\text { r.e. })\end{array}$ \\
\hline Documents to Export (Number) & $\begin{array}{c}0.382^{*} \\
(0.213)\end{array}$ & $\begin{array}{c}0.392^{*} \\
(0.214)\end{array}$ & $\begin{array}{c}0.196 \\
(0.225)\end{array}$ & $\begin{array}{c}0.274 \\
(0.308)\end{array}$ \\
\hline Number of Border Agency (Exports) & $\begin{array}{c}-1.666^{* * *} \\
(0.720)\end{array}$ & $\begin{array}{c}-1.546^{* * *} \\
(0.672)\end{array}$ & $\begin{array}{c}-1.707^{\text {***** }}(0.573)\end{array}$ & $\begin{array}{l}-0.502 \\
(0.498)\end{array}$ \\
\hline Shipments meeting Quality Criteria (\%) & $\begin{array}{c}0.051^{*} \\
(0.029)\end{array}$ & $\begin{array}{c}0.045^{*} \\
(0.027)\end{array}$ & $\begin{array}{c}0.038 \\
(0.024)\end{array}$ & $\begin{array}{c}0.009 \\
(0.022)\end{array}$ \\
\hline Rate of Physical Inspection of Imports (\%) & $\begin{array}{c}0.050^{* * * *} \\
(0.018)\end{array}$ & $\begin{array}{c}0.047^{\text {**** }} \\
(0.017)\end{array}$ & $\begin{array}{c}0.059^{\text {**** }} \\
(0.015)\end{array}$ & $\begin{array}{c}0.022 \\
(0.016)\end{array}$ \\
\hline Clearance Days with Physical Inspection & $\begin{array}{l}0.720^{* *} \\
(0.287)\end{array}$ & $\begin{array}{l}0.664^{* *} \\
(0.264)\end{array}$ & $\begin{array}{c}0.813^{* * *} \\
(0.226)\end{array}$ & $\begin{array}{c}0.206 \\
(0.220)\end{array}$ \\
\hline Clearance days without Physical Inspection & $\begin{array}{c}-0.332^{* *} \\
(0.147)\end{array}$ & $\begin{array}{c}-0.311^{* *} \\
(0.143)\end{array}$ & $\begin{array}{c}-0.291^{* *} \\
(0.136)\end{array}$ & $\begin{array}{l}-0.156 \\
(0.197)\end{array}$ \\
\hline Quality of Infrastructure & $\begin{array}{c}-1.307^{* *} \\
(0.664)\end{array}$ & $\begin{array}{l}-1.258^{*} \\
(0.662)\end{array}$ & $\begin{array}{c}-1.721^{* *} \\
(0.750)\end{array}$ & $\begin{array}{l}-0.357 \\
(0.548)\end{array}$ \\
\hline Regulatory quality & $\begin{array}{c}-2.622^{* *} \\
(1.088)\end{array}$ & $\begin{array}{c}-2.654^{* * *} \\
(1.113)\end{array}$ & $\begin{array}{c}-3.712^{* * * *} \\
(1.420)\end{array}$ & $\begin{array}{c}-2.764^{* *} \\
(1.269)\end{array}$ \\
\hline Control of corruption & $\begin{array}{c}0.094 \\
(1.136)\end{array}$ & $\begin{array}{c}0.073 \\
(1.087)\end{array}$ & $\begin{array}{c}0.890 \\
(1.133)\end{array}$ & $\begin{array}{c}0.529 \\
(1.124)\end{array}$ \\
\hline Exporters Effects & Yes & Yes & Yes & Yes \\
\hline Products Effects & Yes & Yes & Yes & Yes \\
\hline Time Effects & Yes & Yes & Yes & Yes \\
\hline No of Observations & 272 & 272 & 272 & 272 \\
\hline
\end{tabular}

In the Poisson model, the percentage of shipments meeting the domestic company criteria also turns out to be significant factor increasing border rejections. This result implies that export 
shipments meeting domestic companies' quality requirements are usually rejected at the EU border as EU quality criteria are much stricter than those required by the exporting company; this reflects a case of a wide regulatory quality gap. Such a geographical quality gap has serious implications for border rejections and can damage the reputation of exporting countries. This situation is worsened due to the lack of stringently enforced regulatory standards by most African countries which are at least in similitude with those of the EU, as well as the lack of sophisticated standard testing and accreditation facility. Thus, the continuous usage of the less stringent domestic standards and testing facilities may make a large percentage of shipments meet the domestic exporter's quality criteria, but such export products would be subjected to border rejection after the EU's more sophisticated and technologically advanced testing facilities were used. This result is aligned with those of Arvis et al. (2014) which finds a wide gap in shipment quality between low performing developing and high performing developed countries, as the acceptable quality requirement is much more stringent in the latter than in the former. However, in the NBPML model, the variable has no apparent effect on border rejection as its coefficient is statistically insignificant at the conventional level.

The rate of physical inspection of Africa's exports by their importing countries also contribute significantly in determining whether Africa's exports will be rejected at the EU border. Indeed, an increase in the rate at which Africa's exports are physically inspected for health and safety violations increase their chances of being refused entry into the EU. Usually, the EU only inspect a subset of the export product, however, the rate of physical inspection of imports are usually increased in situations when the EU receives an alert about potential violations or with high risk products, or exporters that have previously had a record of having their exports rejected. Thus, in such a situation, a 20 percent increase in the rate of physical inspections would increase border rejections by 1 case.

Other interesting results relate to the variables on customs clearance days both with and without physical inspection. Our results show that export goods which undergo customs clearance days with physical inspection have an increased incidence of border rejections, while those that are cleared without physical inspections have decrease border rejection. During this physical inspection, delays might increase the chances of the export good becoming spoilt, especially highly perishable goods such as fruits and vegetables; such spoilage also increased their susceptibility of being rejected entry into the EU border. For instance, in the case of Benin, it takes about 10 days for the good to be cleared with physical inspection, and about 4 days for the good to be cleared when no physical inspection is required. This implies that increased export times associated with physical inspections in the domestic country increases the incidence of border rejection. Intuitively, one would have thought that when goods are physically inspected for violation of health and SPS regulations in the exporting country, border rejections at the EU would be reduced. However, as previously discussed, due to the regulatory quality gap, border rejection remains high in spite of subjecting the exported goods to physical inspections at the domestic economy. Our result is in support of Moïsé and Le Bris (2013), who find that unreliable time delays affect the deterioration of quality and time-sensitive products. In fact, time delays and export times have been found to pose significant hurdle to export 
performance for many developing countries (Martinez-Zarzoso and Marquez-Ramos, 2008), and impact can be huge for highly perishable and other time sensitive products (Djankov et al., 2010). The results also those of confirm Djankov et al. (2010) and Freund and Rocha (2011) who show that large customs and ports times in Africa pose a significant hurdle to her export performance.

All these results obtained in relation to the impact of trade and customs procedures discussed above are in line with UNESCAP (2011) who posit that customs procedures and documents needed to trade are an important source of delays and inefficiencies, posing significant bottlenecks to trade. These include the duplication of procedures, delays at the border caused by excessive physical inspection procedures, lack of coordination among border agencies, and lengthy custom clearance procedures. Moïsé and Sorescu (2013) also revealed that customs delays have been identified as a major trade problem confronting agro-food exporters from developing countries.

In relation to the first institutional variable, our results reveal that domestic regulatory quality in Africa is a highly negative and significant institutional determinant of border rejections. Indeed, Africa's deteriorating regulatory quality significantly increases the rejection of Africa's exports. This is not surprising as Africa has a 'missing regulatory institution' which is necessary to implement a minimally acceptable food regulation, as well as the non-commitment to regulatory policies for countries that have them. In fact, the literature has pointed out that the impact of importing countries' standards on developing countries has been aggravated them for them to their lack of institutional capacity to satisfy such standards. This results from missing or weak regulatory capacity from the domestic government to implement a testing and certification process, as well as weak domestic regulatory quality (Essaji, 2008; Kim and Reinert, 2009). In relation to the other institutional indicator, the control of corruption in the exporting country is negative, and this is in line with our expectations. This result indicates that a decrease in the control of corruption in the African exporting countries increases their frequency of being rejected at the EU border. In support of this, the incidences of border rejection occurring due to corrupt practices such as fraud and adulteration accounts for about $3 \%$ of the total number of border rejections of Africa's exports between 2008 and 2013. However, counterintuitively, the variable is statistically insignificant at the conventional level.

Finally, our control of the quality of domestic trade related infrastructure turns out to be negative and statistically significant, indicating that Africa's dilapidating infrastructure would increase border rejections. This point out the importance of trade infrastructure in meeting the importing countries' quality criteria, especially those relating to availability of appropriate air or port containers to transport perishable products. For instance, Moïsé and Sorescu (2013) identified the lack of cold storage and cold chain infrastructure as some of the major constraints facing agricultural food firms in developing countries. In addition, Bromley et al. (2011) reported that the lack of availability of cold chain infrastructure presented significant impediments to agricultural trade in West Africa. However, a number of empirics have pointed out the significance of trade infrastructure in boasting export performance and efficiency 
(Iwanow and Kirkpatrick, 2009; Portugal-Perez and Wilson, 2012.) This may have a spill over effect in reducing border rejection when exports are efficiently transported to importing countries in line with international standards. Efficient trade infrastructure spanning road, rail and maritime transport as well as ICT usually ensures less export time and reduces unnecessary spoilage of the export product which is associated with longer export times. For instance, in 2012 it took 2 days for Singapore to export its products in contrast to about 14 days for Ethiopia. Export times are extremely high for most African countries due to their poorly developed infrastructure. This result therefore suggests the need for an improvement in transport-related infrastructure.

\subsection{Conclusion and Policy Recommendation}

This paper investigates the factors driving the rejections of African exports at the EU border. It considers the logistical and institutional factors in the exporting countries that are contributing to the occurrence of such rejections. Our result indicates that geographical hurdles, poor trade infrastructure, inefficient border procedures and a lack of technical personnel all add to Africa's challenges in accessing EU markets. In line with the growing literature, this study finds empirical support for the proposition that institutions, infrastructure and logistical quality are all important for increased market penetration and continuous integration into the world trading system. It is therefore glaring that targeted long term development and policy intervention are needed at ensuring the provision of infrastructure, regulatory policies, and trade facilitation services and procedures at the border to ensure market access.

Our results have several implications for policy formulation and implementation. To move products to the international market more efficiently, African countries must adopt policies to support trade. The issue of export rejections at the border as a non-tariff barrier can be addressed through policy measures that improve both logistics and connectivity. Comprehensive reforms and long term commitments to the implementation of sustained and strategic policy intervention in the area of trade facilitations, involving the private sector, is an important policy imprint. Improving logistics quality is at the core of achieving export competitiveness and economic growth, which will enable African countries to join globally efficient supply chains. Good customs and border management and the improvement of transit regimes are all areas of trade facilitation that would help to improve logistic quality and move goods to market more efficiently and reliably. This would reduce unnecessary trade time and costs as well as bolstering trade competitiveness. For instance, automating customs procedures can facilitate trade and reduce logistical procedures.

Furthermore, investment in both soft and hard infrastructure through public private partnership and coordination would ensure goods are cleared even before they reached the importing countries and would minimise delays that cause food spoilage and border rejections. Streamlining unnecessary border procedures could ensure faster access to the countries' importing markets, especially for highly perishable products which need to be exported on time. Also, concerns about environmental sustainability are emerging as a market drive, with strong indication for green logistics by developed importing countries. Moreover, sustainability is 
becoming more important in food trade. Thus, there is a need to consider the environmental impact of logistics in reducing the trade barrier associated with EU rejections. Coordination therefore remains essential in trade facilitation efforts and should include the introduction of best practices, especially in the areas of the two key areas of trade facilitation: communication and transportation infrastructure, and border management.

As indicated by our results, Africa is missing an institution in the area of regulatory quality; such an absence proves to be a major hindrance to export performance. Thus, policy makers also need to make improved long term institutional changes that are consistent with the fastchanging standards requirements of the developed countries, particularly the EU which remains their most important trading partner. Provision of sophisticated testing and accreditation technology as well as putting in place stringent domestic food safety regulatory policies that are aligned with those required in the EU is one such policy. Lastly, in line with the consensus reached at the 2013 WTO Trade Facilitation Agreement during the ministerial conference held in Bali, African countries should demonstrate a strong commitment to the adoption of modern approaches to customs and border management and other best practices. In addition, as part of the TBT and SPS agreements, donors and developed countries should commit to helping African countries in financing the investment cost of ensuring compliance. Thus, addressing some of these challenges through a strong commitment to policy reforms will be key to not only bypassing stringently enforced EU food safety standards, but also to ensuring market access and deep global trade integration in general.

\section{References}

Arvis, J.F, Mustra, M., Panzer, J., Ojala, L., and Naula, T. (2012). Connecting to compete. Trade logistics in the global economy: the logistics performance index and its indicators. Washington DC: The World Bank.

Arvis, J.F., Saslavsky, D., Ojala, L., Shepherd, B., Busch, C., and Raj, A. (2014). Connecting to compete - the logistics performance index and its indicators. Washington DC: The World Bank.

Baylis, K., Martens, A., and Nogueira, L. (2009). What drives import refusals? American Journal of Agricultural Economics, 91(5), 1477-1483.

Baylis, K., Nogueira, L., and Pace, K. (2010). Food import refusals: Evidence from the European Union. American Journal of Agricultural Economics, 93(2), 566-572.

Bromley, D., Cook, A., Singh, S., and Van Dusen, N. (2011). Regional Agricultural Transport and Trade Policy Study. West Africa Trade Hub Technical Report, 41. Washington DC: United State Agency for International Development (USAID).

Burger, M., van Oort, F., and Linders, G. J. (2009). On the specification of the gravity model of trade: zeros, excess zeros and zero-inflated estimation. Spatial Economic Analysis, 4(2), 167-190.

Cameron, C. A., and Trivedi, P. (1998). Regression analysis of count data (Econometric Society Monographs). Cambridge: Cambridge University Press. 
Disdier, A. C., Fontagne, L., and Cadot, O. (2015). North-South standards harmonization and international trade. World Bank Economic Review, 29(2), 327-352.

Djankov, S., Freund, C., and Pham, C. S. (2010). Trading on time. Review of Economics and Statistics, 92(1), 166-173.

Essaji, A. (2008). Technical regulations and specialization in international trade. Journal of International Economics, 76(2), 166-176.

Faruq, H.A. (2011). How Institutions affect export quality. Economic Systems, 35(4): 586606.

Ferro, E., Otsuki, T., and Wilson, J. S. (2015). The effect of product standards on agricultural exports. Food Policy, 50, 68-79.

Freund, C., and Rocha, N. (2011). What constrains Africa's exports? The World Bank Economic Review, 25(3), 361-386.

Goel R.K., and Korhonen, I. (2011). Exports and cross-national corruption: a disaggregated examination. Economic Systems, 35(1), 109-124.

Grundke, R., and Moser, C. (2014). Hidden protectionism? Evidence from non-tariff barriers to trade in the US. KOF Working Papers No. 369. ETH Zurich: KOF Swiss Economic Institute.

Henson, S., and Jaffee, S. (2008). Understanding developing country strategic responses to the enhancement of food safety standards. World Economy, 31(4), 548-568.

Iwanow, T., and Kirkpatrick, C. (2009). Trade facilitation and manufactured exports: is Africa different? World Development, 37(6), 1039-1050.

Jouanjean, M.-A., Maur, J., and Sheperd, B. (2012). Reputation matters: spillover effects in the enforcement of US SPS measures. World Bank Policy Research Working Paper 5935. Washington DC: The World Bank.

Keener, L., and Roberts, J. (2013). The squeaky wheel: is transportation the watershed for food safety and food defence? Food safety magazine. Retrieved from http://www.foodsafetymagazine.com/magazine-archive1/augustseptember-2013/thesqueaky-wheel-is-transporation-the-watershed-for-food-safety-and-food-defense/ [Accessed February 8, 2015].

Kim, S. J., and Reinert, K. A. (2009). Standards and institutional capacity: an examination of trade in food and agricultural products. The International Trade Journal, 23(1), 54-77.

Kucharčuková, OB, Babecký J, Raiser M (2012) Gravity approach for modelling international trade in South-Eastern Europe and the Commonwealth of Independent States: the role of geography, policy and institutions. Open Economies Review, 23(2) 277-301

Manning, W. G., and Mullahy, J. (2001). Estimating log models: to transform or not to transform? Journal of Health Economics, 20(4), 461-494.

Martínez-zarzoso, I. (2013). The log of gravity revisited. Applied Economics, 45(3), 311-327. 
Martinez-Zarzoso I, Marquez-Ramos L (2008) The effect of trade facilitation on sectoral trade The BE Journal of Economic Analysis and Policy 8 (1), 1-46.

Moïse, E., and Bris, F. Le. (2013). Trade costs: what have we learned? A synthesis report. OECD Trade Policy Paper 150. Paris: Organization of Economic Cooperation and Development (OECD).

Moïsé, E. and Sorescu, S., (2013). Trade facilitation indicators: the potential impact of trade facilitation on developing countries' trade. OECD Trade Policy Paper 144. Paris: Organization of Economic Cooperation and Development (OECD). DOI: http://dx.doi.org/10.1787/5k4bw6kg6ws2-en

Nicita, A., and Gourdon, J. (2013). A preliminary analysis on newly collected data on non-tariff measures. Policy Issues in International Trade and Commodities Study Series No. 53. Geneva: United Nations Commodity Trade and Development (UNCTAD).

OECD. (2005). The economic impact of trade facilitation. OECD Trade Policy Working Paper 21. Paris: Organization of Economic Cooperation and Development (OECD)

Otsuki, T., Wilson, J. S., and Sewadeh, M. (2001). Saving two in a billion: quantifying the trade effect of European food safety standards on African exports. Food Policy, 26(5), 495-514.

Park, R. (1966). Estimation with heteroscedastic error terms. Econometrica, 34(4), 888.

Portugal-Perez, A., and Wilson, J. S. (2012). Export performance and trade facilitation reform: hard and soft infrastructure. World Development, 40(7), 1295-1307.

Ramsey, J. B. (1969). Tests for specification errors in classical linear least-squares regression analysis. Journal of the Royal Statistical Society. Series B (Methodological), 31(2), 350371.

RASFF. (Online Database). European Commission rapid alert system for feed and food. Retrieved from https://webgate.ec.europa.eu/rasff-window/portal/ [Accessed $10 \mathrm{July}$ 2014].

RASFF. (2014). The rapid alert system for food and feed 2014 Annual Report. Retrieved from http://ec.europa.eu/food/safety/rasff/docs/rasff_annual_report_2014.pdf [Accessed September 15, 2015].

Santos Silva, J., and Tenreyro, S. (2006). The log of gravity. The Review of Economics and Statistics, 88(4), 641-658.

Shepherd, B., and Wilson, N. L. W. (2013). Product standards and developing country agricultural exports: The case of the European Union. Food Policy, 42, 1-10.

Steadman, J. (1999). Assessment of risk arising from food alterations during transport, storage and preservation. (J. Heijden, M. Younes, L. Fishbein, and S. Miller, Eds.) International Food Safety Handbook: Science, International Regulations and Control. New York: Marcel Dekker Inc.

UNECA. (2013). Trade facilitation from an African perspective. Addis Ababa: United Nations Economic Commission for Africa (UNECA). Retrieved from 
http://www.uneca.org/publications/trade-facilitation-african-perspective [Accessed July 18, 2015].

UNESCAP. (2011). Facilitating agricultural trade in Asia and the Pacific. Studies in Trade and Investment No. 74, United Nations Economic and Social Commission for Asia and the Pacific. Paris: United Nations. http://www.unescap.org/tid/publication/tipub2616.pdf [Accessed July 18, 2015].

Unnevehr, L. J. (Ed.). (2003). Food safety in food security and food trade. IFPRI Vision 2020 Focus Briefs 10. Washington DC: International Food Policy Research Institute (IFPRI).

Wilson, S., Mann, C., and Otsuki, T. (2005). Assessing the benefits of trade facilitation: A global perspective. World Economy, 28 (6), 841-871

Winkelmann, R. (2008). Econometric Analysis of Count Data. (5th ed.). Berlin: SpringerVerlag.

World Bank. (2012). Africa can help feed Africa: removing barriers to regional trade in food staples. Washington DC: The World Bank. Retrieved from http://siteresources.worldbank.org/INTAFRICA/Resources/Africa-Can-Feed-AfricaReport.pdf [Accessed September 15, 2013].

WTO (2015). Speeding up trade: benefits and challenges of implementing the WTO Trade Facilitation Agreement. World Trade Report. Geneva: World Trade Organization (WTO). https://www.wto.org/english/res_e/booksp_e/world_trade_report15_e.pdf [Accessed February 7, 2016].

Xiong, B., and Beghin, J. (2011). Does European aflatoxin regulation hurt groundnut exporters from Africa? European Review of Agricultural Economics, 39(4), 589-609.

Xiong, B., and Beghin, J. (2014). Disentangling demand-enhancing and trade-cost effects of maximum residue regulations. Economic Inquiry, 52(3), 1190-1203. 


\section{Chapter 6}

\section{General Conclusion}

This dissertation provides some new insights on the issue of non-tariff measures imposed on the food sector by providing cutting edge essays on SPS and TBT with a particular focus on SPS measures on food safety and technical regulation (government mandatory standards) governing the agricultural food sector, and their consequence for African exports. The dissertation also investigates the role of domestic factors in the African countries on their (in)ability to comply with stringent standards using data on border rejections as the conformity assessment indicator. This dissertation has been undertaken in four distinct but interrelated essays.

\subsection{Synopsis of Findings}

The first essay of this thesis is a methodological paper which entails the comparison of the performance of several different estimation techniques which we used to model the impact of EU SPS measures on food safety and technical regulations governing EU food sector on Africa's fish exports. Distinct from previous studies, we have focused on African countries using a previously unexploited dataset of SPS measures and mandatory technical regulations sourced from the Perinorm database (a collection of national and international standards and regulation data). For our analysis, we have employed the gravity model of trade - an important model used in predicting bilateral trade flows. Previous works have identified estimation challenges which revolve around the validity of the logarithmic transformation of the dependent variable of the gravity model in the presence of heteroscedasticity, and the appropriate estimation techniques for analysing zero trade observations. These two issues have generated several challenges concerning the appropriate choice of the estimation techniques. This necessitates a careful consideration of the appropriate estimation techniques that would prevent biased and frequently misinterpreted policy recommendations.

Our work evaluates the performance of alternative estimation techniques in the presence of zero trade observations and checks the validity of their assumptions; we have also looked at their behaviour when their assumptions are not followed, particularly in the event of a departure from the heteroscedasticity assumption. Our analysis was based on a dataset of Africa's fish exports to the EU between 2007 and 2012, which contains over 63\% zero trade observations. Our research provides evidence that choosing the best model depends on the dataset and the process generating the error term; we therefore advocate an encompassing toolkit approach of the methods so as to establish robustness. For most of the estimators, our results show that EU SPS and technical regulations on fish products are not protectionist when compared to the international benchmark recommended by the FAO and WHO. In addition, our results show that the multinomial pseudo maximum likelihood estimator outperforms all other estimators, with the conclusion that this estimator is the most appropriate estimator for our particular dataset and its results are to be relied upon for more efficient and reliable policy outcomes. 
The second essay of the thesis has focused on how the EU SPS standards on pesticides affect Africa's fresh fruit and vegetable exports. Our choice of these products hinges on the fact that they attract the most stringent standards because they are particularly prone to food borne risks; consequently, they are affected by many standards. In addition, they are also among the highest valued commodities traded by Africa. We identified that trade is increasingly playing a significant role in the provision of both food and agricultural export earnings, promotion of economic growth, and a means of poverty reduction especially for the majority of African countries who continue to depend primarily on agriculture for sustenance. However, their trading partners' trade policies such as regulations on food policies (of which SPS measures have been identified as one of the most difficult non-tariff barriers) and other trade policies might jeopardize this role. Thus, we have investigated the actual impacts of the EU pesticide standards on Africa's export of tomatoes and citrus fruits to better understand the actual determinant of bilateral agricultural food exports and help Africa exploit its trading partners' markets. Our focus on fruit and vegetable products was due to the fact that they face a relatively huge number of standards. In addition, they constitute the most rejected export products in Africa and the world at large. Aside from data on EU food safety measures, and as a novel contribution to the existing literature, we have also investigated another non-tariff measure in the form of the EU entry price system for fresh fruits and vegetables.

Our research differs considerably from previous studies. First, we had used a previously unexploited dataset on EU regulation of citrus and tomato standards on pesticides. In addition, we have also analysed the EU entry price system which has a lot of influence on export value; previous studies have failed to take this into account. As a methodological contribution, the Helpman, Melitz and Rubinstein (2008) sample selection model was employed to appropriately deal with the problems relating to zero valued trade flows and to predict both the extensive and intensive margins of trade. The method is advantageous as it allowed us to deal with zero trade observations which are frequent in our data; it also helped us to investigate the impact at both the intensive margin (i.e. the trade relationships that have already been established) and the extensive margin of trade (probability of exporting existing products to new markets, or exporting new products or new varieties of existing products to new markets).

Our results indicate that the trade effect of standards is product specific as standard can either be a catalyst or barrier to export success, depending on the product considered. At the extensive margin of trade, the high stringency of EU pesticide standards prevents new entry into the EU market, drives less productive firms away, and discourages existing exporters from expanding their market base. However, the impacts vary widely at the intensive margin; the export of tomatoes is inhibited, however there is no effect on lime and lemon exports, while Africa's export of oranges to the EU are significantly promoted. Our finding for oranges and limes and lemons imply that standards are not necessarily always trade inhibiting as is the widely held view; they can also act as catalyst to achieve competitive advantage and to penetrate EU markets. Furthermore, our results also reveal that the EU entry price system has no apparent effects on oranges, and limes and lemons exports from Africa. It does, however, act similar to 
an export tax, significantly impeding the export of tomatoes to the EU with a much more trade inhibiting effect than the regulated EU pesticide standards.

In third essay, we have investigated the protectionist extent of EU SPS measures on food safety with particular focus on pesticide standards. In doing so, we have used the same data source used in the second essay. In addition to EU pesticide standards, we also collected the Codex Alimentarius Commission standards - a group of international scientific reference standards regulated jointly by both the FAO and WHO. The essay was motivated by the proposition that NTMs particularly SPS standards can be used to achieve the non-trade objective of protecting consumers' health and safety and also as a trade protection tool to drive a price wedge between domestic and foreign producers. Studies investigating if the uses of NTMs have protectionist intent are rare and this can largely be attributed to the difficulty of differentiating their nontrade policy objectives from their trade policy objectives along with a lack of globally accepted benchmarks for doing this. We have addressed this knowledge gap by comparing EU standards to the international acceptable standards. We formalized the definition of protectionism by comparing EU standards with the internationally scientific referenced benchmark regulated by the FAO and WHO. We have defined an EU standard to have protectionist intent if it exceeds an internationally referenced one, otherwise it is classed as anti-protectionist.

Recent literature on firm heterogeneity reveals that the growth of developing countries' trade was predominantly due to the expansion of trade along the extensive margin rather than due to expansion in the volume of trade. In spite of this assertion, we argue that the ability of African countries to initiate or penetrate new markets might be ultimately constrained by stringent importing countries' market conditions. We have investigated the extent of protectionist intent on only the extensive margin of trade in order to understand the process of entries and exits in export markets and also identify if using standards as a protectionist tool is a constraint to Africa's export competitiveness. Our results show that the EU depends heavily on citrus imports and less heavily on tomato imports to satisfy domestic consumption and processing. Furthermore, our results show that the tomato food sub-sector is overprotected by more stringent standards relative to the international benchmarks recommended by both the WHO and FAO. Meanwhile, the oranges and lime and lemon food sub-sectors are under-protected relative to international standards, indicating that more import dependent sectors are less protected.

In the fourth essay of this thesis, we have investigated into the factors that are driving the ability or inability of countries to comply with EU food safety standards. This research was inspired from reported evidence that selected food exports of many African countries were unable to gain access to the EU market at the border due to their inability to conform with the required EU standards. These rejections amount to a significant loss in exports and signify Africa's inability to comply with importing countries' standards. Additionally, they may indicate a lack of domestic quality standards which are in similitude with those imposed by the importing countries. Thus, we have analysed the extent to which domestic factors can explain compliance or non-compliance to EU food safety standards. We measured exporters' ability to comply with 
standards using the EU rich database on incidences of export products rejected at the EU border following the EU conformity assessment carried out via inspection of exported product, which allows the EU to determine if exporting countries comply with its stipulated food and feed safety standards. We based our analysis on panel data between 2008 and 2013. Detailed data was collated on domestic factors that can propel or reduce the incidences of border rejections; the data span information on institution, corruption, quality of government policy in making and implementing good regulations, detailed trade facilitation measures recently made available through the World Bank, and information on each countries' geographical and cultural indicators.

The evaluation of the EU's rejection of exports from African countries and the food hazards responsible for such rejection allowed us to get a clearer picture of export losses from noncompliance. We established that fruits and vegetables exports remain one of the most important exports from Africa and other continents which face a significant number of rejections by the EU. These rejections amount to a significant export losses, and signify that much effort is needed by Africa to comply with EU standards if trade is to serve as one of the means of generating income and alleviating poverty for the continent.

We find that geographical hurdles, poor trade infrastructure, inefficient border procedures, and a lack of technical personnel all add to Africa's challenges in accessing EU markets. In line with the growing literature, this study finds empirical support for the proposition that institutions are important for increased and continuous integration into the global trading system. As indicated by our results, Africa is missing an institution in the area of regulatory quality; this includes poor government involvement in regulation, a high level of corruption, an absence or inadequate trade facilitating measures, and a huge quality gap between the EU and African countries. In addition, administrative trade barriers such as the high export times, the numerous number of documents required to export, and numerous custom checks and controls reduce the efficient movement of export products from Africa to the EU, thereby increasing delays that cause food spoilage and border rejections.

\subsection{Policy Recommendations}

Overall, our studies reveal that TBT and SPS measures, specifically those governing the agricultural food sector can either be catalysts or barriers to trade. Our results show that the consequences of imposing these measures are less pessimistic than the widely held view that they constitute barriers to exports' success. More specifically, our evidence points out that the increase and tightening of food safety and mandatory technical standards can also serve as catalysts for African countries to participate in international trade if they adhere to the requirements set by importing countries. However, our results also show that standards may act as an impediment to export success either through explicit import rejections on particular product(s), through their usage as protectionist tool, or through the huge cost of complying with stringent standards, which consequently diminishes the competitiveness of exports. The consequences are aggravated for exporters from developing countries, particularly Africa, as 
they lack the financial and technological resources as well as the scientific power to challenge unnecessary stricter standards made by developing countries.

Moreover, even though stringent EU standards and regulations can at times inhibit an exporter's ability of exporting to the EU, the inability to comply with EU standards is not solely due to the huge implementation costs. A further evaluation shows the high number of export rejections from African countries are due in part to their inability to comply with EU standards. Our empirical findings suggest that the rejections of Africa's exports at the EU border are primarily due to unfavourable domestic conditions, particularly geographical hurdles, institutional barriers, weak trade facilitation measures such as weak logistics, poor trade infrastructure, inefficient border procedures and a lack of technical personnel. More importantly, Africa is missing an institution in the area of regulatory quality as many of its countries do not have minimum quality standards. The huge quality gap between the EU and African countries is at the core of the reasons for the latter's inability to ensure compliance with EU standards, indicating a significant market access problem. This points to the fact that the root of Africa's marginalization in food trade cannot be solely attributed to stringent importing countries standards but also to domestic market restraints. These results therefore point to the need for targeted policy interventions for the African continent.

Conclusively, from a policy point of view, fostering the continent's integration with the global economy will require policies targeted at removing both domestic supply constraints and increasing their compliance to importing markets' standards so as to prevent them from being excluded in global markets. For maximum benefit, future trade integration negotiations between African countries and the EU should include sophisticated scientific and technological transfers as well as the provision of both financial and human development assistance to producers and exporters in the agricultural sector. This is especially true for small scale producers who dominate the scene in Africa which need assistant in complying with EU standards and ensuring sustainability practices. Although many African countries are in regional trade agreements with the EU, standards make market access conditional, as most of the existing trade agreements are negotiated on the basis of reduced tariffs and not on the transfer of technical and financial resources to increase conformity to standards. Thus, increased capacity building and technological transfer aimed at fostering African countries' conformity to EU standards would be a welcome policy so as to ensure that the numerous trade agreements that the EU has with Africa help in achieving Africa's developmental goals. If such measures are in place, even if standards are used as a protectionist tool, the effect might be dampened for many of these African countries.

In addition, the barriers created by the rejection of Africa's exports at the EU border due to the non-compliance to EU food safety standards can be addressed through policies that strengthen Africa's institutions and measures that improve logistics. Thus, to move products to international markets more efficiently, African countries must adopt policies to support trade. Targeted long term development and policy intervention should focus at ensuring the provision 
of infrastructure, regulatory policies, adequate trade facilitation services and procedures at the border to ensure increased market access.

First, in the area of institutional development, policy makers should renew their focus and commitment to implementing improved long term institutional changes that are consistent with the fast-changing standards requirements of the developed countries, particularly the EU which remains Africa's most important trading partner. This should include the provision of sophisticated testing and accreditation technology as well as putting in place stringent domestic food safety regulatory policies that are aligned with those required in the EU.

Second, improving logistics quality is at the core of achieving export competitiveness and economic growth; this will enable African countries to join globally efficient supply chains. Targeted long term comprehensive reforms and the implementation of sustained and strategic policy interventions in the area of trade facilitation and procedures at the border will ensure market access. Good customs and border management and the improvement of transit regimes are all areas of trade facilitation that would help to improve the quality of logistics and move products to markets more efficiently and reliably. This would reduce unnecessary trade time and costs as well as bolsters trade competitiveness.

To conclude, SPS measures and mandatory technical standards are legitimate concern for the health and safety of the citizenry and consequently cannot be negotiated away as some other NTMs and tariffs can be. Thus, a wholehearted commitment to the implementation of a strong regulatory framework and the development of strong institutions would boost Africa's capacity to satisfy importing countries' requirements as well as challenge stricter standards, particularly those that lack strong scientific basis.

\subsection{Limitations of the Study and Outlook for Further Research}

This dissertation contributes to the ongoing discussions on the trade impacts of non-tariff measures on developing countries, with a specific focus on SPS measures on food safety and its conformity assessments, as well as the technical regulation (government's mandatory standards) governing the agricultural food sector. However, a number of factors limit the scope of this thesis.

Firstly, this dissertation has made use of both quantitative standards data (such as the maximum residual limits of pesticide standards) and the incidences of occurrence of food safety standards and technical regulations (count data). The latter include Perinorm count datasets on both mandatory standards and SPS standards, as well as the EU border rejection data. While quantitative standards provide a clear picture of the stringency of standards, this is not always the case in the case of incidences of standards. Although counts can give an insight into the proliferation and importance of standards for trade, however, it might also present a mixed problem of muddling together standards with increasing stringency and those with decreasing stringency. However, most of the data on standards that are publicly available in organisations such as the EU RASFF, WTO, FAO and WHO are count data. This shortcoming is beyond the 
individual researchers' control but could be addressed by an improvement in the reporting of standards by including indicators that can adequately identify the level stringency of the reported standards in the databases.

There is thus a need for improved data and this would necessitate meaningful collaborations between researchers, governments and the private sector particular mega food retailers and other stakeholders in order to produce more reliable data and meaningful indicators. In addition to making new data available, an improvement in the reporting of existing data remain an important consideration. For instance, the EU database on the incidences of exports rejected at the EU borders on the basis on non-compliance with its standards remains one of the richest standard databases available. However, the availability of data on the value or volume of the exports rejected would enhance a more robust and richer analysis. Another initiative in the area of good data management and availability could include making the data on compliance costs such as cost of certifications incurred by producers in each country publicly available. Furthermore, as WTO member countries are mandated to notify their new standards to the WTO, reporting of new standards should include an indication that the standard represents an increase or decrease in stringency to previously notified standards to enable a quantitative assessment of the stringency of the standards and allow a more meaningful evidence-based analysis. The availability of such data would enhance other insights into how standards affect international trade and ensure targeted evidence-based policies imprints.

Secondly, using both quantitative and qualitative standards data, this dissertation has found that standards can be catalyst or barrier to trade. A possible direction for future research is to compare if trade impacts of standards would be contingent on different data on standards reported from different sources. This can for instance include comparing standards reported in the WTO database to those reported by the EU, FAO, Perinorm, ITC, ISO and other databases of other standard setting organisations so as to determine if the results previously obtained in the literature might have been sensitive to the source of standards databases used.

Thirdly, our results in the third essay in which we focused on some selected fresh fruits and vegetable products indicate that in comparison to the internationally recommended standards, EU standards are neither always the more stringent of the two nor are is it always the case that they are trade inhibiting. This is in spite of the widely held view that the EU sets one of the strictest collection of standards in the world, while international standards like those from the Codex Alimentarius Commission have been posited as those that maximize global social welfare. Thus, a caveat is worth mentioning: although we found international standards to at times have a weaker trade enhancing effect than domestic standards, this is not to say that countries should refrain from the usage of globally acceptable standards as recommended by the WTO. Clearly, more research is needed in this direction with extensions to other product lines and importing countries. 


\section{Declaration}

\section{Ph.D. program in Economics}

\section{Declaration for the admissions application}

I confirm,

1. that to date, I have not successfully completed a doctoral program or doctoral process, nor discontinued my studies in such a program. Otherwise, I have already indicated this in the application,

2. that no intermediaries were paid for the purpose of informing me about doctoral study opportunities,

3. that in connection with the doctoral studies process and its preparation, no funds or its nonmonetary equivalency were paid and no unpaid services were solicited, contrary to the purpose of the examination procedures,

4. that there is no basis on which to justify the retraction of a doctorate degree.

Date, Signature 